FRANCISCO AGOSTINHO DO NASCIMENTO JÚNIOR

AVALIAÇÃO COMPUTACIONAL DE SOLVENTES PARA EXTRAÇÃO DE LIPÍDIOS DE MICROALGAS

São Paulo

2021 
FRANCISCO AGOSTINHO DO NASCIMENTO JÚNIOR

VERSÃO CORRIGIDA

\section{AVALIAÇÃO COMPUTACIONAL DE SOLVENTES PARA EXTRAÇÃO DE LIPÍDIOS DE MICROALGAS}

Dissertação apresentada à Escola Politécnica da Universidade de São Paulo para obtenção do título de Mestre em Ciências.

Área de Concentração: Engenharia Química

Orientador: Prof. Dr. Moisés Teles dos Santos

São Paulo 
Autorizo a reprodução e divulgação total ou parcial deste trabalho, por qualquer meio convencional ou eletrônico, para fins de estudo e pesquisa, desde que citada a fonte.

Este exemplar foi revisado e corrigido em relação à versão original, sob responsabilidade única do autor e com a anuência de seu orientador.

São Paulo, de de

Assinatura do autor:

Assinatura do orientador:

\section{Catalogação-na-publicação}

Nascimento Jr., Francisco Agostinho do

Avaliação computacional de solventes para extração de lipídios de microalgas / F. A. Nascimento Jr. -- versão corr. -São Paulo, 2021.

$191 \mathrm{p}$.

Dissertação (Mestrado) - Escola Politécnica da Universidade de São Paulo. Departamento de Engenharia Química.

1.Microalgas 2.Seleção de solventes 3.Avaliação econômica 4.Biorrefinarias I.Universidade de São Paulo. Escola Politécnica. Departamento de Engenharia Química II.t. 
Dissertação de autoria de Francisco Agostinho do Nascimento Júnior sob o título "Avaliação computacional de solventes para extração de lipídios de microalga", apresentada à Escola Politécnica da Universidade de São Paulo, para obtenção do título de Mestre em Ciências pelo Programa de Pós-graduação em Engenharia Química, aprovada em 17 de Dezembro de 2020 pela comissão julgadora constituída pelos doutores:

Prof. Dr.

Instituição:

Presidente

Prof. Dr.

Instituição:

Prof. Dr.

Instituição: 
Aos meus pais, por tudo e por tanto.

Aos meus avós. 


\section{AGRADECIMENTOS}

Ao Prof. Dr. Moisés Teles dos Santos, pela orientação, confiança em mim e no meu trabalho, pelos ensinamentos e por todo o apoio dado nessa trajetória. Agradeço a atenção, criatividade e o incentivo dado nos momentos mais difíceis.

Aos meus pais, Laésia e Agostinho, por terem sempre me incentivado a buscar cada vez mais. Agradeço a presença constante, os valores transmitidos e todo o apoio dado desde o início da minha vida.

A Lola por todo o incentivo e apoio nos momentos bons e ruins, sempre ajudando quando possível, além de estar sempre presente nas comemorações dos momentos bons, uma verdadeira companheira de vida. Ao Matheus, por ter inicialmente me acolhido nessa fase e pelo companheirismo e apoio sempre prestado.

Ao pessoal da UnB que veio colonizar a USP: Meire, Kacc, Renata e Tallys. São Paulo tem sido mais agradável com vocês. Também aos meus amigos Marcellus, Thiago, Irlon e Gabriel por sempre me incentivarem e estarem de braços abertos quando volto para casa.

Aos meus professores de engenharia da UnB que desempenharam um papel primordial na minha formação acadêmica.

Ao restante dos meus amigos de Brasília e São Paulo agradeço por dividir bons momentos comigo e contribuírem com o que sou hoje.

A todos os professores e funcionários do Departamento de Engenharia Química da USP pela ajuda e pela estrutura. 
"Valeu a pena? Tudo vale a pena Se a alma não é pequena. Quem quer passar além do Bojador Tem que passar além da dor. Deus ao mar o perigo e o abismo deu, Mas nele é que espelhou o céu." Fernando Pessoa 


\section{RESUMO}

NASCIMENTO JÚNIOR, Francisco Agostinho do; Avaliação computacional de solventes para extração de lipídios de microalgas. 2019. 191f. Dissertação (Mestrado em Ciências) - Escola Politécnica, Universidade de São Paulo, São Paulo, 2020.

A biomassa tem sido colocada em evidência como principal matéria-prima para produção de biocombustíveis, embora seja capaz de produzir diversos compostos como: fármacos, aditivos alimentícios, materiais, entre outros. Dentre as diversas matérias-primas originadas da biomassa, pode-se destacar a microalga para produção não só de combustíveis como diversos químicos de interesse por causa de sua alta produtividade, baixa necessidade de terras aráveis e água pura e sua versatilidade. Entretanto, o processo ainda não se provou financeiramente viável pelo seu alto custo. Diversos trabalhos tem sido feitos avaliando técnicas diferentes de cultivo e diferentes rotas de processamento para produção de diversos combustíveis de forma combinada. Este trabalho tem como propósito avaliar computacionalmente o processo de extração de lipídios da microalga com diferentes solventes para posterior produção de biodiesel. Para isso foi criada uma metodologia multi-step com 3 etapas de avalição: propriedades físico químicas, demanda energética e parâmetros EHS (environmental, health and safety), e uma análise tecnoeconômica preliminar. Um conjunto inicial de 111 solventes foi utilizado para esse trabalho, sendo que 96 candidatos foram avaliados na etapa 1, e 2 candidatos na última etapa. Os 2 solventes avaliados na última etapa foram o DLimoneno e o Palmitato de Metila, sendo o primeiro já utilizado em trabalhos de extração de óleo de microalga e o segundo uma aparição inovadora. A avaliação tecno-econômica de ambos os solventes resultou em um resultado financeiro pior que o benchmark $n$-hexano, embora ainda possa-se considerar benefícios como créditos de carbono, evasão de multas ambientais e menor custo de tratamento. 
Palavras-chave: microalga, seleção de solventes, avaliação econômica, biorrefinarias. 


\begin{abstract}
NASCIMENTO JÚNIOR, Francisco Agostinho do; Computational assessment of solventes for microalgae lipid extraction. 2019. 191p. Dissertation (Master of Science) - Polytechnic School, University of São Paulo, São Paulo, 2020.
\end{abstract}

Biomass has been highlighted as the main raw material for the production of biofuels, although it is capable of producing several compounds such as: drugs, food additives, materials, among others. Among the various raw materials originating from biomass, we can highlight the microalgae for the production of not only fuels but also several chemicals of interest because of its high productivity, low need for arable land and pure water and its versatility. However, the process has not yet proven to be financially viable due to its high cost. Several works have been done evaluating different cultivation techniques and different processing routes for the production of different fuels in a combined way. This work aims to computationally evaluate the process of extracting lipids from microalgae with different solvents for later production of biodiesel. For this, a multi-step methodology was created with 3 evaluation steps: physical chemical properties, energy demand and EHS (environmental, health and safety) parameters, and a preliminary techno-economic analysis. An initial set of 111 solvents was used for this work, with 96 candidates being evaluated in step 1 , and 2 candidates in the last step. The 2 solvents evaluated in the last stage were D-Limonene and Methyl Palmitate, the first being already used in microalgae oil extraction works and the second an innovative appearance. The technoeconomic assessment of both solvents resulted in a worse financial result than the $n$-hexane benchmark, although benefits such as carbon credits, avoidance of environmental fines and lower treatment costs can still be considered.

Keywords: microalgae, solvente selection, economic assessment, biorrefineries. 


\section{LISTA DE FIGURAS}

Figura 1 - Macroprocesso de produção de biodiesel de óleo de microalgas ...........................

Figura 2 - Desenho esquemático das tecnologias de cultivo: (A) lago artificial e (B)

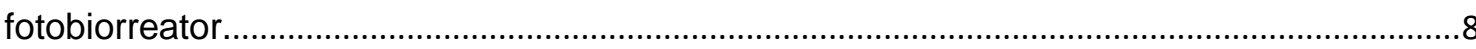

Figura 3 - Tecnologias para ruptura da parede celular das microalgas. .................................10

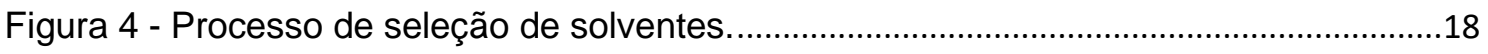

Figura 5 - Abordagem multi-step utilizada no trabalho. .............................................................29

Figura 6 - Conjunto de ferramentas computacionais para avaliação de solventes. ................32

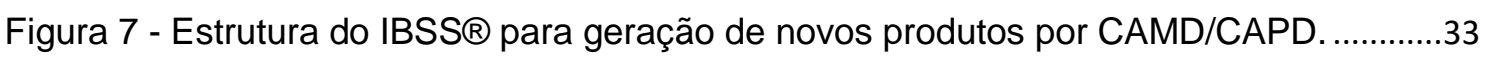

Figura 8 - Estrutura do IBSS $\AA$ no modo de estimativa de propriedades. .................................35

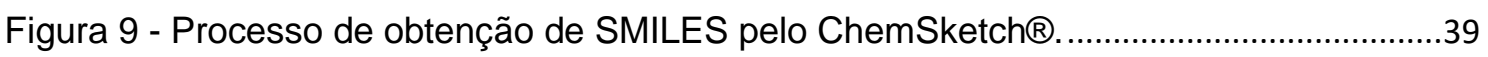

Figura 10 - Delimitação do domínio de simulação avaliado no trabalho..................................57

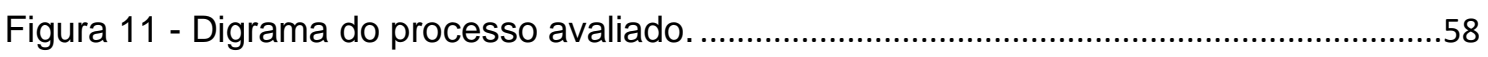

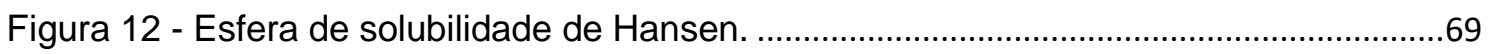

Figura 13 - Comparação entre o desempenho energético dos solventes avaliados..............72

Figura 14 - Análise da influência dos parâmetros na demanda energética de cada uma das

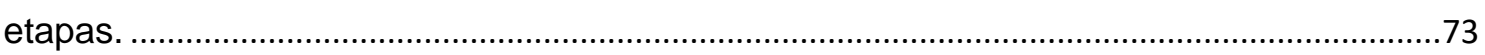

Figura 15 - Comparação entre o n-hexano e o ácido oleico. ……………………………........75

Figura 16 - Capacidade de extração do d-limoneno. ................................................................79

Figura 17 - Comparação da capacidade extração do óleo de microalga na fase orgânica. 80

Figura 18 - Efeito da proporção de solvente e microalga na recuperação de óleo. ...............81

Figura 19 - Painel de comparação de solventes construído no presente trabalho (amostra).

Figura 20 - Projeção de 10 anos da unidade de extração utilizando hexano como solvente. Premissas de preço de venda do óleo de microalga de US\$2,07/kg. Exibição dos 12 primeiros anos por espaço.

Figura 21 - Projeção dos 10 anos restantesda unidade de extração utilizando hexano como solvente. Premissas de preço de venda do óleo de microalga de US $\$ 2,07 / \mathrm{kg}$.

Figura 22 - Projeção de 10 anos da unidade de extração utilizando limoneno como solvente. Premissas de preço de venda do óleo de microalga de US\$2,07/kg. Exibição dos 12 primeiros anos por espaço.

Figura 23 - Projeção de 10 anos restantes da unidade de extração utilizando limoneno como solvente. Premissas de preço de venda do óleo de microalga de US\$ 2,07/ $\mathrm{kg}$.......144 Figura 24 - Projeção de 10 anos da unidade de extração utilizando palmitato de metila como solvente. Premissas de preço de venda do óleo de microalga de US $\$ 2,07 / \mathrm{kg}$.

Exibição dos 12 primeiros anos por espaço.

Figura 25 - Projeção de 10 anos restantes da unidade de extração utilizando palmitato de metila como solvente. Premissas de preço de venda do óleo de microalga de US\$2,07/kg.

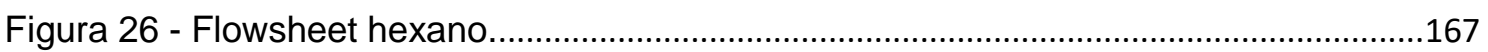

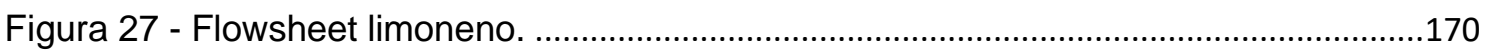

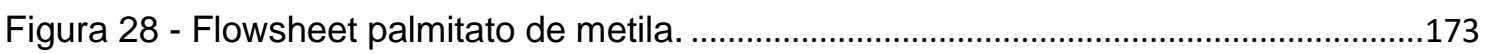




\section{LISTA DE TABELAS}

Tabela 1 - Quadro comparativo de trabalhos sobre extração de lipídio de microalgas........14 Tabela 2 - Quadro comparativo de estudos de viabilidade do processo de valorização de microalgas para produção de biocombustível.

Tabela 3 - Composição em ácidos graxos do óleo da microalga Nannochloropsis sp. em ambiente carente de nutrientes.

Tabela 4 - Composição do lipídio da microalga Nannochloropsis sp. após agrupamento de

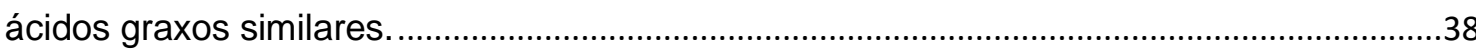

Tabela 5 - Quadro resumo das referências dos métodos de estimativa de propriedade.....39

Tabela 6 - Parâmetros de solubilidade de Hansen para diversos óleos na literatura...........44

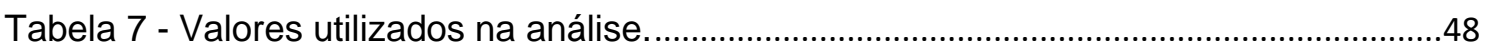

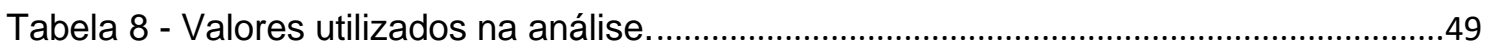

Tabela 9 - Resumo de trabalhos e pacotes termodinâmicos utilizados. ...................................52

Tabela 10 - Composição da microalga utilizada no trabalho. ..................................................53

Tabela 11 - Resumo de trabalhos e premissas de dimensionamento adotadas. ....................54

Tabela 12 - Lista de equipamentos da unidade de extração. ...................................................59

Tabela 13 - Premissas operacionais e financeiras da análise..............................................60

Tabela 14 - Composição do lipídio da microalga Nannochloropsis sp. em FORTRAN.......62

Tabela 15 - Nome e código de cada ácido graxo presente na microalga...............................63

Tabela 16 - Parâmetros de Hansen do óleo de microalga estimados pelo software IBSS $\AA$ através do SMILES de cada triacilglicerol. Legenda: $\delta_{D}$ (parâmetro dispersivo), $\delta_{P}$ (parâmetro de momento dipolo) e $\delta_{H}$ (parâmetro de pontes de hidrogênio). ...........................64 Tabela 17 - Comparação dos parâmetros de solubilidade de Hansen para diversos óleos com o lipídio da microalga Nannochloropsis sp. (A) representa o óleo comparado e (B) o

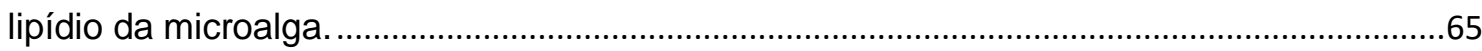

Tabela 18 - RED para cada solvente e usando diferentes raios de interação $\left(R_{0}\right)$ : do óleo de palma, triacetina e biodiesel de óleo de palma. Em verde os solventes que solubilizam o lipídio e em vermelho os solventes que não solubilizam.......................................................66 Tabela 19 - Demanda energética (em MJ gasto/MJ de biodiesel produzido) de cada etapa

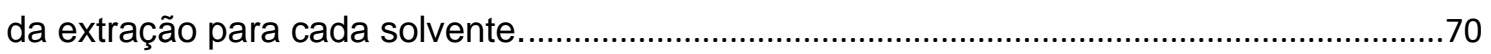

Tabela 20 - Parâmetros normalizados para os solventes avaliados. .......................................74

Tabela 21 - Classificação dos solventes nas perspectivas avaliadas. ......................................76

Tabela 22 - Solventes selecionados para Etapa 3 e comparação do rating process (quanto

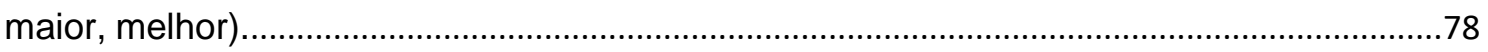

Tabela 23 - Correntes mássicas e energéticas para os três casos. .........................................82

Tabela 24 - Valor das dimensões de projeto de equipamentos para os três casos...............82

Tabela 25 - Detalhamento das componentes para cálculo de CAPEX e OPEX ......................84

Tabela 26 - Comparação do preço mínimo de venda do óleo de microalga sob custos de

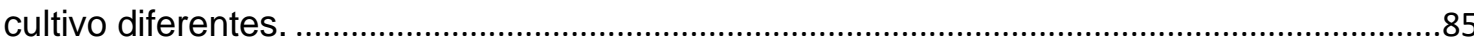

Tabela 27 - Parâmetros para estimativas do custo de equipamento......................................139

Tabela 28 - Parâmetros de ajuste de custos...........................................................................139

Tabela 29 - SMILES dos triacilgliceróis presentes no lipídio da microalga. .........................147 
Tabela 30 - SMILES dos solventes selecionados para estudo 149

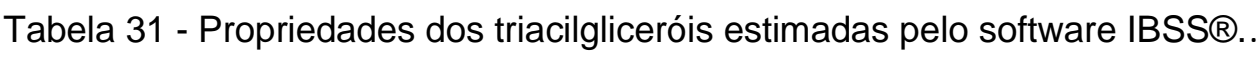

Tabela 32 - Propriedades dos solventes estimadas pelo software IBSS $\AA^{\circ}$ 154

Tabela 33 - Parâmetros EHS dos solventes estimadas pelo software IBSS $\AA$ com o modelo de Weis e Visco (2011). 158

Tabela 34 - Parâmetros de Hansen dos solventes estimados pelo software IBSS $\AA$. 162

Tabela 35 - Correntes da simulação para o n-hexano.

Tabela 36 - Correntes da simulação para o limoneno.

Tabela 37 - Correntes da simulação para o palmitato de metila. .173 


\section{LISTA DE SÍMBOLOS}

\begin{tabular}{|c|c|}
\hline$\delta_{d}$ & Força dispersiva \\
\hline$\delta_{p}$ & Força dipolo-dipolo \\
\hline$\delta_{h}$ & Força de ligação de hidrogênio \\
\hline $\mathrm{Ra}$ & Distância entre soluto e solvente \\
\hline $\mathrm{R}_{0}$ & Raio de solubilidade \\
\hline RED & Densidade energética relativa \\
\hline Ws & Solubilidade aquosa \\
\hline$I_{\text {mix }}$ & Intensidade da mistura \\
\hline tres & Tempo de residência \\
\hline$\Delta \mathrm{H}^{\circ} \mathrm{C}$, Biodiesel & Entalpia de combustão do biodiesel \\
\hline ฤt-esterificação & Rendimento da transesterificação do óleo de microalga \\
\hline$\rho_{\text {mix }}$ & Densidade da mistura \\
\hline$\rho_{w}$ & Densidade da água \\
\hline Psolv & Densidade do solvente \\
\hline & Densidade dos triacilgliceróis \\
\hline PnonTAG & Densidade da biomassa desconsiderando triacilgliceróis \\
\hline $\mathrm{xw}$ & Fração de água \\
\hline XnonTAG & Fração de biomassa desconsiderando triacilgliceróis \\
\hline Xsolv & Fração de solvente \\
\hline XTAG & Fração de triacilgliceróis \\
\hline$S: P$ & Razão entre solvente e pasta de microalga \\
\hline$\%$ TAG & Percentual de lipídios da microalga \\
\hline \%Solids & Percentual de biomassa seca na pasta \\
\hline$P_{\text {cent }}$ & Potência da centrífuga \\
\hline$\dot{\mathrm{m}}_{\mathrm{TAG}}$ & Vazão de lipídio na centrífuga \\
\hline$Q_{\text {cent }}$ & Vazãovolumétrica na centrífuga \\
\hline$V_{g}$ & Velocidade terminal \\
\hline$\Sigma$ & Fator sigma da centrífuga \\
\hline$\lambda_{w}$ & Calor latente de vaporização da água \\
\hline$\lambda_{\text {solv }}$ & Calor latente de vaporização do solvente \\
\hline $\mathrm{K}$ & Volatilização relativa entre solvente e água \\
\hline$\eta_{\text {energy-rec }}$ & Eficiência da separação por evaporação do solvente \\
\hline$\Delta \mathrm{H}^{\circ} \mathrm{C}$, Solvent & Entalpia de combustão do solvente \\
\hline$\varphi_{\text {solv }}$ & Fator de perda de solvente por processamento de microalga \\
\hline$\Phi_{\text {mix }}$ & Densidade energética da etapa de mistura \\
\hline$\Phi_{\text {sep }}$ & Densidade energética de etapa de separação \\
\hline$\Phi_{\text {evap }}$ & Densidade energética da etapa de evaporação \\
\hline$\Phi_{\text {loss }}$ & Densidade energética da perda de solvente \\
\hline$\Phi$ & Densidade energética do processo de extração \\
\hline
\end{tabular}




\section{SUMÁRIO}

1. INTRODUÇÃO

1.1. Objetivos

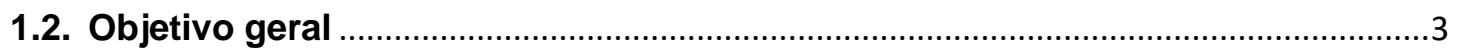

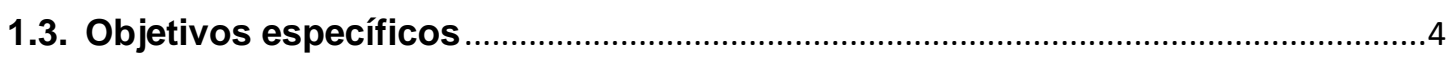

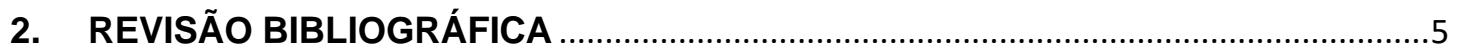

2.1. Processo de produção de biodiesel a partir de microalgas ...................................

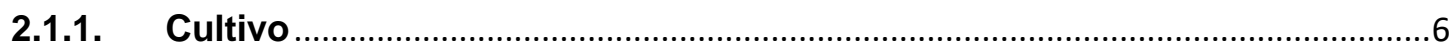

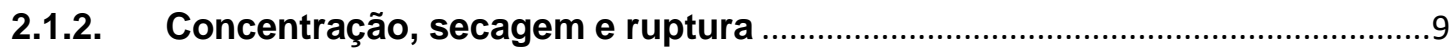

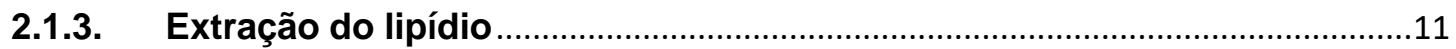

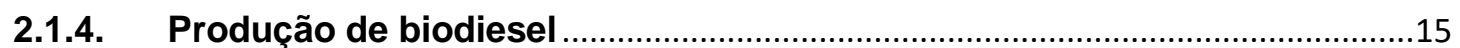

2.2. O solvente: propriedades e green solventes........................................................16

2.3. Seleção de solventes..................................................................................................17

2.4. Ferramentas virtuais de análise e seleção de solventes ........................................21

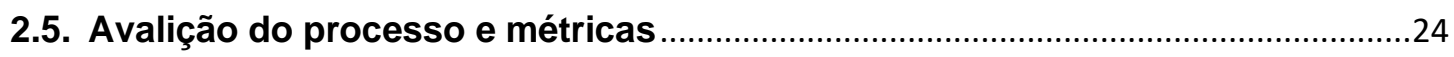

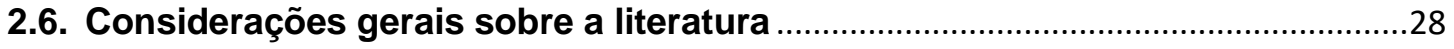

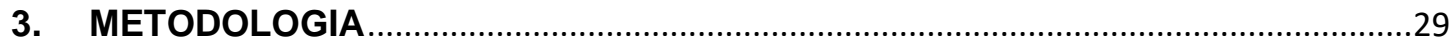

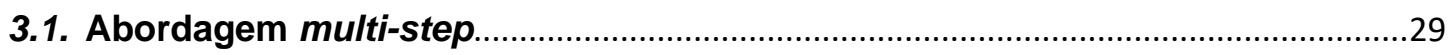

3.1.1. Ferramentas computacionais utilizadas ......................................................

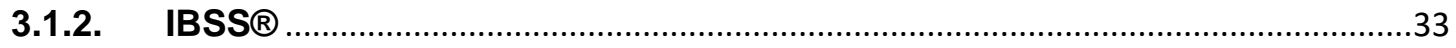

3.1.3. Simulação do processo e análises financeiras.................................................

3.2. Estruturação do ambiente computacional e cálculo das propriedades (Step 0) 36

3.2.1. Definição da composição do lipídio da microalga ………………………........36

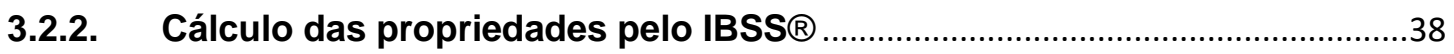

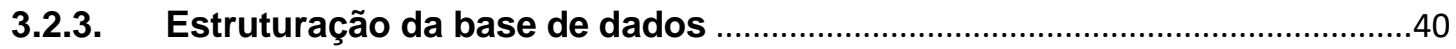

3.3. Análise das propriedades estimadas (Step 1) …...................................................40

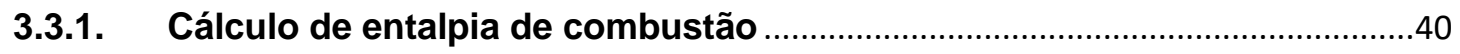

3.3.2. Parâmetros de solubilidade de Hansen ...........................................................

3.3.3. Solubilidade do solvente em água ……………............................................

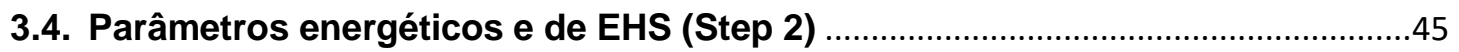

3.4.1. Modelo de demanda energética de Martin ......................................................... 
3.4.2. Ajuste e comparação dos parâmetros EHS e energéticos

3.4.3. Seleção dos solventes.

3.5. Análise tecno-econômica: simulação de processos e modelos econômicos (Step 3).

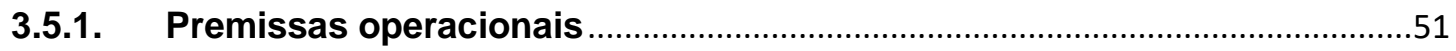

3.5.2. Análises preliminares de capacidade de extração...........................................56

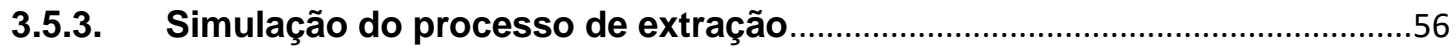

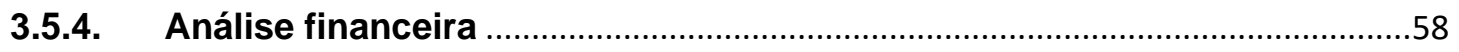

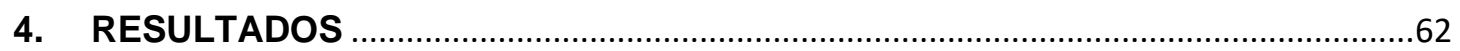

4.1. Cálculo das propriedades do lipídio e do solvente (etapa 0) ..............................62

4.2. Propriedades do solvente e solubilidade (Etapa 1) ..............................................64

4.3. Desempenho energético e EHS (Etapa 2) .................................................................

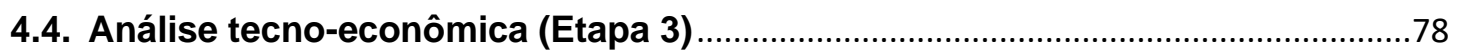

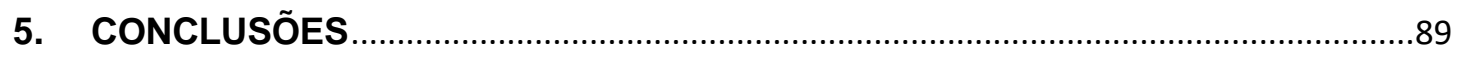

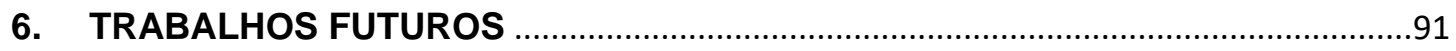

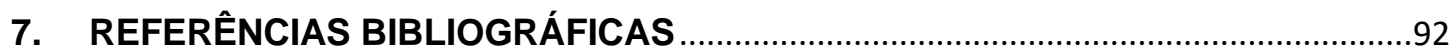

8. APÊNDICE

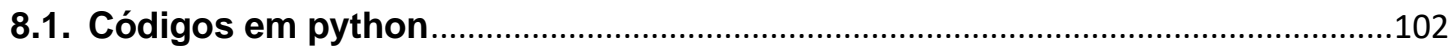

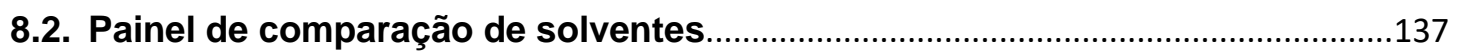

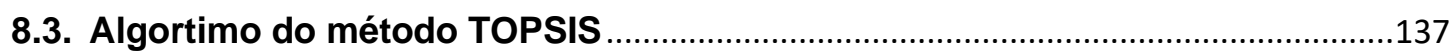

8.4. Análise financeira das unidades de extração de lipídio ......................................139

8.5. SMILES dos compostos utilizados (TAGs e solventes) ………………..............147

8.6. Tabela com propriedades dos compostos utilizados (TAGs e solventes). .....152

8.7. Especificações e correntes da simulação …………………………………..........167 


\section{INTRODUÇÃO}

Atualmente existe uma grande atenção em relação à utilização da biomassa para diversas finalidades, desde a geração de energia elétrica até a produção de químicos que podem servir como base para fármacos, biocombustíveis, solventes, lubrificantes e outros produtos. Neste contexto, realizar o melhor aproveitamento, operacional e ambiental da biomassa é imperativo. Dessa forma, pode-se estender o conceito das refinarias de petróleo para o âmbito da conversão da biomassa e definir a biorrefinaria como uma unidade que processa biomassa e tem a capacidade de produzir um amplo espectro de produtos por meio de diferentes tecnologias de processamento, sejam elas químicas, termoquímicas ou bioquímicas. (CRISTI, 2007)

De uma ampla gama de exemplos de biomassa, podemos destacar as microalgas, que vem ganhando crescente interesse científico e tecnológico. As microalgas são seres unicelulares autotróficos que possuem a capacidade de converter $\mathrm{CO}_{2}$ em diversos produtos de interesse.

Em comparação com outros tipos de biomassa, as microalgas possuem diversas vantagens, tais como; maior produtividade por hectare, não necessitar de terra fértil e arável, não necessitar de água pura, ter alta versatilidade no cultivo para diferentes fins, não competir com a cadeia de suprimentos alimentícia e por ter um crescimento rápido possibilitando uma produção constante e sem sazonalidades.

$\mathrm{Na}$ literatura encontram-se casos de diferentes produtos resultantes do processamento de microalgas, tais como biodiesel, compostos nutricionais, gás de síntese, etanol e plataformas químicas para síntese de fármacos, dentre outros (CRISTI, 2007; WILLIAMS; LAURENS, 2010).

Dentre os casos mencionados, vale destacar a produção de biocombustíveis. As vantagens inerentes ao uso das microalgas como matériaprima de biorrefinarias a posicionam como de grande potencial na matriz energética futura. Além disso, vale ressaltar que existem diversas técnicas para conversão de componentes de microalgas em biocombustíveis, destacando-se os processos termoquímicos (gaseificação, pirólise, liquefação hidrotérmica), 
métodos bioquímicos (fermentação e digestão anaeróbica) e extração do óleo de microalgas e posterior conversão em bio combustível (CHAUDRY; BAHRI; MOHEIMANI, 2015)

Existem três gêneros que recebem destaque na literatura: Scenedemus, Chlorella e Nannochloropsis. Isso se dá ao alto potencial de acúmulo de lipídios, bem como, alta taxa de produtividade, sendo objeto de diversos estudos na literatura. Ressalta-se que, para o presente trabalho, a Nannochloropsis sp. foi utilizada como modelo de estudo. (LAURENS et al., 2017)

Embora muitas vantagens do uso de microalgas tenham sido já identificadas, há um grande desafio em viabilizar a produção de biocombustíveis de microalga em escala industrial. Dentre esses desafios, destacam-se o fato de não haver ainda um profundo conhecimento de como parâmetros e propriedades influenciam no processo e o alto custo envolvido. Em processos que possuem necessidade de uma etapa de secagem, o gasto energético requerido ultrapassa o conteúdo energético do combustível gerado, fazendo assim com que o processo seja inviável energeticamente. Uma das saídas é utilizar técnicas que dispensem a etapa de secagem, como a extração da pasta de microalga com solvente insolúvel em água. (HALIM; DANQUAH; WEBLEY, 2012)

O processo de extração consiste em realizar a ruptura das paredes das microalgas em meio aquoso e realizar uma posterior extração dos lipídios disponíveis com solvente apolar. Dessa forma, um sistema bifásico é obtido com uma fase orgânica e uma aquosa. O objetivo principal é extrair os lipídios apolares para a produção de biodiesel, enquanto o restante dos componentes (proteínas, carboidratos e ácido nucleicos) pode ser separados e utilizados para outros fins, como compostos nutricionais de alto valor, ração para animais e até energia pela queima ou produção de outros biocombustíveis, reforçando o conceito de biorrefinaria. (HALIM; DANQUAH; WEBLEY, 2012)

No processo de extração, o solvente desempenha papel de destaque. Os principais pontos a serem considerados são a imiscibilidade do solvente na água, a capacidade de extração do solvente, a facilidade de recuperação, além do custo e toxicidade. Dessa forma, a seleção de bons solventes (considerando os aspectos energético, ambiental, econômico e toxicológico) é uma forma de 
viabilizar economicamente e ambientalmente a produção de biodiesel por meio da extração do óleo de microalga.

Selecionar o solvente mais adequado é um desafio complexo considerando a diversidade de opções disponíveis atualmente na indústria, além dos possíveis trade-offs entre os parâmetros dos solventes (operacional, econômico e ambiental) (SOH; ECKELMAN, 2016). A princípio, para se levar em consideração as diversas opções existentes de solventes, seriam necessários estudos e experimentos para que os melhores candidatos pudessem ser identificados. Entretanto, partindo do grande número de opções, é contraprodutivo realizar todos os testes na bancada de laboratório. Para endereçar esse problema, pode-se lançar mão de técnicas de simulação computacional para conduzir experimentos in silico. (HEINTZ et al., 2014)

Com a diversidade de dados e opções disponíveis, ferramentas computacionais tem ganhado cada vez mais importância dentro da área de engenharia de produtos, por permitir análises e avaliações variadas e complexas, reduzindo otempo e recursos econômicos para identificação de bons solventes. Essa virtualização de experimentos cria atalhos gerando um número limitado das opções para que se possa realizar os testes de bancada nas condições com maior potencial de sucesso.

Em vários casos, para encontrar a condição ótima de operação, há a necessidade de avaliar as combinações possíveis e seus respectivos critérios de desempenho. Dessa forma, ferramentas computacionais com modelos adequados de predição de propriedades podem ser úteis na prospecção de novos solventes para extração de óleo de microalga.

\subsection{Objetivos}

\subsection{Objetivo geral}

Elaborar e aplicar uma metodologia sistemática para avaliação e seleção de solventes para o processo de extração do lipídio da microalga 
Nannochloropsis sp. via extração com solvente (wet route), avaliado os solventes nos quesitos operacionais e ambientais.

\subsection{Objetivos específicos}

- Criar um banco de dados com todos os solventes a serem avaliados e suas respectivas propriedades;

- Descrever, em termos de propriedades físico-químicas, a microalga para realização dos experimentos virtuais;

- Implementar algoritmos de avaliação computacional de propriedades físico-químicas e seleção de solventes aptos para o processo;

- Implementar um modelo de estimativa de demanda energética para o processo de extração;

- Implementar uma metodologia de comparação de solventes nos quesitos operacionais e ambientais;

- Criar uma abordagem para simulação de processos envolvendo microalgas em simulador comercial;

- Analisar tecno-economicamente o desempenho de solventes no processo de extração de lipídio da microalga. 


\section{REVISÃO BIBLIOGRÁFICA}

\subsection{Processo de produção de biodiesel a partir de microalgas}

Sob uma perspectiva de produção de combustíveis, existem diversas maneiras de se produzir diferentes produtos a partir de microalgas. Vários estudos relataram a possibilidade de produzir energia de variadas formas, como: metano a partir de digestão anaeróbica da biomassa da microalga (SPOLAORE et al., 2006; ZAMALLOA et al., 2011), hidrogênio de forma fotobiológica (FEDOROV et al., 2005; GHIRARDI et al., 2000; KAPDAN; KARGI, 2006; MELIS, 2002), bio-óleo a partir de liquefação hidrotérmica (LÓPEZ BARREIRO et al., 2013) e biodiesel a partir da transesterificação do óleo de microalga (ROESSLER et al., 1994; SAWAYAMA et al., 1995).

Destas opções, a produção de biodiesel a partir dos lipídios contidos na microalga tem como diferencial a possibilidade de aproveitar a composição variada da microalga para produção combinada de outros produtos tais como pigmentos, aditivos alimentícios e compostos bioativos de alto valor, tornando assim a operação da unidade mais atraente financeiramente e versátil (MARTIN, 2016; WILLIAMS; LAURENS, 2010).

Os lipídios presentes na microalga podem ser divididos em três grupos principais: lipídios neutros (NL), fosfolipídios (PL) e glicolipídios (GL). Os fosfolipídios e glicolipídios são geralmente provenientes das membranas da microalga, enquanto os lipídios neutros são acumulados internamente como reserva energética (HALIM; DANQUAH; WEBLEY, 2012).

Os lipídios neutros podem ser encontrados em sua maioria na forma de triacilgliceróis (TAGs), mas também na forma de diacilgliceróis (DAGs), monoacilgliceróis (MAGs) e ácidos graxos livres (FFAs - Free Fatty Acids). Estes compostos podem ser utilizados como matéria-prima para produção de bitodiesel por meio do processo de transesterificação, à semelhança do que ocorre na produção de biodiesel de óleos vegetais. (HALIM; DANQUAH; WEBLEY, 2012; JIMÉNEZ CALLEJÓN et al., 2014; OLMSTEAD et al., 2013) 
A produção de biodiesel a partir do lipídio extraído das microalgas contempla mais de uma rota de processamento e inclui diversas etapas, como pode ser visto na Figura 1.

Figura 1 - Macroprocesso de produção de biodiesel de óleo de microalgas

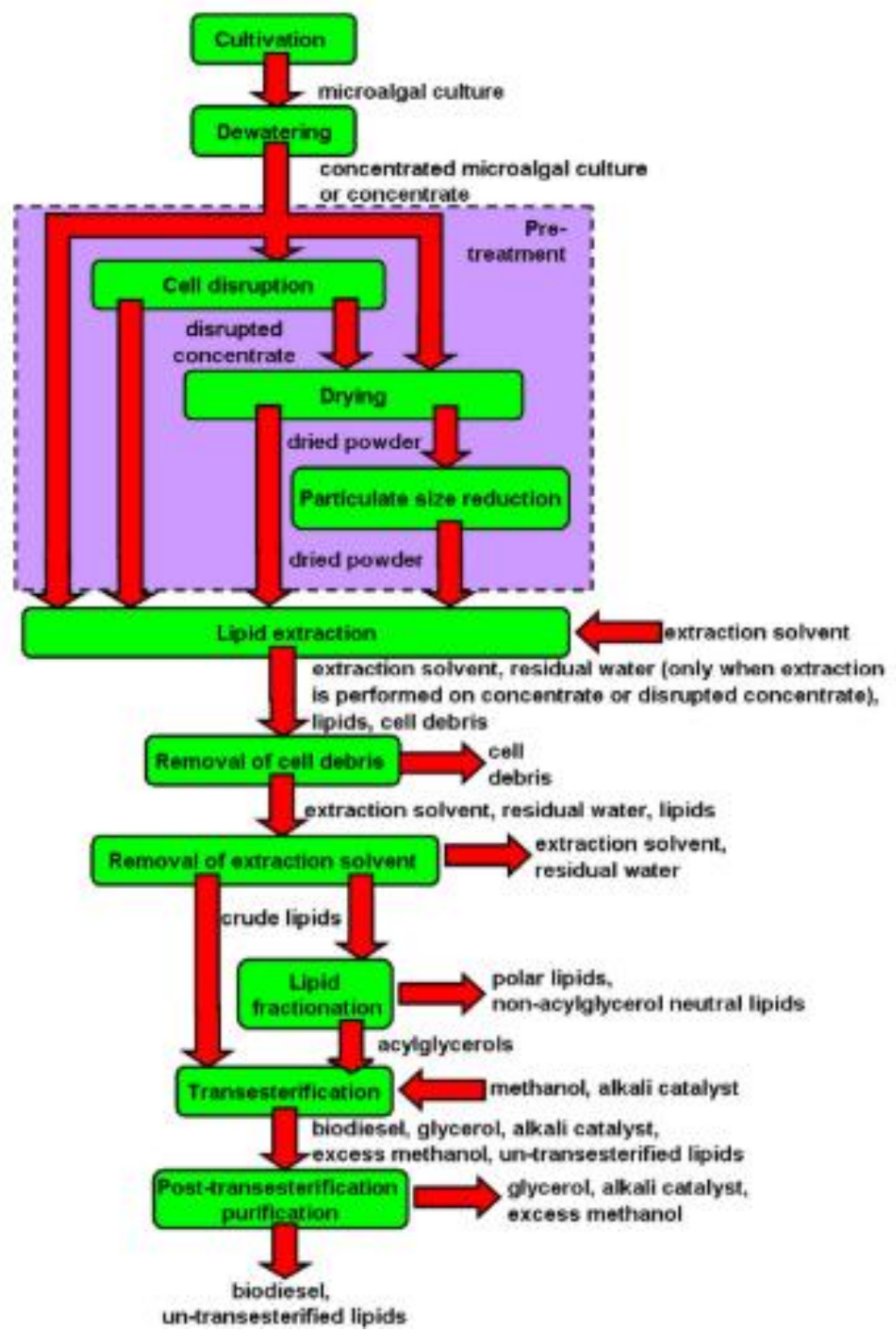

Fonte: (HALIM; DANQUAH; WEBLEY, 2012).

\subsubsection{Cultivo}

O grande desafio da etapa de cultivo de microalgas é selecionar uma tecnologia que permita alta velocidade de crescimento, impeça crescimento de outras espécies, seja economicamente viável e permita o cultivo de microalgas 
com quantidade ótima de lipídio. Atualmente existem duas tecnologias mais aplicadas para cultivo de microalga em larga escala: o cultivo em lagos artificiais (open pond) ou em fotobiorreatores. (CRISTI, 2007)

O cultivo em lagos artificiais é realizado pela recirculação da cultura através de pás rotativas em um canal aberto com profundidade de cerca de 30 centímetros. Nesse tipo de cultivo, a produtividade pode ser afetada por diversos fatores, tais como possibilidade de contaminação da cultura com outras espécies, uso menos eficiente de gás carbônico, menor concentração de biomassa e falta de controle de temperatura (controlada majoritariamente pela evaporação da água). Sua grande vantagem, no entanto, é seu baixo custo operacional e de construção. (CRISTI, 2007)

Já o cultivo em fotobiorreatores é realizado utilizando uma construção mais robusta, com maior controle de temperatura e da concentração de gases dentro de um sistema fechado, que impede a contaminação com outras culturas. Para isso, a cultura entra em uma coluna de desgaseificação, em que ar é borbulhado de forma ascendente para que gases dissolvidos na cultura sejam absorvidos e direcionados para a exaustão, permitindo que a cultura tenha níveis controlados de concentração de gases. (CRISTI, 2007)

Além disso, o controle de temperatura é realizado por meio de água de resfriamento. Da coluna de desgaseificação, a cultura é bombeada para um arranjo de tubos transparentes para captura da luz solar. Esses tubos possuem no máximo 0,1 metro de diâmetro, devido à dificuldade de penetração da luz na cultura concentrada. (CRISTI, 2007)

Dessa forma, com a utilização de soluções concentradas e um maior controle dos parâmetros de operação, esse cultivo é capaz de atingir produtividades muito maiores, porém, a um custo de construção e operação maior. O desenho esquemático das duas tecnologias pode ser visto na Figura 2. 
Figura 2 - Desenho esquemático das tecnologias de cultivo: (A) lago artificial e (B) fotobiorreator.

(A)

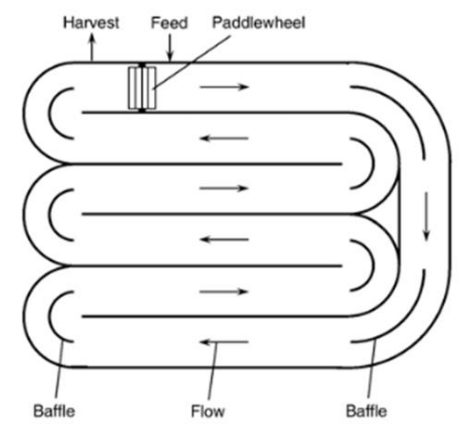

(B)

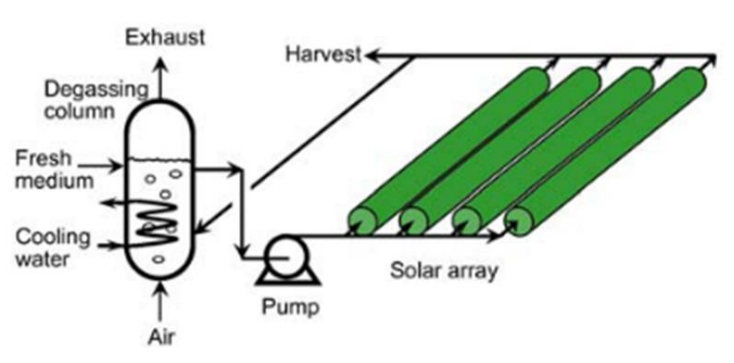

Fonte: (CRISTI, 2007).

Embora o cultivo de microalga não necessite de terras produtivas e em grande quantidade (devido a sua produtividade mais alta em relação a culturas terrestres tradicionais, como soja), ainda existe competição na aquisição de nutrientes com a indústria alimentícia, associado ainda a um custo energético e financeiro das instalações. (STEPHENSON et al., 2010)

Seguido do cultivo, existe também a possibilidade de realizar uma etapa de incubação para eliminar aglomerações de microalgas e enfraquecer suas paredes celulares para se obter maior eficiência na extração dos lipídios. (HALIM; DANQUAH; WEBLEY, 2012)

Olmstead et al. (2013) produziram biodiesel a partir da microalga Nannochloropsis sp. por meio da transesterificação do óleo extraído utilizando n-hexano como solvente. Nesse trabalho, foi realizado uma análise do processo de ruptura das células por meio de homogeneização à alta pressão com ou sem incubação prévia. A cultura foi incubada por períodos entre 5 e $16 \mathrm{~h}$ em um vaso agitado com temperatura de $37^{\circ} \mathrm{C}$ constante e $\mathrm{pH}$ controlado. Os resultados encontrados foram que a incubação facilitou o processo seguinte de ruptura das paredes celulares da microalga, tornando os lipídios mais acessíveis, aumentando a eficiência da extração. Posteriormente, Halim et al. (2016) 
realizaram também a produção de biodiesel pela mesma rota e atingiram resultados similares, reforçando a importância dessa etapa como apoio à etapa de ruptura.

\subsubsection{Concentração, secagem e ruptura}

Após o processo de cultivo, esse meio aquoso contendo microalga deve ser concentrado até atingir um percentual de $25 \% \mathrm{~m} / \mathrm{m}$ de biomassa seca, resultando em uma pasta viscosa para posterior processamento. Esse processo de concentração pode ser realizado por floculação, filtração ou centrifugação (HALIM; DANQUAH; WEBLEY, 2012; OLMSTEAD et al., 2013). A partir desta etapa, existem duas rotas conhecidas para processamento da pasta e extração dos lipídios para produção de biodiesel: a rota seca (dry route) e a rota úmida (wet route) (ROUX; LAMOTTE; ACHARD, 2017).

A rota seca consiste em submeter a cultura a um processo de secagem até atingir um teor maior que $85 \% \mathrm{~m} / \mathrm{m}$ de biomassa. Nesse ponto é possível realizar um processo de extração com solvente polar ou uma combinação de solventes (polar e apolar). Essa rota permite uma maior extração dos lipídios, no entanto, a etapa de secagem até esse nível de concentração pode representar até $85 \%$ da energia consumida por todo o processo, comprometendo a viabilidade operacional do uso dessa rota para produção exclusiva de biodiesel. Dessa forma, esse método pode ser aplicado em processos que almejam isolar compostos de alto valor agregado, como ácidos graxos ômega-3, bem como para uso determinação de quantidade de lipídios em ambientes de testes em laboratórios. (ROUX; LAMOTTE; ACHARD, 2017).

Essa etapa de secagem pode ser realizada empregando duas técnicas, a liofilização e a secagem térmica. A liofilização possui como vantagens o uso de condições de operações mais brandas (temperatura mais baixa) em comparação com a secagem térmica, evitando possível degradação ou evaporação de lipídios e outros compostos de interesse (HALIM; DANQUAH; WEBLEY, 2012) 
Já a rota úmida (wet route), consiste em realizar a extração dos lipídios diretamente na pasta de biomassa com um solvente apolar, formando uma mistura bifásica em que os lipídios neutros se encontram na fase orgânica e o restante dos compostos na fase aquosa. Essa rota possui um potencial de viabilidade operacional maior por dispensar a etapa de secagem térmica. Entretanto, há fatores que comprometem a eficiência na extração dos lipídios, como: transferência de massa dificultada pela presença de água e paredes celulares da microalga intactas tornando os lipídios pouco acessíveis. Para amenizar o problema de acessibilidade dos lipídios, é recomendada uma etapa intermediária de ruptura das células de microalga para que se tornem mais acessíveis para extração.

Atualmente existem várias técnicas utilizadas para realizar a ruptura das células, seja de forma mecânica como não-mecânica, como apresentado na Figura 3. Os métodos mecânicos incluem homogeneização à alta pressão, micro-ondas, ultrassonicação, moagem, entre outros. Já os métodos não mecânicos incluem choque osmótico, quebra enzimática e quebra por utilização de ácidos ou bases (HALIM; DANQUAH; WEBLEY, 2012; ROUX; LAMOTTE; ACHARD, 2017).

Figura 3 - Tecnologias para ruptura da parede celular das microalgas.

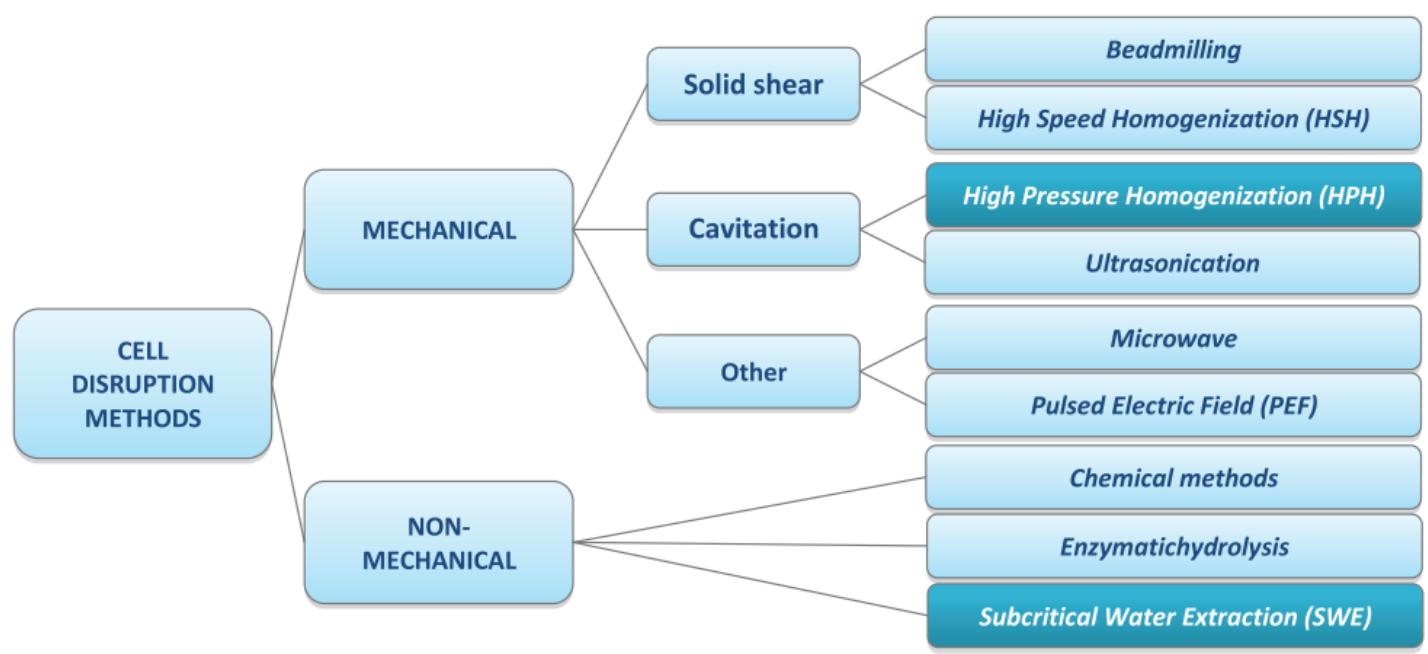

Fonte: (ROUX; LAMOTTE; ACHARD, 2017). 
Para a ruptura de célula em escala de processo, a tecnologia deve ser viável e possuir a capacidade de processar continuamente biomassa com alta viscosidade, sendo energeticamente eficiente, com pouco tempo de residência e causando um mínimo de degradação do produto (YAP et al., 2014).

Dentre os métodos listados, os que possuem maior potencial para serem utilizados em larga escala são a homogeneização à alta pressão e a moagem por esferas (HALIM; DANQUAH; WEBLEY, 2012). A homogeneização à alta pressão é realizada pelo bombeamento do concentrado pelo orifício de uma válvula sob alta pressão para ser liberado em uma câmara de baixa pressão. A colisão das células com as paredes da válvula e a queda de pressão acarretam a desintegração das paredes celulares das microalgas (HALIM; DANQUAH; WEBLEY, 2012).

Lee et al. (1998) obtiveram rendimentos duas vezes maiores ao submeter a microalga a um processo de ruptura antes de extrair os lipídios da microalga Botryococcus braunii utilizando uma mistura de clorofórmio e metanol. Olmstead et al. (2013) utilizaram homogeneização à alta pressão após um período de incubação para extrair lipídios da microalga Nannochloropsis sp. utilizando nhexano, atingindo uma recuperação de 70,4\% dos lipídios disponíveis.

\subsubsection{Extração do lipídio}

Após o pré-tratamento, a biomassa da microalga pode assumir duas formas, dependendo da rota de produção utilizada: pasta concentrada ou em pó seco. Nas duas formas, as paredes celulares devem estar desintegradas para que os compostos de interesse estejam acessíveis para serem solubilizados no solvente.

A etapa de extração apresenta grandes dificuldades operacionais. A rota de biomassa seca requer a etapa anterior de secagem térmica, e inviabiliza o processo por demandar muita energia. Já quando a pasta de biomassa é utilizada, a eficiência é prejudicada pela dificuldade na transferência de massa. 
Muitos processos de extração de lipídio da pasta de biomassa fazem uso de solventes tóxicos e caros, como clorofórmio e metanol (BLIGH, E. J.; DYER, 1959), ou processos operacionalmente inviáveis devido ao gasto energético muito alto (extração via Soxhlet ou uso de temperaturas e pressões altas), misturas de solventes difíceis de se recuperar ou altas proporções de solvente (MARTIN, 2016). Entretanto, diversos trabalhos têm sido desenvolvidos para contornar estas limitações e encontrar rotas alternativas viáveis para o processo. (HALIM; DANQUAH; WEBLEY, 2012)

Essa busca por novos caminhos para a extração de lipídios da microalga para produção de biocombustíveis pode ser associada com o estudo de novos processos de extração e de ruptura de parede celular das microalgas. Além disso, já é reportado na literatura o teste de novas possibilidades englobando solventes tradicionais (menos tóxicos, porém amplamente utilizados na indústria, solventes de origem natural - bio based solvents), líquidos iônicos e fluidos supercríticos, sendo o $\mathrm{CO}_{2}$ o mais comum.(SATI et al., 2019)

Nagle e Lemke (1990) obtiveram até 90\% de recuperação dos lipídios da microalga Chaetoceros muelleri utilizando solventes menos agressivos (1butanol, ou etanol, ou n-hexano/2-propanol). Entretanto, as extrações foram realizadas em temperaturas próximas as de ebulição dos solventes e em razões altas (até 20:1 de solvente:biomassa). Posteriormente, Chen et al. (2012) atingiram os mesmos níveis de recuperação para a microalga Nannochloropsis $\mathrm{sp}$. utilizando misturas de n-hexano/etanol, porém novamente com razões altas (10:1 de solvente:biomassa), temperaturas altas $\left(90^{\circ} \mathrm{C}\right)$ e pressões altas $(1,4$ $\mathrm{MPa})$.

Halim et al. (2011) realizaram um estudo comparativo para extração de lipídio da microalga Nannochloropsis sp. utilizando como solventes n-hexano, nhexano/isopropanol e $\mathrm{CO}_{2}$ supercrítico em pasta de microalga e microalga seca obtendo recuperações entre $14 \%$ ( $n$-hexano em pasta de microalga) e quase $100 \%\left(\mathrm{CO}_{2}\right.$ supercrítico em pasta de microalga, mas com fluxo bastante reduzido).

Dejoye Tanzi et al. (2013) utilizaram terpenos (d-limoneno, alfa-pineno and p-cumeno) em altas razões (até $35: 1$ solvente:biomassa) e atingiram 19\% 
de recuperação por meio de um processo simultâneo de destilação e extração. Embora em condições desfavoráveis, o processo apresentou consumo energético quase quatro vezes menor frente a extração via Soxlet e fez uso de solventes menos nocivos e de origens naturais.

Olmstead et al. (2013) submeteram a microalga Nannochloropsis sp. à incubação e ruptura por meio de homogeneização à alta pressão e utilizaram nhexano em razões baixas (2:1 de solvente:biomassa) em dois estágios de extração e obtiveram uma recuperação de 70\% dos lipídios. Jiménez Callejón et al. (2014) submeteram a microalga Chroloroccum sp. em hexano após etapa de ruptura e obtiveram recuperação de até $66 \%$ dos lipídios.

Halim et al. (2016) realizaram a extração de lipídio da microalga Nannochloropsis sp. em estado de abundância de nutrientes em n-hexano variando quantidade de estágios (1 a 3) e proporção de solvente:pasta de 0,2:1 a 0,8:1 e obtiveram recuperações de lipídio de até 37\%.

A Tabela 1 apresenta um resumo dos trabalhos realizados com foco em extração de lipídios de microalgas utilizando solventes. 
Tabela 1 - Quadro comparativo de trabalhos sobre extração de lipídio de microalgas.

\begin{tabular}{|c|c|c|c|c|}
\hline Autores & Solvente & Condições & Recuperação & Observações \\
\hline Nagle e Lemke (1990) & $\begin{array}{l}\text { 1-butanol, etanol, n-hexano/2- } \\
\text { propanol }\end{array}$ & Proporção 20:1 & $90 \%$ & $\begin{array}{l}\text { Temperaturas próximas à } \\
\text { ebulição }\end{array}$ \\
\hline Chen et al. (2012) & n-hexano/etanol & Proporção 10:1 & $90 \%$ & $\begin{array}{l}\text { Temperatura e pressão } \\
\text { altas }\end{array}$ \\
\hline $\begin{array}{l}\text { Dejoye Tanzi et al. } \\
\text { (2013) }\end{array}$ & $\begin{array}{l}\mathrm{d} \text {-limoneno, alfa-pineno and } \mathrm{p} \text { - } \\
\text { cumeno }\end{array}$ & Proporção 35:1 & $19 \%$ & $\begin{array}{l}\text { Processo de destilação e } \\
\text { extração simultânea }\end{array}$ \\
\hline Olmstead et al. (2013) & n-hexano & Proporção 2:1 & $70 \%$ & $\begin{array}{l}\text { Temperatura e pressão } \\
\text { baixas, rota úmida }\end{array}$ \\
\hline
\end{tabular}

Fonte: Próprio autor. 
O grande desafio da etapa de extração é obter boa recuperação dos lipídios neutros na fase orgânica por meio de solventes de baixo custo, nãonocivos (em aspectos de segurança e impacto ambiental e à saúde humana) em proporções (ou quantidade) baixas e condições brandas de temperatura e pressão. Para isso, é necessário que o solvente apresente as seguintes características básicas: imiscibilidade em água, seletividade, facilidade de recuperação, baixo custo, e seja não nocivo à saúde humana e ao meioambiente. (ANGLES et al., 2017)

\subsubsection{Produção de biodiesel}

A fase orgânica proveniente da extração deve ser evaporada para resultar no lipídio bruto, que poderá ser convertido em diesel renovável ou biodiesel. $O$ diesel renovável pode ser produzido por meio de reações de hidrotratamento (WILLIAMS; LAURENS, 2010).

Já o biodiesel é produzido através da transesterificação dos triacilgliceróis em meio alcóolico (metanol ou etanol) utilizando catalisadores ácidos ou básicos. Essa reação produz o éster metílico (ou etílico, dependendo do álcool usado na reação) de ácido graxo, denominado biodiesel, e glicerol como coproduto. A síntese geralmente é realizada com uso de catálise ácida, básica ou enzimática, de forma homogênea ou heterogênea (CRISTI, 2007; SMITH; GREENWELL; WHITING, 2009)

Existem vários trabalhos publicados na literatura sobre o processo de transesterificação em diferentes condições de operação, com diferentes catalisadores e com diferentes óleos vegetais (óleo de soja, canola, girassol etc.). Além disso, existem trabalhos que relataram a produção de biodiesel in situ, encurtando assim o processo de extração do lipídio. (COONEY; YOUNG; NAGLE, 2009; SMITH; GREENWELL; WHITING, 2009).

Conforme destacado por Ganesan et al. (2020), a busca por matériasprimas alternativas aos óleos vegetais para produção de biodiesel é de grande interesse para a indústria de biocombustíveis. Nesse cenário, os lipídios presentes no óleo de microalga surgem como alternativa promissora. 


\subsection{O solvente: propriedades e green solventes}

O solvente desempenha um papel importante no ciclo de vida do processo em que ele participa, seja nas etapas de downstream (recuperação, purificação e destinação final), como também nas etapas de upstream (produção e transporte). Como existe uma potencial demanda futura de biomassa para diversos fins para produção de energia, biocombustíveis e químicos, uma quantidade expressiva de solventes será requerida para viabilizar o cumprimento dessa demanda. Para isso, é necessário analisar o uso do solvente de forma a se conceber processos mais sustentáveis. (SOH; ECKELMAN, 2016)

Durante a seleção de solventes para processos industriais, há de se considerar diversos fatores como propriedades físico-químicas, solubilidade, custo, impacto ambiental, impacto na saúde humana e segurança. Dentre os guias para seleção de solventes, destacam-se o da Pfizer, Sanofi e GlaxoSmithKline (GSK) (SOH; ECKELMAN, 2016). Muitas propostas de novos solventes têm sido apontadas na literatura e atualmente existe uma grande atenção aos solventes derivados de biomassa, fluidos supercríticos, líquidos iônicos e solventes comutáveis (switchable solvents), porém sua adoção pela indústria é lenta por fatores de custo, atendimento da demanda, propriedades, manuseio e equipamentos necessários. (SOH; ECKELMAN, 2016)

Curzons et al. (1999) realizaram um trabalho de criação de um guia de seleção de solventes considerando aspectos relacionados à segurança, impacto no meio ambiente e na saúde humana. Foram reunidas diversas propriedades como: emissões no processo de incineração, ponto de ebulição, pressão de vapor, temperatura de auto-ignição, entalpia de combustão, dentre outras.

Essas propriedades foram agrupadas em nove categorias-chave: incineração, reciclo, biotratamento, volatilidade, impacto ambiental na água, impacto ambiental no ar, potencial de exposição e risco de segurança em processo. Em seguida, essas nove categorias foram resumidas em quatro grandes áreas: impacto do resíduo, impacto ambiental, impacto à saúde humana e segurança. Dessa forma, cada solvente tem suas propriedades avaliadas e 
uma nota de 1 a 10 é dada em cada uma dessas grandes áreas (sendo 10 a nota correspondente a um baixo impacto). (CURZONS; CONSTABLE; CUNNINGHAM, 1999)

Weis e Visco (2010) realizaram um estudo computacional utilizando CAMD (Computer Aided Molecular Design) para encontrar novos solventes com desempenhos similares aos solventes apresentados no guia de seleção de solventes da GSK de Curzons et al. (1999). Além das quatro áreas, foi adicionada uma nova área referente ao impacto do ciclo de vida do solvente, totalizando assim cinco grandes áreas em que cada solvente é avaliado. (WEIS; VISCO, 2010). A metodologia de Weis e Visco foi posteriormente implementada por Heintz e colaboradores em uma ferramenta de CAMD (IBSS $®$ ) para design de novos solventes derivados da biomassa (Heintz et al., 2014).

\subsection{Seleção de solventes}

A seleção correta de um solvente é uma etapa fundamental no projeto de processos. Além da possibilidade de se variar parâmetros de operação (pressão, temperatura e concentração) e o dimensionamento de equipamentos, é possível também avaliar como diferentes solventes impactam os processos considerados. Com o objetivo de conceber processos mais sustentáveis, uma abordagem sistemática de seleção e screeening de solventes pode resultar em benefícios efetivos do ponto de vista econômico e técnico.

Nhien et al. (2016) realizaram uma avaliação do processo de produção de ácido levulínico através de destilação extrativa utilizando uma abordagem sistemática para seleção de solventes para encontrar o solvente que resultaria no menor custo operacional e emissão de $\mathrm{CO}_{2}$. Inicialmente foram levantados 6 potenciais solventes, mas ao longo das análises das propriedades físicoquímicas, três solventes foram selecionados para a etapa de simulação de processo em Aspen PLUS® (ASPENTECH, 2015). Dos três solventes selecionados (octanol, metil-isobutilcetona e furfural), o furfural foi o solvente que possibilitou maior redução de custos e menores emissões. 
Nhien et al. (2017) realizaram um estudo similar, mas para o processo de purificação do furfural produzido a partir de lignina. Entretanto, nesse estudo 25 solventes foram levantados inicialmente por meio de regras heurísticas e pesquisas na literatura, um número maior que o número do estudo feito por Nhien et al. em 2016. Desses 25 iniciais, 10 solventes foram selecionados após simulações preliminares e somente 3 solventes foram utilizados na simulação mais rigorosa (em Aspen PLUS $®$ ) após duas outras etapas de análise (análise de propriedades, equilíbrio e formação de azeótropos). Os solventes presentes na análise mais rigorosa foram tolueno, benzeno e o cloreto de terc-butila.

Observa-se que nos dois estudos, a abordagem sistemática para seleção de solventes foi similar: com um conjunto inicial de solventes encontrados na literatura, análises de desempenho mais simples são feitas para eliminar os piores candidatos, e somente os melhores são avaliados em etapas posteriores com ferramentas mais sofisticadas. Essas análises são feitas em etapas e sua sofisticação aumenta ao passo que o número de candidatos diminui. Isso faz com que o processo de seleção de solventes seja escalável e eficiente, dispensando grandes esforços em candidatos sem potencial. Essa abordagem pode ser apresentada na Figura 4. (NHIEN et al., 2016, 2017)

Figura 4 - Processo de seleção de solventes.

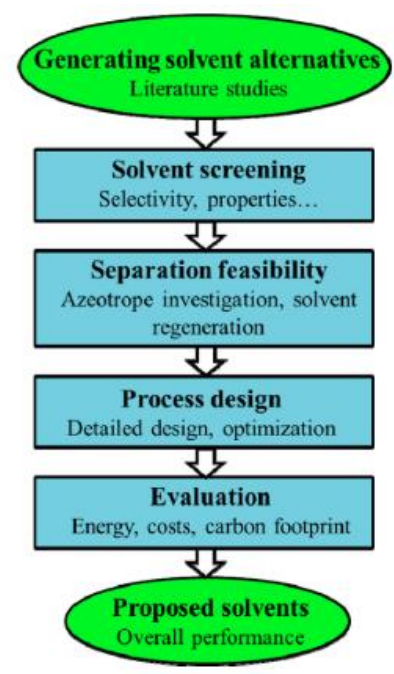

Fonte: (NHIEN et al., 2016) 
Esta abordagem, normalmente conhecida como multi-step approach, é também usada no trabalho de Heintz et al. (2014), em que um modelo rigoroso de equilíbrio termodinâmico (UNIFAC) é usado apenas em solventes previamente selecionados de um conjunto inicialmente amplo de solventes gerados por um algoritmo de Computer-Aided Molecular Design (CAMD). Neste trabalho, os solventes destinavam-se à extração de antioxidantes de plantas.

Dentro do contexto de microalgas, trabalhos foram realizados com 0 intuito de avaliar o processo de extração de lipídio com diferentes solventes, na maioria das vezes experimentalmente. Breil et al. (2016) utilizaram uma abordagem combinada de experimentos em bancada ou em ambiente virtual para analisar a capacidade de extração de lipídio da microalga Yarrowia lipolytica IFP29 por um conjunto de 11 solventes. A abordagem experimental foi a determinação por cromatografia gasosa do extrato contendo solvente e lipídio extraído da biomassa seca.

Já a abordagem virtual foi a análise da solubilidade por dois métodos: parâmetros de Hansen em um software chamado HSPiP® (HANSEN, 2010) e pelo software COSMO-RS, que permite uma análise mais detalhada baseada em química quântica e termodinâmica estatística para prever propriedades termodinâmicas. (BREIL et al., 2016)

Kuan et al. (2016) realizaram um estudo do desempenho de misturas de solventes distintas na extração de lipídio da microalga Chlorella protothecoidesis. O estudo consistiu em avaliar a capacidade de recuperação de 5 solventes hidrofóbicos (n-hexano como padrão de comparação) em mistura contendo metanol, ácido fórmico (para ruptura das paredes celulares) e a água presente na pasta da microalga. Nesse estudo, o diclorometano foi o solvente que possibilitou a maior recuperação de lipídios.

Angles et al. (2017) realizaram um estudo partindo de 11 solventes para determinar a capacidade de extração de lipídios da microalga Nannochloropsis sp. com uma abordagem experimental. Além disso, por meio dos parâmetros de Hansen conseguiram classificar os solventes em termos de solubilidade, mas não se aprofundaram em nenhuma análise baseada em modelagem ou simulação computacional. 
Laboukhi-Khorsi et al. (2017) realizaram um estudo do processo de extração da artermisinina da planta Artemesia annua $L$. partindo de um número inicial de 27 solventes. A seleção foi feita em três etapas. A primeira etapa foi realizada de forma virtual utilizando o software HSPiP® (Hansen Solubility Parameters in Pratice, baseado no uso dos parâmetros de Hansen) para avaliar a solubilidade da artemisinina. $\mathrm{Na}$ segunda etapa, 4 solventes foram selecionados para uma etapa experimental para determinação de solubilidade baseada em gravimetria por meio de HPLC. Na terceira e última etapa, 1 solvente foi selecionado para uma análise mais criteriosa baseada em turbidimetria para determinação de solubilidade.

Em trabalhos de seleção de solventes, é possível utilizar as propriedades físico-químicas como etapa inicial desse processo, eliminando candidatos com propriedades incompatíveis com o uso desejado. Os candidatos remanescentes podem ser classificados de maneira que os candidatos com maior potencial sejam preferidos para uma análise posterior. Essa classificação pode ser feita utilizando diversos atributos como propriedades físico-químicas, propriedades EHS (environmental, health and safety) e custo.

Essa classificação pode se tornar complexa quando esses vários atributos (propriedades) são avaliados de maneira conjunta. Dessa forma, métodos de tomada de decisão multicritério podem ser empregados para avaliar os candidatos, de forma a identificar o conjunto de solventes com propriedades mais próximas dos valores desejados. Bystrzanowska et al. (2018) realizaram um estudo levantando diversos algoritmos de tomada de decisão multi-critério que avaliam as propriedades de maneira integrada.

Tobiszewskia et al. (2018) realizaram um estudo de seleção de solventes utilizando um algoritmo sistemático de decisão multicritério avaliando diversas propriedades concomitantemente. Estes autores partiram de um número inicial de 151 solventes e realizaram o agrupamento desses solventes e comparação com outros guias de seleção de solvente, como o da Pfizer, GlaxoSmithKline e AstraZeneca.

Nesses trabalhos, é possível observar a tendência e necessidade de testar o processo de extração de lipídios com novos solventes. Entretanto, em 
ambiente de bancada, esses testes são custosos, restringindo o escopo de exploração de novas possibilidades de solventes. E nesse ponto uma abordagem sistemática e faseada de seleção de solventes pode ser útil para que seja possível explorar novas possibilidades em diversas etapas virtuais e selecionar somente os melhores candidatos para etapas finais de bancada, tornando esse processo de exploração mais abrangente, ágil e econômico, como visto nos trabalhos de Breil et al. (2016) e Laboukhi-Khorsi et al. (2017).

\subsection{Ferramentas virtuais de análise e seleção de solventes}

O desafio de encontrar alternativas mais atraentes de solventes com a clássica abordagem de tentativa e erro, demanda tempo, consome recursos e pode não gerar os resultados almejados. Em termos de tempo e recursos, é inviável realizar experimentos em bancada ou simulações rigorosas para cada solvente possível. Se consideramos a possibilidade de uso de misturas de solventes, de forma a aproveitar o efeito sinérgico do processo de solubilização, o problema torna-se ainda mais complexo: o efeito combinatório de diferentes solventes e a composição como um grau de liberdade a mais torna o teste exaustivo impraticável.

A técnica de Computer-Aided Molecular Design (CAMD) é uma abordagem de engenharia reversa que tem como objetivo encontrar novas moléculas (ou misturas) que satisfazem um conjunto de propriedades previamente determinadas. Essa abordagem, que foi criada nos anos $1980 \mathrm{e}$ tem ganhado mais importância, permite a estimativa de propriedades alvo de um produto de forma virtual (in silico) para cumprir alguma finalidade definida pelo usuário. A sistemática de automatizar essa busca de soluções in silico em um espaço amplo de possibilidades tem sido denominada de forma mais ampla por Computer-Aided Product Design (CAPD). (CHEN et al., 2005; GANI; NIELSEN; FREDENSLUND, 1991; HEINTZ et al., 2014)

Para que seja possível, o CAPD se apoia em quatro grandes pilares: modelos de estimativa de propriedades, critério de desempenho, algoritmo de otimização e um modelo de representação molecular. Esses quatro pilares se 
relacionam para que o objetivo de gerar novas moléculas com propriedades desejadas possa ser alcançado. (HEINTZ et al., 2014)

Ao se definir as propriedades alvo, o CAMD combina fragmentos (grupos funcionais) para criar uma série de moléculas e estima as propriedades de cada molécula. Com as propriedades estimadas, é realizada a comparação com as propriedades alvo e com base no resultado de um conjunto inicial de moléculas, as estruturas moleculares podem ser alteradas com a adição ou substituição de outros fragmentos para uma nova análise. Ao fim do processo iterativo, é gerada uma lista com os melhores candidatos e suas propriedades estimadas.

A função do algoritmo de otimização é analisar os resultados obtidos e gerar populações de candidatos (novos compostos ou misturas) cada vez melhores, com propriedades mais próximas das propriedades alvo. Para que se possa automatizar computacionalmente a tarefa de combinar fragmentos e gerar novas moléculas/produtos, é necessária uma forma de representar computacionalmente uma estrutura molecular. A notação SMILES (Simplified molecular-input line-entry system), grafos moleculares e índices topológicos tem sido encontrado com frequência na literatura, como nos trabalhos de Heintz et al. (2014) e Weis e Visco (2010).

Além disso, os próprios métodos de estimativa de propriedades devem ser capazes de realizar os cálculos com pouca (ou nenhuma) informação além da estrutura molecular; dessa forma, lança-se mão de métodos de contribuição de grupos para tal tarefa. Combinando a predição de propriedades com os critérios de desempenho, a abordagem CAMD funciona de forma eficiente e consegue gerar estruturas moleculares que são possíveis candidatas a satisfazer os requisitos para uma dada aplicação.

Na literatura, a abordagem CAMD varia em termos de construção. Vários trabalhos usam métodos estocásticos na etapa de otimização, tais como: algoritmo genético (HERRING III; EDEN, 2014), Tabu Search (LIN et al., 2005) e simulated annealing (OURIQUE; SILVA TELLES, 1998). No entanto, métodos determinísticos também podem ser encontrados. Cignitti et al. (2019) formularam recentemente um problema específico MINLP (Mixed-Integer Non-Linear 
Programming) no software GAMS $\AA^{\circ}$ e 0 aplicaram para a geração de novos solventes para destilação extrativa com objetivo de separar acetona de metanol.

Chen et al. (2005) construíram uma rotina para aplicação de CAMD em Visual Basic, porém de forma mais simplificada e orientada a geração de solventes para destilação extrativa de dois sistemas: propano/propileno e nbutano/1-buteno.

Heintz et al. (2014) construíram um software chamado IBSS ${ }^{\circledR}$ (em ambiente .NET com linguagem C\# e DLL de cálculo de propriedades em Visual Basic) com interface de usuário e um conjunto amplo de métodos de estimativa de propriedades disponível para escolha pelo usuário. Foram testados vários casos de aplicação, como a geração de novos solventes para a extração de metil p-cumarato e solubilização de princípios ativos de um caso industrial. (HEINTZ et al., 2014)

Weis e Visco (2010) utilizaram a abordagem CAMD para encontrar novos solventes com propriedades semelhantes aos 47 solventes presentes no guia de seleção de solventes da GlaxoSmithKline. Essas propriedades são reagrupadas em cinco áreas: impacto do resíduo, impacto ambiental, saúde, segurança e ciclo de vida. A abordagem permitiu a geração de uma grande quantidade de novos solventes verdes para posterior estudo.

As abordagens assistidas por computador (Computer-Aided Design) permitem, portanto, uma análise mais abrangente das possíveis soluções para novos produtos de uma forma muito mais rápida e menos custosa do que tentativa e erro por experimentos. Entretanto, uma grande desvantagem é que não há garantia em relação a viabilidade técnica do uso dos melhores candidatos, podendo serem geradas soluções que nunca tenham sido sintetizadas e/ou possuam rotas de síntese inviável para a finalidade proposta. (MOITY et al., 2016)

Além disso, é possível aplicar diversos níveis de precisão (modelos mais ou menos robustos) para a estimativa de propriedades em diferentes momentos da execução da rotina de busca, iniciando-se com modelos simplificados que são gradativamente aumentando a robustez e complexidade ao passo que 0 número de candidatos diminui. (MOITY et al., 2016) 
Graças à presença de um módulo de predição de propriedades é possível entrar com uma lista grande de solventes com seus respectivos identificadores (SMILES ou grafos moleculares) para gerar o valor estimado das propriedades por métodos de contribuição de grupos. Hoje, simuladores comerciais também são capazes de fazer estimativas de propriedades utilizando como entrada a estrutura da molécula.

Essas funcionalidades podem apoiar abordagens de seleção de solventes para estimar propriedades de um número grande de solventes (candidatos) e possibilitar a eliminação de solventes que não são aptos para o processo. Após uma etapa de avaliação das propriedades estimadas, os candidatos aptos (que apresentam maior potencial) seriam levados para etapas mais refinadas de análise, como uma etapa de simulação (análise de métricas tecno-econômicas e ambientais) ou testes em bancada.

\subsection{Avalição do processo e métricas}

Ao se projetar um sistema de larga escala para produção de uma fonte de energia a partir da microalga (biodiesel, diesel renovável, bio-óleo, hidrogênio, metano, etanol ou outras possibilidades), deve-se projetar e implementar um processo viável sob as perspectivas energéticas, financeiras e ambientais. Essa análise detalhada do processo é crítica para determinação da viabilidade geral do processo e permite também levantar possíveis pontos de melhoria para melhorar a eficiência operacional. Com a eminência do interesse em produção de combustíveis a partir das microalgas, diversos estudos têm sido realizados para endereçar essa questão. (MARTIN, 2016)

Lardon et al. (2009) realizaram uma análise de ciclo de vida considerando toda a cadeia, desde construção da infraestrutura e cultivo até a combustão do biodiesel no motor. Esse estudo considerou diferentes formas de cultivo da microalga Chlorella vulgaris em ambientes de abundância e carência de nutrientes e também a rota de extração do lipídio (rota seca ou úmida). Entretanto, os parâmetros utilizados para estimativa do impacto da etapa de 
extração foram os utilizados para extração de óleo da soja, por falta de dados específicos disponíveis na literatura.

Além disso, não foi considerada a perspectiva de possíveis novos solventes de extração que possam gerar menor impacto, sendo utilizado somente o n-hexano na análise. Para essa análise, a extração pela rota úmida da microalga em ambiente de carência de nutrientes resultou em um balanço positivo de energia, considerando também utilização do rafinado (proteínas, carboidratos, ácidos nucleicos, lipídios não neutros e água, denominado oil cake no trabalho) para geração exclusiva de energia. (LARDON; HÉLIAS; SIALVE, 2009)

Stephenson et al. (2010) realizaram uma análise de ciclo de vida do processo de produção de biodiesel por meio da wet route utilizando n-hexano como solvente e gerando energia a partir dos resíduos por meio de digestão anaeróbica. Na etapa de cultivo, foi considerando o gás carbônico como reaproveitado de emissões de outras fontes. Foram realizadas análises de sensibilidade variando produtividade, concentração de CO2 na alimentação da etapa de cultivo e método de ruptura de parede de celular para avaliar os efeitos no consumo energético e no potencial de aquecimento global. Nesse trabalho, chegou-se à conclusão de que o cultivo em lagos artificiais é mais favorável do ponto de vista energético e ambiental.

Xu et al. (2011) realizaram uma análise energética para a mesma microalga por meio da rota úmida e seca. Entretanto, para a rota úmida, o combustível produzido foi o diesel renovável produzido pelo hidrotratamento do lipídio de microalga. Além disso, as correntes não-lipídicas (oil cake) foram aproveitadas para geração de energia por meio de pirólise. Assim, a microalga foi aproveitada nesse estudo para produção exclusiva de energia, resultando em um balanço de energia favorável para as duas rotas.

Outros trabalhos, como o de Wigmosta e colaboradores (2011) abordam a etapa de cultivo da microalga, com foco no uso de terra e de água. Este trabalho serve como base para trabalhos que realizam análise de ciclo de vida para o processamento da microalga por meio de liquefação hidrotérmica para aproveitamento total da microalga para produção de energia em comparação 
com a rota de hidro-processamento para produção de diesel renovável. (FRANK et al., 2013; VENTERIS et al., 2014)

Davis et al. (2011) realizaram uma análise tecno-econômica baseada em dados provenientes de simulações em Aspen PLUS® comparando o cultivo em lago artificial e fotobiorreator para produção de diesel renovável através de hidrotratamento. O processo de extração do lipídio é realizado utilizando o butanol como solvente. Ao fim, foi estimado o preço mínimo de venda de combustível (MFSP - minimum fuel selling price) partindo das premissas operacionais e financeiras adotadas. Com base nas análises realizadas, o cultivo utilizando lagos artificiais se mostrou mais viável financeiramente.

Já Collet et al. (2014) chegaram à conclusão de que a etapa de cultivo tem um grande papel no balanço energético do processo, ressaltando a origem da energia utilizada e produtividade da microalga. Nesse trabalho, foi feita uma análise do ciclo de vida da produção de biodiesel por meio da extração do lipídio da microalga Nannochloropsis occulata com n-hexano e metanol.

Martin (2016) propôs um modelo que explicita parâmetros operacionais para estimar a demanda energética de cada de etapa do processo para extração e conversão do lipídio para produção de $1 \mathrm{MJ}$ de biodiesel. No trabalho de Martin as etapas consideradas são: ruptura de parede celular, mistura, separação por centrifugação, evaporação do solvente, perdas de emissões relacionadas ao solvente e transesterificação. (MARTIN, 2016)

Ainda no modelo de Martin (2016) é possível testar e estimar o consumo energético variando diversos parâmetros operacionais por meio das equações do modelo, permitindo explorar diversas alternativas. No trabalho de Martin (2016) foi avaliada a extração do lipídio da pasta de microalga utilizando nhexano como solvente.

Os trabalhos de Delrue et al. (2012) e Batan et al. (2016) realizaram análises tecno-econômicas do processo de produção de biocombustível a partir de microalga adicionando uma camada de incerteza na análise financeira por meio de simulações de Monte Carlo. 
Dutta et al. (2016) realizaram uma análise tecno-econômica e uma análise de ciclo de vida comparando duas rotas de processamento de microalga: uma consistindo na extração do lipídio da microalga para produção de biodiesel (transesterificação) e outra produzindo etanol (fermentação da pasta), diesel e nafta (hidrotratamento do lipídio) e biogás (digestão anaeróbica dos resíduos). A rota que produziu mais produtos gerou os melhores resultados em termos ambientais e econômicos.

Sun et al. (2019) realizaram uma análise econômica preliminar da produção de biodiesel e energia (a partir dos resíduos) a partir de um processo proprietário de processamento de microalga. Também adicionaram um fator de correção para os custos do processo com base no conceito de curva de aprendizado (redução de custos com efeito do tempo).

A Tabela 2 resume os trabalhos supracitados, explicitando o tipo de análise realizada e diferenciais apresenteados.

Tabela 2 - Quadro comparativo de estudos de viabilidade do processo de valorização de microalgas para produção de biocombustível.

\begin{tabular}{lll}
\hline Autores & Tipo de análise & Diferenciais \\
\hline Lardon et al. (2009 & Análise de ciclo de vida & Uso de dados de extração de óleo da soja \\
Stephenson et al. (2010) & Análise de ciclo de vida & $\begin{array}{l}\text { Rota úmida e aproveitamento de resíduo para } \\
\text { gerar energia }\end{array}$ \\
Xu et al. (2011) & Análise de ciclo de vida & Comparação entre rota seca e úmida \\
Wigmosta et al. (2011) & Análise de ciclo de vida & Análise do uso de terra e água \\
Davis et al. (2011) & Análise de ciclo de vida & Comparação entre cultivo de fotobiorreator e \\
Collet et al. (2014) & Análise de ciclo de vida & $\begin{array}{l}\text { Extração com n-hexano e metanol } \\
\text { Martin (2016) }\end{array}$ \\
Balanço de energia & Equações com variação de parâmetros \\
Batan et al. (2016) & Análise tecno- & $\begin{array}{l}\text { Aplicação de incertezas nos parâmetros e } \\
\text { avaliação financeira }\end{array}$ \\
Sun et al. (2019) & Análise tecno- & $\begin{array}{l}\text { Aplicação do conceito de curva de } \\
\text { aprendizado para diminuição futura de custos }\end{array}$ \\
\hline
\end{tabular}

Fonte: Próprio autor. 


\subsection{Considerações gerais sobre a literatura}

Na literatura existem diversos trabalhos com foco nas etapas de cultivo ou em rotas de valorização do lipídio da microalga ou outras correntes (carboidratos e resíduos gerados) utilizando dados de simuladores ou extrapolações de dados experimentais (análises de ciclo de vida e tecno-econômicas).

Entretanto, observa-se pouca presença de estudoa voltados a avaliar novas formas de extrair o lipídio da pasta de microalga; que podem ser feitos utilizando solventes, fluidos supercríticos e líquidos iônicos. Os trabalhos que endereçam esse tema em geral possuem viés experimental, muitas vezes se limitando a um número reduzido de opções de solventes e condições de operação. Além disso, poucos trabalhos trazem luz para o uso de solventes verdes, seleção de solventes e exploração de novas possibilidades.

Logo, existe uma grande oportunidade em se avaliar novos solventes de forma in silico com foco na extração de lipídio da microalga, possibilitando a avaliação, comparação e classificação desses solventes sob perspectivas financeiras, energéticas, ambientais, de segurança e saúde.

Essa tendência pode alavancar a exploração de novas formas de extrair lipídio de microalga para produção de biodiesel e também os outros componentes disponíveis para geração de combustíveis, energia ou outros químicos de interesse (como aditivos alimentícios e plataformas químicas). 


\section{METODOLOGIA}

\subsection{Abordagem multi-step}

Para avaliar o uso de novos solventes no processo de extração de lipídio da microalga Nannochloropsis sp., este trabalho faz uso de uma abordagem do tipo multi-step. Essa abordagem tem como objetivo tornar o processo mais escalável, tendo como input uma quantidade grande de solventes que serão gradativamente selecionados para a etapa posterior. Ao longo dessas etapas, os solventes com maior potencial avançam para etapas seguintes, enquanto os que não tem potencial são descartados.

A microalga Nannochloropsis sp. foi eleita como modelo de estudo para o presente trabalho pela sua relevência e recorrência em trabalhos de engenharia de processos, e também por dispor de uma quantidade maior de dados disponíveis. Além disso, sua alta produtividade e proporção de lipídio a tornam favorável para produção de biocombustíveis.

As etapas iniciais avaliam um grande número de candidatos e tem como característica serem mais simples. Com o avançar do processo, etapas mais robustas são utilizadas já para um número reduzido de candidatos. Essas etapas mais avançadas consomem mais tempo e necessitam de mais dados, estudos e ajustes. Um desenho esquemático da abordagem pode ser visto na Figura 5.

Figura 5 - Abordagem multi-step utilizada no trabalho. 


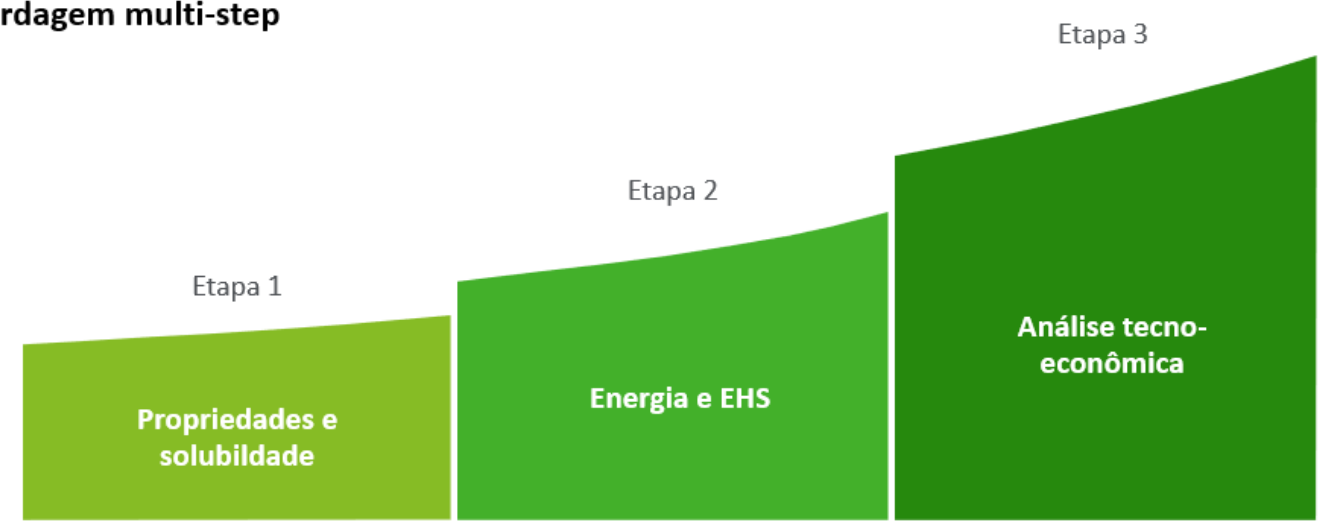

Mais robustez

Menos candidatos

Fonte: Próprio autor.

Como pode ser visto na Figura 5, neste trabalho serão realizadas 3 etapas de análise, sendo elas:

- Etapa 1: análise de propriedades físico-químicas estimadas com apoio do software IBSS $₫$ para selecionar solventes que de maneira imediata não servem para o processo de extração. Serão utilizadas propriedades como solubilidade em água, entalpia de combustão e parâmetros de solubilidade de Hansen.;

- Etapa 2: utilização do modelo de Martin (2016) para estimativa da demanda energética do processo de extração de lipídio para cada solvente, bem como a utilização dos parâmetros EHS (environmental, health and safety) calculados pelo software IBSS $\AA$ com base nos modelos de Weis e Visco (2010). Os parâmetros serão combinados e o solvente será avaliado tanto na perspectiva energética quanto de EHS;

- Etapa 3: análise utilizando o simulador comercial Aspen PLUS® para avaliar com mais profundidade o desempenho de cada solvente no processo de extração. Os melhores solventes serão avaliados sob a perspectiva de processo (evaporação, separação e reciclo), e, por fim, 
serão avaliados financeiramente. Essa etapa é uma análise tecnoeconômica preliminar.

Essas etapas serão detalhadas a seguir.

\subsubsection{Ferramentas computacionais utilizadas}

Para as etapas 1 e 2, foi desenvolvido neste trabalho um conjunto de rotinas em linguagem python. A justificativa para tal linguagem é o fato de possuir bibliotecas numéricas, gráficas, tratamento de base de dados e uma biblioteca específica para química computacional, chamada RDKit. (LANDRUM, 2006)

Em algumas atividades das etapas 1 e 2 foram utilizadas ainda as seguintes ferramentas computacionais:

- Código em FORTRAN (desenvolvido previamente pelo grupo de pesquisa) para obtenção dos triacilgliceróis (TAGs) presentes em maior quantidade com base na composição do lipídio em termos de ácidos graxos livres (FFAs). Para maiores detalhes, recomenda-se a leitura de Teles dos Santos et al. (2013).

- ChemSketch $\AA$ (ACD, 2019) para desenho das estruturas dos triacilgliceróis (TAGs) presentes no óleo de microalga e posterior versão destas estruturas em notação SMILES;

- IBSS® (desenvolvido previamente pelo grupo de pesquisa do Moisés dos Santos na França) para o cálculo das propriedades do solvente e dos triacilgliceróis a partir da notação SMILES. Para maiores detalhes, recomenda-se a leitura de Heintz et al. (2014).

Dessa forma a rotina em python desenvolvida neste trabalho parte da base de dados de TAGs e a de solventes para realizar as seguintes análises:

- Cálculo da entalpia de combustão;

- Avaliação do critério de solubilidade em água; 
- Avaliação do critério dos parâmetros de solubilidade de Hansen (estimativa do RED - Relative energy density e criação da esfera de solubilidade de Hansen do óleo de microalga);

- Estimativa da demanda energética do processo extrativo por meio do modelo proposto por Martin (2016);

- Criação de escala de parâmetros energéticos e EHS utilizando o algoritmo de tomada de decisão multicritério TOPSIS (YADAV et al., 2019);

- Limpezas e ajustes nos dados utilizados.

Para executar esses passos, uma estrutura foi criada combinando

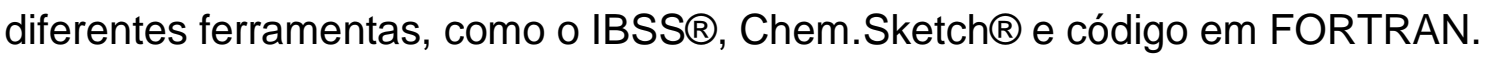
O código em python (detalhado no Apêndice 8.1) realiza a conexão das fontes de dados e realiza as atividades presentes na etapa 1 e 2 . A estrutura do código é mostrada na Figura 6.

O objetivo das etapas 1 e 2 é a construção de uma metodologia sistemática de avaliação das propriedades e seleção dos solventes aptos sem necessitar de mais nenhuma inserção de informação (nenhuma interferência humana). Em alguns solventes, o IBSS $\AA$ não conseguirá realizar a estimativa de propriedades do solvente, ou a metodologia de estimativa da entalpia de combustão não se encaixe em algum solvente.

Nesses casos, devido a escalabilidade da análise, esses solventes são considerados inaptos e deixados para trás. Em uma abordagem com um número mais reduzido de solventes, ou com uma abordagem mais discricionária, seria realizada alguma pesquisa para inserir o dado faltante para que esse solvente ainda fosse avaliado.

Figura 6 - Conjunto de ferramentas computacionais para avaliação de solventes. 


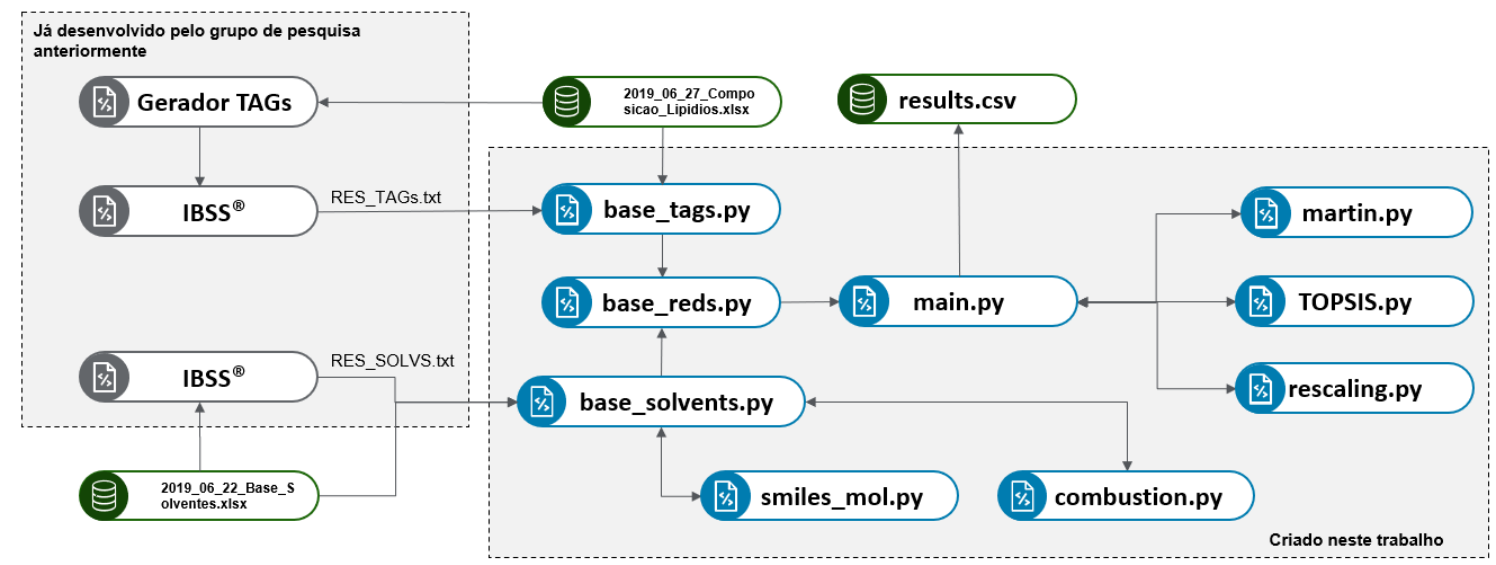

Fonte: Próprio autor.

\subsubsection{IBSS ${ }^{\circledR}$}

O IBSS® é um software de CAMD (desenvolvido em 2012 pelo grupo de pesquisa do Moisés dos Santos na França) que auxilia a busca de novos compostos/misturas para satisfazer critérios de desempenho em usos variados.

A ferramenta combina 5 pilares para seu funcionamento: interface gráfica de usuário, representação de moléculas por meio de grafos, modelos de predição de propriedades por meio de contribuição de grupos, algoritmo genético para geração de novas populações de moléculas/misturas e um critério de desempenho para avaliação do desempenho das moléculas/misturas geradas. A visão geral do software para a geração de novas moléculas por CAMD pode ser vista na Figura 7. (HEINTZ et al., 2014)

Figura 7 - Estrutura do IBSS® para geração de novos produtos por CAMD/CAPD. 


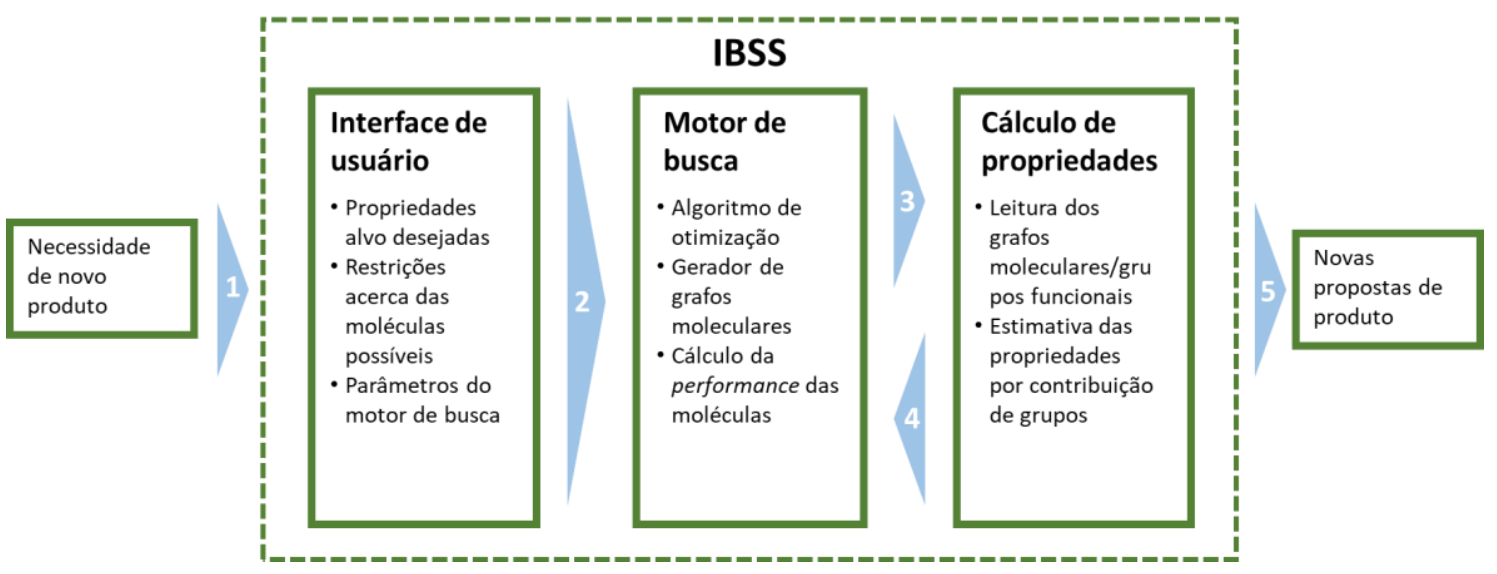

Fonte: Próprio autor.

Embora com uma abordagem de engenharia reversa que permite encontrar as moléculas com a propriedades desejadas, o software permite também a abordagem convencional ou direta, estimando propriedades de moléculas especificadas por meio do SMILES como entrada. (HEINTZ et al., 2014)

Dessa forma o IBSS $\AA$ permite a estimativa de diversas propriedades dos solventes e dos triacilgliceróis por meio de um ou mais modelos de estimativa de contribuição de grupos a partir de suas estruturas moleculares fornecidas no formato SMILES.

Propriedades estimadas pelo IBSS®:

- Massa molar;

- Densidade;

- Ponto de fusão;

- Ponto de ebulição;

- Ponto de fulgor;

- Temperatura de auto-ignição;

- Pressão de vapor;

- Parâmetros de solubilidade de Hansen e de Hildebrand;

- Tensão superficial;

- Viscosidade;

- Volume molar; 
- Propriedades críticas (temperatura, pressão e volume);

- Fator acêntrico;

- Entalpia de formação, fusão e vaporização;

- Energia livre de Gibbs;

- Entropia de fusão e vaporização;

- Impacto no meio ambiente, saúde humana e segurança (EHS) de Weis e Visco (2010);

- Coeficiente de partição entre octanol e água;

- Solubilidade aquosa.

Para o presente trabalho, foi utilizado o IBSS $\AA$ no modo de cálculo das seguintes propriedades:

- Densidade (modelo MB2010);

- Entalpia de vaporização (modelo HSKASG2012);

- Entalpia de formação (modelo HSKASG2012);

- Solubilidade em água (modelo MG2002);

- Parâmetro de solubilidade de Hildebrand (modelo HSKASG2012);

- Parâmetros de solubilidade de Hansen (componente dispersivo, componente de polaridade e componente de pontes de hidrogênio, pelo modelo MB2010);

- Parâmetros EHS (Weis e Visco 2010).

O funcionamento do IBSS $\AA$ pode ser entendido de forma esquemática na Figura 8.

Figura 8 - Estrutura do IBSS $\AA$ no modo de estimativa de propriedades.

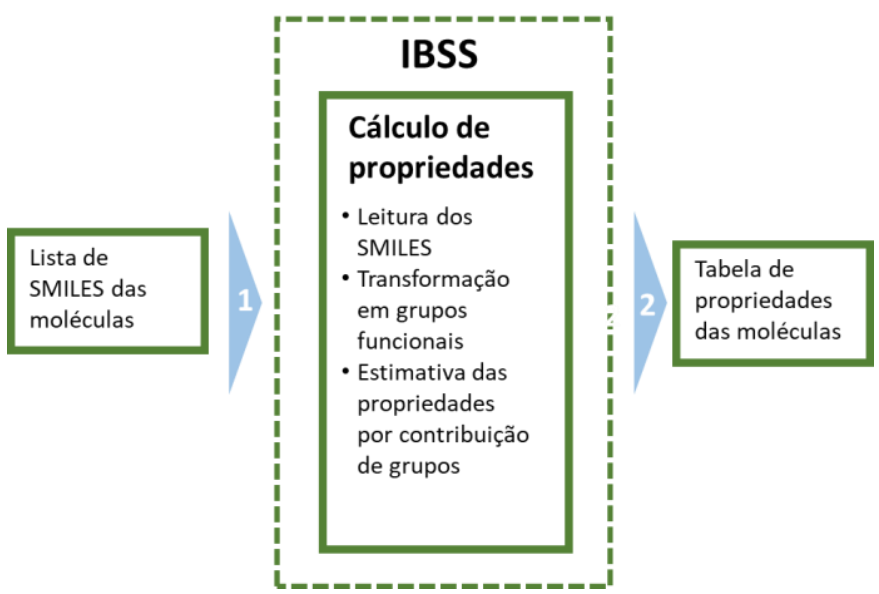


Fonte: Próprio autor.

Arquivos do tipo .txt são usados para a criação da lista de SMILES das moléculas e para armazenamento dos resultados dos cálculos. O conjunto de propriedades a serem calculadas, seus parâmetros de cálculo e os modelos a serem usados são fornecidos em um arquivo do tipo XML (eXtensible Markup Language).

\subsubsection{Simulação do processo e análises financeiras}

Na etapa 3 foi feita uma análise tecno-econômica preliminar do processo de extração do lipídio de microalga com os solventes selecionados das etapas anteriores. Para isso foi utilizado o simulador comercial Aspen PLUS® V8.8 para levantamento dos dados das correntes (mássicas e energéticas), de equilíbrio de fases e de dimensionamento de equipamentos. (ASPENTECH, 2015)

Para as análises financeiras do processo de extração, foi utilizado o MS Excel® 2019 para a criação dos fluxos de caixa projetados e análises de viabilidade e sensibilidade. Os cálculos financeiros são descritos com detalhes na seção 3.5.4. (MICROSOFT, 2019)

\subsection{Estruturação do ambiente computacional e cálculo das propriedades (Step 0)}

\subsubsection{Definição da composição do lipídio da microalga}

A composição em ácidos graxos do óleo da microalga Nannochloropsis sp. utilizada neste trabalho foi a obtida pelo estudo realizado por Olmstead et al. (2013). Essa composição é mostrada na Tabela 3. Observa-se que os ácidos graxos presentes em maior quantidade são o ácido palmitoleico (C16:1) e o ácido palmítico (C16:0). 
Tabela 3 - Composição em ácidos graxos do óleo da microalga Nannochloropsis sp. em ambiente carente de nutrientes.

\begin{tabular}{|c|c|c|c|c|c|}
\hline Ácido Graxo & $\begin{array}{r}\text { Lipídios } \\
\text { neutros } \\
(\mathrm{mg} / \mathrm{g})\end{array}$ & $\begin{array}{r}\text { Glicolipídio } \\
(\mathrm{mg} / \mathrm{g})\end{array}$ & $\begin{array}{r}\text { Fosfolipídios } \\
(\mathrm{mg} / \mathrm{g})\end{array}$ & Total $(\mathrm{mg} / \mathrm{g})$ & $\%(m / m)$ \\
\hline C14:0 & 3,3 & 0,33 & 0,09 & 3,72 & 3,12 \\
\hline C16:0 & 43,7 & 1,5 & 1 & 46,2 & 39,75 \\
\hline C18:0 & 2,8 & 0,3 & 0,12 & 3,22 & 2,70 \\
\hline C16:1 & 49,8 & 1,6 & 1,1 & 52,5 & 44,04 \\
\hline C18:1n9c & 3,1 & 0,02 & 0,18 & 3,3 & 2,77 \\
\hline C18:1n9t & 0,44 & 0,02 & 0,01 & 0,47 & 0,39 \\
\hline C18:2n6c & 0,35 & 0,01 & 0,17 & 0,53 & 0,44 \\
\hline C18:2n6t & 0,26 & 0,01 & 0,12 & 0,39 & 0,44 \\
\hline C18:3n6 & 0 & 0 & 0 & 0 & 0,00 \\
\hline $\mathrm{C} 20: 4 \mathrm{n} 6$ & 0,35 & 0,05 & 0,74 & 1,14 & 0,96 \\
\hline C20:5n3 & 1,9 & 2 & 1,8 & 5,7 & 4,78 \\
\hline C20:3n3 & 0,3 & 0 & 0,05 & 0,35 & 0,29 \\
\hline Outros & 1,4 & 0,05 & 0,25 & 1,7 & 1,43 \\
\hline Total & 107,7 & 5,89 & 5,63 & 119,22 & $100 \%$ \\
\hline
\end{tabular}

Fonte: Olmstead et al. (2013).

Para simplificação do problema, ácidos graxos isômeros presentes em menor quantidade foram agrupados em uma única molécula, como é o caso do ácido linoleico (C18:2n6c e C18:2n6t). O perfil de composição final assumido para o presente trabalho é apresentado na Tabela 4. 
Tabela 4 - Composição do lipídio da microalga Nannochloropsis sp. após agrupamento de ácidos graxos similares.

\begin{tabular}{lllr}
\hline Ác. Graxo & Código & Nome & $\%(\mathbf{m} / \mathbf{m})$ \\
\hline C14:0 & Myr & Myristic Acid & 3,12 \\
C16:0 & Pam & Palmitic Acid & 38,75 \\
C18:0 & Ste & Stearic Acid & 2,70 \\
C16:1 & Dpa & Palmitoleic Acid & 44,04 \\
C18:1n9 & Ole & Oleic Acid & 3,16 \\
C18:2n6 & Lin & Linoleic Acid & 0,77 \\
C20:3n3 & D3A & Epoxyeicosatrienoic Acid & 0,29 \\
C20:4n6 & D4A & Arachidonic Acid & 5,74 \\
Total & & & 98,57 \\
\hline
\end{tabular}

Fonte: Próprio autor.

Observa-se na Tabela 4 que a soma dos ácidos graxos equivale a 98,57\% em massa, sendo o restante não especificado no trabalho de Olmstead et al. (2013). Com a composição presente na Tabela 4, os triacilgliceróis (TAGs) teoricamente presentes foram gerados usando uma rotina em FORTRAN já desenvolvida pelo próprio grupo de pesquisa e descrita em Teles dos Santos et al. (2013).

\subsubsection{Cálculo das propriedades pelo IBSS ${ }^{\circledR}$}

Com a lista de triacilgliceróis (TAGs) da microalga, foi realizado um trabalho de desenho das estruturas moleculares dos TAGs para obtenção do SMILES (Figura 9) de cada triacilglicerol e criação de uma base de dados com informações de código do TAG, composição e SMILES, chamada 2019_06_27_Composicao_Lipidios.xIsx. 
Figura 9 - Processo de obtenção de SMILES pelo ChemSketch®.

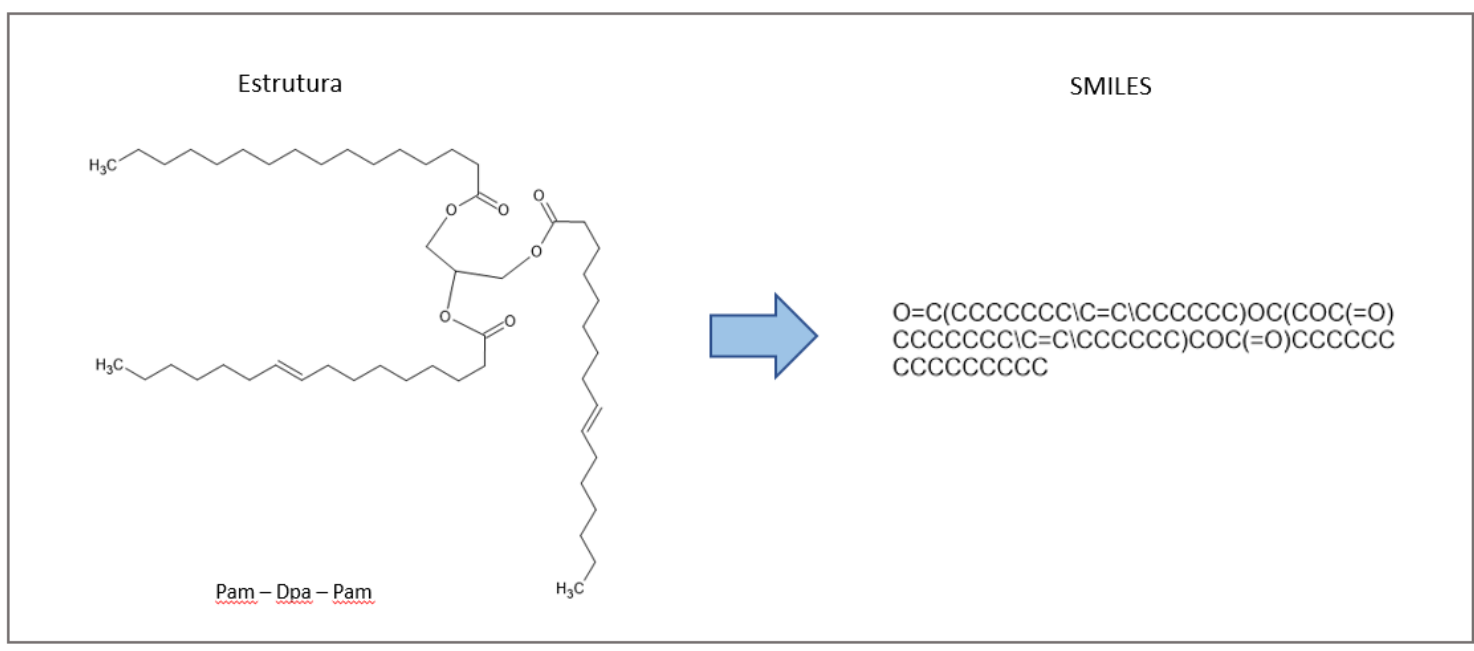

Fonte: Próprio autor.

Os cálculos de propriedades dos solventes foram realizados tendo como base o arquivo 2019_06_22_Base_Solventes.xIsx, contendo 111 solventes com seus respectivos nomes e código SMILES. O IBSS® foi executado no modo de predição de propriedades tanto paras triacilgliceróis como para os solventes, resultando nos arquivos RES_TAGs.txte RES_SOLVENTS.txt, respectivamente (Figura 6).

Os SMILES dos TAGs e dos Solventes presentes nas bases de dados podem ser vistos no Apêndice 8.1.

A Tabela 5 resume os métodos utilizados para predição de cada propriedade utilizada neste trabalho.

Tabela 5 - Quadro resumo das referências dos métodos de estimativa de propriedade.

\begin{tabular}{ll}
\hline Propriedade & Referência \\
\hline Entalpia de vaporização & Hukkerikar et al. (2012) \\
Entalpia de formação & Hukkerikar et al. (2012) \\
Parâmetros EHS & Weis e Visco (2010) \\
Solubilidade aquosa & Marrero e Gani (2002) \\
Parâmetro de solubilidade de Hlldebrand & Hukkerikar et al. (2012) \\
Densidade & Yamamoto (2010) \\
Parâmetro de solubilidade de Hansen & Yamamoto (2010) \\
\hline
\end{tabular}

Fonte: Próprio autor 


\subsubsection{Estruturação da base de dados}

A consolidação das bases únicas de triacilgliceróis e solventes foi feita em python, utilizando a biblioteca pandas (MCKINNEY, 2010). Foram geradas as seguintes bases: solvents_final.csve tags_final.csv. A base de dados é formada por 31 TAGs e 111 solventes que deverão ser avaliados para extração do óleo formado pelos 31 TAGs.

\subsection{Análise das propriedades estimadas (Step 1)}

\subsubsection{Cálculo de entalpia de combustão}

Dentro da perspectiva de criar uma abordagem sistemática de estimativa de propriedades e análises, foi necessário encontrar uma abordagem de cálculo da entalpia de combustão de moléculas com base somente na estrutura, fornecida em formato SMILES.

Lozano et al. (2019) apontaram uma forma de cálculo da entalpia, baseada numa reação genérica de combustão completa de biomassa, partindo da fórmula molecular representada na equação 1. (LOZANO; PEDERSEN; ROSENDAHL, 2019)

$$
\begin{aligned}
C_{\varphi} H_{\alpha} O_{\beta} N_{\gamma} S_{\delta} & +\left(\varphi+\frac{\alpha}{4}-\frac{\beta}{2}+\gamma+\delta\right) O_{2} \\
& \rightarrow \varphi C O_{2}+\frac{\alpha}{2} H_{2} O+\gamma N_{2}+\delta S O_{2}
\end{aligned}
$$

Com base na fórmula molécula e com a entalpia de formação (calculada pelo IBSS®), pode-se calcular a entalpia de combustão pela equação 2 . (LOZANO; PEDERSEN; ROSENDAHL, 2019)

$$
\begin{gathered}
H H V=\Delta h_{f, \mathrm{Comp}_{f}}^{\circ}+\left(\varphi+\frac{\alpha}{4}-\frac{\beta}{2}+\gamma+\delta\right) \Delta h_{f, \mathrm{O}_{2}}^{\circ}-\varphi \Delta h_{f, \mathrm{CO}_{2}}^{\circ}-\frac{\alpha}{2} \Delta h_{f, \mathrm{H}_{2} O}^{\circ} \\
-\gamma \Delta h_{f, \mathrm{NO}_{2}}^{\circ}-\delta \Delta h_{f, \mathrm{SO}_{2}}^{\circ}
\end{gathered}
$$


Para realizar esse cálculo, é necessário ter a fórmula molecular explicitando a quantidade de átomos de carbono, hidrogênio, oxigênio, nitrogênio e enxofre, a qual não existia na base de dados. A única informação estrutural que existia era o SMILES de cada solvente.

Para obter essa informação, foi criada uma rotina em python que extraía a informação de número de átomos a partir do SMILES. Para realizar essa tarefa, foi utilizada a biblioteca de química computacional RDKit (LANDRUM, 2006). Com essa informação foi possível estimar a entalpia de combustão de cada solvente para utilização na etapa 2, no modelo de Martin (2016).

Como pode ser visto nas Equações 1 e 2, os solventes que possuem átomos diferentes como flúor, cloro e outros, não foram calculados. Logo, não avançaram para a etapa 2. Além disso, para o presente trabalho, solventes contendo flúor e cloro seriam eliminados por apresentar tendências de serem nocivos ao meio ambiente. (HEINTZ et al., 2014)

\subsubsection{Parâmetros de solubilidade de Hansen}

No processo de extração do lipídio (óleo) da pasta de microalga, desejase a formação de duas fases líquidas, uma orgânica e uma aquosa. Na fase orgânica, encontra-se o solvente e os lipídios neutros, e na fase aquosa encontram-se a água e lipídios polares. O foco inicial do processo é a recuperação do lipídio neutro na fase orgânica, sendo ele o soluto de interesse. Para realizar a determinação virtual da capacidade de um solvente solubilizar ou não o soluto foram utilizados os parâmetros de solubilidade de Hansen.

Os parâmetros de solubilidade de Hansen permitem caracterizar a interação soluto-solvente de forma simples pela abordagem clássica "apolar dissolve apolar, polar dissolve polar". Esses parâmetros baseiam-se no conceito de que a densidade energética coesiva total é aproximada pela soma das densidades energéticas necessárias para superar as forças dispersivas atômicas $\left(\delta_{d^{2}}{ }^{2}\right)$, moleculares polares advindas de momentos de dipolo $\left(\delta_{p}{ }^{2}\right)$ e 
ligações de hidrogênio entre as moléculas $\left(\delta h^{2}\right)$, representado pela equação (3). (HANSEN, 2007)

$$
\delta_{\text {total }}^{2}=\delta d^{2}+\delta p^{2}+\delta h^{2}
$$

A capacidade de o solvente solubilizar o soluto pode ser definida pelo valor da energia relativa (RED, do inglês relative energy difference), que pode ser calculada pela Equação (4).

$$
R E D=\frac{R a}{R_{0}}
$$

O termo Ra se refere à distância entre soluto e o solvente no espaço tridimensional de solubilidade de Hansen. O termo Ro é o raio de solubilidade do soluto (neste caso, o lipídio da microalga) e geralmente é estimado utilizando dados de parâmetro de Hansen de diversos solventes, tanto os que solubilizam o soluto quanto os que não solubilizam.

Se Ra for maior que $\mathrm{R}_{0}$, indica que o solvente está fora da esfera de solubilidade de Hansen do soluto. Logo, se RED $\geq 1$, é um indicativo de imiscibilidade, e se RED < 1, é um indicativo de miscibilidade; o termo Ra pode ser estimado pela Equação (5):

$$
R a=\sqrt{4\left(\delta_{d}^{A}-\delta_{d}^{B}\right)^{2}+\left(\delta_{p}^{A}-\delta_{p}^{B}\right)^{2}+\left(\delta_{h}^{A}-\delta_{h}^{B}\right)^{2}}
$$

Em que o sobrescrito $A$ é referente ao solvente e $B$ ao soluto. Assim, é realizado um ajuste dos dados para determinar o Ro que mais se aproxima dos dados experimentais utilizando um algoritmo de otimização. (BREIL et al., 2016)

É comum também a análise desses parâmetros pela representação da esfera de Hansen. Essa esfera de solubilidade do soluto tem o centro representado pelos parâmetros de Hansen do soluto $\left(\delta_{d}, \delta_{p}\right.$ e $\left.\delta_{h}\right)$ e o raio pelo raio de interação do soluto $\left(R_{0}\right)$.

O lipídio bruto da microalga é uma classe que possui um número elevado de componentes (vários triacilgliceróis, diacilgliceróis, ácidos graxos livres, entre 
outros), inviabilizando uma análise individual dos parâmetros de Hansen de cada componente em cada solvente. Dessa forma, é necessário encontrar uma forma de representar o lipídio de uma maneira agregada.

Assim, os parâmetros de Hansen da mistura que representam o lipídio (ou óleo da microalga) foram estimados com base na Equação (6), que representa uma regra simples de mistura e que é usada comumente para cálculo dos parâmetros de Hansen de uma mistura a partir dos parâmetros das espécies presentes na mistura.

$$
\delta_{(d, p \text { ou } h), \text { mistura }}=\sum_{i=1}^{n_{\text {componentes }}} x_{i} \times \delta_{(d, p \text { ou } h), i}
$$

Assim, com base na composição de cada um dos triacilgliceróis e seus respectivos parâmetros de solubilidade de Hansen, é possível estimar um conjunto de parâmetros de solubilidade de Hansen ( $\delta_{d}, \delta_{p}$ e $\left.\delta_{h}\right)$ global do óleo da microalga utilizada neste trabalho.

O valor de $\mathrm{R}_{0}$ do óleo de microalga Nannochloropsis sp. não foi encontrado por não haver estudos na literatura com esse fim, e também pelo fato da composição do lipídio da microalga ser variada e mudar de acordo com condições de cultivo.

$\mathrm{Na}$ falta dessas informações, foi realizada uma busca na literatura de óleos de outras origens para a possível utilização do raio de solubilização como possível substituto, caso tenha parâmetros de Hansen semelhantes. Foi realizada uma busca mais direcionada para óleos de origem vegetais, que são frequentemente estudados com a finalidade de aprofundar o entendimento para processos de conversão em biocombustíveis, como óleo de soja, palma, mamona, entre outros.

Os óleos encontrados são mostrados na Tabela 6 com seus respectivos parâmetros de solubilidade de Hansen, que foram comparados com os parâmetros obtidos para o lipídio da microalga em estudo. Neste trabalho, é proposta a adoção de um $\mathrm{R}_{0}$ do óleo com maior similaridade, considerando a 
diferença dos desvios quadráticos entre os parâmetros de solubilidade de Hansen $\left(\delta_{d}, \delta_{p}\right.$ e $\left.\delta_{h}\right)$.

Tabela 6 - Parâmetros de solubilidade de Hansen para diversos óleos na literatura.

\begin{tabular}{lrrrrl}
\hline Óleo & $\boldsymbol{\delta}_{\mathbf{D}}$ & $\boldsymbol{\delta}_{\mathbf{P}}$ & $\boldsymbol{\delta}_{\mathbf{H}}$ & $\mathbf{R}_{\mathbf{0}}$ & Referência \\
\hline Óleo de Côco & 14,95 & 4,63 & 6,98 & 9,80 Batista et al. (2015) \\
Óleo de Palma & 17,54 & 3,34 & 4,08 & 7,48 Batista et al. (2015) \\
Biodiesel Soja & 15,03 & 3,69 & 8,92 & 11,33 Batista et al. (2015) \\
Biodiesel Côco & 15,12 & 3,99 & 9,25 & 10,92 Batista et al. (2015) \\
Biodiesel Palma & 15,43 & 5,28 & 6,61 & 10,54 Batista et al. (2015) \\
Biodiesel Mamona & 16,1 & 6,72 & 9,11 & 11,78 Batista et al. (2015) \\
Triacetina & 16,5 & 4,5 & 9,1 & 12,00 Halim et al. (2012) \\
Biodiesel de óleo de fritura usado & 15,03 & 3,69 & 8,92 & 11,33 Batista et al. (2015) \\
Diesel & 14,51 & 3,18 & 5,97 & 10,6 Batista et al. (2015) \\
\hline
\end{tabular}

Fonte: Próprio autor.

A partir dessas informações (parâmetros de Hansen do lipídio de microalga e do solvente) foi possível utilizar as Equações (4) e (5) para prever a solubilidade do lipídio em diversos solventes.

\subsubsection{Solubilidade do solvente em água}

Deseja-se que o solvente seja insolúvel em água para que existam duas fases líquidas. Pode-se utilizar diversas abordagens para endereçar essa questão, sendo uma delas a estimativa da solubilidade aquosa por métodos de contribuição de grupos, como o de Marrero e Gani (2002). Esse método está implementado no software IBSS $\AA$ por meio da propriedade Log[Ws]. (MARRERO; GANI, 2002)

Para a presente aplicação, deseja-se que o solvente seja o menos solúvel em água possível, para que sejam formadas duas fases líquidas. Com base nas estimativas feitas no IBSS $\AA^{\circ}$ neste trabalho, o n-hexano possui valor de $\log _{10}$ [Ws] de 3,03, equivalente a $1,08 \mathrm{~g} / \mathrm{L}$ em água. O Ws é dado em $\mathrm{mg} / \mathrm{L}$ no IBSS $\AA_{\text {, }}$ ou seja, se $\log _{10}\left[\mathrm{Ws}\right.$ e é igua a 3,03 , Ws é igual a $10^{3,03} \mathrm{mg} / \mathrm{L}$. 
Dessa forma, foi definido para este trabalho um valor limite de $1,5 \mathrm{~g} / \mathrm{L}$, 0 que representa um valor de $\log _{10}[\mathrm{Ws}]$ de 3,18. Qualquer solvente com um valor de Log ${ }_{10}[\mathrm{Ws}]$ maior que 3,18 , não será avaliado em etapas posteriores.

\subsection{Parâmetros energéticos e de EHS (Step 2)}

\subsubsection{Modelo de demanda energética de Martin}

Martin (2016) propôs um modelo que permite a estimativa da demanda energética de cada etapa do processo de extração do lipídio da microalga Nannochloropsis sp. via rota úmida utilizando $\mathrm{n}$-hexano como solvente para produção de biodiesel. Esse processo foi conduzido de forma experimental em outros estudos do grupo de pesquisa do próprio Martin e publicados por Olmstead et al. (2013) e Halim et al. (2016).

O modelo permite a estimativa da demanda energética (energia necessária para a produção do equivalente a $1 \mathrm{MJ}$ de biodiesel) de cada etapa: mistura, separação, evaporação e perdas por emissões. O restante das etapas (cultivo, incubação, ruptura, transporte, transesterificação e processamento dos outros intermediários) não fizeram parte do escopo da análise.

A primeira etapa da extração consiste em realizar a mistura do solvente com a pasta para habilitar a transferência dos lipídios neutros da pasta para o solvente. $O$ gasto energético normalizado (para a produção do equivalente a 1 MJ de biodiesel) é calculado pela Equação 7:

$$
\Phi_{\text {mix }}=\frac{I_{\text {mix }} \times t_{\text {res }} \times 3,6 \frac{\mathrm{MJ}}{\mathrm{kWh}}}{x_{T A G} \times \rho_{\text {mix }} \times \Delta H_{C, \text { Biodiesel }}^{\circ} \times \eta_{\text {t-esterificação }}}
$$

Sendo $I_{\text {mix }}$ a intensidade da mistura em $\left(\mathrm{kW} / \mathrm{m}^{3}\right)$, tres o tempo de residencial em (h), $\Delta H^{\circ}$ C, Biodiesel ( $M J / k g$ de biodiesel) o calor de combustão do biodiesel e $\eta_{t-}$ esterificação o rendimento da reação de transesterificação em $(\mathrm{kg}$ de TAG/kg de biodiesel). Os parâmetros pmix e XTAG podem ser estimados pelas equações (8) e (9). 


$$
\begin{gathered}
\rho_{\text {mix }}=x_{\text {solv }} \times \rho_{\text {solv }}+x_{w} \times \rho_{w}+x_{\text {non-TAG }} \times \rho_{\text {non-TAG }}+x_{T A G} \times \rho_{T A G} \\
x_{T A G}=\left(1-\frac{S: P}{1+S: P}\right) \times\left(\frac{\text { Solids } \%}{100}\right) \times\left(\frac{T A G \%}{100}\right)
\end{gathered}
$$

Da Equação (8), o subscrito "w" representa a água, "non-TAG" é a biomassa sem os triacilgliceróis e "TAG" são os triacilgliceróis. Da equação (9), $\mathrm{S}: \mathrm{P}$ é a proporção de solvente e pasta ( $\mathrm{kg}$ de solvente/kg de pasta de biomassa e água) e Solids\% é o percentual de biomassa seca na pasta, enquanto TAG\% é o percentual de triacilgliceróis da microalga.

Após a etapa de mistura, o sistema formará duas fases líquidas e uma sólida por meio de um processo de centrifugação. A fase orgânica conterá majoritariamente lipídios neutros, enquanto a fase aquosa conterá compostos polares solúveis em água e os resíduos insolúveis se depositarão no fundo. $\mathrm{O}$ gasto energético normalizado para a etapa de centrifugação pode ser estimado pelas Equações (10) - (12):

$$
\begin{gathered}
\Phi_{\text {sep }}=\frac{P_{\text {cent }} \times \frac{60}{1.000 .000} \frac{M J / \mathrm{min}}{W}}{\dot{m}_{T A G} \times \Delta H_{C, \text { Biodiesel }}^{\circ} \times \eta_{\text {transest }}} \\
\dot{m}_{T A G}=x_{T A G} \times Q_{\text {cent }} \times \rho_{\text {mix }} \\
Q_{\text {cent }}=v_{g} \times \Sigma
\end{gathered}
$$

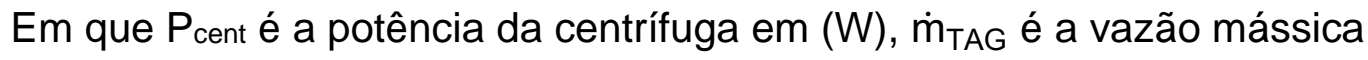
que passa pela centrífuga em (kg de TAG/min), Qcent é a vazão volumétrica em $\left(\mathrm{m}^{3} / \mathrm{min}\right), v_{\mathrm{g}}$ é a velocidade terminal da partícula em $(\mathrm{m} / \mathrm{min})$ e $\Sigma$ é o fator sigma da centrífuga $\left(e m \mathrm{~m}^{2}\right)$.

Após a retirada da fase orgânica, o solvente deve ser evaporado para que o lipídio possa ser destinado para a etapa de transesterificação, sendo o gasto energético normalizado dessa etapa indicado na Equação (13). 


$$
\Phi_{\text {evap }}=\frac{\frac{x_{\text {solv }}}{x_{T A G}} \times\left(\lambda_{\text {solv }}+\frac{1}{K} \lambda_{W}\right) \times\left(1-\eta_{\text {energy-rec }}\right)}{\Delta H_{C, \text { Biodiesel }}^{\circ} \times \eta_{\text {transest }}}
$$

Na equação acima, $\lambda_{w}$ e $\lambda_{\text {solv }}$ são os calores latentes de vaporização da água e do solvente respectivamente (em $\mathrm{MJ} / \mathrm{kg}$ ). A variável $\mathrm{K}$ representa a volatilização relativa da água com o solvente (kg de água/ kg de solvente) e П energy-rec representa a eficiência na recuperação da energia na evaporação da água e do solvente.

Ao longo de todo o processo, o solvente pode ser perdido por evaporação, dessa forma, pode-se estimar o gasto energético normalizado referente a essa perda pela equação (14).

$$
\Phi_{\text {loss }}=\frac{x_{\text {solv }}}{x_{T A G}} \times \varphi_{\text {solvent }} \times \frac{\Delta H_{C, \text { Solvent }}^{\circ}}{\Delta H_{C, \text { Biodiesel }}^{\circ} \times \eta_{\text {transest }}}
$$

Em que $\Delta \mathrm{H}^{\circ} \mathrm{c}$, Solvent é a entalpia de combustão do solvente (em $\mathrm{MJ} / \mathrm{kg}$ de

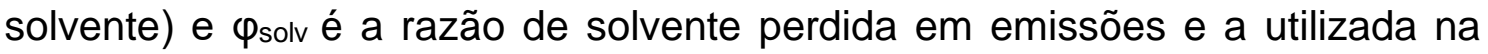
extração (kg de solvente/ ton de solvente).

No fim, o gasto energético da extração pode ser obtido somando todas as equações (7), (10), (13) e (14).

$$
\Phi_{\text {extração }}=\Phi_{\text {mix }}+\Phi_{\text {sep }}+\Phi_{\text {evap }}+\Phi_{\text {loss }}
$$

Esse modelo resulta em 8 equações com parâmetros que podem ser alterados para avaliar o gasto energético da extração em diversos cenários. Há parâmetros específicos do solvente, da biomassa, da água e o restante de condições operacionais do processo, conforme indicado.

Martin (2016) realizou a avaliação da influência de diversos desses parâmetros no gasto energético por meio de análise de sensibilidade, entretanto, não houve nenhuma avaliação do efeito do solvente (mantido sempre como nhexano). Dessa forma, neste trabalho o modelo de Martin foi extrapolado para diversos solventes com a finalidade de se obter um entendimento maior da 
influência do solvente no gasto energético do processo e explorar novas possibilidades.

Neste trabalho, os parâmetros de Martin foram avaliados e reagrupados em três grupos: parâmetros do solvente, parâmetros constantes (referentes a biomassa e a água) e parâmetros de processo (que sofrem influência do solvente utilizado), como mostrado nos tópicos a seguir:

- Parâmetros do Solvente: $\rho_{\text {solv }}, \lambda_{\text {solv }}, \Delta \mathrm{H}^{\circ} \mathrm{C}$, Solvent

- Parâmetros do Processo: Imix, tres, S:P, $P_{\text {cent, }} v_{g}, \Sigma, K, \varphi_{\text {solv }}$, $\eta_{\text {energy-rec }}$

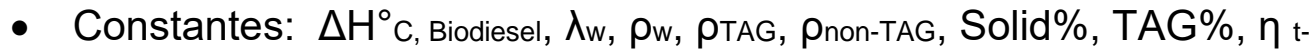
esterificação

Através das equações listadas acima e os parâmetros calculados para cada solvente, é possível realizar uma avaliação de novos solventes no desempenho energético do processo de extração de lipídio da microalga Nannochloropsis sp.

Por meio do IBSS® é possível estimar a entalpia de vaporização e a densidade de cada solvente para realizar a análise. Além disso, foi estimada com base na estrutura a entalpia de combustão de cada solvente, conforme já descrito.

Para os demais parâmetros, os valores utilizados foram idênticos aos do trabalho realizado por Martin (2016) e podem ser vistos na Tabela 7. Os valores dos parâmetros constantes podem ser vistos na Tabela 8.

Tabela 7 - Valores utilizados na análise.

\begin{tabular}{llll}
\hline Propriedade & Valor & Propriedade & Valor \\
\hline$\rho_{\text {solv }}$ & Estimado & $\mathrm{S}: \mathrm{P}$ & $0,6: 1(\mathrm{~kg}$ solvente/kg Pasta) \\
$\lambda_{\text {solv }}$ & Estimado & $\mathrm{P}_{\text {cent }}$ & $9800 \mathrm{~W}$ \\
$\Delta \mathrm{H}^{\circ} \mathrm{C}$,Solvent & Estimado & $\mathrm{V}_{\mathrm{g}}$ & $3,8 \times 10^{-7} \mathrm{~m} / \mathrm{min}$ \\
$I_{\text {mix }}$ & $1 \mathrm{~kW} / \mathrm{m}^{3}$ & $\Sigma$ & $20000 \mathrm{~m}^{2}$ \\
tres & $2,5 \mathrm{~h}$ & $\varphi$ solv & $0,5 \mathrm{~kg}$ solvente perdido/ ton \\
& & & solvente utilizado \\
$\eta_{\text {nenergy-rec }}$ & 0,50 & &
\end{tabular}

Fonte: Próprio autor. 
Tabela 8 - Valores utilizados na análise.

\begin{tabular}{llll}
\hline Propriedade & Valor & Propriedade & Valor \\
\hline$\Delta \mathrm{H}^{\circ} \mathrm{C}$, Biodiesel & $37,50 \mathrm{MJ} / \mathrm{kg}$ & Pnon-TAG & $1100 \mathrm{~kg} / \mathrm{m}^{3}$ \\
$\lambda_{\mathrm{w}}$ & $2,72 \mathrm{MJ} / \mathrm{kg}$ & Solid\% & $24,4 \%(\mathrm{~kg} \mathrm{TAG} / \mathrm{kg}$ Pasta) \\
$\rho_{\mathrm{w}}$ & $1000 \mathrm{~kg} / \mathrm{m}^{3}$ & TAG\% & $11,58 \%(\mathrm{~kg}$ TAG $/ \mathrm{kg}$ Pasta $)$ \\
$\rho_{\text {PTG }}$ & $923,86 \mathrm{~kg} / \mathrm{m}^{3}$ & $\eta_{\text {t-esterificação }}$ & $0,9 \mathrm{~kg}$ Biodiesel $/ \mathrm{kg}$ TAG \\
\hline
\end{tabular}

Fonte: Próprio autor.

\subsubsection{Ajuste e comparação dos parâmetros EHS e energéticos}

Após a estimativa da demanda energética do processo por meio da metodologia apresentada na seção 3.4.1, é possível estimar os parâmetros EHS calculados pelo IBSS $\AA$, baseado na metodologia de Weis e Visco (2010).

Os parâmetros EHS de Weis e Visco são cinco: Environmental waste, Environmental impact, Health, Safety e Life cycle. Esses parâmetros são calculados com base em propriedades físico-químicas, de acordo com Curzons et al. (1999) no guia de seleção de solventes da GlaxoSmithKline. (CURZONS; CONSTABLE; CUNNINGHAM, 1999)

A escala desses parâmetros vai de 1 (ruim) a 10 (bom). Porém, como o IBSS $\AA^{\circ}$ utiliza métodos de contribuição de grupos para estimar parâmetros, alguns valores fogem da faixa entre 1 a 10 .

Para trazer todos os valores para a faixa de 1 a 10 , foi feito 0 reescalonamento dos dados, mantando sua distribuição original. Essa técnica é muito utilizada para processamento de sinais, otimização e ciência de dados e pode ser feita utilizando a equação 16.

Dado um conjunto de dados $\mathrm{X}$, e uma observação $\mathrm{x}_{\mathrm{i}}$, temos que para um reescalonamento para uma faixa de valores entre a (menor) e $b$ (maior):

$$
x_{i, a d j}=a+\frac{\left(x_{i}-\min (X)\right)(b-a)}{\max (X)-\min (X)}
$$


Nos parâmetros EHS, quanto maior (mais próximo de 10), melhor. Entretanto, para o parâmetro energético, que tem um valor acima de 0 , quanto menor melhor (quanto menor o gasto de energia, melhor para o processo). Para que se possa comparar de maneira coerente os parâmetros energéticos e EHS, é preciso compará-los na mesma escala.

Logo, foi feito um reescalonamento inverso para o parâmetro energético, invertendo a escala com base na equação 17.

$$
x_{i, a d j}=a+\left[1-\frac{\left(x_{i}-\min (X)\right)(b-a)}{\max (X)-\min (X)}\right]
$$

Assim, o solvente que tiver a demanda energética mais próxima de zero, ou seja, o mais eficiente, receberá o novo parâmetro no valor máximo (dez). Fazendo com que todos os parâmetros possam ser avaliados da mesma maneira: entre 1 (ruim) e 10 (bom).

\subsubsection{Seleção dos solventes}

Com os parâmetros de demanda energética e EHS normalizados para a mesma escala, é possível visualizar o desempenho de todos os solventes avaliados na etapa 2 de uma maneira holística.

Foram abordadas duas maneiras de trabalhar com os resultados obtidos pelo reescalonamento dos parâmetros. A primeira foi a possibilidade de criar visualizações que comparam um solvente com o outro, por meio de elementos visuais. Essa visualização foi feita utilizando MS Excel e permite comparar qualquer par de solventes dentre os avaliados, trazendo informações como propriedades físico-químicas, detalhamento do modelo de Martin e parâmetros EHS. Um exemplo é apresentado no Apêndice 8.3.

A segunda maneira tem um viés quantitativo que visa comparar os seis atributos (Demanda energética, Environmental waste, Environmental impact, Health, Safety e Life cycle) de maneira conjunta por meio de um algoritmo de 
tomada de decisão multicritério, o TOPSIS (Technique for Order of Preference by Similarity to Ideal Solution).

O TOPSIS é um algoritmo que permite avaliar diversos atributos de vários candidatos e retornar um índice único que permite comparar os candidatos entre si. Essa avaliação avalia a distância dos atributos de um candidato em relação a solução ideal (conjunto dos melhores valores de todos os atributos avaliados). Nesse algoritmo, é possível dar pesos diferentes para cada atributo, porém nesse trabalho todos os atributos foram avaliados de forma igualitária. Mais detalhes do algoritmo podem ser encontrados no Apêndice 8.2. (YADAV et al., 2019)

Foi criado um índice chamado Rating process aplicando o método TOPSIS para os seis atributos (Demanda energética, Environmental waste, Environmental impact, Health, Safety e Life cycle).

Além disso foi criado uma classificação dos solventes com base na diferença entre o parâmetro de solubilidade de Hildebrand do solvente e do lipídio para avaliar e ordenar os solventes que apresentam um potencial maior de miscibilidade com o lipídio, facilitando o processo de extração.

Com as informações de demanda energética, Rating process e solubilidade foi possível realizar classificações para selecionar os solventes para a Etapa 3.

\subsection{Análise tecno-econômica: simulação de processos e modelos econômicos (Step 3)}

\subsubsection{Premissas operacionais}

Para o estudo do processo de extração de lipídios no Aspen, é necessária a definição de algumas premissas operacionais, sendo elas: pacote termodinâmico utilizado, representação da microalga no Aspen PLUS® e 
dimensionamento da capacidade de processamento da planta (vazão mássica de pasta de microalga processada).

\section{Pacote termodinâmico}

$\mathrm{Na}$ literatura, foram realizados diversos trabalhos que envolvem 0 processamento de óleos em ambientes computacionais. A Tabela 9 mostra diversos trabalhos e o pacote termodinâmico utilizado por cada um. A Tabela 9 não é exaustiva e indica apenas alguns exemplos que podem ser encontrados na literatura.

Tabela 9 - Resumo de trabalhos e pacotes termodinâmicos utilizados.

\begin{tabular}{ll}
\hline Trabalho & Pacote termodinâmico \\
\hline Vicente et al. (2011) & UNIQUAC \\
Silva et al. (2014) & UNIQUAC-LL \\
Quinn et al. (2015) & PRSK \\
Kong et al. (2016) & NRTL \\
Piemonte et al. (2016) & NRTL \\
Silva et al. (2016) & PC-SAFT \\
Okullo (2017) & NRTL \\
\hline
\end{tabular}

Fonte: Próprio autor.

Como o processo em questão é conduzido a condições brandas e não possui eletrólitos, o pacote NRTL (Non-random two-liquid model) foi utilizado neste trabalho, em consonância com o que é realizado na literatura.

\section{Representação da microalga}

Em diversos trabalhos que utilizam simuladores comerciais para estudo de processos de conversão e tratamento de óleos, a trioleína geralmente é utilizada para representar o lipídio da cultura estudada (microalga ou vegetal). 
(OKULLO, 2017; PIEMONTE et al., 2016; SILVA et al., 2016; VICENTE et al., 2011)

Silva et al. (2014) realizaram um trabalho em que a representação do lipídio foi baseada em diferentes triacilgliceróis. Com base na composição em ácidos graxos livres, a composição em triacilgliceróis foi a mesma para 0 triacilglicerol formato por três ácidos graxos iguais. Para exemplificar, para o ácido palmítico (C14:0, Pam), apresentando uma composição de 81,79\%, os autores consideram uma composição do triacilglicerol correspondente tripalmitina (Pam-Pam-Pam) de 81,79\%, (SILVA et al., 2014). Trata-se de um modelo bastante simplificado, que não é usado neste trabalho.

No presente trabalho, um modelo efetivo de construção de TAGs a partir da composição em ácidos graxos é considerado, inclusive para o cálculo da fração de cada TAG individual. A representação do lipídio da microalga é então baseada nos triacilgliceróis gerados na seção 3.2.1.

Além disso as frações de carboidratos e proteínas são representadas na etapa de simulação de processos pela sacarose e pela fenilalanina, como no trabalho de Piemonte et al. (2016). A composição das classes de componentes foram baseadas na literatura (WAN; BAI; ZHAO, 2013). A Tabela 10 mostra a composição em massa de cada componente.

Tabela 10 - Composição da microalga utilizada no trabalho.

\begin{tabular}{llr}
\hline Classe & Componente & $\% \mathbf{m} / \mathbf{m}$ \\
\hline Lipídio & Pam-DPa-DPa & $17,30 \%$ \\
Lipídio & Pam-Pam-DPa & $15,14 \%$ \\
Lipídio & DPa-DPa-DPa & $6,59 \%$ \\
Lipídio & Pam-Pam-Pam & $4,42 \%$ \\
Lipídio & DPa-DPa-D4A & $1,53 \%$ \\
Lipídio & Pam-D4A-DPa & $4,00 \%$ \\
Proteína & Fenilalanina & $24,00 \%$ \\
Carboidrato & Sacarose & $27,03 \%$ \\
\hline
\end{tabular}

Fonte: Próprio autor. 
Os TAGs serão inseridos de maneira customizada (user defined) por meio das estruturas em formato.$m o l$ geradas pelo ChemSketch ${ }^{\circledR}$ na seção 3.2.1. As propriedades dos TAGs foram calculadas com base na estrutura molecular pelos modelos do software Aspen PLUS®.

\section{Dimensionamento da capacidade de processamento}

Para determinação da capacidade de processamento da unidade de extração de óleo de microalga é necessário definir valores de produtividade, dias de produção por ano e área de cultivo.

Diversos trabalhos adotaram premissas diferentes, que serviram como base para o dimensionamento realizado neste trabalho, conforme mostrado na Tabela 11.

Tabela 11 - Resumo de trabalhos e premissas de dimensionamento adotadas.

\begin{tabular}{lllrr} 
Autor & Cultivo & Produtividade & Área (ha) & Dias/ano \\
\hline Sun et al. (2019) & Fotobiorreator & $23 \mathrm{~g} / \mathrm{m}^{2}$.dia & 111 & 330 \\
Wu et al. (2018) & Lago artificial & $50 \mathrm{ton} / \mathrm{ha}$.ano & 1616 & 365 \\
Xin et al. (2018) & Fotobiorreator & $34,6 \sim 57,1 \mathrm{~g} / \mathrm{m}^{2}$. dia & 2,58 & 320 \\
Dutta et al. (2016) & Lago artificial & $30 \mathrm{~g} / \mathrm{m}^{2}$. dia & 4050 & 330 \\
Delrue et al. (2012) & Lago artificial & $20-30 \mathrm{~g} / \mathrm{m}^{2}$.dia & 333,3 & $\mathrm{~N} / \mathrm{A}$ \\
Amer et al. (2011) & Lago artificial & $\mathrm{N} / \mathrm{A}$ & $50-5000$ & $\mathrm{~N} / \mathrm{A}$ \\
Xu et al. (2011) & Lago artificial & $38,3 \mathrm{ton} / \mathrm{m}^{2}$. ano & 100 & $\mathrm{~N} / \mathrm{A}$ \\
Davis et al. (2011) & Lago artificial & $25 \mathrm{~g} / \mathrm{m}^{2}$. dia & 1950,8 & 330 \\
\hline
\end{tabular}

Fonte: Próprio autor.

Além disso, foi realizado um estudo do volume de biodiesel produzido no Brasil em 2020, baseado em dados da ANP. De acordo com a base de dados publica, a produção mensal média de biodiesel em 2020 é de $485.000 \mathrm{~m}^{3}$ por mês, somando todas as 51 usinas, o que resulta em uma média de 9.509,90 $\mathrm{m}^{3}$ por mês por usina. (AGÊNCIA NACIONAL DE PETRÓLEO, 2017; GRANOL, 2010) 
Isso significa que cada usina produz em média 12,68 toneladas por hora de biodiesel (utilizando a premissa de 330 dias de operação por ano a 24h, resultando em 7.920 horas por ano). Adiciona-se também o fato de que a usina de biodiesel recebe óleo vegetal de diversas fontes e de diferentes origens. A Granol, por exemplo, possui 4 unidades industriais e 33 unidades de armazenamento, corroborando essa hipótese de que uma usina recebe matériaprima de várias fontes.

Com base nos dados da Tabela 11, pode-se adotar como uma premissa que a unidade estudada neste trabalho é capaz de produzir $25 \mathrm{~g} / \mathrm{m}^{2}$.dia por 330 dias num ano utilizando uma área cultivada de 500 hectares.

Com esses dados, pode-se calcular a produção de microalga seca pela Equação 18.

$$
\text { Produção }=\frac{25 \mathrm{~g}}{\mathrm{~m}^{2} . \text { dia }} 500 \mathrm{ha} \frac{10.000 \mathrm{~m}^{2}}{\mathrm{ha}} \frac{330 \mathrm{dia}}{\text { ano }} \frac{1 \text { ton }}{10^{6} \mathrm{~g}}
$$

Com essas premissas, a produção de biomassa seca seria de 5,21 toneladas por hora. Considerando que será processada biomassa com concentração de $25 \% \mathrm{~m} / \mathrm{m}$, então a vazão de pasta de microalga seria de 20,83 toneladas por hora.

Branco-Vieira et al. (2020) realizaram uma análise de ciclo de vida e chegaram na conclusão de que cada 12 unidades de massa de biomassa seca geram 1 unidade de massa de biodiesel (proporção 1:12 de biodiesel:biomassa seca).

Com essas premissas, a unidade nessas condições (500 ha, $25 \mathrm{~g} / \mathrm{m}^{2}$.dia e 330 dias por ano de operação) contribuiria com 3,42\% da produção de biodiesel média de uma usina. Para esse volume produzido, seriam necessários 37 mil hectares de cultivo de soja.

Dessa forma, para este trabalho, serão utilizadas as premissas de 500 ha, $25 \mathrm{~g} / \mathrm{m}^{2}$.dia e 330 dias por ano de operação, que estão na faixa contemplada na literatura. 


\subsubsection{Análises preliminares de capacidade de extração}

Os solventes eleitos para a etapa 3 foram levados para o ambiente Aspen PLUS® para estudos mais aprofundados levando em consideração o desempenho na extração do lipídio considerando dados de equilíbrio termodinâmico gerados em simulação.

Para isso, foi definida a corrente de pasta de microalga na concentração de $25 \% \mathrm{~m} / \mathrm{m}$, com componente e composições definidos na seção 3.5. Para efeitos de estudos preliminares, uma vazão de $4 \mathrm{~kg} / \mathrm{h}$ de pasta foi utilizada, sendo $1 \mathrm{~kg} / \mathrm{h}$ de biomassa seca.

Além disso foi definida uma corrente de solvente puro a uma vazão igual a vazão de biomassa seca, $1 \mathrm{~kg} / \mathrm{h}$ (proporção $1: 1$ de solvente em relação a biomassa seca) para efeitos de estudo. O bloco de simulação utilizado no Aspen foi o decanter pois leva em consideração o equilíbrio das duas fases líquidas esperadas.

Essas duas correntes entram em contato no decantador e duas fases se formam, uma aquosa com maiores percentuais em massa de água, carboidratos e proteínas e uma orgânica, rica em solvente e lipídio. Os solventes são comparados em relação a sua capacidade de recuperação de solvente na fase orgânica.

Além disso, foram feitas análises de sensibilidade variando a vazão mássica de solvente $(1 \mathrm{~kg} / \mathrm{h}$ a $2 \mathrm{~kg} / \mathrm{h})$. Essa análise foi feita para $\mathrm{n}$-hexano, benchmark da análise. Os dois melhores solventes são levados então para uma análise mais ampla do processo de extração.

\subsubsection{Simulação do processo de extração}

$\mathrm{Na}$ etapa final de simulação, os solventes são analisados sob uma perspectiva mais abrangente do processo. A pasta de microalga e o solvente são misturados em um tanque e depois bombeadas para o decantador. A corrente 
aquosa do decantador (rica em carboidratos e proteínas) não é estudada neste trabalho.

Já a corrente orgânica (rica em lipídios) é parcialmente vaporizada em um refervedor e enviada para um vaso em que ocorre a separação das fases vapor e líquida. A fase vapor é condensada e reciclada para ser utilizada na extração (é utilizado um bloco separator para retirar resíduos de carboidrato e proteínas). Já a fase líquida é o lipídio bruto a uma concentração de $95 \% \mathrm{~m} / \mathrm{m}$, produto da análise em questão. A Figura 10 representa o domínio do processo avaliado neste trabalho.

Figura 10 - Delimitação do domínio de simulação avaliado no trabalho.

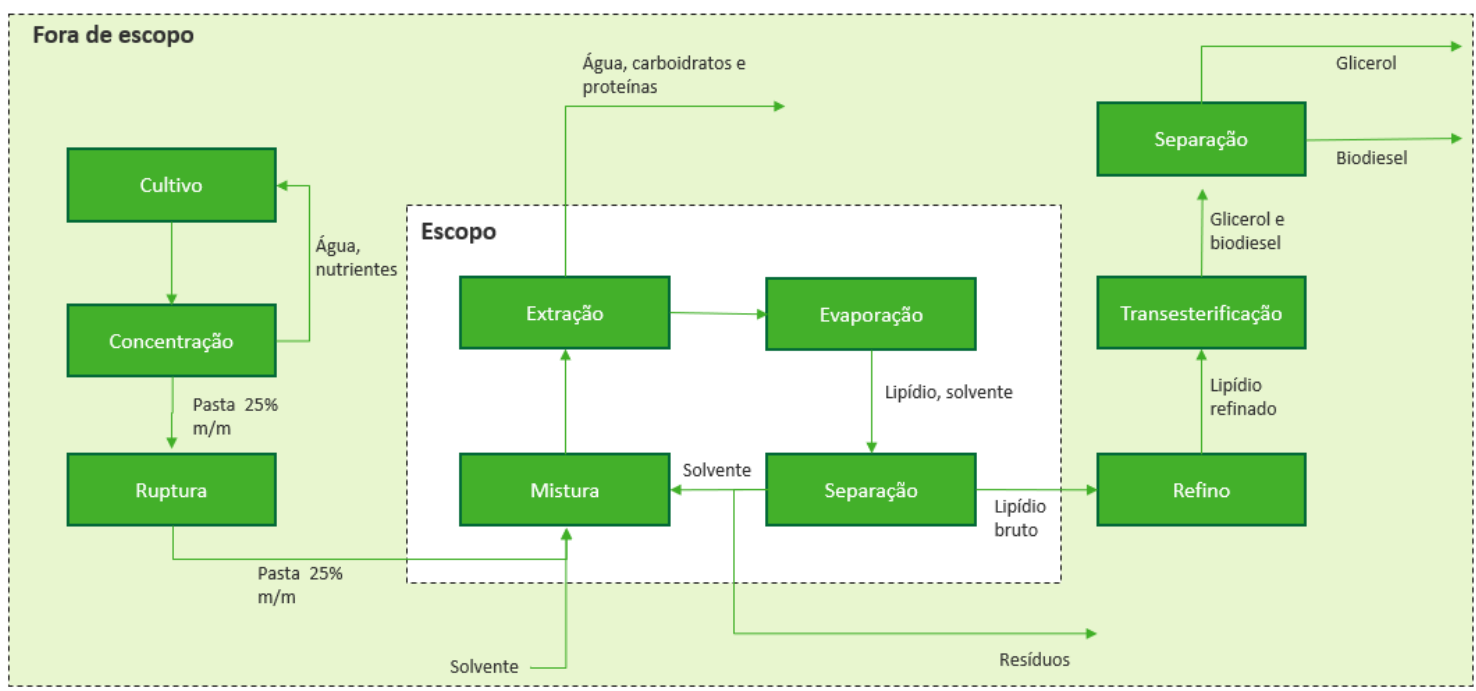

Fonte: Próprio autor.

Nessa análise, as vazões utilizadas são as definidas na seção 3.5 (equivalentes a uma área de cultivo de 500 hectares), conforme dimensionamento descrito. Além disso, não só os balanços materiais são considerados, como também as correntes energéticas. Foi utilizado também o módulo do Aspen de dimensionamento de equipamentos para apoiar na análise financeira da seção 3.5.3. A Figura 11 representa o diagrama do processo avaliado. 
Figura 11 - Digrama do processo avaliado.

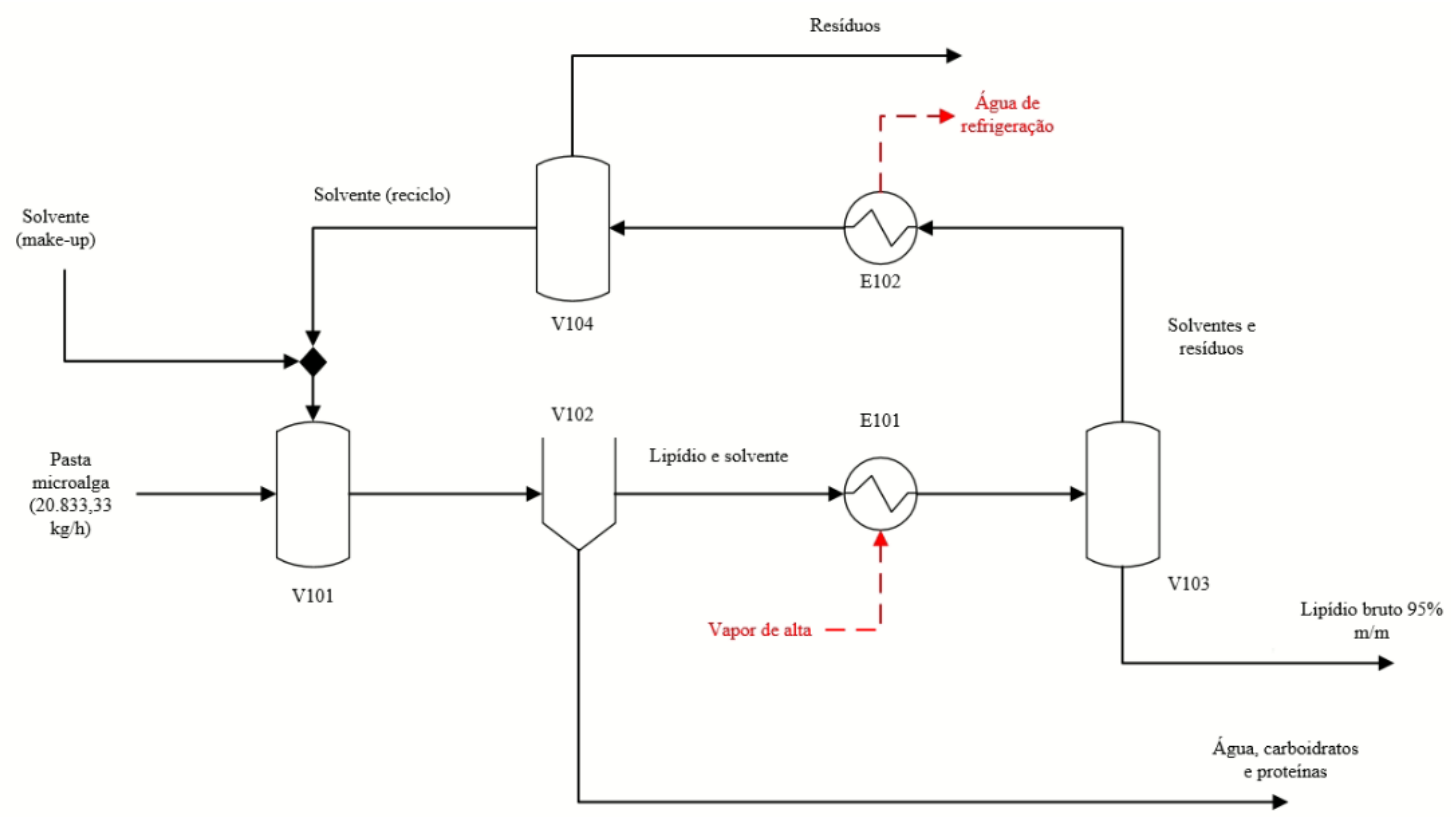

Fonte: Próprio autor.

\subsubsection{Análise financeira}

Para a análise financeira foram utilizados os dados de correntes materiais e energéticas obtidos na seção 3.5.3 e o dimensionamento dos equipamentos realizado pelo Aspen. Além disso, foram definidas algumas premissas operacionais e financeiras para construção da projeção financeira, descritas a seguir.

Para realizar o dimensionamento da unidade, o tipo de equipamento foi fornecido para cada bloco de simulação no Aspen. A Tabela 12 lista os equipamentos utilizados, seus respectivos códigos e o tipo de equipamento para dimensionamento do Aspen. 
Tabela 12 - Lista de equipamentos da unidade de extração.

\begin{tabular}{lll}
\hline Equipamento & Função & Nome equip. \\
\hline V101 & Separador L-L & Tanque Horizontal \\
V102 & Separador L-V & Tanque Vertical \\
V103 & Separador & Tanque Vertical \\
V104 & Agitador pasta & Tanque Vertical \\
E101 & Refervedor & Refervedor Kettle \\
E102 & Condensador & Condensador U-Tube \\
P101 & Bomba centrífuga & Bomba centrífuga \\
P102 & Bomba centrífuga & Bomba centrífuga \\
P103 & Bomba centrífuga & Bomba centrífuga \\
P104 & Bomba centrífuga & Bomba centrífuga \\
P105 & Bomba centrífuga & Bomba centrífuga \\
P106 & Bomba centrífuga & Bomba centrífuga \\
P107 & Soprador & Centrifugal radial fan \\
P108 & Bomba centrífuga & Bomba centrífuga \\
P109 & Bomba centrífuga & Bomba centrífuga \\
\hline
\end{tabular}

Fonte: Próprio autor.

O valor do custo de capital (CAPEX - Capital expenditure) foi estimado para cada equipamento por meio das correlações baseadas na capacidade de equipamento, com os devidos ajustes de escala (regra dos seis décimos) e tempo (correção pelo CEPCI). (TURTON, RICHARD; BAILLIE RICHARD; WHITING, WALLACE; SHAEIWITZ, 1998)

Os custos operacionais (OPEX - Operational expenditure) foram estimados por meio da metodologia de Turton et al. (1998), por meio da estimativa dos seguintes componentes:

- Investimento de capital (FCI): equipamentos, instalação e contingências;

- Custo de matéria-prima ( $\left.\mathrm{C}_{\mathrm{RM}}\right)$ : custo anual do solvente e da pasta de microalga;

- Custo de utilidades (Cut): custo anual do vapor, água de refrigeração e eletricidade;

- Custo de mão-de-obra (CoL): custo do trabalho das pessoas envolvidas no processo. 
O custo de tratamento de resíduos ( $\mathrm{C}_{\mathrm{WT}}$ ) não foi considerado neste trabalho. Todas as componentes supracitadas foram utilizadas para o cálculo do custo operacional total da unidade (OPEX). No Apêndice 8.4 se encontram mais detalhes da estimativa do CAPEX e do OPEX.

Com base no escopo definido na seção 3.5.3, o produto da unidade desse trabalho é o óleo de microalga bruto a uma concentração de $95 \% \mathrm{~m} / \mathrm{m}$. As outras correntes não tiveram rotas de valorização propostas. Dessa forma, a receita gerada é o produto entre a quantidade de óleo produzida e seu preço de venda. Nenhuma outra fonte de receita foi considerada na análise.

Com as informações de receita, CAPEX, e OPEX é possível realizar projeções e estudos financeiros. Para isso é necessária a definição de premissas financeiras e operacionais, que são mostradas na Tabela 13.

Tabela 13 - Premissas operacionais e financeiras da análise.

\begin{tabular}{lll}
\hline Premissa & Valor & Referência \\
\hline Período de construção & 2 anos & Própria \\
Período de operação & 20 anos & Própria \\
Dias de operação no ano & 330 dias & Própria \\
CAPEX construção & $40 \%$ no ano 1/60\% no ano 2 & Própria \\
Depreciação & $10 \%$ ao ano (linear) por 10 anos & Própria \\
Inflação & Não considerada & Própria \\
Receita de outros produtos & Não considerada & Própria \\
Custo eletricidade & 0,10 US $\$ /$ Wh & Arora (2020) \\
Custo refrigeração & 0,54 US $\$ / G J$ & Wu et al. (2020) \\
Custo vapor de alta & 25 US $\$$ /ton & Arora (2020) \\
Entalpia vapor de alta & 1699,3 kJ/kg & Turton et al. (1998) \\
Custo de capital (TMA) & $7,55 \%$ a.a. ou 11,55\% a.a. & Damoraran (2020) \\
Custo médio operating labor & US\$64.300/ano & Turton et al. (1998) \\
Impostos sobre lucro & $20 \%$ & Própria \\
Valor residual equipamento & Não considerado & Própria \\
\hline
\end{tabular}

Fonte: Próprio autor. 
O fluxo de caixa foi projetado para os 20 anos de operação trazidos a valor presente por meio da taxa de desconto de $7,55 \%$ (com um cenário alternativo para uma taxa desconto mais elevada). As métricas de avaliação de projeto aplicadas foram VPL (valor presente líquido), e MFSP (preço mínimo de venda do combustível, encontrado quando VPL é igual a 0). 


\section{RESULTADOS}

\subsection{Cálculo das propriedades do lipídio e do solvente (etapa 0)}

Com base nos procedimentos da seção 3.2, foi possível obter a composição do lipídio da microalga Nannochloropsis sp. em termos de triacilgliceróis, como pode ser visto na Tabela 14.

Tabela 14 - Composição do lipídio da microalga Nannochloropsis sp. em

FORTRAN.

\begin{tabular}{|c|c|c|c|c|}
\hline Código TAG & Fração molar & Fração massica & $\begin{array}{r}\text { Massa molar } \\
{[\mathrm{g} / \mathrm{mol}]}\end{array}$ & $\begin{array}{r}\text { Densidade } \\
{\left[\mathrm{kg} / \mathrm{m}^{3}\right]}\end{array}$ \\
\hline PamDPaDPa & 0,1808 & 0,1791 & 803,29 & 924,00 \\
\hline PamPamDPa & 0,1578 & 0,1567 & 805,30 & 920,00 \\
\hline DPaDPaDPa & 0,1035 & 0,1023 & 801,27 & 929,00 \\
\hline DPaPamDPa & 0,0904 & 0,0895 & 803,29 & 924,00 \\
\hline PamDPaPam & 0,0789 & 0,0784 & 805,30 & 920,00 \\
\hline PamPamPam & 0,0689 & 0,0686 & 807,32 & 916,00 \\
\hline DPaDPaD4A & 0,0226 & 0,0237 & 851,33 & 936,00 \\
\hline PamD4ADPa & 0,0197 & 0,0207 & 853,35 & 932,00 \\
\hline PamDPaD4A & 0,0197 & 0,0207 & 853,35 & 932,00 \\
\hline DPaPamD4A & 0,0197 & 0,0207 & 853,35 & 932,00 \\
\hline PamPamD4A & 0,0172 & 0,0181 & 855,36 & 928,00 \\
\hline MyrDPaDPa & 0,0163 & 0,0156 & 775,24 & 927,00 \\
\hline DPaDPaOle & 0,0134 & 0,0137 & 829,33 & 926,00 \\
\hline MyrDPaPam & 0,0143 & 0,0137 & 777,25 & 923,00 \\
\hline PamMyrDPa & 0,0143 & 0,0137 & 777,25 & 923,00 \\
\hline MyrPamDPa & 0,0143 & 0,0137 & 777,25 & 923,00 \\
\hline PamOleDPa & 0,0117 & 0,0120 & 831,34 & 922,00 \\
\hline MyrPamPam & 0,0125 & 0,0120 & 779,27 & 918,00 \\
\hline PamDPaOle & 0,0117 & 0,0120 & 831,34 & 922,00 \\
\hline DPaPamOle & 0,0117 & 0,0120 & 831,34 & 922,00 \\
\hline DPaD4ADPa & 0,0113 & 0,0118 & 851,33 & 936,00 \\
\hline SteDPaDPa & 0,0114 & 0,0116 & 831,34 & 922,00 \\
\hline PamPamOle & 0,0102 & 0,0105 & 833,36 & 917,00 \\
\hline PamDPaSte & 0,0099 & 0,0102 & 833,36 & 917,00 \\
\hline StePamDPa & 0,0099 & 0,0102 & 833,36 & 917,00 \\
\hline PamSteDPa & 0,0099 & 0,0102 & 833,36 & 917,00 \\
\hline PamD4APam & 0,0086 & 0,0091 & 855,36 & 928,00 \\
\hline PamPamSte & 0,0087 & 0,0089 & 835,37 & 913,00 \\
\hline DPaMyrDPa & 0,0082 & 0,0078 & 775,24 & 927,00 \\
\hline DPaOleDPa & 0,0067 & 0,0068 & 829,33 & 926,00 \\
\hline PamMyrPam & 0,0062 & 0,0060 & 779,27 & 918,00 \\
\hline
\end{tabular}

Fonte: Próprio autor. 
Os códigos de cada ácido graxo que compões os triacilgliceróis são apresentados na Tabela 15.

Tabela 15 - Nome e código de cada ácido graxo presente na microalga.

\begin{tabular}{ll}
\hline Código & Nome do ácido \\
\hline Myr & Ácido mirístico \\
Pam & Ácido palmítico \\
Ste & Ácido esteárico \\
Dpa & Ácido palmitoleico \\
Ole & Ácido oleico \\
Lin & Ácido linoleico \\
D3A & Ácido Epoxieicosatrienoico \\
D4A & Ácido aracdônico \\
\hline
\end{tabular}

Fonte: Próprio autor.

Os triacilgliceróis presentes em maior quantidade são formados por combinações dos três ácidos graxos presentes em maior quantidade: $O$ ácido palmitoleico (DPa), o ácido palmítico (Pam) e o ácido aracdônico (D4A).

Com os triacilgliceróis e os seus respectivos SMILES gerados pelo ChemSketch ${ }^{\circledR}$ (Tabela 29, Apêndice 8.5), foi possível obter as propriedades por meio do software IBSS $\AA$. Na Tabela 31, do Apêndice 8.5 é possível visualizar as propriedades estimadas para cada um dos 31 triacilgliceróis.

O mesmo procedimento foi realizado para a base de SMILES de solventes, para estimativa das respectivas propriedades, que podem ser consultadas nas Tabelas 32, 33 e 34 do Apêndice 8.6.

Como mencionado, as bases contendo ID, nome e SMILES foram unidas com as propriedades calculadas pelo IBSS $\Theta$ para a criação de um conjunto de dados dos TAGs e um para os solventes. 


\subsection{Propriedades do solvente e solubilidade (Etapa 1)}

Com posse dos resultados gerados pelo IBSS $\circledast$ para os 111 solventes presentes na base de dados, foi realizada a estimativa da entalpia de combustão. Essa estimativa usa como base a entalpia de formação e a estrutura molecular de cada solvente para estimar o parâmetro por meio das Equações 1 e 2 .

Para alguns casos, alguns métodos de estimativa de propriedades IBSS $\circledast$ não conseguiram estimar as propriedades para uma dada molécula, e assim foi atribuído um valor de -9999,999 indicando erro de cálculo. Isso pode acontecer em casos de inconsistência como grupos funcionais não aceitos pelo método, ou algum erro de entrada de valores.

Para o caso da entalpia de combustão, calculada pelo método proposto, o solvente que possuísse átomos não contemplados pelo método foi também eliminado.

Os solventes que se enquadram nesses casos acima foram eliminados da análise por não atingirem os requisitos da análise sistemática. Ao todo, 15 solventes foram eliminados por esses critérios.

Os 96 solventes remanescentes tiveram sua capacidade de solubilizar o lipídio avaliadas pelos parâmetros de solubilidade de Hansen. Para isso, é necessário determinar os parâmetros de Hansen do lipídio estudado. Por meio da Equação 6 foi possível obter esses valores, mostrados na Tabela 16.

Tabela 16 - Parâmetros de Hansen do óleo de microalga estimados pelo software IBSS® através do SMILES de cada triacilglicerol. Legenda: $\delta_{D}$ (parâmetro dispersivo), $\delta_{\mathrm{P}}$ (parâmetro de momento dipolo) e $\delta_{H}$ (parâmetro de pontes de hidrogênio).

\begin{tabular}{lrrr}
\hline Composto & $\delta_{\mathrm{D}}$ & $\boldsymbol{\delta}_{\mathrm{P}}$ & $\boldsymbol{\delta}_{\mathrm{H}}$ \\
\hline Lipídio de Nannochloropsis sp. & 16,35 & 3,33 & 3,64
\end{tabular}

Fonte: Próprio autor. 
Os parâmetros de Hansen de diversos óleos encontrados na literatura (Tabela 6 apresentada na seção 3.3.2) foram comparados com os obtidos para o lipídio da microalga, como mostrado na Tabela 17.

Tabela 17 - Comparação dos parâmetros de solubilidade de Hansen para diversos óleos com o lipídio da microalga Nannochloropsis sp. (A) representa o óleo comparado e (B) o lipídio da microalga.

\begin{tabular}{|c|c|c|c|c|}
\hline Óleo (A) & $4\left(\delta_{d}{ }^{A}-\delta_{d}{ }^{B}\right)^{2}$ & $\left(\delta_{p}{ }^{A}-\delta_{p}{ }^{B}\right)^{2}$ & $\left(\delta_{h}{ }^{A}-\delta_{h}{ }^{B}\right)^{2}$ & $\Sigma$ \\
\hline Óleo de Côco & 7,84 & 1,69 & 11,16 & 20,69 \\
\hline Óleo de Palma & 5,66 & 0,00 & 0,19 & 5,86 \\
\hline Biodiesel Soja & 6,97 & 0,13 & 27,88 & 34,98 \\
\hline Biodiesel Côco & 6,05 & 0,44 & 31,47 & 37,96 \\
\hline Biodiesel Palma & 3,39 & 3,80 & 8,82 & 16,01 \\
\hline Biodiesel Mamona & 0,25 & 11,49 & 29,92 & 41,66 \\
\hline Triacetina & 0,09 & 1,37 & 29,81 & 31,27 \\
\hline Biodiesel de óleo de fritura usado & 6,97 & 0,13 & 27,88 & 34,98 \\
\hline Diesel & 13,54 & 0,02 & 5,43 & 18,99 \\
\hline
\end{tabular}

Fonte: Próprio autor.

Pela Tabela 17, observa-se que o óleo de palma é o óleo que tem parâmetros de Hansen mais semelhantes com os obtidos para o óleo de microalga, analisando a soma dos quadrados dos desvios.

Para estimar a solubilidade, foram realizadas três análises considerando diferentes raios de solubilidade de óleos estudos na literatura, listados na Tabela 17. Os raios de solubilidade considerados foram do óleo de palma, triacetina e o biodiesel produzido através do óleo de palma por apresentarem características semelhantes ao lipídio da microalga, como pode ser visto na Tabela 17.

Por meio das Equações 4 e 5 (apresentadas na seção 3.3.2) foi possível calcular o Ra e o RED para cada solvente. Observa-se que foram analisados três raios de interação $\left(R_{0}\right)$ diferentes, resultando em três RED para cada solvente. $O$ intuito foi avaliar os efeitos da hipótese da escolha de um deles para conduzir a análise, como pode ser visto na Tabela 18. 
Tabela 18 - RED para cada solvente e usando diferentes raios de interação $\left(R_{0}\right)$ : do óleo de palma, triacetina e biodiesel de óleo de palma. Em verde os solventes que solubilizam o lipídio e em vermelho os solventes que não solubilizam.

(continua)

\begin{tabular}{|c|c|c|c|}
\hline Solvente & $\begin{array}{r}\text { RED ( } \mathbf{R}_{0} \\
\text { Triacetina) }\end{array}$ & $\begin{array}{r}\text { RED ( } \mathbf{R}_{0} \\
\text { Palma) } \\
\end{array}$ & $\begin{array}{r}\text { RED ( } \mathbf{R}_{0} \\
\text { Biodiesel) }\end{array}$ \\
\hline p-cumeno & 0,391 & 0,628 & 0,446 \\
\hline 1,3-Dioxan-5-ol & 1,503 & 2,412 & 1,712 \\
\hline 1,3-Dioxolano & 0,521 & 0,835 & 0,593 \\
\hline 1,3-Dioxolano-4-metanol & 1,421 & 2,279 & 1,617 \\
\hline 1,3-Propanodiol & 2,124 & 3,407 & 2,418 \\
\hline 1,4-Cineol & 0,109 & 0,174 & 0,124 \\
\hline 1,8-Cineol & 0,125 & 0,201 & 0,142 \\
\hline 1-Butanol & 1,057 & 1,695 & 1,203 \\
\hline 1-Decanol & 0,508 & 0,814 & 0,578 \\
\hline 1-Octanol & 0,634 & 1,017 & 0,722 \\
\hline 2-Metiltetraidrofurano & 0,161 & 0,258 & 0,183 \\
\hline 2-Pirrolidona & 1,148 & 1,842 & 1,307 \\
\hline Ácido 3-hidroxipropanoico & 1,881 & 3,017 & 2,141 \\
\hline 3-Metoxi-3-metil-1-butanol & 0,800 & 1,284 & 0,911 \\
\hline 5-Hidroximetilfurfural & 1,570 & 2,519 & 1,788 \\
\hline Ácido acético & 1,038 & 1,666 & 1,182 \\
\hline Acetona & 0,583 & 0,935 & 0,663 \\
\hline Álcool benzílico & 0,930 & 1,492 & 1,059 \\
\hline Benzoato de benzila & 0,632 & 1,014 & 0,720 \\
\hline Butanona & 0,451 & 0,724 & 0,514 \\
\hline Etanoato de butila & 0,295 & 0,473 & 0,336 \\
\hline Laurato de butila & 0,053 & 0,085 & 0,060 \\
\hline Miristato de butila & 0,099 & 0,158 & 0,112 \\
\hline Palmitato de butila & 0,087 & 0,140 & 0,099 \\
\hline Estearato de butila & 0,146 & 0,234 & 0,166 \\
\hline Cicloexano & 0,242 & 0,388 & 0,275 \\
\hline Éter ciclopentilmetílico & 0,052 & 0.084 & 0.059 \\
\hline Sebacato de dibutil & 0.108 & 0.174 & 0.124 \\
\hline Diidromircenol & 0.542 & 0.870 & 0.617 \\
\hline Succinato de diisoamila & 0.226 & 0.363 & 0.258 \\
\hline Glutarato de Diisobutil & 0.276 & 0.442 & 0.314 \\
\hline Succinato de diisooctilo & 0.111 & 0.178 & 0.126 \\
\hline Dimetil 2-metil glutarato & 0.409 & 0.657 & 0.466 \\
\hline Dimetil glutarato & 0.515 & 0.826 & 0.586 \\
\hline Dimetil isossorbida & 0.511 & 0.819 & 0.581 \\
\hline
\end{tabular}


(continua)

\begin{tabular}{|c|c|c|c|}
\hline Solvente & $\begin{array}{r}\text { RED ( } \mathbf{R}_{\mathbf{0}} \\
\text { Triacetina) }\end{array}$ & $\begin{array}{r}\text { RED ( } \mathbf{R}_{0} \\
\text { Palma) }\end{array}$ & $\begin{array}{r}\text { RED (R } \\
\text { Biodiesel) }\end{array}$ \\
\hline D-Limoneno & 0,153 & 0,245 & 0,174 \\
\hline Etanol & 1,426 & 2,288 & 1,623 \\
\hline Acetato de etila & 0,391 & 0,628 & 0,446 \\
\hline Éter etílico & 0,242 & 0,388 & 0,275 \\
\hline Lactato de etila & 1,011 & 1,622 & 1,151 \\
\hline Laurato de etila & 0,141 & 0,226 & 0,160 \\
\hline Linoleato de etila & 0,061 & 0,097 & 0,069 \\
\hline Linolenato de etila & 0,094 & 0,151 & 0,107 \\
\hline Miristato de etila & 0,125 & 0,201 & 0,143 \\
\hline Oleato de etila & 0,088 & 0,142 & 0,100 \\
\hline Palmitato de etila & 0,125 & 0,201 & 0,143 \\
\hline Etilenoglicol & 1,563 & 2,508 & 1,780 \\
\hline Álcool furfurílico & 1,369 & 2,196 & 1,558 \\
\hline Geraniol & 0,531 & 0,852 & 0,605 \\
\hline Acetato de geranil & 0,205 & 0,330 & 0,234 \\
\hline Glicerol & 1,872 & 3,004 & 2,132 \\
\hline Carbonato de glicerol & 2,018 & 3,237 & 2,297 \\
\hline Triacetato de glicerol & 0,535 & 0,858 & 0,609 \\
\hline Éter glicerol-1,2,3-tributílico & 0,121 & 0,194 & 0,138 \\
\hline Éter glicerol-1,2,3-trietílico & 0,187 & 0,301 & 0,213 \\
\hline Éter glicerol-1,2,3-trimetílico & 0,403 & 0,647 & 0,459 \\
\hline Éter glicerol-1,3-dietílico & 0,541 & 0,867 & 0,616 \\
\hline Éter glicerol-1,3-dimetílico & 0,840 & 1,347 & 0,956 \\
\hline n-Hexano & 0,316 & 0,507 & 0,360 \\
\hline Acetato de isoamila & 0,224 & 0,359 & 0,255 \\
\hline Álcool isoamílico & 0,751 & 1,205 & 0,855 \\
\hline Acetato de isobutila & 0,260 & 0,417 & 0,296 \\
\hline Álcool isobutílico & 0,886 & 1,422 & 1,009 \\
\hline Isodecano & 0,175 & 0,280 & 0,199 \\
\hline Álcool isopropílico & 0,992 & 1,591 & 1,129 \\
\hline Palmitato de isopropila & 0,058 & 0,093 & 0,066 \\
\hline Metanol & 1,991 & 3,194 & 2,266 \\
\hline Abietato de metila & 0,197 & 0,316 & 0,225 \\
\hline Acetato de metila & 0,455 & 0,730 & 0,518 \\
\hline Laurato de metila & 0,124 & 0,199 & 0,142 \\
\hline Linoleato de Metila & 0,046 & 0,074 & 0,052 \\
\hline Linolenato de metila & 0,082 & 0,132 & 0,094 \\
\hline Miristato de metila & 0,094 & 0,151 & 0,107 \\
\hline
\end{tabular}




\begin{tabular}{|c|c|c|c|}
\hline Solvente & $\begin{array}{r}\text { RED ( } \mathbf{R}_{0} \\
\text { Triacetina) }\end{array}$ & $\begin{array}{r}\text { RED ( } \mathbf{R}_{0} \\
\text { Palma) }\end{array}$ & $\begin{array}{r}\text { (conclusão) } \\
\text { RED (Ro } \\
\text { Biodiesel) }\end{array}$ \\
\hline Oleato de metila & 0,060 & 0,096 & 0,068 \\
\hline Palmitato de metila & 0,096 & 0,154 & 0,109 \\
\hline Ricinoleato de metila & 0,389 & 0,624 & 0,443 \\
\hline Estearato de metila & 0,120 & 0,192 & 0,137 \\
\hline N, N-Dimetildecanamida & 0,332 & 0,532 & 0,378 \\
\hline N, N-Dimetiloctanamida & 0,405 & 0,650 & 0,461 \\
\hline Nopol & 0,235 & 0,377 & 0,267 \\
\hline Acetato de n-propila & 0,296 & 0,475 & 0,337 \\
\hline Ácido Oleico & 0,140 & 0,224 & 0,159 \\
\hline Álcool oleílico & 0,368 & 0,590 & 0,419 \\
\hline p-Cumeno & 0,391 & 0,628 & 0,446 \\
\hline Ácido propiônico & 0,776 & 1,245 & 0,884 \\
\hline Carbonato de propileno & 1,279 & 2,052 & 1,456 \\
\hline Propilenoglicol & 1,731 & 2,776 & 1,970 \\
\hline Ácido ricinoléico & 0,556 & 0,892 & 0,633 \\
\hline Solketal & 0,986 & 1,582 & 1,123 \\
\hline Álcool tetrahidrofurfurílico & 1,090 & 1,749 & 1,241 \\
\hline a-Pineno & 0,243 & 0,390 & 0,277 \\
\hline$\alpha$-Terpineol & 0,542 & 0,870 & 0,618 \\
\hline a-Farneseno & 0,141 & 0,227 & 0,161 \\
\hline$\beta$-Mirceno & 0,151 & 0,243 & 0,172 \\
\hline$\beta$-Terpineol & 0,637 & 1,022 & 0,725 \\
\hline Contagem RED < 1 & 78 & 67 & 74 \\
\hline
\end{tabular}

Fonte: Próprio autor.

Utilizando o raio de solubilidade do óleo de palma, 67 solventes atingiram RED menor que 1. Já para a triacetina, o raio de solubilidade é maior, tornando a esfera de solubilidade também maior e englobando mais solventes, justificando assim o número maior de solventes que solubilizariam o óleo de microalga. Além disso, estruturalmente, a triacetina é um composto mais polar que o lipídio da microalga por ter uma cadeia hidrofóbica menor.

Dos 96 solventes testados, 78 estariam aptos utilizando o raio de solubilidade da triacetina, e 74, caso seja utilizado o raio do biodiesel de óleo de palma, mostrando que a escolha da melhor representação do lipídio da microalga pode gerar resultados bastante diferentes. 
Com base nos resultados obtidos na Tabela 17, para análise da solubilidade do lipídio em cada solvente, foi utilizado o raio de interação do óleo de palma por ter características mais similares ao lipídio da microalga. Então, dos 96 solventes analisados, 29 foram eliminados por não apresentarem potencial de solubilizar o lipídio (RED > 1 utilizando o Ro do óleo de palma), restando 67 candidatos.

A Figura 12 representa a esfera de solubilidade de Hansen do lipídio da Nannochloropsis sp. (utilizando o Ro do óleo de palma), em que os pontos azuis são os solventes que apresentam potencial de solubilizar o lipídio.

Figura 12 - Esfera de solubilidade de Hansen.

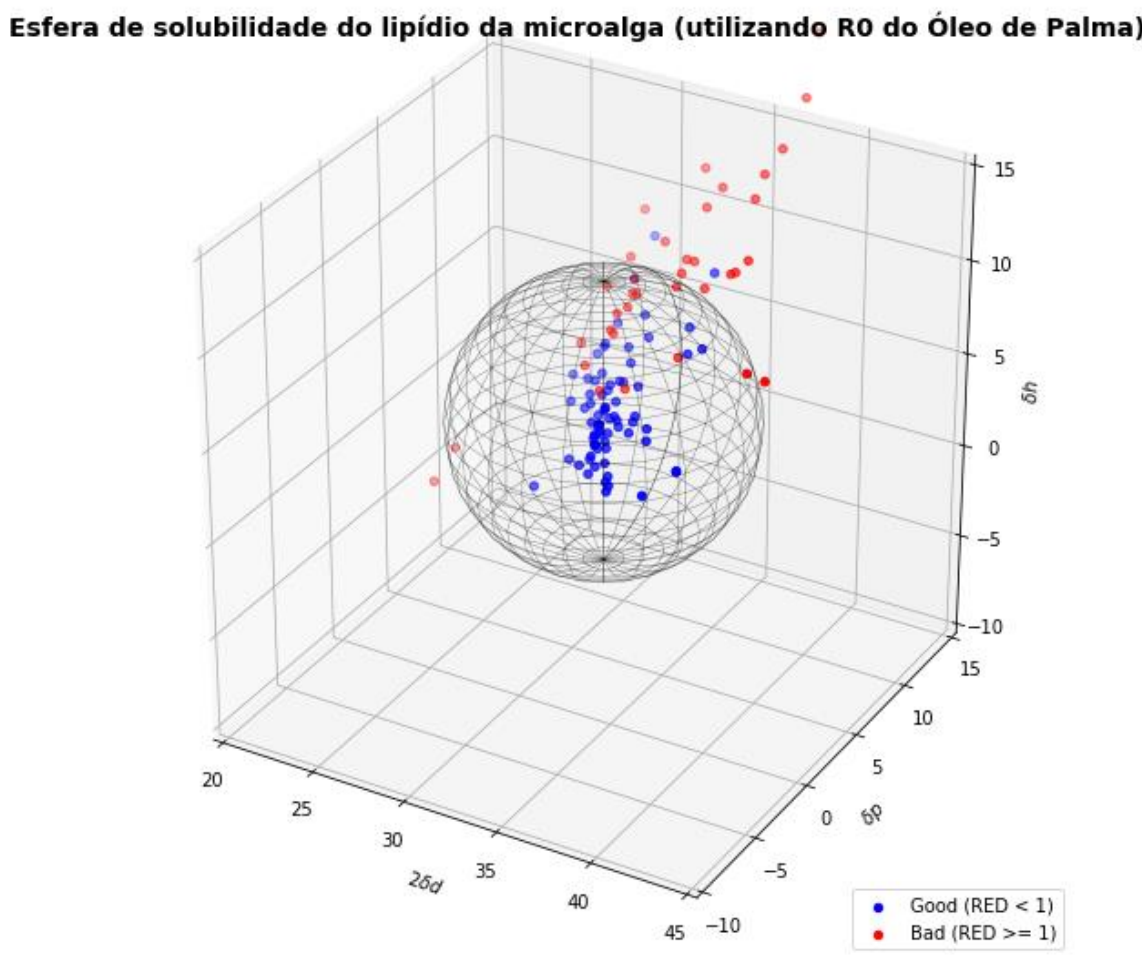

Fonte: Próprio autor.

Observa-se que muito dos solventes que atingiram menor valor de RED são ácidos graxos ou derivados orgânicos da biomassa. Isso levanta uma oportunidade de estudo do uso de compostos derivados da biomassa para substituir compostos tradicionais derivados do petróleo no processamento da biomassa. 
Os 67 solventes restantes, com capacidade de solubilizar o lipídio, foram avaliados em relação a sua solubilidade em água. Essa avaliação foi feita utilizando o parâmetro de solubilidade aquosa ( $\log _{10}[\mathrm{Ws}]$ ) calculado pelo IBSS®. Com base na premissa adotada de uma solubilidade máxima permitida de $1,5 \mathrm{~g}$ por litro de água, foi aplicado este filtro nos 67 solventes e 26 apresentaram uma solubilidade maior que o limite definido. Como é de interesse que o solvente não seja solúvel em água para que durante o processo sejam formadas duas fases, então somente 41 solventes foram considerados aptos para a etapa 2.

\subsection{Desempenho energético e EHS (Etapa 2)}

Os 41 solventes restantes da etapa 1 foram levados para a etapa de análise da demanda energética no processo de extração de lipídio. Essa demanda energética foi estimada partindo do modelo de Martin (2016), como mencionado anteriormente.

Assim, os 41 solventes foram avaliados pelo modelo utilizando os parâmetros de cada solvente como entrada do modelo (enquanto as condições operacionais permaneceram inalteradas), como pode ser visto nas Tabelas $7 \mathrm{e}$ 8. As demandas energéticas foram estimadas para cada um dos 41 solventes presentes na análise. Os resultados obtidos por etapa são apresentados na Tabela 19.

Tabela 19 - Demanda energética (em MJ gasto/MJ de biodiesel produzido) de cada etapa da extração para cada solvente.

(continua)

\begin{tabular}{lrrrrr}
\hline Solvente & $\boldsymbol{\varphi}_{\text {mix }}$ & $\boldsymbol{\varphi}_{\text {sep }}$ & $\boldsymbol{\varphi}_{\text {loss }}$ & $\boldsymbol{\varphi}_{\text {evap }}$ & $\boldsymbol{\varphi}_{\text {total }}$ \\
\hline p-Cumeno & 0,0142157 & 0,2036753 & 0,0072117 & 0,4006710 & 0,6257737 \\
1,4-Cineol & 0,0142152 & 0,2036678 & 0,0071647 & 0,3846301 & 0,6096777 \\
1-Decanol & 0,0142160 & 0,2036797 & 0,0076515 & 0,4427854 & 0,6683326 \\
Laurato de butila & 0,0142158 & 0,2036760 & 0,0069331 & 0,3985298 & 0,6233546 \\
Miristato de butila & 0,0142158 & 0,2036761 & 0,0070804 & 0,3979835 & 0,6229557 \\
Palmitato de butila & 0,0142158 & 0,2036761 & 0,0072012 & 0,3975353 & 0,6226284 \\
Estearato de butila & 0,0142158 & 0,2036762 & 0,0073021 & 0,3971609 & 0,6223549 \\
Sebacato de diisobutila & 0,0142151 & 0,2036672 & 0,0058018 & 0,3986548 & 0,6223389
\end{tabular}


(conclusão)

\begin{tabular}{|c|c|c|c|c|c|}
\hline Solvente & $\varphi_{\text {mix }}$ & $\varphi_{\text {sep }}$ & $\varphi$ loss & $\varphi_{\text {evap }}$ & $\varphi_{\text {total }}$ \\
\hline Succinato de diisoamila & 0,0142150 & 0,2036653 & 0,0052125 & 0,3938789 & 0,6169716 \\
\hline Glutarato de Diisobutil & 0,0142150 & 0,2036647 & 0,0050279 & 0,3939299 & 0,6168376 \\
\hline Succinato de diisooctila & 0,0142152 & 0,2036685 & 0,0060022 & 0,3936605 & 0,6175464 \\
\hline Succinato de dioctila & 0,0142152 & 0,2036680 & 0,0060168 & 0,3981908 & 0,6220908 \\
\hline D-Limoneno & 0,0142159 & 0,2036778 & 0,0075631 & 0,3750159 & 0,6004727 \\
\hline Laurato de etila & 0,0142157 & 0,2036755 & 0,0067496 & 0,3992103 & 0,6238512 \\
\hline Linoleato de etila & 0,0142156 & 0,2036736 & 0,0069492 & 0,3963870 & 0,6212253 \\
\hline Linolenato de etila & 0,0142155 & 0,2036721 & 0,0068206 & 0,3958016 & 0,6205098 \\
\hline Miristato de etila & 0,0142157 & 0,2036756 & 0,0069331 & 0,3985298 & 0,6233542 \\
\hline Oleato de etila & 0,0142157 & 0,2036748 & 0,0070760 & 0,3969649 & 0,6219313 \\
\hline Palmitato de etila & 0,0142157 & 0,2036757 & 0,0070804 & 0,3979835 & 0,6229553 \\
\hline Geraniol & 0,0142156 & 0,2036741 & 0,0071101 & 0,4395304 & 0,6645302 \\
\hline Acetato de geranila & 0,0142154 & 0,2036703 & 0,0060668 & 0,4003973 & 0,6243497 \\
\hline Éter glicerol-1,2,3-tributílico & 0,0142157 & 0,2036746 & 0,0066351 & 0,3890791 & 0,6136045 \\
\hline n-Hexano & 0,0142173 & 0,2036980 & 0,0091166 & 0,4052873 & 0,6323192 \\
\hline Isodecano & 0,0142158 & 0,2036761 & 0,0074489 & 0,3860887 & 0,6114295 \\
\hline Palmitato de isopropila & & & & & 0,6201767 \\
\hline Abietato de metila & 0,0142145 & 0,2036586 & 0,0063394 & 0,37 & 0,5979122 \\
\hline Laur & & & & & 0,6 \\
\hline Linoleato de Metila & 0,0142156 & 0,2036733 & 0,0068788 & 0,3965488 & 0,6213165 \\
\hline Linolenato de metila & 0,0142155 & 0,2036718 & 0,0067436 & 0,3959364 & 0,6205673 \\
\hline Miristato de metila & 0,0142157 & 0,2036754 & 0,0068467 & 0,3988504 & 0,6235882 \\
\hline Oleato de metila & 0,0142157 & 0,2036746 & 0,0070121 & 0,3971529 & 0,6220553 \\
\hline Palmitato de metila & 0,0142157 & 0,2036756 & 0,0070105 & 0,3982425 & 0,6231443 \\
\hline Ricinoleato de metila & 0,0142152 & 0,2036685 & 0,0064835 & 0,4175978 & 0,6419650 \\
\hline Estearato de metila & 0,0142157 & 0,2036757 & 0,0071436 & 0,3977488 & 0,6227839 \\
\hline N, N-Dimetildecanamida & 0,0142156 & 0,2036744 & 0,0070628 & 0,4252250 & 0,6501778 \\
\hline Ácido oleico & 0,0142155 & 0,2036723 & 0,0069067 & 0,3997126 & 0,6245071 \\
\hline Álcool oleílico & 0,0142159 & 0,2036775 & 0,0078340 & 0,4216529 & 0,6473803 \\
\hline p-Cumeno & 0,0142157 & 0,2036753 & 0,0072117 & 0,4006710 & 0,6257737 \\
\hline Ácido ricinoléico & 0,0142150 & 0,2036657 & 0,0063589 & 0,4209811 & 0,6452207 \\
\hline a-Farneseno & 0,0142161 & 0,2036807 & 0,0079514 & 0,3930040 & 0,6188522 \\
\hline$\beta$-Mirceno & 0,0142164 & 0,2036851 & 0,0080081 & 0,3959955 & 0,6219050 \\
\hline p-Cumeno & 0,0142157 & 0,2036753 & 0,0072117 & 0,4006710 & 0,6257737 \\
\hline 1,4-Cineol & 0,0142152 & 0,2036678 & 0,0071647 & 0,3846301 & 0,6096777 \\
\hline 1-Decanol & 0,0142160 & 0,2036797 & 0,0076515 & 0,4427854 & 0,6683326 \\
\hline
\end{tabular}

Fonte: Próprio autor.

Ao se levar em consideração a demanda energética total $\varphi$ total (Equação 15), existem 34 solventes com desempenho energético melhor que o $n$-hexano, levando em consideração que os únicos parâmetros que se alteraram foram as propriedades do solvente (densidade, entalpia de combustão e entalpia de 
vaporização). Os demais parâmetros (de processo e constantes) se mantiveram inalterados por não terem métricas definidas para essa etapa de análise. A Figura 13 mostra um gráfico com o desempenho de todos os solventes avaliados.

Figura 13 - Comparação entre o desempenho energético dos solventes avaliados.

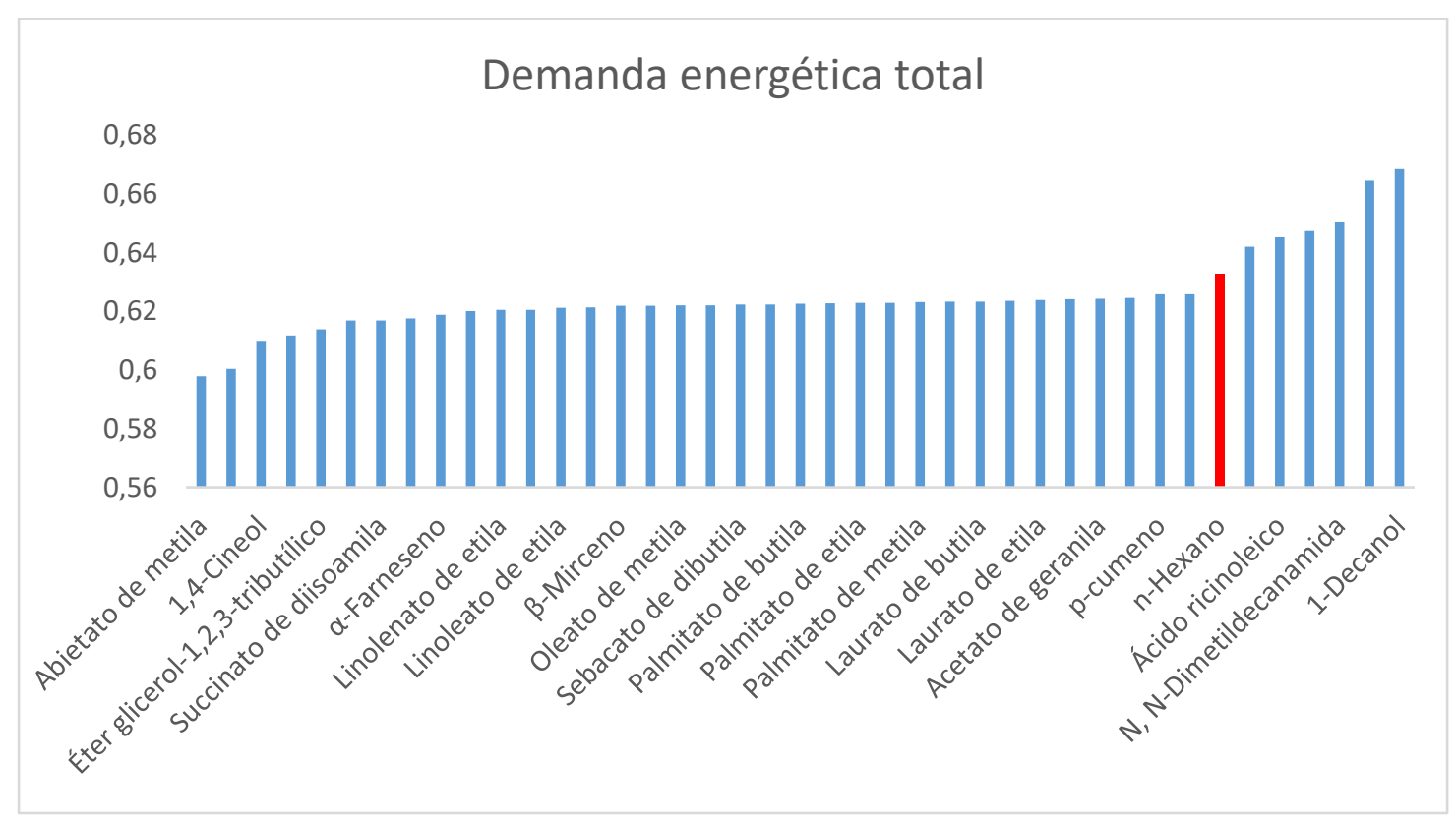

Fonte: Próprio autor.

Somente três parâmetros foram alterados com a escolha do solvente. Os parâmetros de processo se mantiveram inalterados. Porém, esses parâmetros de processo podem ter seu valor alterado em virtude da mudança do solvente.

Para obter um maior entendimento do comportamento do modelo e da influência de cada parâmetro (propriedade do solvente ou parâmetro operacional), foi realizada uma análise de sensibilidade para avaliar a variação da demanda energética em função dos parâmetros do solvente e do processo. 
Para isso, foram realizadas várias simulações com acréscimo de 10\% (em relação aos valores base definidos) no valor de cada parâmetro. A Figura 14 representa um mapa de calor gerado em python com a variação percentual da demanda energética causada por cada parâmetro em cada etapa.

Figura 14 - Análise da influência dos parâmetros na demanda energética de cada uma das etapas.

\begin{tabular}{|c|c|c|c|c|c|c|c|c|c|c|c|}
\hline-4.7 & 0 & 0 & 10 & 10 & 5 & 0 & 0 & 0 & 0 & 0 & 0 \\
\hline-4.7 & 0 & 0 & 0 & 0 & 5 & 10 & -9.1 & -9.1 & 0 & 0 & 0 \\
\hline 0 & 10 & 0 & 0 & 0 & 10 & 0 & 0 & 0 & 0 & 0 & 10 \\
\hline 0 & 0 & 7.3 & 0 & 0 & 4.8 & 0 & 0 & 0 & -2.5 & -40 & 0 \\
\hline-2.2 & 2.9 & 1.8 & 0.88 & 0.88 & 6.4 & 3.8 & -3.4 & -3.4 & -0.61 & -9.8 & 2.9 \\
\hline$\rho_{s o / v}$ & Sarve & $\lambda_{\text {salv }}$ & $I_{m / x}$ & $T_{\text {RES }}$ & S.P & $P_{C E N T}$ & Vg & $\Sigma$ & $\mathrm{K}$ & $\eta_{\text {Recov }}$ & $\phi_{\text {salv }}$ \\
\hline
\end{tabular}

Fonte: Próprio autor.

Observa-se que a razão mássica entre solvente e pasta (S:P), a eficiência

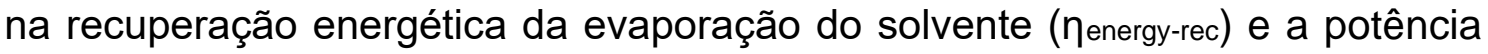
da centrífuga ( $P_{\text {Cent) }}$ são os fatores que possuem maior influência no valor da demanda energética total do processo de extração.

O uso de modelos de estimativa desses parâmetros de processo utilizando as propriedades do solvente como entrada poderia trazer um ganho de precisão. Porém, por questões de escopo, optou-se por avaliar a demanda energética utilizando somente as propriedades do solvente, mantendo as outras variáveis inalteradas.

Pode-se destacar que um diferencial da metodologia desenvolvida nesse trabalho é a incorporação de parâmetros de processo (consumo energético) já na etapa de seleção do solvente, evitando-se com isso que solventes com boa 
performance em escala de bancada, mas inviáveis industrialmente, sejam considerados.

Com posse da demanda energética (estimado pelo modelo de Martin) e dos parâmetros EHS (estimados pelo IBSS $®$ ), foi possível realizar comparações para se fazer uma seleção de solventes para a Etapa 3.

Utilizando as Equações 16 (parâmetros EHS) e 17 (demanda energética) foi possível criar uma escala de avaliação com valores entre 1 (ruim) e 10 (bom), permitindo a comparação entre os solventes. Os parâmetros normalizados são mostrados na Tabela 20.

Tabela 20 - Parâmetros normalizados para os solventes avaliados.

(continua)

\begin{tabular}{lrrrrrr}
\hline Solvente & Env_Waste & Env_Impact & Health & Safety & Life_Cycle & Energy \\
\hline p-Cumeno & 2,80 & 7,60 & 3,13 & 1,12 & 10,00 & 6,44 \\
1,4-Cineol & 1,88 & 10,00 & 6,26 & 1,15 & 9,51 & 8,50 \\
1-Decanol & 1,67 & 8,66 & 5,37 & 1,32 & 7,93 & 1,00 \\
Laurato de butila & 2,80 & 8,06 & 7,20 & 2,02 & 6,33 & 6,75 \\
Miristato de butila & 3,11 & 7,88 & 7,91 & 2,38 & 6,33 & 6,80 \\
Palmitato de butila & 3,42 & 7,70 & 8,63 & 2,81 & 6,33 & 6,84 \\
Estearato de butila & 3,73 & 7,52 & 9,35 & 3,32 & 6,33 & 6,88 \\
Sebacato de dibutila & 4,19 & 9,65 & 4,24 & 3,13 & 5,91 & 6,88 \\
Succinato de deisoamila & 5,85 & 9,56 & 1,36 & 2,84 & 5,91 & 7,56 \\
Glutarato de diisobutila & 5,69 & 9,76 & 1,00 & 2,67 & 5,91 & 7,58 \\
Diisooctyl succinate & 6,78 & 8,33 & 3,52 & 4,25 & 5,91 & 7,49 \\
Succinato de dioctila & 4,50 & 9,42 & 4,95 & 3,56 & 5,91 & 6,91 \\
D-Limoneno & 1,72 & 7,98 & 2,44 & 1,11 & 6,74 & 9,67 \\
Laurato de etila & 2,49 & 8,24 & 6,48 & 1,73 & 6,33 & 6,68 \\
Linoleato de etila & 3,11 & 7,29 & 7,20 & 2,76 & 6,33 & 7,02 \\
Linolenato de etila & 2,96 & 7,19 & 6,48 & 2,69 & 6,33 & 7,11 \\
Miristato de etila & 2,80 & 8,06 & 7,20 & 2,02 & 6,33 & 6,75 \\
Oleato de etila & 3,27 & 7,46 & 7,91 & 2,80 & 6,33 & 6,93 \\
Palmitato de etila & 3,11 & 7,88 & 7,91 & 2,38 & 6,33 & 6,80 \\
Geraniol & 1,36 & 8,41 & 3,21 & 1,51 & 7,93 & 1,49 \\
Acetato de geranila & 1,87 & 8,24 & 3,60 & 1,61 & 6,33 & 6,62 \\
Éter glicerol-1,2,3-tributílico & 2,39 & 6,66 & 4,27 & 2,55 & 4,67 & 7,99 \\
n-Hexano & 1,00 & 8,23 & 2,80 & 1,00 & 6,74 & 5,60 \\
Isodecano & 10,00 & 1,00 & 10,00 & 10,00 & 5,50 & 8,27 \\
Palmitato de isopropila & 3,27 & 7,35 & 8,62 & 2,80 & 6,74 & 7,15 \\
Abietato de metila & 7,93 & 6,73 & 4,79 & 2,80 & 7,95 & 10,00
\end{tabular}


(conclusão)

\section{Solvente}

Laurato de metila

Linoleato de Metila

Linolenato de metila

Miristato de metila

Oleato de metila

Palmitato de metila

Ricinoleato de metila

Estearato de metila

$\mathrm{N}, \mathrm{N}$-Dimetildecanamida

Ácido oleico

Álcool oleílico

$\mathrm{p}$-Cumeno

Ácido ricinoléico

a-Farneseno

$\beta$-Mirceno

\section{Env_Waste Env_Impact Health Safety Life_Cycle}

Energy

2,34

8,44

6,23

1,48

6,95

2,37

2,34

7,45

6,23

6,95

1,70

2,38

$7,77 \quad 7,67$

8,17

7,67

2,00

2,70

2,36

8,39

8,04

2,98

2,06

2,14

2,25

7,53

3,13

1,12

2,48

9,17

8,48

7,15

2,80

1,61

$\begin{array}{lll}7,92 & 2,08 & 1,14\end{array}$

$1,15 \quad 7,92 \quad 2,08 \quad 1,14$

7,95

7,95

7,95

7,95

7,95

7,95

9,56

7,95

1,00

8,35

7,93

10,00

9,95

6,74

6,74
6,65

7,01

7,10

6,72

6,91

6,78

4,37

6,82

3,32

6,60

3,68

6,44

3,95

7,32

6,93

Fonte: Próprio autor.

A Figura 15 mostra uma comparação entre o n-hexano e o ácido oleico (um dos solventes analisados). No Apêndice 8.2 há uma amostra do painel dinâmico criado para comparação de solventes.

Figura 15 - Comparação entre o n-hexano e o ácido oleico.

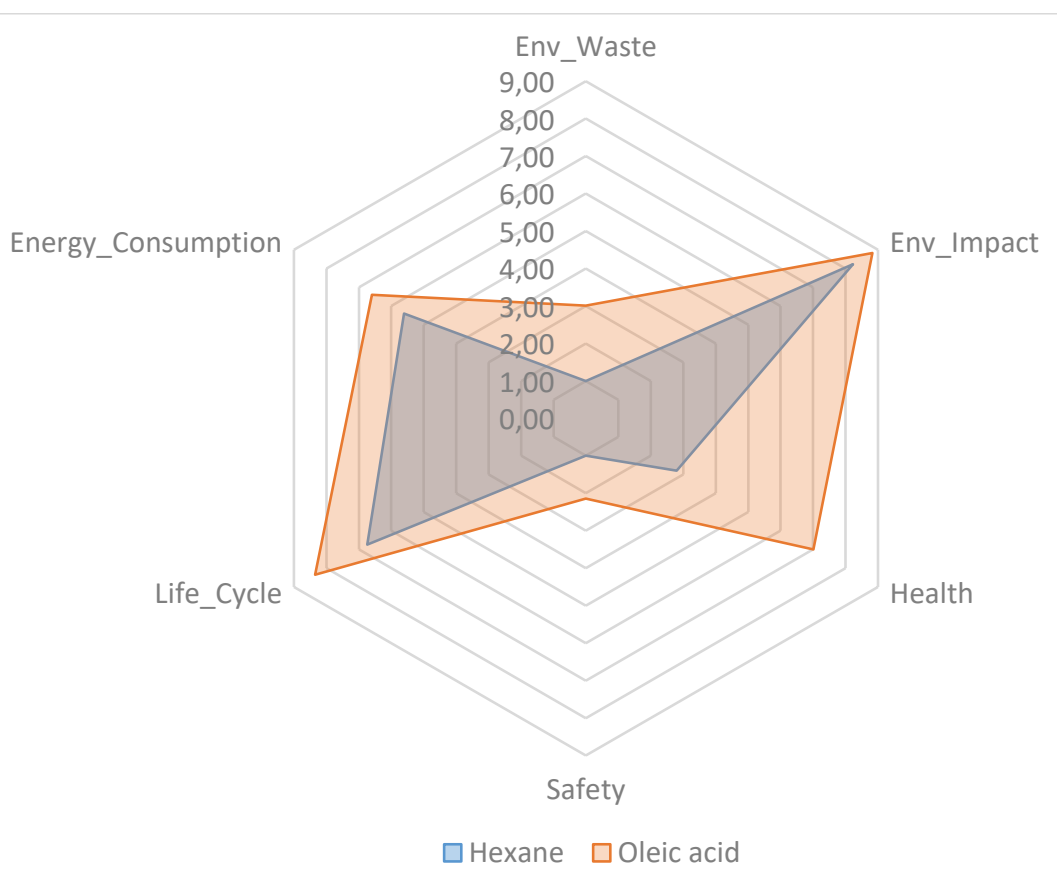


Fonte: Próprio autor.

Foi utilizado o algoritmo TOPSIS (seção 3.4.3) para criar um índice que levasse em consideração os cinco parâmetros EHS e a demanda energética de uma maneira conjunta. A saída do algoritmo foi atribuída a uma variável chamada Rating process (quanto maior, melhor energeticamente e melhor em relação aos 5 parâmetros EHS de Weis e Visco).

Com base no ranking de demanda energética, rating process e Hildebrand (potencial de miscibilidade), foi possível criar classificações dos solventes nas diferentes perspectivas, conforme mostrado na Tabela 21.

Tabela 21 - Classificação dos solventes nas perspectivas avaliadas.

(continua)

\begin{tabular}{|c|c|c|c|}
\hline$\#$ & Demanda energética & Rating process & Hildebrand \\
\hline 1 & Abietato de metila & Isodecano & Laurato de metila \\
\hline 2 & D-Limoneno & Abietato de metila & Laurato de etila \\
\hline 3 & 1,4-Cineol & Succinato de diisoctila & Succinato de diisoamila \\
\hline 4 & Isodecano & Estearato de butila & Abietato de metila \\
\hline 5 & Éter glicerol-1,2,3-tributílico & Succinato de dioctila & Miristato de metila \\
\hline 6 & Glutarato de Diisobutil & Succinato de diisoamila & Glutarato de Diisobutil \\
\hline 7 & Succinato de diisoamila & Ricinoleato de metila & p-cumeno \\
\hline 8 & Succinato de diisoctila & Ácido ricinoleico & p-Cumeno \\
\hline 9 & $\alpha$-Farneseno & Glutarato de Diisobutil & D-Limoneno \\
\hline 10 & Palmitato de isopropila & Palmitato de butila & Laurato de butila \\
\hline 11 & Linolenato de etila & Palmitato de isopropila & Miristato de etila \\
\hline 12 & Linolenato de metila & Sebacato de dibutila & n-Hexano \\
\hline 13 & Linoleato de etila & Estearato de metila & Acetato de geranila \\
\hline 14 & Linoleato de Metila & Oleato de etila & Palmitato de metila \\
\hline 15 & $\beta$-Mirceno & Oleato de metila & Miristato de butila \\
\hline 16 & Oleato de etila & Ácido oleico & Palmitato de etila \\
\hline 17 & Oleato de metila & Linoleato de etila & Sebacato de dibutila \\
\hline 18 & Succinato de dioctila & Palmitato de etila & Succinato de dioctila \\
\hline 19 & Sebacato de dibutila & Miristato de butila & Estearato de metila \\
\hline 20 & Estearato de butila & Linoleato de Metila & Palmitato de butila \\
\hline 21 & Palmitato de butila & Palmitato de metila & Succinato de diisooctilo \\
\hline 22 & Estearato de metila & 1,4-Cineol & Estearato de butila \\
\hline 23 & Palmitato de etila & Linolenato de etila & Oleato de metila \\
\hline 24 & Miristato de butila & Linolenato de metila & Oleato de etila \\
\hline
\end{tabular}


(conclusão)

\begin{tabular}{|c|c|c|c|}
\hline \# & Demanda energética & Rating process & Hildebrand \\
\hline 25 & Palmitato de metila & Mististato de metila & Éter glicerol-1,2,3-tributílico \\
\hline 26 & Miristato de etila & Miristato de etiça & Palmitato de isopropila \\
\hline 27 & Laurato de butila & Laurato de butila & Linoleato de Metila \\
\hline 28 & Miristato de metila & Álcool oleílico & Linoleato de etila \\
\hline 29 & Laurato de etila & Laurato de metila & Álcool oleílico \\
\hline 30 & Laurato de metila & Laurato de etila & Linolenato de metila \\
\hline 31 & Acetato de geranila & p-cumeno & 1,4-Cineol \\
\hline 32 & Ácido oleico & $\mathrm{p}$-Cumeno & $\beta$-Mirceno \\
\hline 33 & p-cumeno & Éter glicerol-1,2,3-tributílico & Linolenato de etila \\
\hline 34 & p-Cumeno & D-Limoneno & Ricionoleato de metila \\
\hline 35 & n-Hexano & Acetato de geranila & Geraniol \\
\hline 36 & Methyl ricinoleate & a-Farneseno & Ácido oleico \\
\hline 37 & Ácido riciloleico & 1-Decanol & a-Farneseno \\
\hline 38 & Álcool oleílico & $\beta$-Mirceno & 1-Decanol \\
\hline 39 & N, N-Dimetildecanamida & Geraniol & $\mathrm{N}, \mathrm{N}$-Dimetildecanamida \\
\hline 40 & Geraniol & n-Hexano & Isodecano \\
\hline 41 & 1-Decanol & N, N-Dimetildecanamida & Ácido ricinoleico \\
\hline
\end{tabular}

Fonte: Próprio autor.

Observa-se na Tabela 21 uma grande quantidade de ésteres (metílicos, etílicos e butílicos) de ácidos graxos. Além disso, o d-limoneno e p-cumeno aparecem na lista, compostos que inclusive já foram utilizados em trabalhos de extração de óleos. (MAMIDIPALLY; LIU, 2004; TANZI et al., 2012) O n-hexano foi o segundo pior colocado considerando o índice rating process gerado pelo TOPSIS, perdendo somente para o N,N-Dimethyldecanamide.

Ésteres metílicos de ácidos graxos (FAMEs - Fatty acid methyl esters) são utilizados como combustível e recebem a denominação de biodiesel, produto da transesterificação dos triacilgliceróis de óleo da microalga. Assim, a utilização do biodiesel como próprio solvente dentro do processo de produção pode trazer sinergias de custos. Este resultado do presente trabalho é coerente com o trabalho de $\mathrm{Hu}$ et al (2004), que identificou boas qualidades solventes em diferentes ésteres de ácidos graxos.

Sabendo que existem 39 solventes com índices Rating process melhores que o n-hexano, é possível escolher estes solventes para uma análise mais 
aprofundada. Foram escolhidos 7 solventes (além do n-hexano, benchmark da análise), mostrados na Tabela 22.

Tabela 22 - Solventes selecionados para Etapa 3 e comparação do rating process (quanto maior, melhor).

\begin{tabular}{ll}
\hline Solvente & Rating process \\
\hline Palmitato de metila & 0,3614 \\
Miristato de metila & 0,3414 \\
Miristato de etila & 0,3395 \\
Laurato de metila & 0,3246 \\
Laurato de etila & 0,3195 \\
p-Cumeno & 0,3128 \\
D-Limoneno & 0,3002 \\
n-Hexano & 0,2472 \\
\hline
\end{tabular}

Fonte: Próprio autor.

Os solventes d-limoneno, laurato de metila, miristato de metila, p-cumeno, laurato de etila e miristato de etila possuem um potencial alto de miscibilidade, além de possuírem índice Rating process melhor do que o n-hexano.

O palmitato de metila foi levado para a etapa seguinte por ser um éster metílico de um dos ácidos graxos presentes em maior quantidade no lipídio da microalga desse estudo, assim possui uma similaridade maior com o biodiesel eventualmente gerado na biorrefinaria em questão. Além disso, entre os selecionados, possui maior índice de Rating process.

\subsection{Análise tecno-econômica (Etapa 3)}

Os 7 solventes selecionados na etapa anterior foram então analisados no simulador de processos Aspen $\AA^{\circledR}$ Plus utilizando as premissas adotadas na seção 3.5.1:

- Pacote termodinâmico NRTL;

- Composição: $48,97 \%$ lipídio, 24\% proteína e 27,03\% carboidratos; 
- Concentração da pasta: $25 \% \mathrm{~m} / \mathrm{m}$ de biomassa seca e $75 \% \mathrm{~m} / \mathrm{m}$ de água.

Foi avaliada a capacidade do solvente de recuperar o lipídio na fase orgânica. Os 7 solventes foram avaliados sob as mesmas condições de operação (pressão 1 bar, temperatura $25^{\circ} \mathrm{C}$ ).

A simulação realizada consiste na mistura da corrente de pasta de microalga a uma vazão de $4 \mathrm{~kg} / \mathrm{h}$ com uma corrente de $1 \mathrm{~kg} / \mathrm{h}$ do solvente (proporção de 1 parte de solvente para 1 parte de microalgas seca) num bloco de simulação decanter. A corrente pesada (aquosa) e leve (orgânica) tiveram suas respectivas composições e vazões analisadas.

Foram feitas avaliações do percentual de recuperação do óleo, solvente, água e resíduo (carboidrato e proteína) nas duas correntes para que se pudesse entender como se dá a separação de fases. A Figura 16 mostra um caso de simulação da extração do óleo com o d-limoneno como solvente.

Figura 16 - Capacidade de extração do d-limoneno.

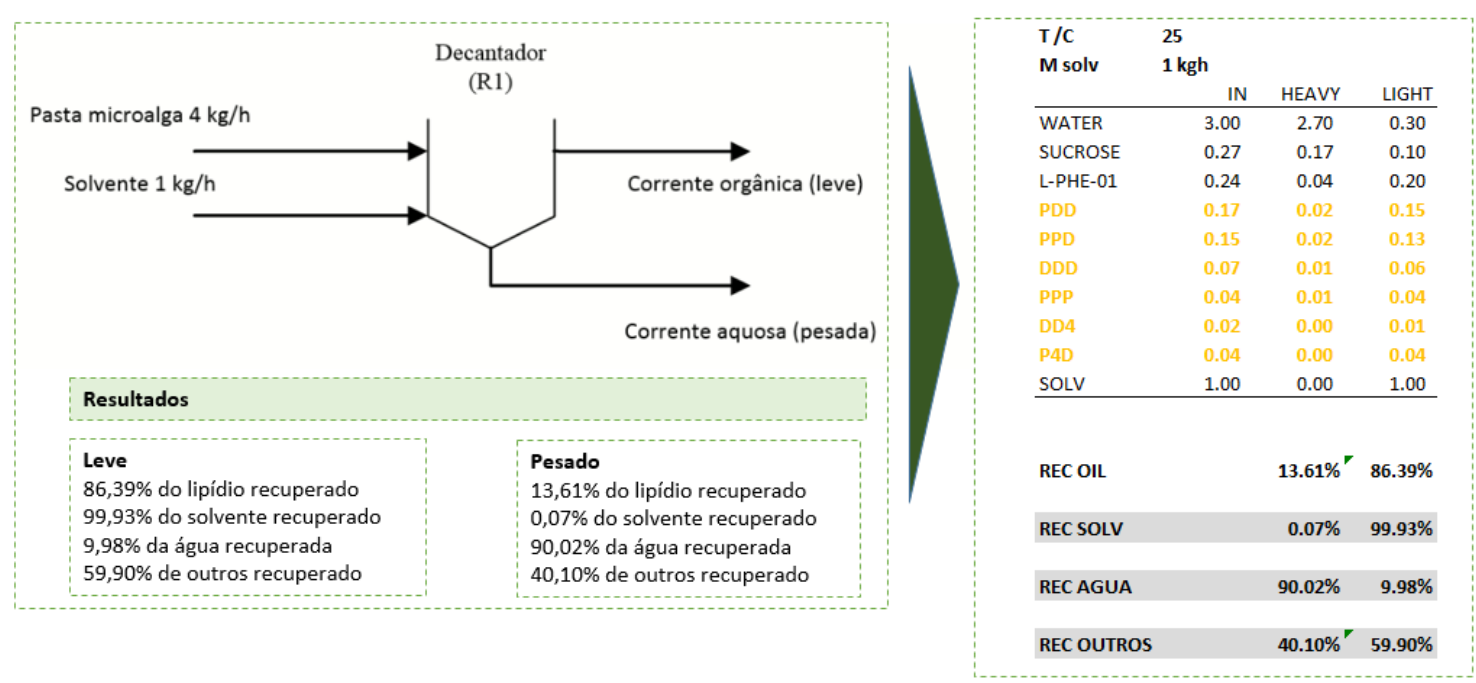

Fonte: Próprio autor.

Observa-se que o d-limoneno possui uma boa capacidade de extração do óleo da microalga na fase orgânica. Essa capacidade de recuperação será parâmetro de comparação entre os solventes. 
A mesma análise foi realizada para o $n$-hexano e os outros 7 solventes, como pode ser visto na Figura 17.

Figura 17 - Comparação da capacidade extração do óleo de microalga na fase orgânica.

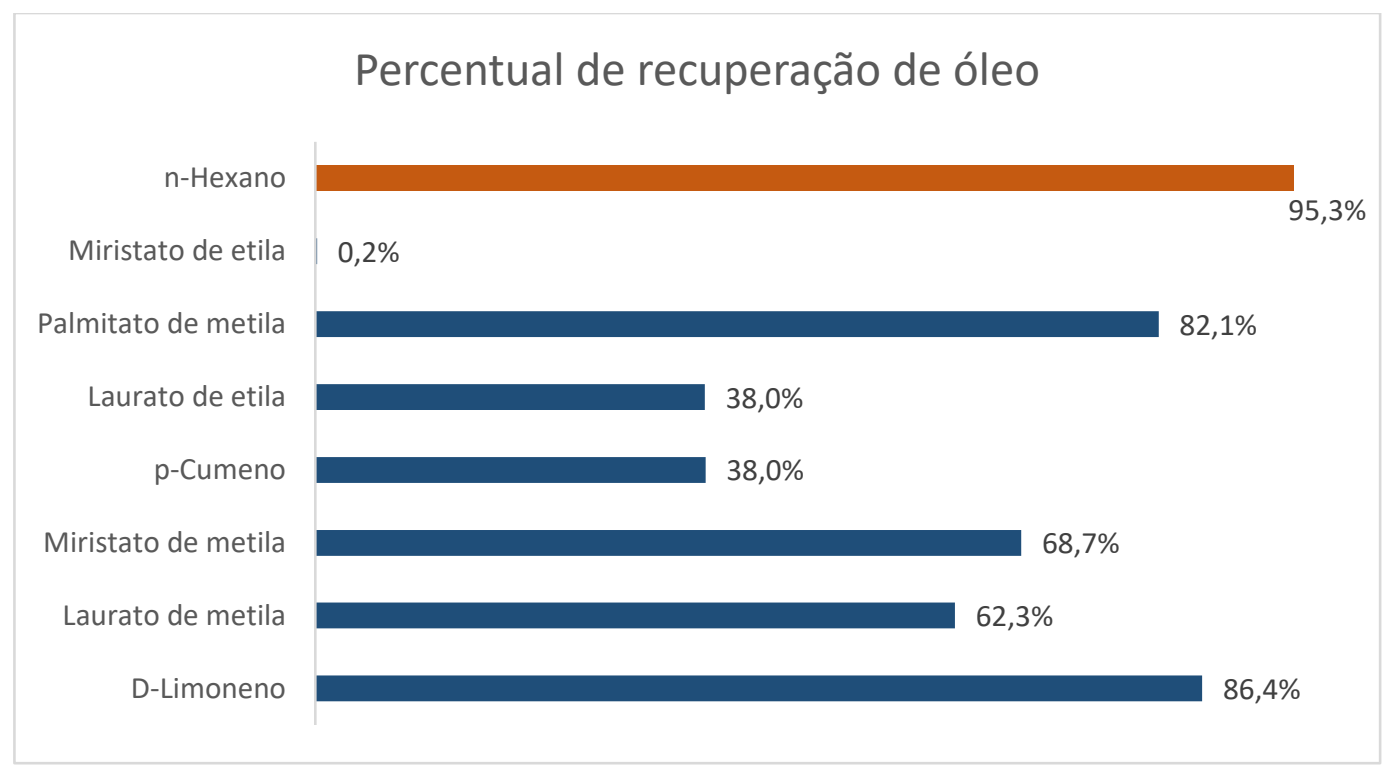

Fonte: Próprio autor.

Pela Figura 17 é possível observar que o n-hexano possui a melhor capacidade de extração. O limoneno e o palmitato de metila se destacaram com possibilidade de recuperar mais de $80 \%$ dos lipídios.

Observa-se que o miristato de etila não conseguiu realizar a extração do lipídio na fase orgânica, atingindo somente 0,2\%. Foi identificado que o miristato de metila possui miscibilidade em água, fazendo com que a fase aquosa possua grandes quantidades de água, solvente e lipídio, além de ser a fase presente em maior massa, em comparação com a orgânica. Dito isso, o miristato de metila não apresentou viabilidade técnica para ser usado como solvente nesse caso.

Foi realizada então uma análise de sensibilidade variando a proporção de solvente em relação a microalga seca: de $1 \mathrm{~kg} / \mathrm{h}$ até $2 \mathrm{~kg} / \mathrm{h}$. A Figura 18 mostra os resultados para cada um dos 7 solventes analisados. 
Figura 18 - Efeito da proporção de solvente e microalga na recuperação de óleo.

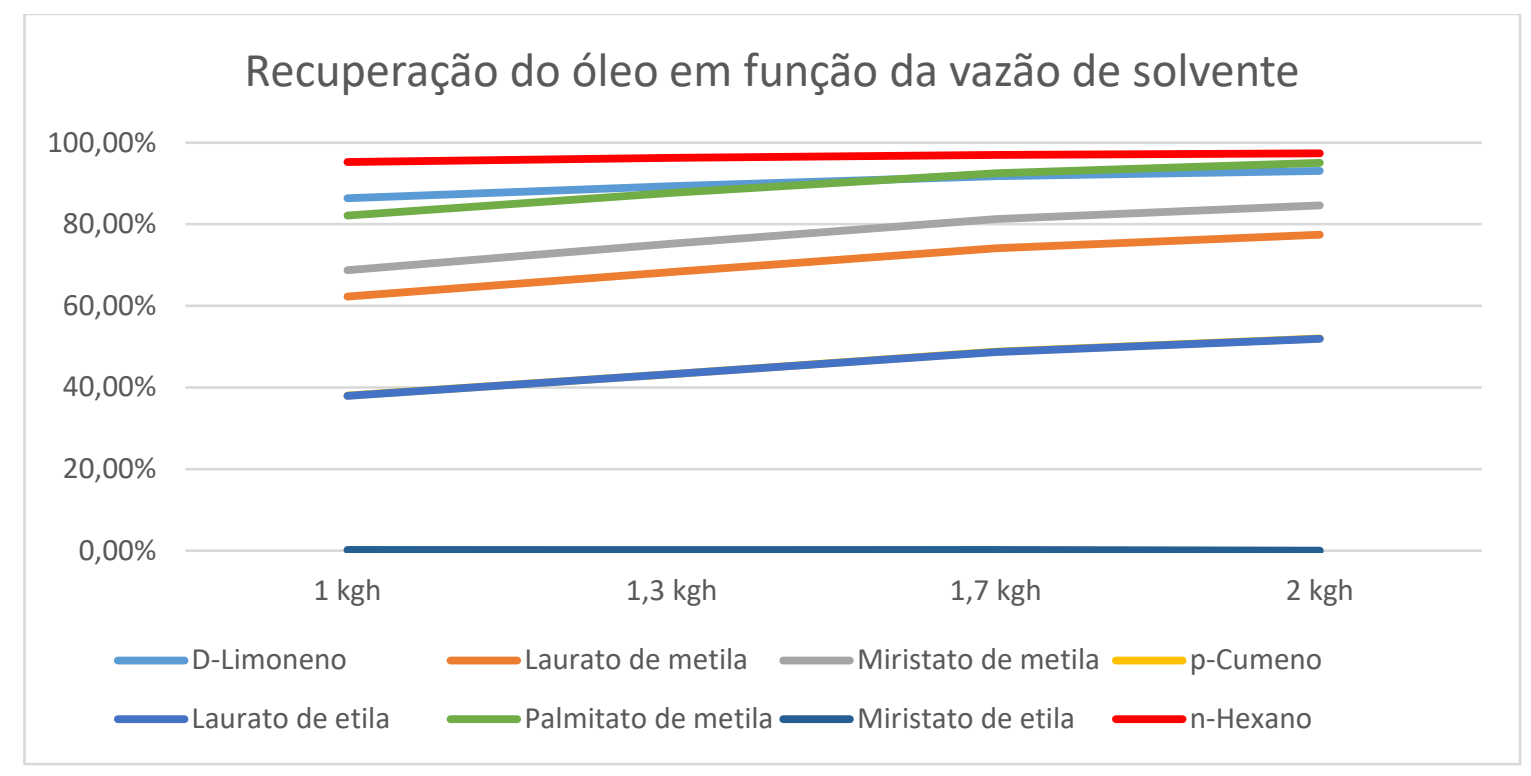

Fonte: Próprio autor.

A uma vazão de $2 \mathrm{~kg} / \mathrm{h}$, a recuperação de lipídio utilizando o palmitato de metila como solvente chega a 95\%, enquanto para as mesmas condições o dlimoneno atinge $93 \%$ de recuperação. O restante dos solventes apresenta aumento de desempenho na recuperação do óleo.

Com base nos resultados obtidos, o n-hexano teve o melhor desempenho operacional dentre os solventes analisados, porém, possui piores valores de parâmetros de EHS. Com base nos resutados de capacidade de recuperação, o d-limoneno e o palmitato de metila mostraram potecial de uso no processo de extração de lipídio da microalga, pois conseguiram atingir um valor alto de recuperação do lipídio na fase orgânica.

Dos 7 solventes avaliados, o d-limoneno e o palmitato de metila foram eleitos para a etapa seguinte, uma análise tecno-econômica do processo, que tem como objetivo avaliar financeiramente o investimento em capital e o custo operacional da unidade de extração de óleos.

Com base na escala de produção definida na seção 3.5.1 de 500 ha de área de cultivo, a unidade foi projetada para processar aproximadamente 20,8 ton/h de pasta de microalga. Foram feitos 3 casos separados, um para cada 
solvente: $\mathrm{n}$-hexano (caso base de comparação), d-limoneno e palmitato de metila. Para todos os três casos as premissas operacionais e financeiras são iguais.

Foram reunidas na Tabela 23 dados de vazão de reposição de solvente, gasto energético do refervedor, gasto energético do condensador e vazão de óleo bruto produzido. Além disso, informações referentes à dimensão necessária para cada equipamento foram levantadas no simulador Aspen para estimativa do investimento em equipamentos, infraestrutura e construção (CAPEX).

Tabela 23 - Correntes mássicas e energéticas para os três casos.

\begin{tabular}{lrrrr}
\hline Solvente & $\begin{array}{r}\text { Vazão solvente } \\
(\mathbf{k g} / \mathbf{h})\end{array}$ & $\begin{array}{r}\text { Energia } \\
\text { refervedor (kW) }\end{array}$ & $\begin{array}{r}\text { Energia } \\
\text { condensador (kW) }\end{array}$ & $\begin{array}{r}\text { Vazão óleo } \\
\text { bruto (kg/h) }\end{array}$ \\
n-Hexano & 58,95 & 2104,18 & $-1689,732$ & 2547,43 \\
D-Limoneno & 273,48 & 3776,00 & $-3358,756$ & 2300,51 \\
Palmitato de metila & 363,06 & 9292,05 & $-8924,932$ & 2310,00 \\
\hline
\end{tabular}

Fonte: Próprio autor.

Pelos dados da Tabela 23, é possível predizer que o n-hexano tem o melhor desempenho operacional comparado com os demais, pois, há um consumo menor de solvente e energia gerando uma quantidade maior de produto (óleo burto). Entre o palmitato de metila e o d-limoneno; este último mostrou um resultado mais favorável operacionalmente. Vale destacar que o hexano é usado como base de comparação no presente trabalho. O objetivo é a avaliação de alternativas a este produto. Nesse contexto, regulamentações e normas (como a europeia REACH) podem contribuir para o uso de químicos renováveis e menos tóxicos. (REACH, 2006)

Os equipamentos foram dimensionados para os três casos. Os valores apresentados na Tabela 24 são as dimensões utilizadas como parâmetro de entrada para o cálculo do custo do equipamento.

Tabela 24 - Valor das dimensões de projeto de equipamentos para os três casos. 


\begin{tabular}{lrrrr}
\hline Equipamento & $\begin{array}{r}\text { Dimensão } \\
\text { hexano }\end{array}$ & $\begin{array}{r}\text { Dimensão } \\
\text { limoneno }\end{array}$ & $\begin{array}{r}\text { Dimensão } \\
\text { palmitato }\end{array}$ & Unidade \\
\hline V101 & 1,701 & 1,601 & 2,861 & $\mathrm{~m}^{3}$ \\
V102 & 2,402 & 2,402 & 5,404 & $\mathrm{~m}^{3}$ \\
V103 & 3,269 & 3,269 & 3,269 & $\mathrm{~m}^{3}$ \\
V104 & 4,087 & 4,087 & 5,338 & $\mathrm{~m}^{3}$ \\
E101 & 41,39 & 124,79 & 211,78 & $\mathrm{~m}^{2}$ \\
E102 & 58,93 & 104,44 & 289,20 & $\mathrm{~m}^{2}$ \\
P101 & 1,259 & 1,259 & 1,259 & $\mathrm{~kW}$ \\
P102 & 0,004 & 0,016 & 0,023 & $\mathrm{~kW}$ \\
P103 & 1,621 & 1,559 & 1,738 & $\mathrm{~kW}$ \\
P104 & 0,863 & 0,784 & 0,472 & $\mathrm{~kW}$ \\
P105 & 0,758 & 0,732 & 1,234 & $\mathrm{~kW}$ \\
P106 & 0,046 & 0,042 & 0,042 & $\mathrm{~kW}$ \\
P107 & 0,876 & 1,951 & 6,498 & $\mathrm{~m} / \mathrm{s}$ \\
P108 & 0,018 & 0,149 & 0,474 & $\mathrm{~kW}$ \\
P109 & 0,384 & 0,294 & 0,405 & $\mathrm{~kW}$ \\
\hline F0nte: Propris
\end{tabular}

Fonte: Próprio autor.

Foi feita a projeção financeira da unidade para os três casos operando por 20 anos, após 2 anos de construção. O CAPEX e o OPEX foram calculados com base nas premissas adotadas na Tabela 13, metodologia proposta por Turton et al. (1998) e dados obtidos do simulador comercial.

Além disso, com base no escopo da análise, não foi considerada a etapa de cultivo da microalga. Para tornar a análise mais verossímil, mesmo que os três casos processem a mesma quantidade de pasta de microalga (em termos de fluxo de caixa incremental não precisaria ser considerado), foi consultado na literatura custos médios referentes ao cultivo da microalga e concentração para pasta. Esse custo pode variar entre US\$ $\$, 35 / \mathrm{kg}$ até US $\$ 1,07 / \mathrm{kg}$ de acordo com a literatura e as premissas adotadas. (DAVIS; ADEN; PIENKOS, 2011; HOFFMAN et al., 2017; SLADE; BAUEN, 2013)

Para o presente trabalho foi adotado o valor de US $\$ 0,35 / \mathrm{kg}$ como custo de cultivo de microalga. Já para os solventes foram considerados os seguintes custos:

- Limoneno: US\$ 0,89/kg (BECERRA; VILLA, 2020);

- Palmitato de metila: US $\$ 0,86 / \mathrm{kg}$ (preço do metil éster de óleo de soja em período anterior à pandemia de COVID19) (NESTE, 2020); 
- Hexano: US\$ 0,40/kg (HEO; HEO; LEE, 2019).

O detalhamento das componentes de custos pode ser visto na Tabela 25.

Tabela 25 - Detalhamento das componentes para cálculo de CAPEX e OPEX.

\begin{tabular}{lrrr}
\hline Componente & $\begin{array}{r}\text { Hexano } \\
\text { (US\$) }\end{array}$ & $\begin{array}{r}\text { Limoneno } \\
\text { (US\$) }\end{array}$ & $\begin{array}{r}\text { Palmitato de } \\
\text { metila (US\$) }\end{array}$ \\
\hline Investimento em capital & $645.126,88$ & $1.093 .235,72$ & $1.552 .499,11$ \\
Custo matéria-prima & $57.935 .829,60$ & $59.676 .781,82$ & $60.221 .950,27$ \\
Custo de utilidades & $1.033 .951,90$ & $1.909 .800,34$ & $4.940 .269,93$ \\
$\begin{array}{l}\text { Custo operating labor por } \\
\text { ano }\end{array}$ & $771.899,52$ & $771.899,52$ & $771.899,52$ \\
\hline
\end{tabular}

Fonte: Próprio autor.

Pode ser visto na Tabela 25 que o palmitato de metila possui custos de utilidades muito maiores (eletricidade, água de refrigeração e vapor de água). 0 n-hexano apresenta os menores custos tanto de capital quanto operacional, seguido do d-limoneno.

Com a estrutura de custos e o modelo financeiro das três unidades, foi possível determinar o preço mínimo de venda do óleo de microalga produzido. Esse preço é o valor que faz com que o valor presente líquido do fluxo de caixa seja zero, indicando o menor preço de venda possível para que o projeto não seja inviável financeiramente. Essa métrica permite uma visão mais tangível da viabilidade do projeto e facilita a comparação de cenários diferentes.

Conforme mencionado, o caso base de cultivo de microalga tem um custo de US\$ $0,35 / \mathrm{kg}$. Para avaliar o efeito do cultivo da microalga na viabilidade financeira, foi feita também uma análise um cenário alternativo com o custo de microalga a US\$ $0,20 / \mathrm{kg}$, considerando uma potencial redução no custo de produção para um patamar mais próximo de culturas mais estabelecidas.

Além disso, foi elaborado também um caso alternativo hipotético em que o palmitato de metila não tenha custo de aquisição na planta (US\$0,00/kg). Nesse cenário, o palmitato de metila, que é um éster metílico de ácido graxo, 
seria um produto da própria cadeia de produção (por meio da transesterificação do óleo da microalga), produzido e e reciclado na própria biorrefinaria em que a unidade está instalada.

Logo, em uma visão financeira, não exisitia custo de aquisição de solvente no processo de extração, embora haja um custo de oportunidade de usar o palmitato de metila (éster metílico de ácido graxo) em vez de comercializá-lo, não considerado na análise.

A Tabela 26 apresenta o preço mínimo de venda do óleo de microalga em dois cenários (custo de cultivo da microalga a US\$ 0,35/kg e US\$ 0,20/kg) para quatro opções de processo (hexano, limoneno, palmitato de metila e palmitato de metila sem custo).

Tabela 26 - Comparação do preço mínimo de venda do óleo de microalga sob custos de cultivo diferentes.

\begin{tabular}{lllll}
\hline $\begin{array}{l}\text { Custo de cultivo da } \\
\text { microalga }\end{array}$ & Limoneno & $\begin{array}{l}\text { Palmitato } \\
\text { metila }\end{array}$ & $\begin{array}{l}\text { de } \\
\text { Palmitato de metila } \\
\text { (US\$ 0/kg) }\end{array}$ \\
\hline Cultivo a US\$ 0,35/kg & US\$ 3,77/kg & US\$ 4,35kg & US\$ 4,58/kg & US\$ 4,41/kg \\
Cultivo a US\$ 0,20/kg & US\$2,07/kg & US\$2,63/kg & US\$2,87/kg & US\$2,70/kg \\
\hline
\end{tabular}

Fonte: Próprio autor.

Mesmo com custo de aquisição do palmitato de metila zerado, o processo conduzido com palmitato de metila ainda é menos vantajoso que o processo que utiliza d-limoneno, fazendo com que o d-limoneno seja um candidato com mais potecial para a extração de lipídio de microalgas, em comparação com o palmitato de metila.

Pelos resultados obtidos nas Tabelas 25 e 26, nenhum candidato conseguiu superar o desempenho financeiro do n-hexano. Entretanto, na atual análise do processo, não foi considerada a perspectiva ambiental para a comparação dos candidatos. De acordo com os parâmetros EHS obtidos para os três solventes, o n-hexano atingiu o pior posicionamento nesses quesitos, o que desfavorece o uso do n-hexano. 
Em decorrência dessa toxicidade do n-hexano e a tendência de buscar processos menos nocivos à saúde, meio ambiente e segurança; políticas ambientais com efeitos financeiros podem surgir, como:

- Multas por não-conformidades com regulamentações ambientes (uso de compostos proibidos, excesso de emissões);

- Créditos de carbono por adotar medidas que geram menos impactos ambientais;

- Incentivos e isenções fiscais por utilizar rotas e tecnologias mais alinhadas com princípios de sustentabilidade ambiental.

Esses efeitos financeiros não foram considerados no presente trabalho. Caso fossem, a possibilidade de os candidatos serem melhores substitutos aumentaria, devido ao custo ambiental do n-hexano e possíveis favorecimentos financeiros de solventes de origem verde. Dessa forma, a abordagem multi-step possibilitou a análise simultânea de 111 solventes para ao fim obter 2 possíveis candidatos para a extração de óleo de microalga.

Os 2 solventes obtidos ao fim da abordagem foram o d-limononeno e o palmitato de metila, compostos originários da própria biomassa e que reforçam o conceito de new green solvents.

O d-limoneno já foi estudado algumas vezes nos últimos anos com a finalidade de analisar sua capacidade de extração de óleos, como mostrado anteriormente. Já o palmitato de metila é uma possibilidade inovadora que não havia sido contemplada antes para essa finalidade, visto que não foram publicados trabalhos utilizando metil-éster de ácido graxo para extração de óleo de microalgas. (DEJOYE TANZI; ABERT VIAN; CHEMAT, 2013)

Mesmo sendo algo não estudado para a extração de óleo de microalga, existem estudos na literatura que avaliam a possibilidade de usar o biodiesel como solvente em processos. Os resultados do presente trabalho reforçam essa tendência e abre novas possibilidades de solventes para extração de óleo de microalga, utilizando componentes da própria cadeia, gerando sinergias por meio da economia circular. (HU et al., 2004) 
Além disso, as Tabelas 25 e 26 mostram que o cultivo da microalga possui um grande peso na viabilidade da operação. A queda no peço do cultivo considerada foi de $42,9 \%$ (de US\$ 0,35/kg para US\% 0,20/kg), fazendo com que os preços mínimos de venda caíssem $37 \%$ para o palmitato de metila, 39\% para o limoneno e $45 \%$ para o hexano.

Dessa forma, resultados sugerem que o cultivo da microalga exerce uma forte influência no custo do combustível produzido a partir de microalgas, em consonância com o que é discutido na literatura, visto na seção 2.5 do presente trabalho.

Observa-se também que para todos os cenários considerados, os preços de venda do óleo de microalga são elevados em comparação ao diesel comum, indicando a inviabilidade atual do processo para produção de óleo somente. Entrentanto, em diversos trabalhos ainda não foi possível chegar em valores competitivos com os combustíveis fósseis. (HEO; HEO; LEE, 2019; HOFFMAN et al., 2017)

Os trabalhos da literatura reportam o preço de venda mínimo para o biodiesel e o presente trabalho considera somente o óleo bruto extraído da microalga. Já foram reportados valores na faixa entre US\$4,77/kg e US\$ 9,92/kg de biodiesel a partir de processos convencionais. Considerando que o presente trabalho estima o preço do óleo bruto, mesmo aplicando uma margem para levar em consideração o processo de transesterificação, o preço obtido estaria numa faixa similar ao reportado na literatura. (HEO; HEO; LEE, 2019)

Pesa sobre os resultados também o fato que o presente trabalho não leva em consideração a valorização de nenhuma outra corrente do processo (carboidratos, proteínas e correntes de resíduos) para produção de outros produtos, o que aumentaria a performance econômica do processo, diminuindo os preços de venda do óleo.

Para melhorar a viabilidade econômica do processo, algumas ações podem ser tomadas:

- Adição da etapa de transesterificação na análise para geração de produtos de um valor agregado maior do que o óleo bruto extraído, 
o biodiesel e o coproduto glicerol que pode ter outras rotas de valorização;

- Aproveitamento da corrente de carboidratos para fermentação e valorização com produção de químicos (exemplo: bio-etanol);

- Digestão anaeróbica de qualquer outra corrente de resíduo para produção de biogás;

- Isolamento de compostos de maior valor agregado para uso na indústria de alimentos, cosméticos e afins;

- Considerações de créditos ambientais, isenções fiscais e outros incentivos (como considerado em alguns trabalhos);

- Teste de misturas de solventes (blends) com o intuito de explorar sinergia entre solventes diferentes, atingindo um desempenho operacional elevado;

- Integração energética e otimização mais robusta do fluxograma de processos. 


\section{CONCLUSÕES}

Com base no trabalho desenvolvido, as seguintes conclusões gerais podem ser mencionadas:

- A análise dos parâmetros de Hansen e propriedades físico-químicas é efetiva para seleção inicial de solventes;

- O modelo de Martin possui como vantagem a possibilidade de se variar diferentes parâmetros, mas esses parâmetros não podem ser variados arbitrariamente. Para avaliar solventes diferentes, é necessário a construiçao de metodologias de cálculo dos parâmetros de processo;

- O óleo da microalga, embora de composição complexa e variada, pode ser representado de diversas maneiras e suas propriedades podem ser levantadas por meio de compostos semelhantes;

- A abordagem sistemática partiu de 111 solventes, percorreu 3 grandes etapas, culminando em uma análise mais aprofundada de 2 solventes;

- Dos 2 solventes analisados na última etapa, 1 representa uma abordagem inovadora para o estudo de microalgas: a utilização do metil éster de ácido palmítico;

- O processo de cultivo, embora não tenha sido o foco do trabalho, tem grande relevância nos custos de produção;

- Não foi possível, com base nos estudos realizados, encontrar uma opção melhor (energeticamente e financeiramente) que o $\mathrm{n}$-hexano, solvente amplamente utilizado na indústria e tóxico; no entanto, a metodologia proposta permite uma avaliação preliminar do desempenho técnico e econômico de diferentes solventes que possam ser avaliados como alternativa para o caso base (hexano).

- Solventes alternativos e de baixo impacto ambiental e toxicológico podem favorecer o desempenho da biorrefinaria de microalgas.

- O desepenho econômico do processo como um todo pode se beneficar diretamente dos ganhos em produtividade e redução de custos na etapa de cultivo.

- É de fundamental importância a integração de diferentes dimensões (técnicas, econômicas, ambientais e toxicológicas) no desenvolvimento 
de novos solventes para a etapa de extração, de forma que os esforços em P\&D sejam direcionados a solventes com bom desepenho não só do ponto de vista de bancada, mas também do ponto de vista industrial.

Com base nos objetivos traçados, foi possível elaborar uma metodologia sistemática para estudo de novos solventes para a extração de óleo de microalga. 


\section{TRABALHOS FUTUROS}

Como recomendações para trabalhos futuros, destacam-se:

- Implementar uma abordagem CAMD para gerar novos solventes e realizar análises tecno-econômicas;

- Implementar uma abordagem de síntese de processos considerando as diversas rotas de produção de biocombustíveis;

- Combinar uma abordagem Hansen + COSMO-RS para aumentar a robustez na predição do desempenho de solventes com maior poder de solubilização do lipídio;

- Análise tecno-econômica mais robusta comparando um número reduzido de solventes e considerando incerteza nos preços de utilidades e de componentes em diferentes cenários de preços e custos;

- Avaliar o impacto das premissas de representação da microalga e pacote termodinâmico utilizado;

- Implementar métricas ambientais como apoio na comparação de opções distintas em análises tecno-econômicas. 


\section{REFERÊNCIAS BIBLIOGRÁFICAS}

ACD. ACD/ChemSketchTorontoAdvanced Chemistry Development, Inc., , 2019. Disponível em: <http://www.acdlabs.com/> AGÊNCIA NACIONAL DE PETRÓLEO, G. N. E B. Informações de mercado. Disponível em: <http://www.anp.gov.br/producao-debiocombustiveis/biodiesel/informacoes-de-mercado>. Acesso em: 26 jul. 2020. AMER, L.; ADHIKARI, B.; PELLEGRINO, J. Technoeconomic analysis of five microalgae-to-biofuels processes of varying complexity. Bioresource Technology, v. 102, n. 20, p. 9350-9359, 2011.

ANGLES, E. et al. Wet lipid extraction from the microalga Nannochloropsis sp.: Disruption, physiological effects and solvent screening. Algal Research, v. 21, p. 27-34, 2017.

ARORA, A.; SINGH, V. Biodiesel production from engineered sugarcane lipids under uncertain feedstock compositions: Process design and techno-economic analysis. Applied Energy, v. 280, n. April, p. 115933, 2020.

ASPENTECH. Aspen PLUS, 2015. Disponível em:

$<$ https://www.aspentech.com/en/products/engineering/aspen-plus>

BATAN, L. Y.; GRAFF, G. D.; BRADLEY, T. H. Techno-economic and Monte Carlo probabilistic analysis of microalgae biofuel production system.

Bioresource Technology, v. 219, p. 45-52, 2016.

BECERRA, J. A.; VILLA, A. L. Techno-Economic Evaluation of d-Limonene and $\alpha$-Pinene Separation from Citrus and Turpentine Oils. Chemical Engineering and Technology, n. 52, p. 1-13, 2020.

BLIGH, E. J.; DYER, W. J. A rapid method of total lipid extraction and purification. The Canadian Journal of Biochemistry and Physiology, v. 37, n. 8, p. 911-917, 1959.

BRANCO-VIEIRA, M. et al. A life cycle inventory of microalgae-based biofuels production in an industrial plant concept. Energy Reports, v. 6, p. 397-402, 
2020.

BREIL, C. et al. Bio-based solvents for green extraction of lipids from oleaginous yeast biomass for sustainable aviation biofuel. Molecules, v. 21, n. 2, p. 1-14, 2016.

BYSTRZANOWSKA, M.; TOBISZEWSKI, M. How can analysts use multicriteria decision analysis? TrAC - Trends in Analytical Chemistry, v. 105, p. 98-105, 2018.

CHAUDRY, S.; BAHRI, P. A.; MOHEIMANI, N. R. Pathways of processing of wet microalgae for liquid fuel production: A critical review. Renewable and Sustainable Energy Reviews, v. 52, p. 1240-1250, 2015.

CHEN, B. et al. Application of CAMD in separating hydrocarbons by extractive distillation. AIChE Journal, v. 51, n. 12, p. 3114-3121, 2005.

CHEN, M. et al. Subcritical co-solvents extraction of lipid from wet microalgae pastes of Nannochloropsis sp. European Journal of Lipid Science and Technology, v. 114, n. 2, p. 205-212, 2012.

CIGNITTI, S. et al. CAMD for entrainer screening of extractive distillation process based on new thermodynamic criteria. Chemical Engineering Research and Design, v. 147, p. 721-733, 2019.

COLLET, P. et al. Biodiesel from microalgae - Life cycle assessment and recommendations for potential improvements. Renewable Energy, v. 71, p. 525-533, 2014.

COONEY, M.; YOUNG, G.; NAGLE, N. Separation \& Purification Reviews Extraction of Bio-oils from Microalgae. Separation and Purification Reviews, v. 38, n. 4, p. 291-325, 2009.

CRISTI, Y. Biodiesel from microalgae. Biotechnology Advances, v. 25, p. 294-306, 2007.

CURZONS, A. D.; CONSTABLE, D. C.; CUNNINGHAM, V. L. Solvent selection guide: a guide to the integration of environmental, health and safety criteria into the selection of solvents. Clean Technologies and Environmental Policy, v. 1, n. 2, p. 82-90, 1999. 
DAMODARAN, A. Cost of Capital by Sector. Disponível em:

<http://pages.stern.nyu.edu/ adamodar/>. Acesso em: 25 ago. 2020.

DAVIS, R.; ADEN, A.; PIENKOS, P. T. Techno-economic analysis of autotrophic microalgae for fuel production. Applied Energy, v. 88, n. 10, p. 3524-3531, 2011.

DEJOYE TANZI, C.; ABERT VIAN, M.; CHEMAT, F. New procedure for extraction of algal lipids from wet biomass: A green clean and scalable process. Bioresource Technology, v. 134, p. 271-275, 2013.

DELRUE, F. et al. An economic, sustainability, and energetic model of biodiesel production from microalgae. Bioresource Technology, v. 111, p. 191-200, 2012.

DUTTA, S.; NETO, F.; COELHO, M. C. Microalgae biofuels: A comparative study on techno-economic analysis \& life-cycle assessment. Algal Research, v. 20, p. 44-52, 2016.

FEDOROV, A. S. et al. Continuous hydrogen photoproduction by

Chlamydomonas reinhardtii: Using a novel two-stage, sulfate-limited chemostat system. Applied Biochemistry and Biotechnology - Part A Enzyme Engineering and Biotechnology, v. 121, n. 1-3, p. 403-412, 2005.

FRANK, E. D. et al. Life cycle comparison of hydrothermal liquefaction and lipid extraction pathways to renewable diesel from algae. Mitigation and

Adaptation Strategies for Global Change, v. 18, n. 1, p. 137-158, 2013.

GANESAN, R. et al. A review on prospective production of biofuel from microalgae. Biotechnology Reports, v. 27, p. e00509, 2020.

GANI, R.; NIELSEN, B.; FREDENSLUND, A. A Group Contribution Approach to Computer- Aided Molecular Design. v. 37, n. 9, 1991.

GHIRARDI, M. L. et al. Microalgae: A green source of renewable H2. Trends in Biotechnology, v. 18, n. 12, p. 506-511, 2000.

GRANOL. Onde estamos. Disponível em:

<http://www.granol.com.br/granol/onde+estamos/>. 
HALIM, R. et al. Oil extraction from microalgae for biodiesel production.

Bioresource Technology, v. 102, n. 1, p. 178-185, 2011.

HALIM, R.; DANQUAH, M. K.; WEBLEY, P. A. Extraction of oil from microalgae for biodiesel production: A review. Biotechnology Advances, v. 30, n. 3, p. 709-732, 2012.

HALIM, R.; WEBLEY, P. A.; MARTIN, G. J. O. The CIDES process:

Fractionation of concentrated microalgal paste for co-production of biofuel, nutraceuticals, and high-grade protein feed. Algal Research, v. 19, p. 299-306, 2016.

HANSEN, C. Hansen Solubility Parameters in Practice. Disponível em: <https://www.hansen-solubility.com/HSPiP/>. Acesso em: 1 maio. 2020.

HANSEN, C. M. Hansen Solubility Parameters - A User's Handbook. Boca Raton: CRC Press, 2007.

HEINTZ, J. et al. Computer aided product design tool for sustainable product development. Computers and Chemical Engineering, v. 71, p. 362-376, 2014.

HEO, H. Y.; HEO, S.; LEE, J. H. Comparative Techno-Economic Analysis of Transesterification Technologies for Microalgal Biodiesel Production. Industrial and Engineering Chemistry Research, v. 58, n. 40, p. 18772-18779, 2019.

HERRING III, R. H.; EDEN, M. R. De Novo Molecular Design using a GraphBased Genetic Algorithm Approach. [s.I.] Elsevier, 2014. v. 33

HOFFMAN, J. et al. Techno-economic assessment of open microalgae production systems. Algal Research, v. 23, p. 51-57, 2017.

$\mathrm{HU}$, J. et al. Study on the solvent power of a new green solvent: Biodiesel. Industrial and Engineering Chemistry Research, v. 43, n. 24, p. 7928-7931, 2004.

HUKKERIKAR, A. S. et al. Group-contribution + $(\mathrm{GC}+)$ based estimation of properties of pure components: Improved property estimation and uncertainty analysis. Fluid Phase Equilibria, v. 321, p. 25-43, 2012. 
JIMÉNEZ CALLEJÓN, M. J. et al. Extraction of saponifiable lipids from wet microalgal biomass for biodiesel production. Bioresource Technology, v. 169, p. 198-205, 2014.

KAPDAN, I. K.; KARGI, F. Bio-hydrogen production from waste materials. Enzyme and Microbial Technology, v. 38, n. 5, p. 569-582, 2006.

KONG, W. et al. Improving the solvent-extraction process of rice bran oil. Chemical Engineering Research and Design, v. 104, p. 1-10, 2015. LABOUKHI-KHORSI, S.; DAOUD, K.; CHEMAT, S. Efficient Solvent Selection Approach for High Solubility of Active Phytochemicals: Application for the Extraction of an Antimalarial Compound from Medicinal Plants. ACS Sustainable Chemistry and Engineering, v. 5, n. 5, p. 4332-4339, 2017. LANDRUM, G. RDKit: Open-source cheminformatics, 2006.

LARDON, L.; HÉLIAS, A.; SIALVE, B. Life-cycle assessment of biodiesel production from microalgae. Environmental science \& technology, v. 43, n. 17, p. 6475-6481, 2009.

LAURENS, L. M. L. et al. Development of algae biorefinery concepts for biofuels and bioproducts; a perspective on process-compatible products and their impact on cost-reduction. Energy and Environmental Science, v. 10, n. 8, p. 1716-1738, 2017.

LEE, S. J.; YOON, B. D.; OH, H. M. Rapid method for the determination of lipid from the green alga Botryococcus braunii. Biotechnology Techniques, v. 12, n. 7, p. 553-556, 1998.

LIN, B. et al. Computer-aided molecular design using Tabu search. Computers and Chemical Engineering, v. 29, n. 2, p. 337-347, 2005.

LÓPEZ BARREIRO, D. et al. Hydrothermal liquefaction (HTL) of microalgae for biofuel production: State of the art review and future prospects. Biomass and Bioenergy, v. 53, n. 0, p. 113-127, 2013.

LOZANO, E. M.; PEDERSEN, T. H.; ROSENDAHL, L. A. Modeling of thermochemically liquefied biomass products and heat of formation for process energy assessment. Applied Energy, v. 254, n. July, p. 113654, 2019. 
MAMIDIPALLY, P. K.; LIU, S. X. First approach on rice bran oil extraction using limonene. European Journal of Lipid Science and Technology, v. 106, n. 2, p. 122-125, 2004.

MAREK TOBISZEWSKIA, STEFAN TSAKOVSKIB, VASIL SIMEONOVB, JACEK NAMIEŚNIKA, FRANCISCO PENA- PEREIRAA, C. Solvent selection guide based on chemometrics and multicriteria decision. Green Chemistry, v. 6, n. 35, 2018.

MARRERO, J.; GANI, R. Group-contribution-based estimation of octanol/water partition coefficient and aqueous solubility. Industrial and Engineering Chemistry Research, v. 41, n. 25, p. 6623-6633, 2002.

MARTIN, G. J. O. Energy requirements for wet solvent extraction of lipids from microalgal biomass. Bioresource Technology, v. 205, p. 40-47, 2016.

MCKINNEY, W. Data Structures for Statistical Computing in Python.

Proceedings of the 9th Python in Science Conference, v. 1, n. Scipy, p. 5661, 2010.

MELIS, A. Green alga hydrogen production: Progress, challenges and prospects. International Journal of Hydrogen Energy, v. 27, n. 11-12, p. 1217-1228, 2002.

MICROSOFT. Excel, 2019. Disponível em: <https://www.microsoft.com/pt-br/> MOITY, L. et al. A "top-down" in silico approach for designing ad hoc bio-based solvents: Application to glycerol-derived solvents of nitrocellulose. Green Chemistry, v. 18, n. 11, p. 3239-3249, 2016.

NAGLE, N.; LEMKE, P. Production of methyl ester fuel from microalgae.

Applied Biochemistry and Biotechnology, v. 24-25, n. 1, p. 355-361, 1990.

NESTE. Biodiesel prices (SME \& FAME). Disponível em:

<https://www.neste.com/investors/market-data/biodiesel-prices-sme-fame>.

NHIEN, L. C. et al. Design and Assessment of Hybrid Purification Processes through a Systematic Solvent Screening for the Production of Levulinic Acid from Lignocellulosic Biomass. Industrial and Engineering Chemistry

Research, v. 55, n. 18, p. 5180-5189, 2016. 
NHIEN, L. C. et al. Techno-economic assessment of hybrid extraction and distillation processes for furfural production from lignocellulosic biomass.

Biotechnology for Biofuels, v. 10, n. 1, p. 1-12, 2017.

OKULLO, A. Process Simulation of Biodiesel Production from Jatropha Curcas Seed Oil. American Journal of Chemical Engineering, v. 5, n. 4, p. 56, 2017.

OLMSTEAD, I. L. D. et al. Low solvent, low temperature method for extracting biodiesel lipids from concentrated microalgal biomass. Bioresource Technology, v. 148, p. 615-619, 2013.

OURIQUE, J. E.; SILVA TELLES, A. Computer-aided molecular design with simulated annealing and molecular graphs. Computers and Chemical Engineering, v. 22, n. SUPPL.1, p. 0-3, 1998.

PIEMONTE, V. et al. Biodiesel production from microalgae: Ionic liquid process simulation. Journal of Cleaner Production, v. 111, p. 62-68, 2016.

QUINN, J. C.; DAVIS, R. The potentials and challenges of algae based biofuels: A review of the techno-economic, life cycle, and resource assessment modeling. Bioresource Technology, v. 184, p. 444-452, 2015.

REACH. Regulation text, corrigendum and amendments. Disponível em: <https://ec.europa.eu/environment/chemicals/reach/reach_en.htm>.

ROESSLER, P. G. et al. Genetic Engineering Approaches for Enhanced Production of Biodiesel Fuel from Microalgae. n. 2, p. 255-270, 1994.

ROUX, J. M.; LAMOTTE, H.; ACHARD, J. L. An Overview of Microalgae Lipid Extraction in a Biorefinery Framework. Energy Procedia, v. 112, n. October 2016, p. 680-688, 2017.

SATI, H. et al. Microalgal lipid extraction strategies for biodiesel production: A review. Algal Research, v. 38, n. July 2018, p. 101413, 2019.

SAWAYAMA, S. et al. CO2 fixation and oil production through microalga. Energy Conversion and Management, v. 36, n. 6-9, p. 729-731, 1995.

SILVA, C. et al. Commercial-scale biodiesel production from algae. Industrial and Engineering Chemistry Research, v. 53, n. 13, p. 5311-5324, 2014. 
SILVA, C. et al. Phase equilibria of triolein to biodiesel reactor systems. Fluid Phase Equilibria, v. 409, p. 171-192, 2016.

SLADE, R.; BAUEN, A. Micro-algae cultivation for biofuels : Cost , energy balance, environmental impacts and future prospects. Biomass and Bioenergy, v. 53, n. 0, p. 29-38, 2013.

SMITH, B.; GREENWELL, H. C.; WHITING, A. Catalytic upgrading of triglycerides and fatty acids to transport biofuels. Energy and Environmental Science, v. 2, n. 3, p. 262-271, 2009.

SOH, L.; ECKELMAN, M. J. Green Solvents in Biomass Processing. ACS Sustainable Chemistry \& Engineering, v. 4, n. 11, p. 5821-5837, 7 nov. 2016.

SPOLAORE, P. et al. Commercial applications of microalgae. Journal of Bioscience and Bioengineering, v. 101, n. 2, p. 87-96, 2006.

STEPHENSON, A. L. et al. Life-cycle assessment of potential algal biodiesel production in the united kingdom: A comparison of raceways and air-lift tubular bioreactors. Energy and Fuels, v. 24, n. 7, p. 4062-4077, 2010.

SUN, J. et al. Microalgae biodiesel production in China: A preliminary economic analysis. Renewable and Sustainable Energy Reviews, v. 104, n. May 2018, p. 296-306, 2019.

TANZI, C. D. et al. Terpenes as green solvents for extraction of oil from microalgae. Molecules, v. 17, n. 7, p. 8196-8205, 2012.

TELES DOS SANTOS, M.; GERBAUD, V.; ROUX, G. A. C. L. Modeling and simulation of melting curves and chemical interesterification of binary blends of vegetable oils. Chemical Engineering Science, v. 87, p. 14-22, 2013.

TURTON, RICHARD; BAILLIE RICHARD; WHITING, WALLACE; SHAEIWITZ, $J$. Analysis, synthesis, and design of chemical processes. Third Edit ed. [s.I.] Prentice Hall, 1998.

VENTERIS, E. R. et al. A national-scale comparison of resource and nutrient demands for algae-based biofuel production by lipid extraction and hydrothermal liquefaction. Biomass and Bioenergy, v. 64, p. 276-290, 2014. 
VICENTE, G. et al. Liquid-liquid equilibria for separation of tocopherol from olive oil using ethyl lactate. Chemical Engineering Journal, v. 172, n. 2-3, p. 879884, 2011.

WAN, C.; BAI, F. W.; ZHAO, X. Q. Effects of nitrogen concentration and media replacement on cell growth and lipid production of oleaginous marine microalga Nannochloropsis oceanica DUT01. Biochemical Engineering Journal, v. 78, p. 32-38, 2013.

WEIS, D. C.; VISCO, D. P. Computer-aided molecular design using the Signature molecular descriptor: Application to solvent selection. Computers and Chemical Engineering, v. 34, n. 7, p. 1018-1029, 2010.

WIGMOSTA, M. S. et al. National microalgae biofuel production potential and resource demand. Water Resources Research, v. 47, n. 4, p. 1-13, 2011.

WILLIAMS, P. J. L. B.; LAURENS, L. M. L. Microalgae as biodiesel \& biomass feedstocks: Review \& analysis of the biochemistry, energetics \& economics. Energy and Environmental Science, v. 3, n. 5, p. 554-590, 2010.

WU, L. et al. Techno-economic analysis of co-processing of vacuum gas oil and algae hydrothermal liquefaction oil in an existing refinery. Energy Conversion and Management, v. 224, n. June, 2020.

WU, W.; LIN, K. H.; CHANG, J. S. Economic and life-cycle greenhouse gas optimization of microalgae-to-biofuels chains. Bioresource Technology, v. 267, n. May, p. 550-559, 2018.

XIN, C. et al. Waste-to-biofuel integrated system and its comprehensive technoeconomic assessment in wastewater treatment plants. Bioresource Technology, v. 250, n. November 2017, p. 523-531, 2018.

$\mathrm{XU}$, L. et al. Assessment of a dry and a wet route for the production of biofuels from microalgae: Energy balance analysis. Bioresource Technology, v. 102, n. 8, p. 5113-5122, 2011.

YADAV, V. et al. PyTOPS: A Python based tool for TOPSIS. SoftwareX, v. 9, p. 217-222, 2019.

YAMAMOTO, H. HSPIP V3.0. 2010 Y-MB model. Disponível em: 
$<$ http://www.pirika.com/NewHP/Y-MB/Y-MB.html>.

YAP, B. H. J. et al. A mechanistic study of algal cell disruption and its effect on lipid recovery by solvent extraction. Algal Research, v. 5, n. 1, p. 112-120, 2014.

ZAMALLOA, C. et al. The techno-economic potential of renewable energy through the anaerobic digestion of microalgae. Bioresource Technology, v. 102, n. 2, p. 1149-1158, 2011. 


\section{APÊNDICE}

\subsection{Códigos em python}

Projeto de pesquisa de mestrado em engenharia química

Autor: Francisco do Nascimento Júnior

\section{Códigos}

- base_tags.py

- base_solvents.py

- base_reds.py

- smiles_mol.py

- combustion.py

- martin.py

- update.py

- TOPSIS.py

- rescaling.py

- main.py

- esferahansen.py

- sensibilidade.py

\section{Descrição}

base_tags.py: rotina para realizar o tratamento e junção das bases de composição de triacilgliceróis e propriedades dos triacilgliceróis estimadas pelo IBSS 
base_solvs.py: rotina para realizar o tratamento e junção das bases de solventes e propriedades desses solventes estimadas pelo IBSS

base_reds.py: rotina para calcular o RED de cada solvente utilizando os parâmetros de Hansen e também a retirada de solventes incapazes de solubilizar o lipídio da microalga

smiles_mol.py: rotina para criação de um campo de fórmula molecular através do SMILES de cada solvente por meio da biblioteca rdkit

combustion.py: rotina para cálculo da entalpia de combustão com base no trabalho de Lozano et al.(2019).

martin.py: rotina com modelo publicado por Martin em 2016 para estimar demandar energética normalizada para as etapas de mistura, separação, perda e evaporação

TOPSIS.py: rotina para aplicação do algoritmo TOPSIS para tomada de decisão multicritério.

rescaling.py: rotina para normalização min-max dos dados.

main.py: rotina para cálculo das demandas energéticas das etapas supracitadas para cada solvente elegível resultante da rotina base_reds.py

esferahansen.py: rotina para plotagem dos solventes no espaço de Hansen por meio dos resultados dos códigos base_reds.py e base_tags.py

sensibilidade.py: rotina para análise da sensibilidade do modelo de Martin através de um ponto base definido pelos artigos publicados pelo grupo

\section{Como executar (ordem)}




\section{Atualização das bases: update.py}

\section{Análise complexa: main.py}

Plot da esfera de Hansen:base_tags.py > base_solvs.py > smiles_mol.py > base_reds.py > esferahansen.py

Análise de sensibilidade: sensibilidade.py

\section{base_tags.py}

Título: Criação da base de triglicerídeos para análise Autor: Francisco

Objetivo: Reunir a base de resultados do IBSS por SMILES com a base de composição de solventes com nome e SMILES para criação do dataset de triglicerídeos do trabalho.

' ' '

print('\tIniciando código de atualização da base de TAGs ... \n')

import pandas as pd

\#\#\# Leitura da Base de Composições dos TAGs

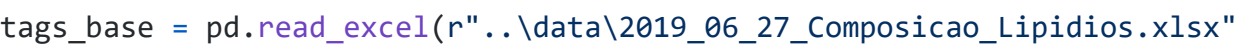

, sheet_name $=$ 'TAGs', header $=1$ )

\#\#\# Retirando coluna desnecessária

tags_base = tags_base[tags_base.columns.drop $\left(\right.$ list $\left.\left.(\text { tags_base.filter }(\text { like }=\text { 'Unnamed' }))^{\prime}\right)\right]$

\#tags base.drop (columns $=$ ['TAG number', 'FA1', 'FA2', 'FA3'], axis $=1$, inplace $=$ True) 
\#\#\# Renomeando colunas de MW e Density

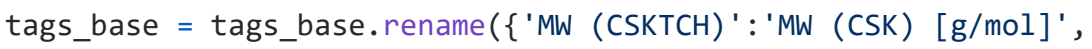

'MW (MTS) ' : 'MW (MTS) [g/mol]',

'Density (CSKTCH)': 'Density (CSK) $[\mathrm{kg} / \mathrm{m} 3]$ '\}, axis = 1)

\#\#\# Leitura do resultado do IBSS para os 31 TAGs submetidos, leitura de .txt com \tab como separador

ibss_tags $=$ pd.read_csv $\left(r " . . \backslash\right.$ data $\backslash$ RES_TAGs.txt", sep $=$ ' $\left.\backslash t^{\prime}\right)$

\#\#\# Retirar colunas do Data Frame que possuam o termo Perf pois não serão utilizadas

ibss_tags $=$ ibss_tags[ibss_tags.columns.drop(list(ibss_tags.filter $\left(\right.$ like $=$ 'Perf' $\left.^{\prime}\right)$ ))]

\#\#\# Retirar colunas do Data Frame que possuam o termo Unnamed pois não serão utilizadas

ibss_tags = ibss_tags[ibss_tags.columns.drop(list(ibss_tags.filter $($ like ='Unnamed') )) ]

\#\#\# Retirar coluna de Comp pois não será utilizada

ibss_tags.drop(columns $=$ 'Comp', axis $=1$, inplace $=$ True)

\#\#\# Renomear coluna SMILES para Smiles

ibss_tags = ibss_tags.rename $(\{$ 'SMILES':'Smiles' $\}$, axis $=1)$

\#\#\# Seleção das 31 linhas dos respectivos 31 TAGs analisados, exclusão dos reports abaixo

ibss_tags $=$ ibss_tags.dropna $($ axis $=0$, subset $=[$ 'Molecular Weight $[\mathrm{g} / \mathrm{mol}]$ '] $)$

"""Junção das duas tabelas, a primeira com as informações da composição de TAGs

e a segunda com os parâmetros calculados para cada TAG "" "

tags_final $=$ pd.merge(tags_base, ibss_tags, how $=$ 'inner', on = 'Smiles') 
\#\#\# Export da base resultante para arquivo .csv

tags_final.to_csv( $r^{\prime} \ldots \backslash$ data $\backslash$ tags_final.csv', sep $={ }^{\prime} \mid$ ', index $=$ False $)$

print('\tCódigo base tags.py executado com sucesso! \n')

\section{base_solvents.py}

Título: Criação da base de solventes para análise

Autor: Francisco

Objetivo: Reunir a base de resultados do IBSS por SMILES com a base de solventes com nome e SMILES

para criação do dataset de solventes do trabalho.

' '

print('\tIniciando código de atualização da base de solventes ... \n')

import pandas as pd

\#\#\# Leitura do resultado do IBSS para os 31 TAGs submetidos, leitura de .txt com \tab como separador

ibss_solv $=$ pd.read_csv $\left(r "\right.$. \data \RES_SOLVENTS.txt", sep $=$ ' $\left.\backslash t^{\prime}\right)$

\#\#\# Retirar colunas do Data Frame que possuam o termo Perf pois não serão utilizadas

ibss_solv = ibss_solv[ibss_solv.columns.drop(list (ibss_solv.filter $\left(\right.$ like $=$ 'Perf' $\left.\left.^{\prime}\right)\right)$ )] 
\#\#\# Retirar colunas do Data Frame que possuam o termo Unnamed pois não serão utilizadas

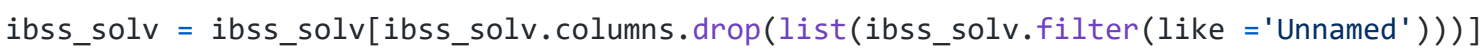

\#\#\# Retirada da coluna COMP

ibss_solv.drop(columns $=$ 'COMP', axis $=1$, inplace $=$ True $)$

\#\#\# Renomear coluna SMILES para Smiles

ibss_solv = ibss_solv.rename $(\{$ 'SMILES': 'Smiles' $\}$, axis $=1)$

\#\#\# Seleção das 111 linhas dos respectivos 31 TAGs analisados, exclusão dos reports abaixo

\#\#\# Encontrar maneira de não precisar definir o número, alguma lógica de programação

ibss_solv $=$ ibss_solv.dropna $\left(\right.$ axis $=0$, subset $\left.\left.=[\text { 'Molecular Weight }[\mathrm{g} / \mathrm{mol}]]^{\prime}\right]\right)$

\#\#\# Leitura da base de solventes com ID, nome do solvente e respectivos SMILES

solvents_base $=$ pd.read_excel $\left(r " . . \backslash\right.$ data $\backslash 2019 \_06 \_22 \_B a s e \_S o l v e n t e s . x l s x "$,

sheet name $=$ 'Solventes', header $=1$ )

\#\#\# Manter só as colunas que tenho interesse, ID, Solvente, e Smiles (chave primária)

solvents_base = solvents_base[['ID' , 'Solvente' , 'Smiles']]

\#\#\# Junção da tabela inicial de solventes com os resultados do IBSS

solvents final $=$ pd.merge (solvents base, ibss solv, how $=$ 'inner', on $=$ 'Smiles') 
\#\#\# Export da base resultante para arquivo .csv

solvents_final.to_csv( $r^{\prime}$. \data \solvents_final.csv', index $=$ False $)$

print('\t\t** Número de solventes inicial: ', solvents_final.shape[0], ' $\backslash n$ ')

print('\tCódigo base_solvents.py executado com sucesso! \n')

\section{base_reds.py}

Título: Rotina para cálculo do RED através dos parâmetros de Hansen

Autor: Francisco

objetivo: Reunir a base final de solventes e triglicerídeos para a determinação da capacidade

do solvente solubilizar o lipídio da microalga Nannochloropsis

, ,

print('\tIniciando código para seleção do solventes por HSP... \n')

import pandas as pd

\#\#\# Leitura da base de triglicerídeos com propriedades calculadas pelo IBSS

tags_final $=$ pd.read_csv $\left(r ' \ldots \backslash\right.$ data $\backslash$ tags_final.csv', sep $\left.={ }^{\prime} \mid '\right)$

\#\#\# Leitura da base de solventes com propriedades calculadas pelo IBSS

solvents final $=$ pd.read $c s v\left(r^{\prime} \ldots \backslash\right.$ data $\backslash$ solvents final.csv' $)$

\#\#\# Criação do dicionário com propriedades de interesse do lipídio calculadas com base na composição

TAG = \{'MolecularWeight' : round(sum(tags_final['Molar Fraction']*tags_final['MW (CSK) [g/mol] ']), 2), 'Density':round(sum(tags final['Molar Fraction']*tags final['Density (CSK) [kg/m3]']),2) 


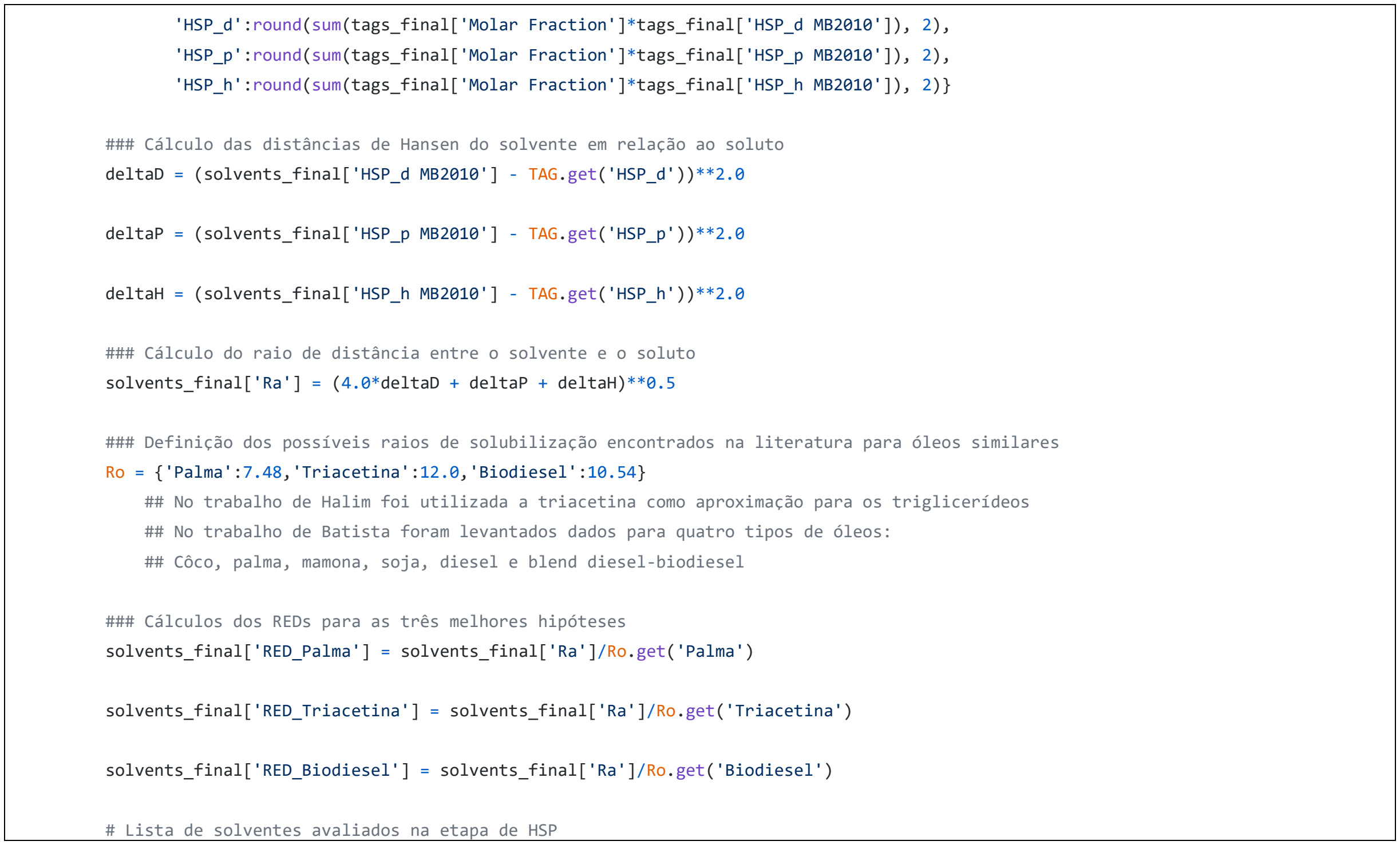


\#SO = solvents_final['Solvente'].values.tolist()

\#\#\# Eliminação dos solventes sem capacidade de solubilizar de acordo com o critério adotado solvents_final_2 = solvents_final[solvents_final['RED_Palma'] $<1.0]$.copy ()

\# Lista de solventes avaliados que passaram na etapa de HSP \#S1 = solvents_final_2['Solvente'].values.tolist()

print('\t\t** Número de solventes que solubilizam lipídio: ', solvents_final_2.shape[0], '\n')

\#\#\# Eliminação dos solventes solúveis em água através do filtro da coluna 'Log(Ws) MG2002 [mg.L-1]'

\# Quando $\log (W s)=3.18$, Ws $=1.5 \mathrm{~g} / \mathrm{L}$. Logo, utilizará esse filtro para corte de solventes

solvents_final_2 = solvents_final_2[solvents_final_2['Log(Ws) MG2002 [mg.L-1]']<= 3.18]

\# Lista de solventes avaliados que passaram na etapa de HSP

$\#$ \#2 = solvents_final_2['Solvente'].values.tolist()

print('\t\t**Número de solventes insolúveis em água: ', solvents_final_2.shape[0], ' \n')

\#\#\# Cálculo do calor latente de vaporização

solvents_final_2['Latent Heat [MJ/kg]'] = solvents_final_2['Enthalpy of vaporization at 298K HSKASG2012 [k].mol-

1]'].values/solvents_final_2['Molecular Weight [g/mol]'].values

\#\#\# Exportação do resultado completo para .csv

solvents_final_2.to_csv('..\data \solvents_final_selected.csv', index = False)

\#\#\# Criação de um novo dataframe com informações relacionadas a solubilidade

solvents_red = solvents_final.filter(items=['Solvente', 'HSP_d MB2010', 


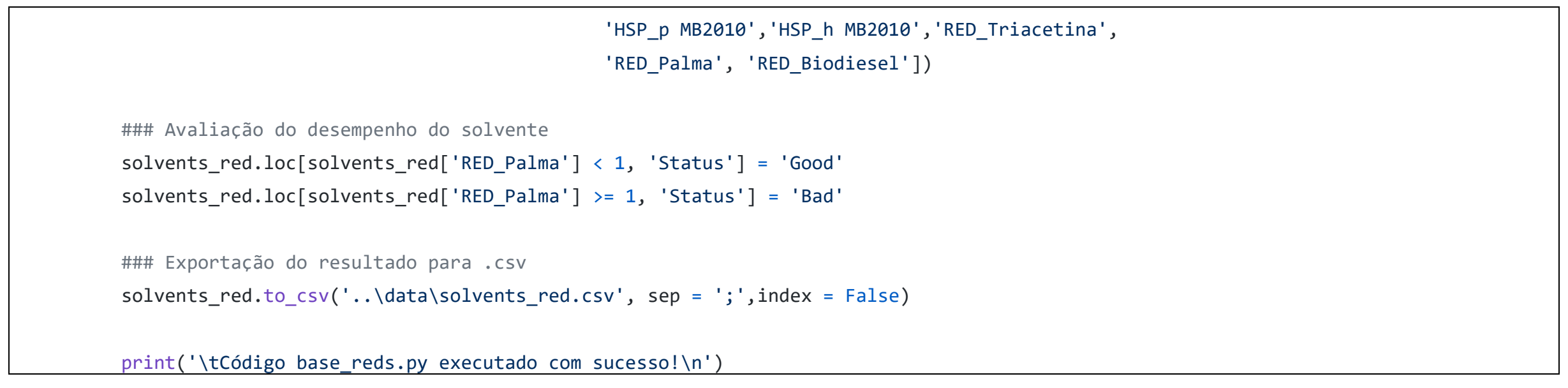

\section{smiles_mol.py}

Título: Rotina para determinação da formula molecular
Autor: Francisco
Objetivo: Utilizar a biblioteca rdkit para obter o campo de fórmula molecular
através do SMILES do solvente
' ' '
print(' 'ttiniciando código para interpretação do SMILES... \n')
\#\# Inclusão das bibliotecas necessárias
from rdkit import Chem
from rdkit.Chem import rdMolDescriptors
import pandas as pd
import numpy as np




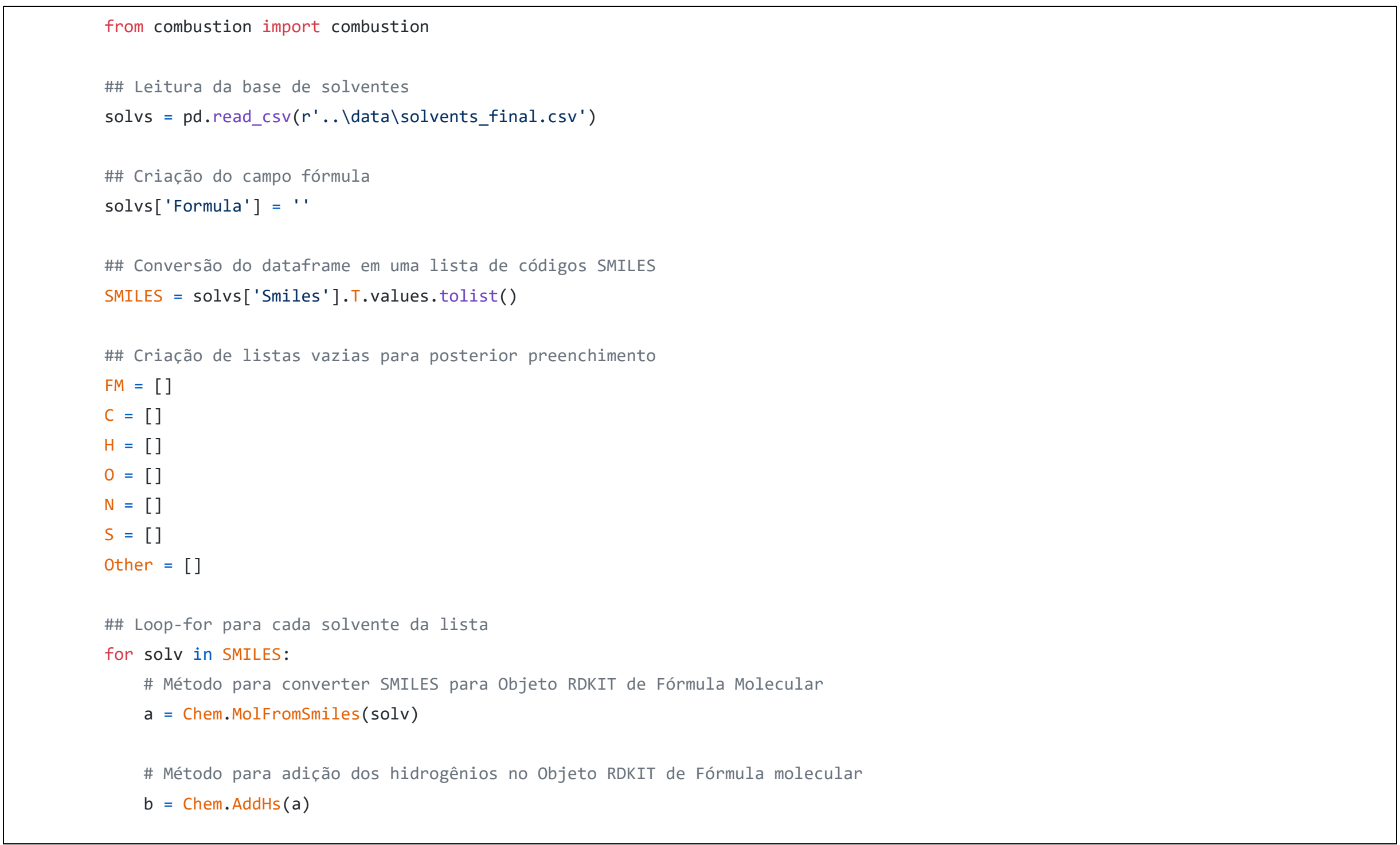


\# Conversão do objeto em um string de fórmula molecular e adição na lista FM

FM.append(rdMolDescriptors.CalcMolFormula(a))

\# Criação de uma lista vazia de elementos para cada linha/solvente

elements $=[]$

\# Iteração dentro dos átomos objeto RDKIT de fórmula molecular

for atom in b.GetAtoms():

\# Criação da lista dos símbolos dos elementos que aparecem na fórmula

elements.append(atom.GetSymbol())

\# Adição da contagem de Carbonos da lista de elementos

C.append(elements. count ( ' $\left.C^{\prime}\right)$ )

\# Adição da contagem de Hidrogênios da lista de elementos

H. append(elements.count (' $\left.\mathrm{H}^{\prime}\right)$ )

\# Adição da contagem de Oxigênios da lista de elementos

0 . append(elements. count ('O'))

\# Adição da contagem de Nitrogênios da lista de elementos

N. append (elements.count ('N'))

\# Adição da contagem de Enxofres da lista de elementos

S.append (elements. count ('S'))

\# Adição da contagem de qualquer elemento que não tenha sido citado acima 
Other.append(len(elements) - elements.count('C') - elements.count('H') -

elements.count('O') - elements.count('N') - elements.count('S'))

\#\# Fim do loop-for para cada solvente da lista

\# Atribuição das listas no dataframe de solventes

solvs['Formula'] $=$ FM

solvs['Carbon_number'] $=\mathrm{C}$

solvs ['Hydrogen_number'] $=\mathrm{H}$

solvs['Oxygen_number'] $=0$

solvs['Nitrogen_number'] $=\mathrm{N}$

solvs['Sulphur_number'] $=\mathrm{S}$

solvs['Other_elements'] $=$ other

\# Criação de array com entalpias de formação por meio do método HSKAG2012

formation = solvs['Enthalpy of formation at 298K HSKASG2012 [KJ.mol-1]'].values

\# Criação de array com as massas molares dos solvente

molar_mass $=$ solvs ['Molecular Weight $[\mathrm{g} / \mathrm{mol}]$ '] .values

\# Cálculo da entalpia de combustão por meio da reação

combustion_kJmol $=$ combustion(formation, $n p \cdot \operatorname{array}(C), n p \cdot \operatorname{array}(H), n p \cdot \operatorname{array}(0), n p \cdot \operatorname{array}(N), n p \cdot \operatorname{array}(S)$ )

\# Conversão da unidade da entalpia de $\mathrm{kJ} / \mathrm{mol}$ para $\mathrm{MJ} / \mathrm{kg}$

combustion_MJkg = combustion_kJmol/molar_mass

\# Atribuição do resultado a uma coluna do dataframe solvs

solvs['Combustion_Enthalpy'] = combustion_MJkg 
\# Exclusão das linhas em que não foi possível colocar a entalpia de formação do solvente

\# 0 método de contribuição de grupos insere o valor de -9999.9999 quando não possível calcular

\# Lista de solventes iniciais

\#SO = solvs['Solvente']. values.tolist()

solvs $=$ solvs[solvs['Enthalpy of formation at 298K HSKASG2012 [k].mol-1]'] >-9999].copy()

print('\t\t** Número de solventes com entalpia de formação calculada pelo IBSS: ', solvs.shape[0], '\n')

\# Lista de solventes com entalpia de formação calculada pelo IBSS

$\#$ \#1 = solvs['Solvente']. values.tolist()

\# Retirada dos solventes que possuem outros elementos químicos além de C, H, O, N e S

solvs $=$ solvs $[$ solvs['Other_elements' $]==0] \cdot \operatorname{copy}()$

\# Lista de solventes em que não foi possível calcular a entalpia de combustão

\#S2 = solvs['Solvente'].values.tolist()

print('\t\t** Número de solventes com entalpia de combustão calculada: ', solvs.shape[0], '\n')

\# Exportação da base com resultados novos

solvs.to_csv( $r^{\prime} . . \backslash$ data $\backslash$ solvents_final.csv', index $=$ False)

\#\# Finalização

print('\tCódigo smiles_mol.py executado com sucesso! \n') 


\section{combustion.py}

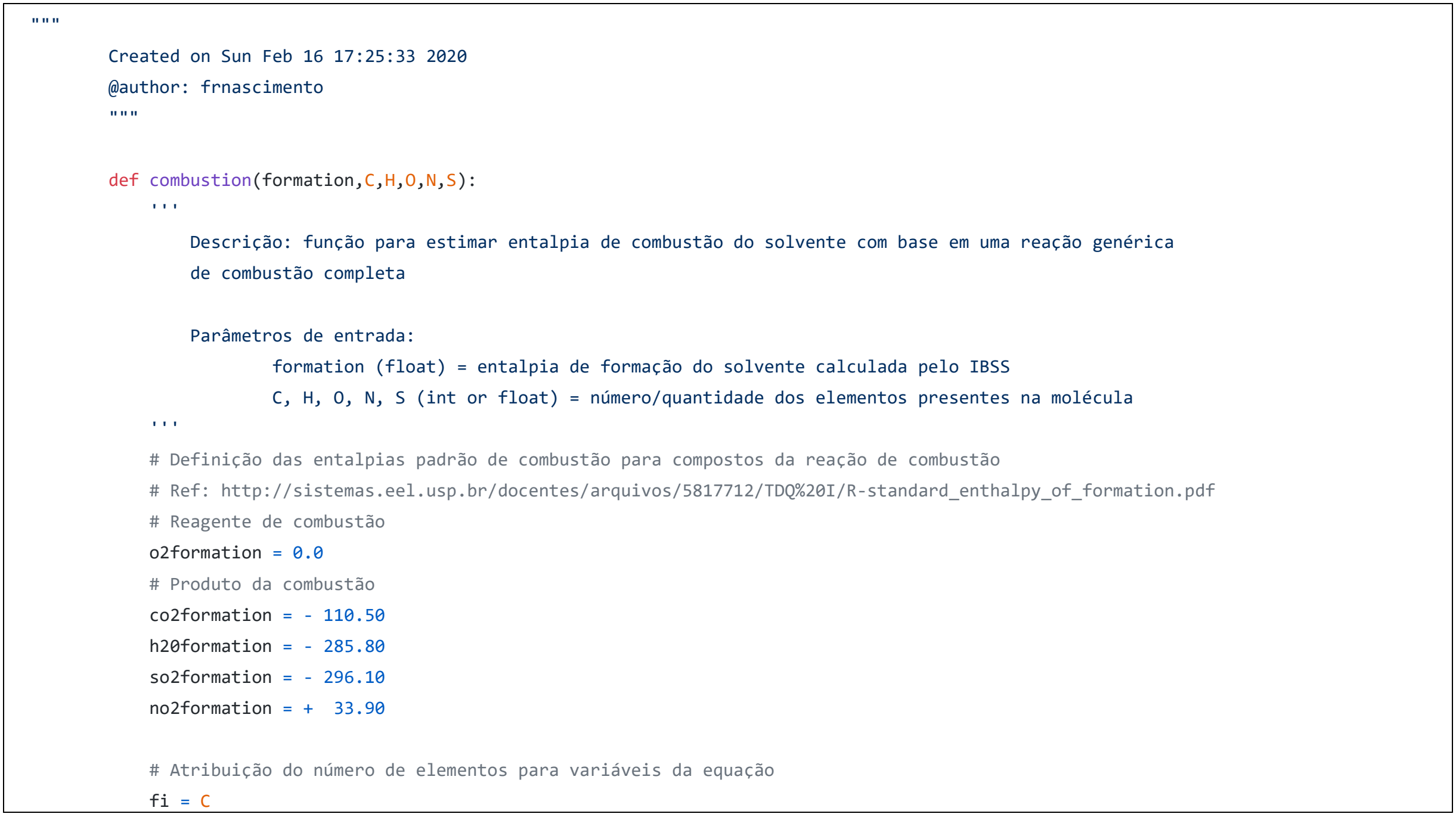




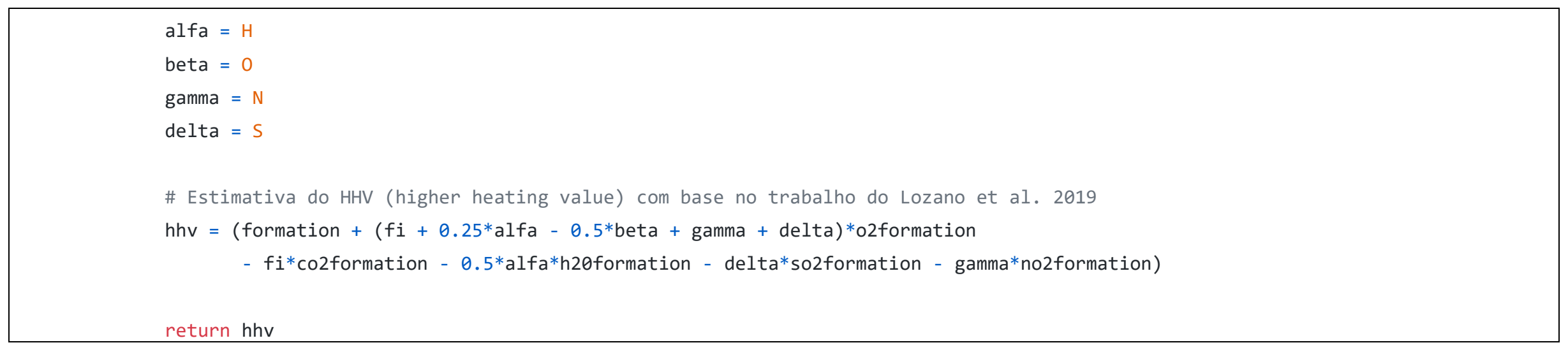

\section{updates.py}

Título: Rotina para atualização das bases
Autor: Francisco
Objetivo: Atualizar todas as bases de dados
' '
print('Iniciando código principal (update.py) $\ldots . . \backslash n$ ')
print('Atualizando bases de dados... \n')
import base_tags
import base_solvents
import smiles_mol
import base_reds


print('Bases atualizadas ... $n^{\prime}$ ')

\section{martin.py}

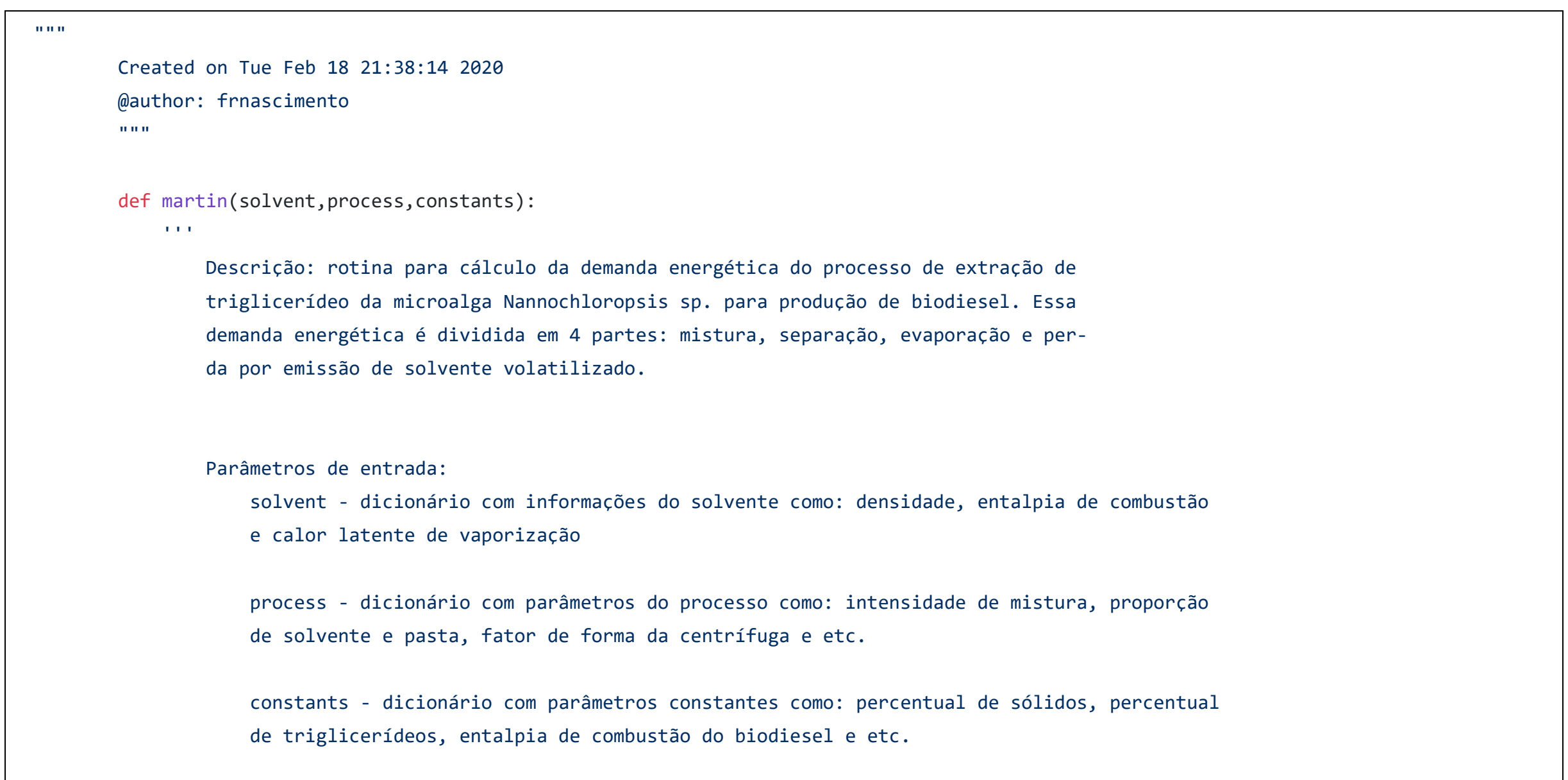




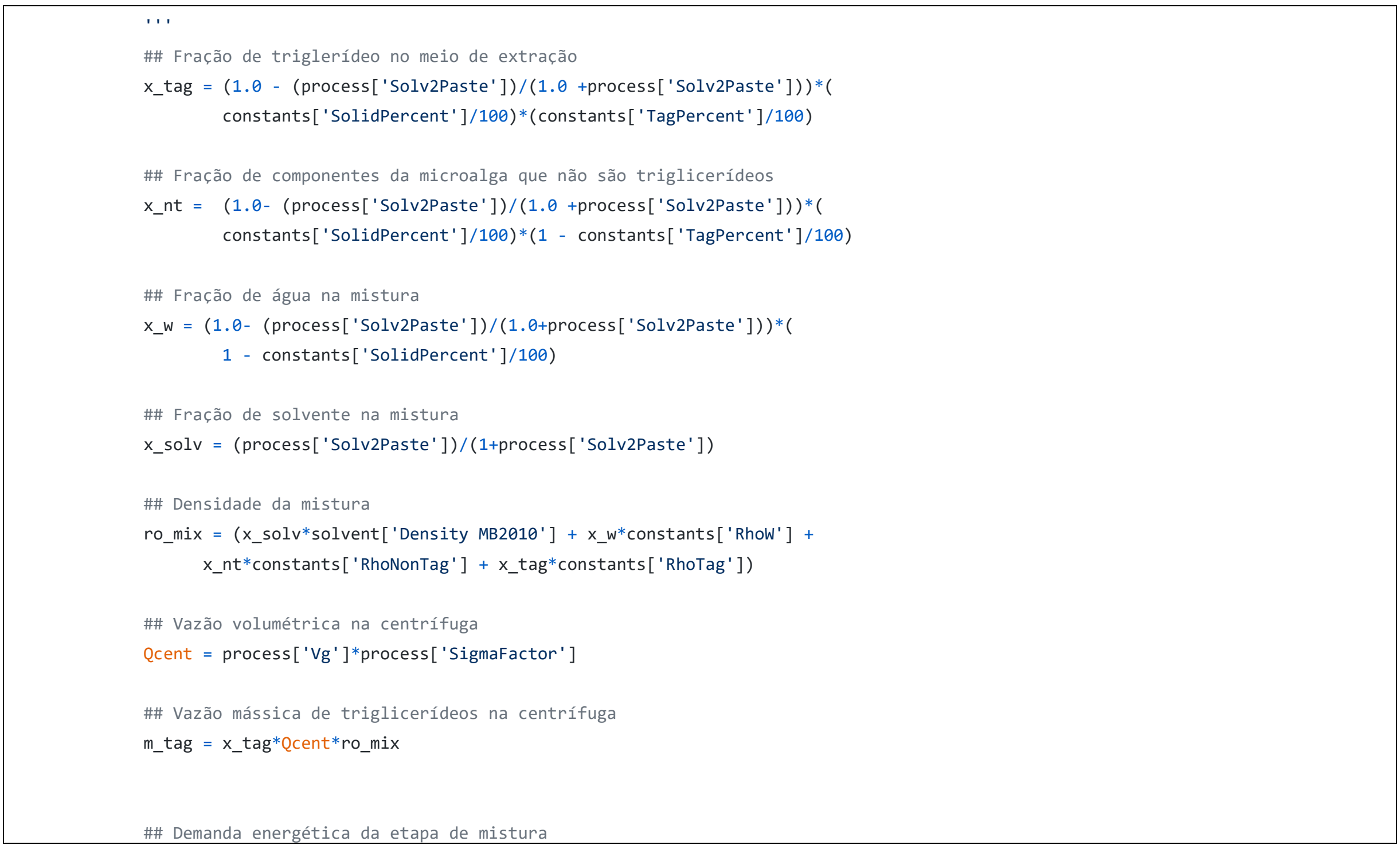




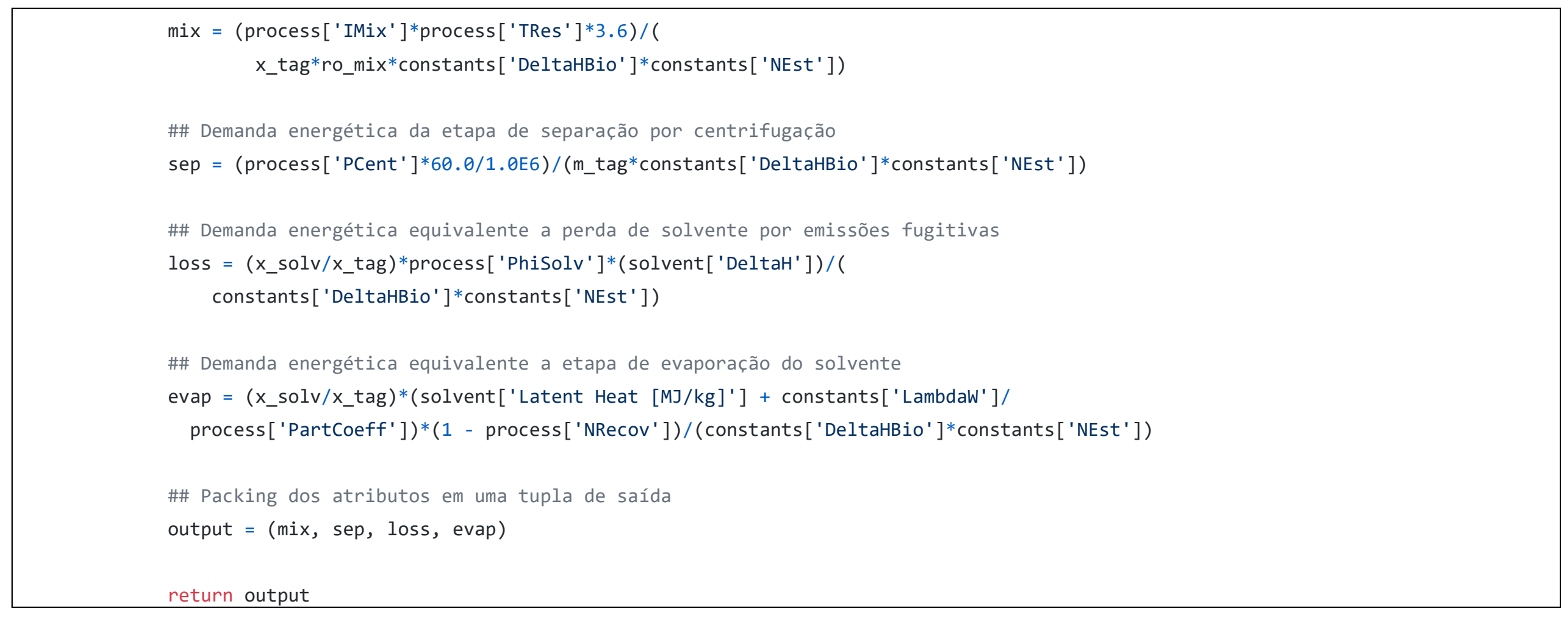

\section{rescaling.py}

, '

Título: Rotina para re-escalonar dados de uma escala definida pelo usuário

Autor: Francisco

Objetivo: Situar cada solvente na esfera de Hansen

a capacidade de solubilizaÃßÃfo ou nÃ£o do lipÃdio da microalga.

, ' 


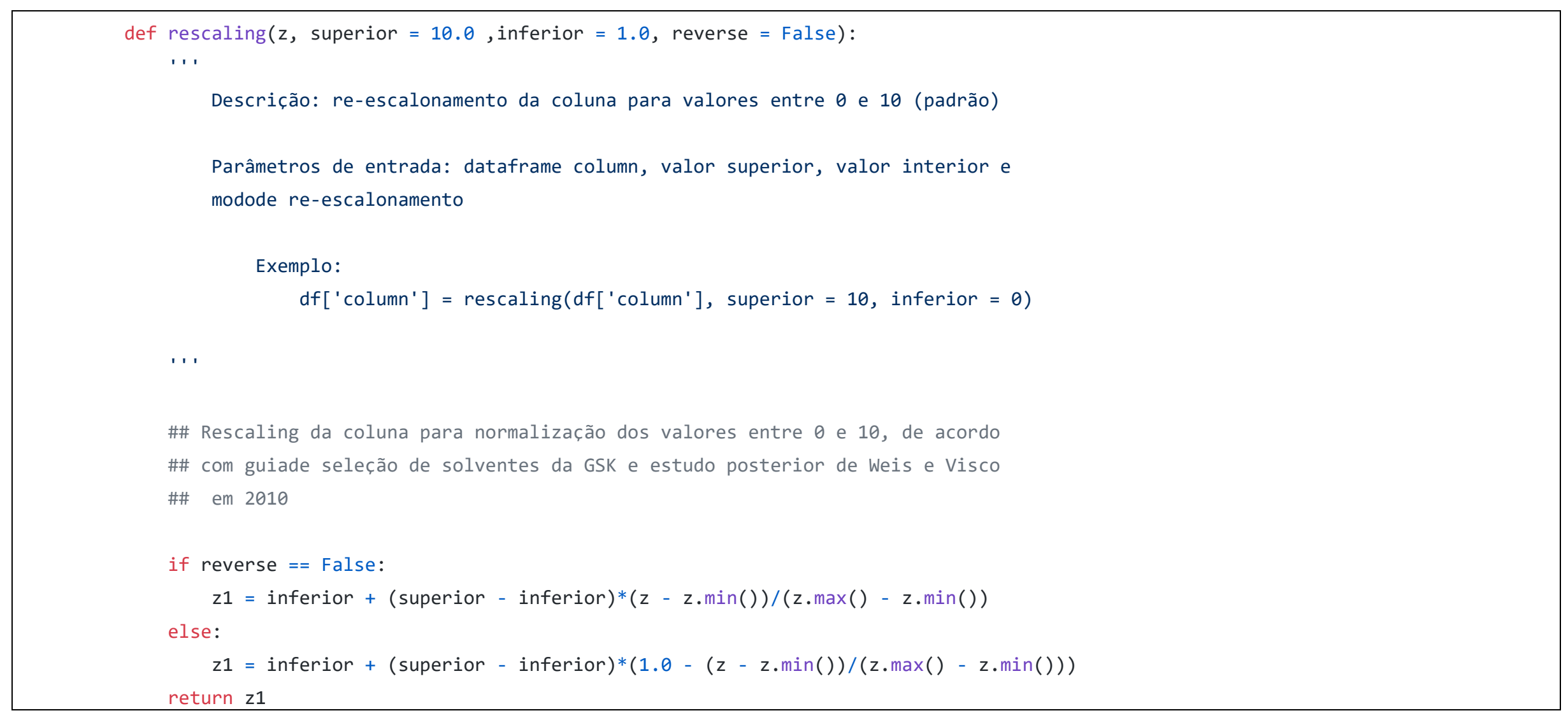

\section{TOPSIS.py}

def

TOPSIS (df, 


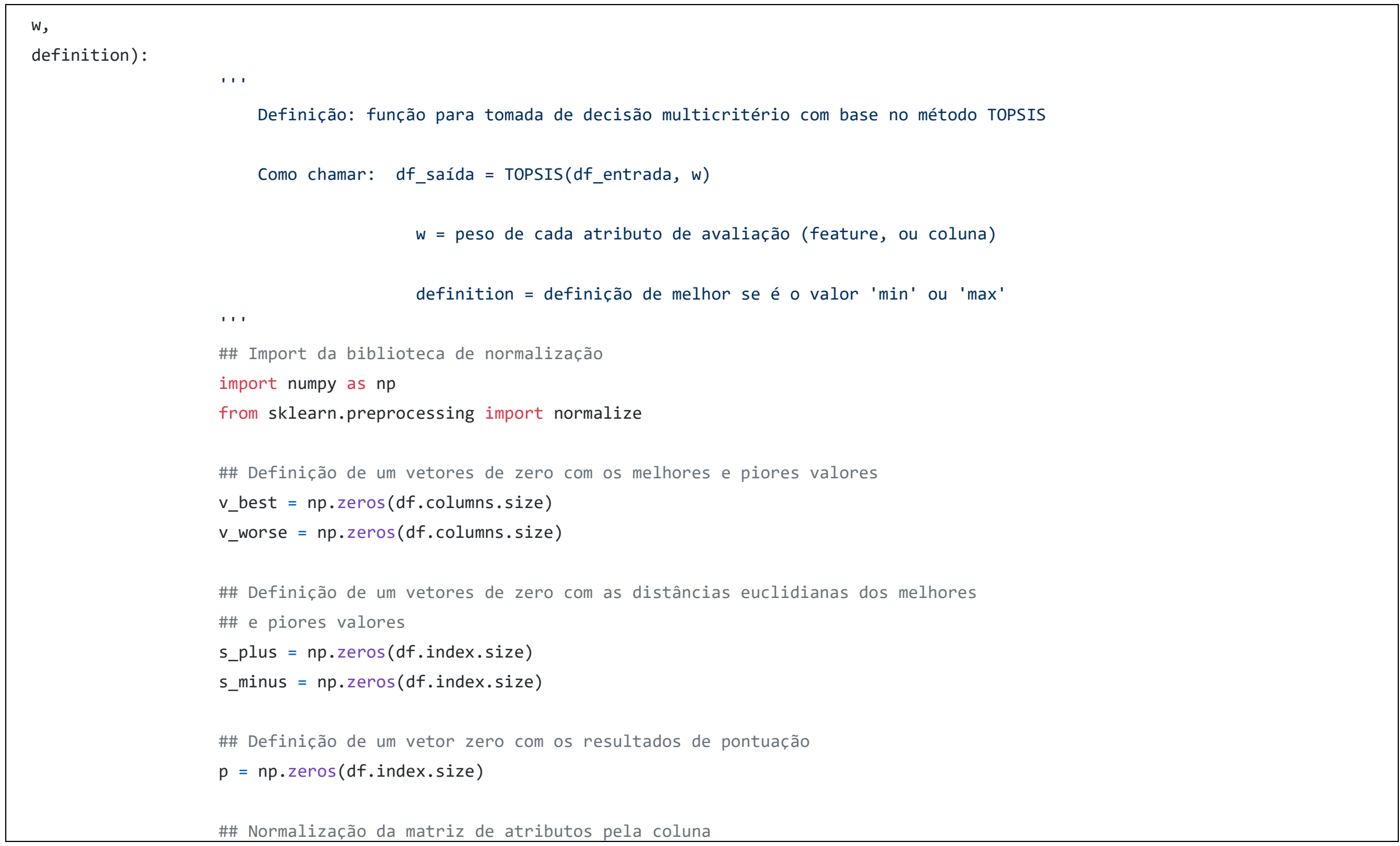




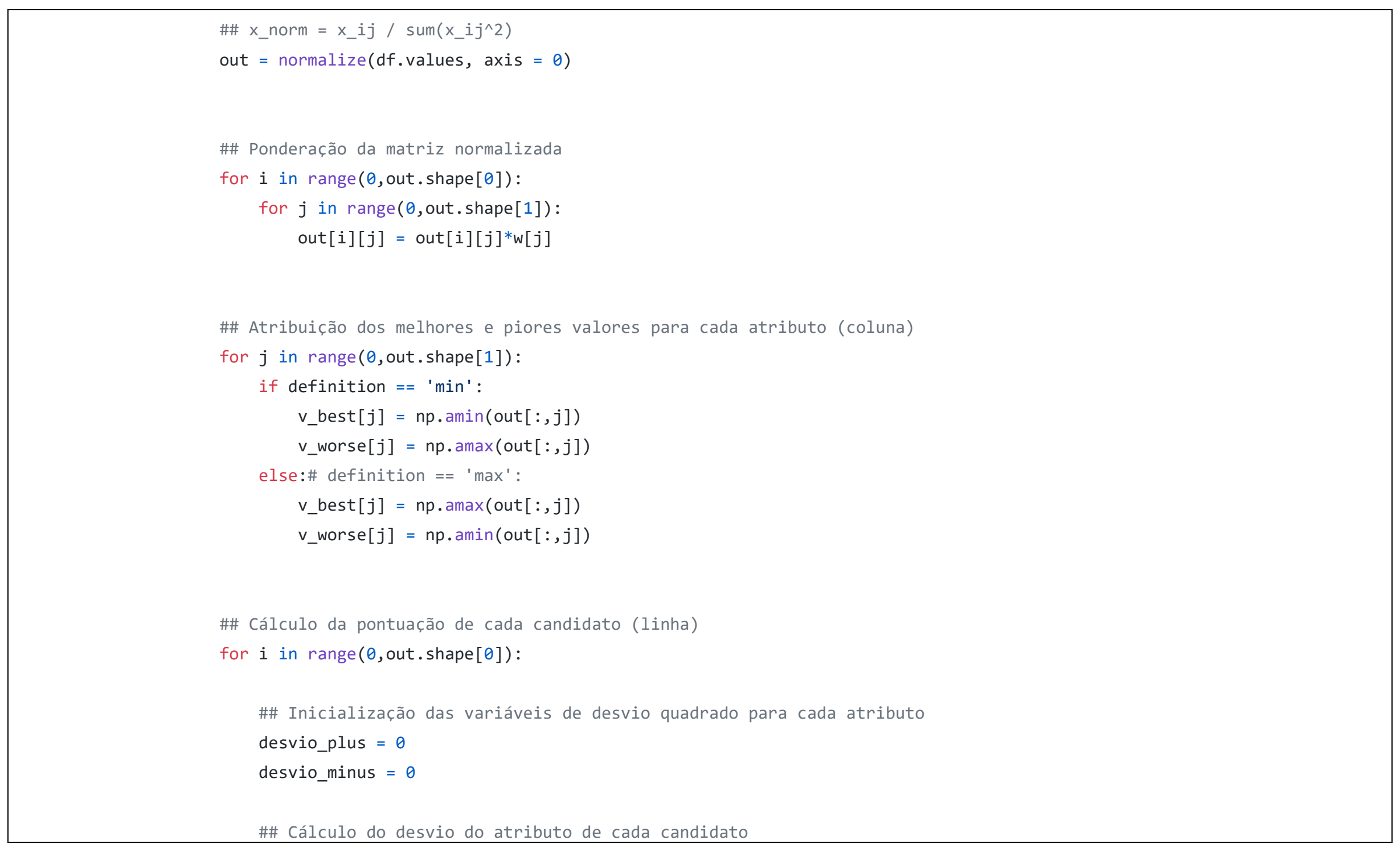




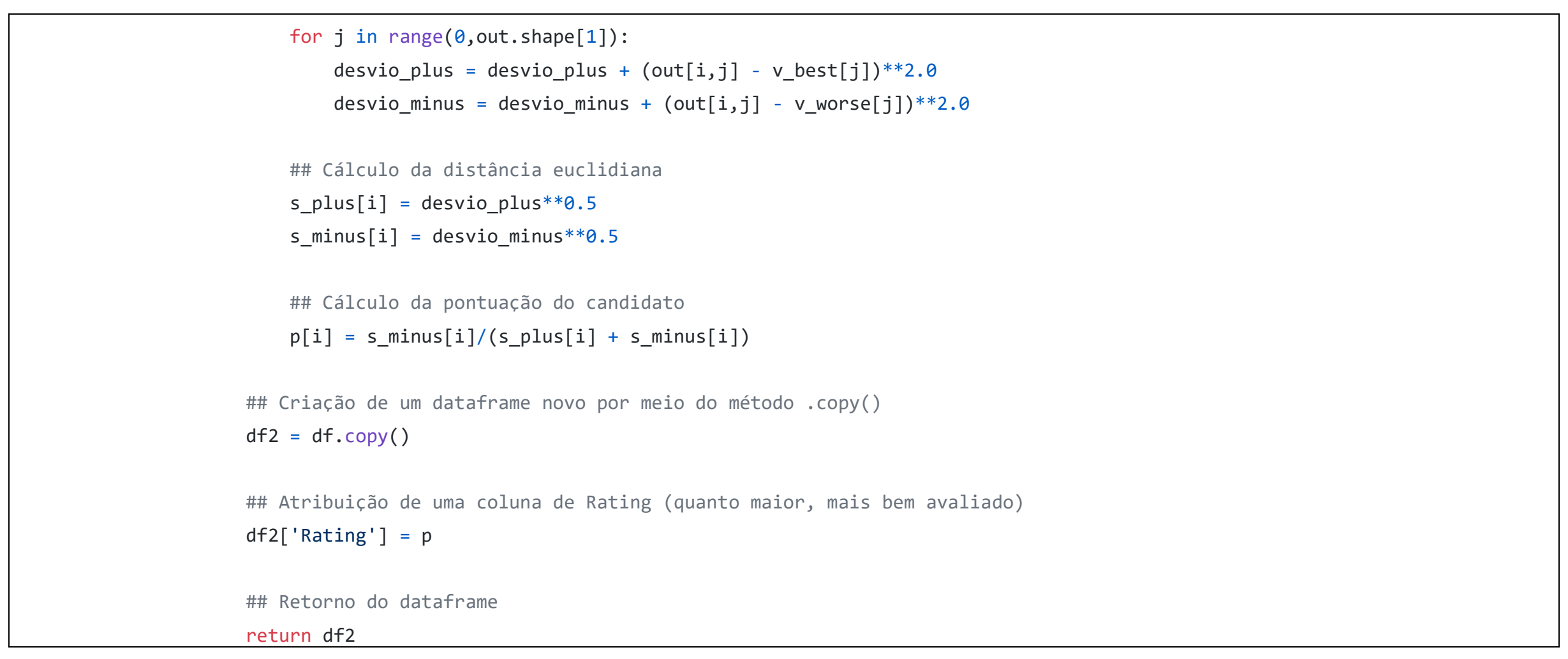

\section{main.py}

Título: Rotina para cálculo do das demandas energéticas normalizadas
Autor: Francisco
Objetivo: Utilizar os modelos de Martin (2016) para estimar demanda energética para o
processo de extração de lipídio utilizando parâmetros calculados pelo IBSS e mapeados


na literatura para solventes com capacidade de solubilizar o solvente.

, , ,

print('Iniciando código principal (main.py) ...\n')

\#\# Inclusão das bibliotecas necessárias

import numpy as np

import pandas as pd

from martin import martin

from rescaling import rescaling

from tqdm import tqdm

from TOPSIS import TOPSIS

print('Atualizando bases de dados... \n')

import base_tags

import base_solvents

import smiles_mol

import base_reds

print('Iniciando estimativas para os solventes da base... (n')

\#\# Declaração de um dicionário com as constantes utilizadas no modelo de Martin

\#\# Os valores foram retirados da literatura, Martin (2016)

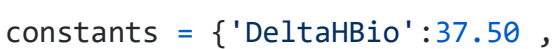

'NEst' : 0.90 ,

'LambdaW' : 2.72 ,

'SolidPercent': 24.40,

'TagPercent' : $24.40 * 47.45 / 100$ 
'Rhow' : 1000.00 ,

'RhoTag': 923.86 , \#\# Densidade a ser corrigida com propriedades calculadas

'RhoNonTag' : 1100.00$\}$

\#\# Declaração de um dicionário com os parâmetros de processo utilizados no modelo de Martin

\#\# Os valores foram retirados da literatura, Martin (2016) e Olmstead et al (2013)

process $=\{$ 'IMix': 1.00

'TRes' : 1.50 ,

'Vg': $3.80 \mathrm{E}-7$,

'PCent' : 9800.00

'SigmaFactor' : 2.00E4,

'PartCoeff': 3.0 ,

'Solv2Paste' : 0.60 ,

'NRecov' : 0.50 ,

'PhiSolv' : $0.5 \mathrm{E}-3\}$

\#\# Esses valores podem sofrer modificações com a mudança de solvente, entretanto,

\#\# o modelo atual não abrange esse ponto. Dessa forma, foram utilizados os valores já

\#\# praticados experimentalmente. Como próximo passo, deve-se construir modelos que consigam

\#\# atribuir valores de acordo com as propriedades do solvente utilizado.

\#\# Leitura da base final de solventes que possuem RED < 1 , considerando o R0 do óleo de Palma \#\# Essa base foi gerada no código base_reds.py, presente no diretório

solvents_final $=$ pd.read_csv('..\data\solvents_final_selected.csv')

\#\# Exclusão de casos em que não houve sucesso no cálculo da propriedade Latent Heat

solvents_final $=$ solvents_final[solvents_final['Latent Heat $\left.\left.[\mathrm{MJ} / \mathrm{kg}]{ }^{\prime}\right]>0\right] \cdot \operatorname{copy}()$ 
\#\# Criação das listas vazias para recebimento das demandas energéticas

phi_mix $=[]$

phi_sep $=[]$

phi_evap $=[]$

phi_loss $=[]$

phi_total $=[]$

\#\# Loop for para cálculo das demandas energéticas para cada solvente do dataframe

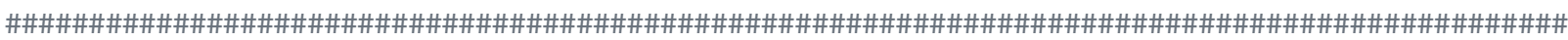

for index in $\operatorname{tqdm}(\operatorname{range}(\theta$, solvents_final.shape $[\theta]))$ :

\#for index in range( $\theta$, solvents_final.shape[0]):

\#\# Seleção da linha do dataframe em .iloc[i] e criação de um dicionário a partir da linha solvent $=\{$ 'Latent Heat $[\mathrm{MJ} / \mathrm{kg}]$ ': solvents_final['Latent Heat $[\mathrm{MJ} / \mathrm{kg}]$ '].iloc $[$ index $]$,

'DeltaH' : solvents_final['Combustion_Enthalpy'].iloc[index],

'Density MB2010':solvents_final['Density MB2010'].iloc[index]\}

\#\# Utilização dos modelos de Martin para estimativa da demanda energética

mix, sep, loss, evap $=\operatorname{martin}($ solvent, process, constants)

\# Armazenamento dos resultados em listas

phi_mix.append(mix)

phi_sep.append(sep)

phi_loss.append(loss)

phi_evap.append(evap)

phi_total.append(mix+sep+loss+evap) 


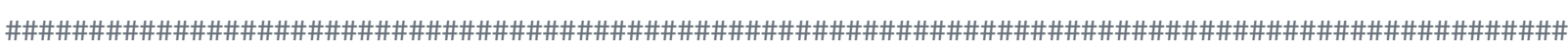

\#\# Atribuição das saídas da função para as colunas do dataframe de resultados finais

solvents_final['Phi_Mix'] = phi_mix

solvents_final['Phi_Sep'] = phi_sep

solvents_final['Phi_Loss'] = phi_loss

solvents_final['Phi_Evap'] = phi_evap

solvents_final['Phi_Total'] = phi_total

\#\# Rescaling das colunas dos parâmetros de EHS

solvents_final['Env_Waste'] = rescaling(solvents_final['Env. Waste Weis2009'])

solvents_final['Env_Impact'] = rescaling(solvents_final['Env. Impact Weis2009'])

solvents_final['Health'] = rescaling (solvents_final['Health Weis2009'])

solvents_final['Safety'] = rescaling (solvents_final['Safety Weis2009'])

solvents_final['Life_Cycle'] = rescaling(solvents_final['LCA Weis2009'])

\#\# Rescaling das colunas das demandas energéticas Phi

solvents_final['Phi_Total_Grade'] = rescaling(solvents_final['Phi_Total'], reverse = True)

\#\# Análise da proximidade do parâmetro de Solubilidade do solvente com o lipídio

solvents_final['HildebrandSolub'] = abs(solvents_final['HildebrandSolub Parameter HSKASG2012'] - 17.0780853727811)

\#\# Parâmetros que se deseja avaliar o solvente

parameters = ['Env_Waste', 'Env_Impact', 'Health', 'Safety', 'Life_Cycle', 'Phi_Total_Grade']

\#\# Slicing do dataframe

$c=$ solvents final[parameters] 
\#\# Peso para cada um dos atributos, a demanda energética e os parâmetros EHS receberam o mesmo peso

$w=[2,2,2,2,2,2]$

soma $=\operatorname{sum}(\mathrm{W})$

for $i$ in range $(\theta, \operatorname{len}(w))$ :

$w[i]=w[i] /$ soma

\#\# Execução do MCDA pelo algortimo TOPSIS

$d=\operatorname{TOPSIS}(c, w$, definition $=$ 'max')

solvents_final['Rating_Process'] = d['Rating']

\#\# Parâmetros que se deseja avaliar o solvente

parameters $=$ ['Boiling Point HSKASG2012 [K]', 'Log(Ws) MG2002 [mg.L-1]', 'Viscosity CMMG2008(268.15K) [mPa.s]', 'Enthalpy of vaporization at 298K HSKASG2012 [kJ.mol-1]', 'Latent Heat [MJ/kg]',

'Density MB2010', 'HildebrandSolub']

\#\# Slicing do dataframe

$c=$ solvents_final[parameters]

\#\# Peso para cada um dos atributos, as propriedades físico-químicas receberam o mesmo peso

$w=[2,2,2,2,2,2,2]$

soma $=\operatorname{sum}(w)$

for $i$ in $\operatorname{range}(\theta, l e n(w))$ :

$w[i]=w[i] /$ soma

\#\# Execução do MCDA pelo algortimo TOPSIS

$d=\operatorname{TOPSIS}(c, w$, definition = 'min')

solvents_final['Rating_Properties'] = d['Rating']

\#\# Exportação dos resultados para csV 
print(' $\backslash n$... escrevendo arquivos .csv ...')

solvents_final.to_csv( $r$ '../data/results.csv', index $=$ False, sep $=$ ' $^{\prime}$ ')

\#\# Finalização

print('\nCódigo executado com sucesso!' )

\section{sensibilidade.py}

Titulo: Rotina para analise de sensibilidade do modelo

Autor: Francisco

Objetivo: Realizar a analisa de sensibilidade do modelo em relacao aos parametros ajustaveis

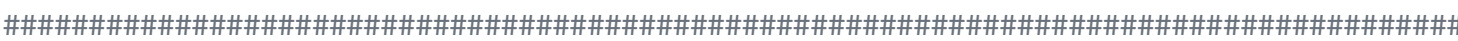

def sensibilidade (degrau $=1.05$, plot $=$ 'off' $)$

Descrição: função para realizar análise de sensibilidade em torno de um ponto inicial

definido no trabalhos de Martin 2016 e olmstead 2013 com um degrau definido pelo usuário.

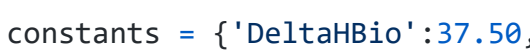

'NEst' : 0.90 ,

'LambdaW' : 2.72,

'SolidPercent' : 24.4,

'TagPercent' : 11.58 , 


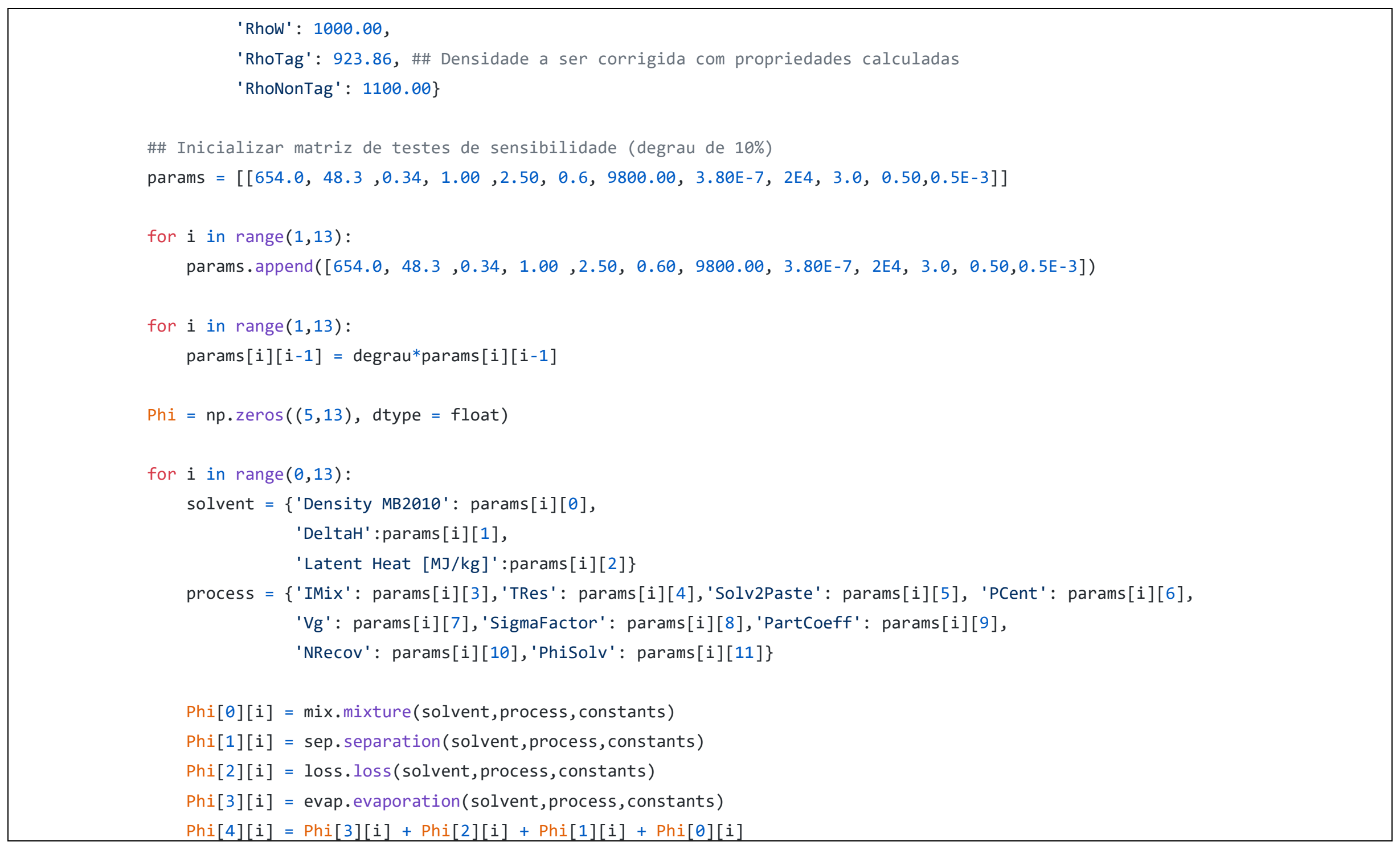


for $i$ in range $(1,13)$ :

$\operatorname{Phi}[\theta][i]=100 *(\operatorname{Phi}[\theta][i]-\operatorname{Phi}[\theta][\theta]) / \operatorname{Phi}[\theta][\theta]$

$\operatorname{Phi}[1][i]=100 *(\operatorname{Phi}[1][i]-\operatorname{Phi}[1][0]) / \operatorname{Phi}[1][0]$

$\operatorname{Phi}[2][i]=100 *(\operatorname{Phi}[2][i]-\operatorname{Phi}[2][0]) / \operatorname{Phi}[2][0]$

$\operatorname{Phi}[3][i]=100 *(\operatorname{Phi}[3][i]-\operatorname{Phi}[3][0]) / \operatorname{Phi}[3][0]$

$\operatorname{Phi}[4][i]=100 *(\operatorname{Phi}[4][i]-\operatorname{Phi}[4][0]) / \operatorname{Phi}[4][0]$

for $i$ in range $(\theta, 5)$ :

$\operatorname{Phi}[i][0]=0.0$

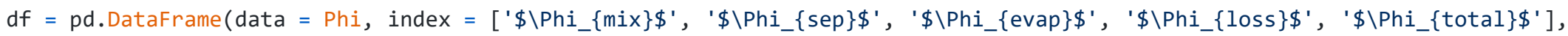

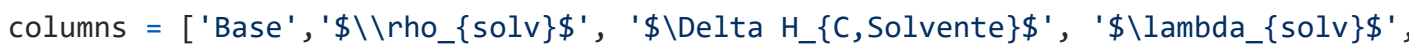

'\$I_\{mix $\} \$ 1$, '\$T_\{RES $\} \$ 1$, 'S:P', '\$P_\{CENT $\} \$ 1$, 'Vg',

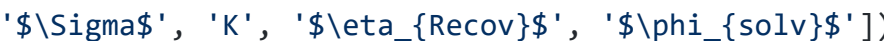

df.drop('Base', inplace $=$ True, axis $=1$ )

if plot $==$ 'off' :

pass

else:

sns.set $(r c=\{$ 'figure.figsize' $:(12,4)\})$

graf $=$ sns.heatmap $(\mathrm{df}$, annot $=$ True, cmap $=" \mathrm{GnBu} "$, linewidths $=0.3$,

center $=$ df.loc ['\$\Phi_loss\}\$','\$I_mix\}'], cbar kws=\{'label': '\% de variação'\})

return $d f$

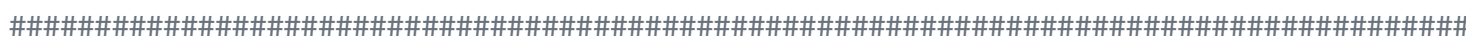




print('Iniciando codigo $\ldots$ ')
import mixture as mix
import separation as sep
import evaporation as evap
import loss
import pandas as pd
import numpy as $\mathrm{np}$
import seaborn as sns
sensibilidade(degrau $=1.05$, plot $=$ 'on')
print('Código executado com sucesso!')

\section{esferahansen.py}

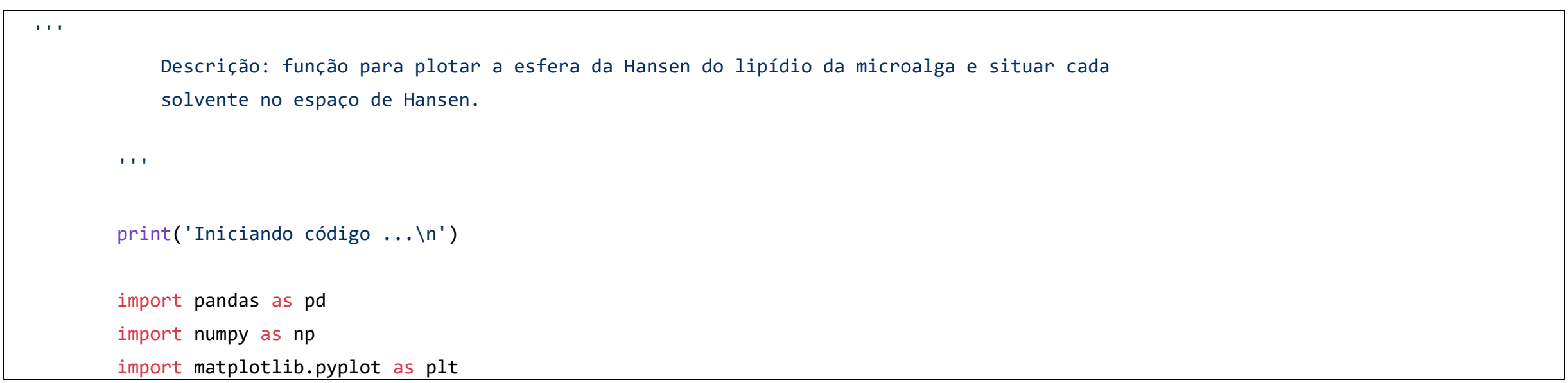


from mpl_toolkits.mplot3d import Axes3D

\#\# Leitura da base de dados

solvents_red $=$ pd.read_csv ('..\data \solvents_red.csv', sep = '; ')

\#\# Chamando função para plot

\#esferaHansen(solvents_red, save $=$ 'off' )

save $=$ 'on'

\#\#\# Leitura da base de triglicerÃdeos com propriedades calculadas pelo IBSS

tags_final $=$ pd.read_csv $\left(r ' . . \backslash\right.$ data $\backslash$ tags_final.csv', sep $\left.={ }^{\prime} \mid{ }^{\prime}\right)$

\#\#\# Contabilização dos dados do lipídio

TAG $=\{$ 'MolecularWeight' $:$ round (sum(tags_final['Molar Fraction']*tags_final['MW (CSK) [g/mol]']), 2),

'Density' :round(sum(tags_final['Molar Fraction']*tags_final['Density (CSK) [kg/m3] ']), 2),

'HSP_d':round(sum(tags_final['Molar Fraction']*tags_final['HSP_d MB2010']), 2),

'HSP_p':round(sum(tags_final['Molar Fraction']*tags_final['HSP_p MB2010']), 2),

'HSP_h':round(sum(tags_final['Molar Fraction']*tags_final['HSP_h MB2010']), 2),

'Ro' : 7.48$\}$

\#\# Inicialização do quadro da figura

fig $=$ plt.figure $($ figsize $=[10,10]$, facecolor $=$ "White" $)$

ax $=$ plt.axes (projection=' $3 d^{\prime}$ ')

ax.set_aspect('equal')

\#\# Plot dos solventes bons no espaÃßo de solubilidade em azul

$\mathrm{x} 1=2 *$ solvents_red[solvents_red['RED_Palma' $]<1][$ 'HSP_d MB2010'] 
$\mathrm{y} 1$ = solvents_red[solvents_red['RED_Palma']<1]['HSP_p MB2010']

$\mathrm{z} 1$ = solvents_red[solvents_red['RED_Palma']<1]['HSP_p MB2010']

ax.scatter $(x 1, y 1, z 1$, color = 'blue' $)$ \# Good Solvents

\#\# Plot dos solventes ruins no espaÃßo de solubilidade em vermelho

$x 2=2 *$ solvents_red[solvents_red['RED_Palma']>=1]['HSP_d MB2010']

y2 = solvents_red[solvents_red['RED_Palma'] $>=1][$ 'HSP_p MB2010']

$z 2$ = solvents_red[solvents_red['RED_Palma']>=1]['HSP_p MB2010']

ax.scatter $(x 2, y 2, z 2$, color = 'red') \# Bad Solvents

plt.legend (['Good (RED < 1)', 'Bad (RED >=1)'], loc='lower right', ncol=1, )

\#\# Plot da esfera de solubilidade do lipÃdio com centro nos parÃłmetros de Hansen do lipÃdio

$\mathrm{u}=\mathrm{np} . \operatorname{linspace}(\theta, \mathrm{np} . \mathrm{pi}, 25)$

$v=n p . l i n s p a c e(\theta, 2 * n p . p i, 25)$

\#\# Plot do raio de solubilidade utilizando como centro os parÃłmetros de Hansen do lipÃdio

$x=T A G \cdot g e t\left({ }^{\prime} R o^{\prime}\right) * n p \cdot o u t e r(n p \cdot \sin (u), n p \cdot \sin (v))+2 * T A G \cdot g e t($ 'HSP_d')

$y=$ TAG.get('Ro')*np.outer (np.sin(u), np.cos(v)) + TAG.get('HSP_p')

$z=T A G \cdot g e t\left(\right.$ Ro' $^{*}$ *np.outer $(n p \cdot \cos (u)$, np.ones_like $(v))+$ TAG.get('HSP_h' $)$

\#\# Plot da esfera

ax.plot wireframe $(x, y, z, I w=0.4$, color $=$ 'black', alpha $=0.5)$

\#\# Ajustes nos eixos

ax.set_xlim(20,45)

ax. set $y \lim (-10,15)$

ax. set $z \lim (-10,15)$ 
\#\# Definição de títulos dos eixos e do gráfico

ax.set_xlabel( $r^{\prime} \$ 2 \backslash$ delta $\left.d \$ \prime^{\prime}\right)$

ax.set_ylabel( $r^{\prime} \$ \backslash$ delta $\left.p \$ \prime^{\prime}\right)$

ax.set_zlabel(r'\$\delta $\left.h \$ \prime^{\prime}\right)$

\#ax.set_title('Esfera de solubilidade do lipídio da microalga (utilizando Ro do Óleo de Palma)', fontsize =

14, fontweight= ' bold ' )

if save == 'off':

pass

else:

fig.savefig('Esfera_Hansen_Palma.png', dpi=150)

plt.show() 


\subsection{Painel de comparação de solventes}

Figura 19 - Painel de comparação de solventes construído no presente trabalho (amostra).

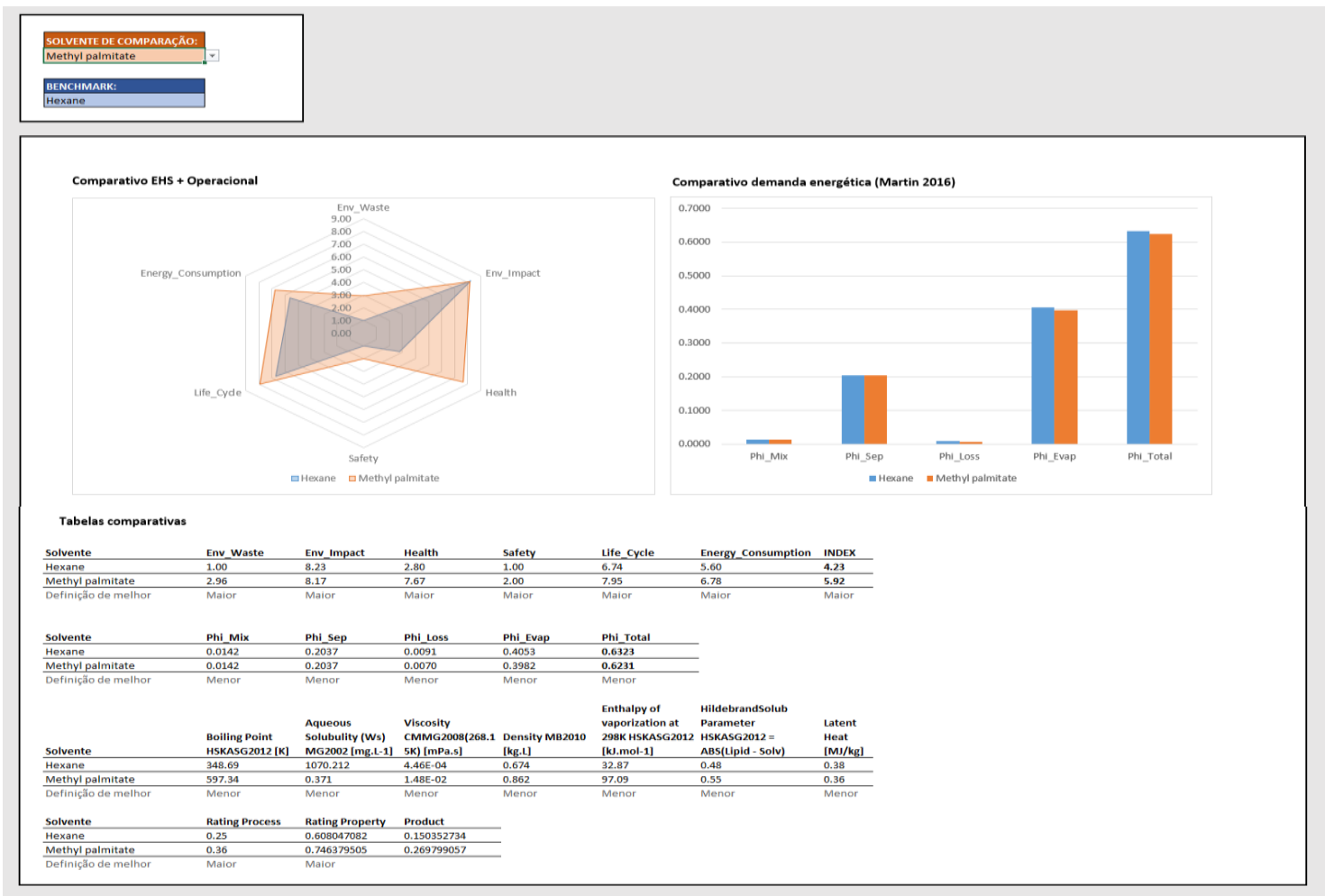

Fonte: Próprio autor.

\subsection{Algortimo do método TOPSIS}

\section{Algoritmo TOPSIS}

0. Dada uma matriz A de i candidatos e j atributos. Cada atributo pode ter um peso $\mathrm{W}$, definido por quem conduz a análise:

$$
\begin{gathered}
A=\left(\begin{array}{ccc}
x_{11} & \cdots & x_{1 j} \\
\vdots & \ddots & \vdots \\
x_{i 1} & \cdots & x_{i j}
\end{array}\right) \\
W=\left(\begin{array}{lll}
w_{1} & \cdots & w_{j}
\end{array}\right)
\end{gathered}
$$

1. Construir matriz normalizada A':

$$
A^{\prime}=\left(\begin{array}{ccc}
r_{11} & \cdots & r_{1 j} \\
\vdots & \ddots & \vdots \\
r_{i 1} & \cdots & r_{i j}
\end{array}\right)
$$

Em que: 


$$
r_{i j}=\frac{x_{i j}}{\sqrt{\sum_{i=1}^{m} x_{i j}^{2}}}, \forall j
$$

2. Construir matriz normalizada com pesos atribuídos A":

$$
\begin{gathered}
v_{i j}=r_{i j} w_{j}, \forall i, j \\
A^{\prime \prime}=\left(\begin{array}{ccc}
v_{11} & \cdots & v_{1 j} \\
\vdots & \ddots & \vdots \\
v_{i 1} & \cdots & v_{i j}
\end{array}\right)
\end{gathered}
$$

3. Determinação da solução ideal (B) e a não ideal (W):

$$
\begin{aligned}
& B=\left\{\left(\max v_{i j} \mid i \in I\right),\left(\min v_{i j} \mid i \in I^{\prime}\right) ; \forall j\right\}=\left\{\begin{array}{lll}
v_{1}^{+} & \ldots & v_{1 j}^{+}
\end{array}\right\} \\
& W=\left\{\left(\max v_{i j} \mid i \in I\right),\left(\min v_{i j} \mid i \in I^{\prime}\right) ; \forall j\right\}=\left\{\begin{array}{lll}
v_{1}^{-} & \ldots & v_{1 j}^{-}
\end{array}\right\}
\end{aligned}
$$

Cada atributo terá dentro dos canditados o melhor e o pior valor. O melhor valor pode ser o maior número, ou o menor, dependendo da característica do atributo.

4. Calcular a distância do valor em relação a melhor e a pior solução:

$$
\begin{aligned}
& S^{+}=\sqrt{\sum_{i=1}^{n}\left(v_{i j}-v_{i}^{+}\right)^{2}} ; \forall j \\
& S^{-}=\sqrt{\sum_{i=1}^{n}\left(v_{i j}-v_{i}^{-}\right)^{2}} ; \forall j
\end{aligned}
$$

5. Calcular a distância relativa da solução ideal:

$$
C_{j}^{+}=\frac{S_{J}^{+}}{S_{J}^{-}+S_{J}^{+}}
$$

6. Classificar candidatos com base no $\mathrm{Cj}^{+}$

7. Fim. 


\subsection{Análise financeira das unidades de extração de lipídio}

Para cada equipamento foi calculado o custo de capital levando-se em consideração a sua dimensão (capacidade). Os parâmetros foram consultados no Turton et al. (1998), conforme Tabela 27.

Tabela 27 - Parâmetros para estimativas do custo de equipamento.

\begin{tabular}{|c|c|c|c|c|c|c|c|c|c|c|c|}
\hline Nome Turton & Nome análise & K1 & K2 & K3 & Min & Max & $\begin{array}{r}\text { Fator } \\
\text { material } \\
\text { (FM) }\end{array}$ & $\begin{array}{r}\text { Fator } \\
\text { pressão } \\
(F p)\end{array}$ & B1 & B2 & $\mathrm{F}_{\mathrm{BM}}$ \\
\hline Centrifugal pump & $\begin{array}{l}\text { Bomba } \\
\text { centrífuga }\end{array}$ & 3.3892 & 0.0536 & 0.1538 & 1 & 300 & 1.6 & 1 & 1.89 & 1.35 & 4.05 \\
\hline Kettle reboiler & Refervedor & 4.4646 & $0.5277^{-}$ & 0.3955 & 10 & 100 & 1 & 1 & 1.63 & 1.66 & 3.29 \\
\hline U-tube & Condensador & 4.1884 & 0.2503 & 0.1974 & 10 & $\begin{array}{r}100 \\
0\end{array}$ & 1 & 1 & 1.63 & 1.66 & 3.29 \\
\hline Process vessel $\mathrm{H}$ & Horizontal & 3.5565 & 0.3776 & 0.0905 & 0.1 & 628 & 1 & 1 & 1.49 & 1.52 & 3.01 \\
\hline Process vessel V & Vertical & 3.4974 & 0.4483 & 0.1074 & 0.3 & 520 & 1 & 1 & 2.25 & 1.82 & 4.07 \\
\hline Centrifugal radial fan & Soprador & 3.3591 & 0.3533 & 0.4477 & 1 & 100 & 1 & 1 & 1.89 & 1.35 & 3.24 \\
\hline
\end{tabular}

Fonte: Próprio autor.

Os custos e preços dos equipamentos foram ajustados para o ano de 2019 utilizando o CEPCI, conforme mostrado na Tabela 28.

Tabela 28 - Parâmetros de ajuste de custos.

\begin{tabular}{lr}
\hline Índice & Valor \\
\hline CEPCI 2019 & 607.5 \\
CEPCI 2001 & 397 \\
\hline
\end{tabular}

Fonte: Próprio autor.

Em seguida, foi feita a estimativa do custo de cada equipamento, com base na equação 19. O custo total de capital da planta foi estimado pelas equações 20 e 21. Para o custo operacional, foram calculados o custo de mão de obra, de matéria-prima e de utilidades, pelas equações 24,22 e 23 , respectivamente. 


$$
\begin{aligned}
& \log _{10} C_{p}^{0}=K_{1}+K_{2} \log _{10} A+2 K_{3}\left(\log _{10} A\right) \\
& C_{B M}=C_{P}^{0}\left(B_{1}+B_{2} F_{p} F_{M}\right) \\
& F C I=1,18 \sum C_{B M, i} \\
& C_{R M}=330.24 \cdot\left(C_{\text {solv }}\left(\frac{U S \$}{k g}\right) \cdot m_{\text {solv }}+C_{\text {paste }}\left(\frac{U S \$}{k g}\right) \cdot m_{\text {paste }}\right) \\
& C_{U T}=C_{\text {energia }}(U S \$ / a n o)+C_{\text {vapor }}(U S \$ / \text { ano })+C_{\text {refrigeração }}(U S \$ / \text { ano }) \\
& C_{O L}=U S \$ 64 \cdot 324,96 \cdot 4,5 \cdot\left(6,29+0,23 N_{n p}\right)^{0,5} \\
& C O M=0,280 F C I+2,73 C_{O L}+1,23\left(C_{U T}+C_{R M}\right) \\
& \text { Total Costs }=C_{R M}+C_{U T}+2,215 C_{O L}+0,190 C O M+1,146 F C I+0,10 F C I \\
& \text { OPEX = Total Costs } \\
& C A P E X=F C I \\
& \text { Revenue }=C_{\text {oil }}\left(\frac{U S \$}{\mathrm{~kg}}\right) \cdot m_{\text {oll }}^{\cdot} \\
& =C_{R M}+C_{U T}+1,33 C_{O L}+0,003 C O M+0,0069 F C I
\end{aligned}
$$

Custos gerais de fabricação $=0,177 C_{O L}+0,009 F C I+0,16 C O M$

$$
\text { Depreciação }=0,10 F C I
$$

O custo operacional foi estimado pelas equações 25 e 26. Com isso, temse o CAPEX (equação 28) e o OPEX (equação 27) da unidade de extração de óleo de microalga. É possível calcular a receita por meio da equação 29 e construir um fluxo de caixa de 20 anos de operação e 2 anos de construção ( $40 \%$ do CAPEX no ano 1 e $60 \%$ do CAPEX no ano 2 ).

O fluxo é trazido a valor presente utilizando uma taxa de desconto de $7,55 \%$, dentro da realidade do mercado. O OPEX do fluxo de caixa é segmentado nas 4 componentes das equações 30-33. 
Figura 20 - Projeção de 10 anos da unidade de extração utilizando hexano como solvente. Premissas de preço de venda do óleo de microalga de US\$2,07/kg. Exibição dos 12 primeiros anos por espaço.

\begin{tabular}{|c|c|c|c|c|c|c|c|c|c|c|c|c|c|}
\hline Fluxo de caixa de venda de produtos & & & & & & & & & & & & & \\
\hline TMA & $7.55 \%$ & & & & & & & & & & & & \\
\hline & Construção & & eração & & & & & & & & & & \\
\hline Ano & 0 & 1 & 2 & 3 & 4 & 5 & 6 & 7 & 8 & 9 & 10 & 11 & 12 \\
\hline Receita $(+)$ & - & - & $41,814,968$ & $41,814,968$ & $41,814,968$ & $41,814,968$ & $41,814,968$ & $41,814,968$ & $41,814,968$ & $41,814,968$ & $41,814,968$ & $41,814,968$ & $41,814,968$ \\
\hline Custos e despesas totais (-) & - & - & $74,989,670$ & $74,989,670$ & $74,989,670$ & $74,989,670$ & $74,989,670$ & $74,989,670$ & $74,989,670$ & $74,989,670$ & $74,989,670$ & $74,989,670$ & $74,989,670$ \\
\hline Custos diretos de fabricação & - & - & $62,285,544$ & $62,285,544$ & $62,285,544$ & $62,285,544$ & $62,285,544$ & $62,285,544$ & $62,285,544$ & $62,285,544$ & $62,285,544$ & $62,285,544$ & $62,285,544$ \\
\hline Custos fixos de fabricação & - & - & 590,373 & 590,373 & 590,373 & 590,373 & 590,373 & 590,373 & 590,373 & 590,373 & 590,373 & 590,373 & 590,373 \\
\hline Despesas gerais de fabricação & - & - & $12,113,753$ & $12,113,753$ & $12,113,753$ & $12,113,753$ & $12,113,753$ & $12,113,753$ & $12,113,753$ & $12,113,753$ & $12,113,753$ & $12,113,753$ & $12,113,753$ \\
\hline Depreciação (-) & - & - & 64,513 & 64,513 & 64,513 & 64,513 & 64,513 & 64,513 & 64,513 & 64,513 & 64,513 & 64,513 & - \\
\hline Lucro bruto $(=)$ & - & - - & $33,239,215$ - & $33,239,215$ - & $33,239,215$ - & $33,239,215$ & $33,239,215$ & $33,239,215$ & $33,239,215$ - & $33,239,215$ - & $33,239,215$ - & $33,239,215$ - & $33,174,702$ \\
\hline Lucro líquido (=) & - & - - & $33,239,215$ - & $33,239,215$ - & $33,239,215$ - & $33,239,215$ - & $33,239,215$ - & $33,239,215$ - & $33,239,215$ - & $33,239,215$ - & $33,239,215$ - & $33,239,215$ - & $33,174,702$ \\
\hline $\operatorname{CAPEX}(-)$ & 258,051 & 387,076 & - & - & - & - & - & - & - & - & - & - & - \\
\hline Depreciação (+) & - & - & 64,513 & 64,513 & 64,513 & 64,513 & 64,513 & 64,513 & 64,513 & 64,513 & 64,513 & 64,513 & - \\
\hline Fluxo de caixa $(\Rightarrow)$ & 258,051 - & 387,076 - & $33,174,702$ - & $33,174,702$ - & $33,174,702$ - & $33,174,702$ - & $33,174,702$ & $33,174,702$ - & $33,174,702$ - & $33,174,702$ - & $33,174,702$ - & $33,174,702$ - & $33,174,702$ \\
\hline Fator de desconto & 1 & 1 & 1 & 1 & 1 & 1 & 1 & 1 & 1 & 1 & 0 & 0 & 0 \\
\hline Fluxo de caixa descontado $(=)$ & 258,051 & 359,903 & $28,680,466$ & $26,667,100$ & $24,795,072$ & $23,054,460$ & $21,436,039$ & $19,931,231$ & $18,532,061$ & $17,231,112$ & $16,021,489$ & $14,896,782$ & $13,851,030$ \\
\hline Fluxo de caixa acumulado descontado $(=)$ - & 258,051 & 617,954 & $29,298,420$ & $55,965,520$ & $80,760,592$ & $103,815,053$ & $125,251,092$ & $145,182,323$ & $163,714,384$ & $180,945,496$ & $196,966,985$ & $211,863,768$ - & $225,714,797$ \\
\hline VPL (USS) & $-288,733,911.87$ & & & & & & & & & & & & \\
\hline Recovery factor (CRF) & $10.64 \%$ & & & & & & & & & & & & \\
\hline TAC (USS) & $-75,055,396.36$ & & & & & & & & & & & & \\
\hline CAPEX anualizado (USS) & - $\quad 65,725.94$ & & & & & & & & & & & & \\
\hline
\end{tabular}


Figura 21 - Projeção dos 10 anos restantesda unidade de extração utilizando hexano como solvente. Premissas de preço de venda do óleo de microalga de US\$2,07/kg.

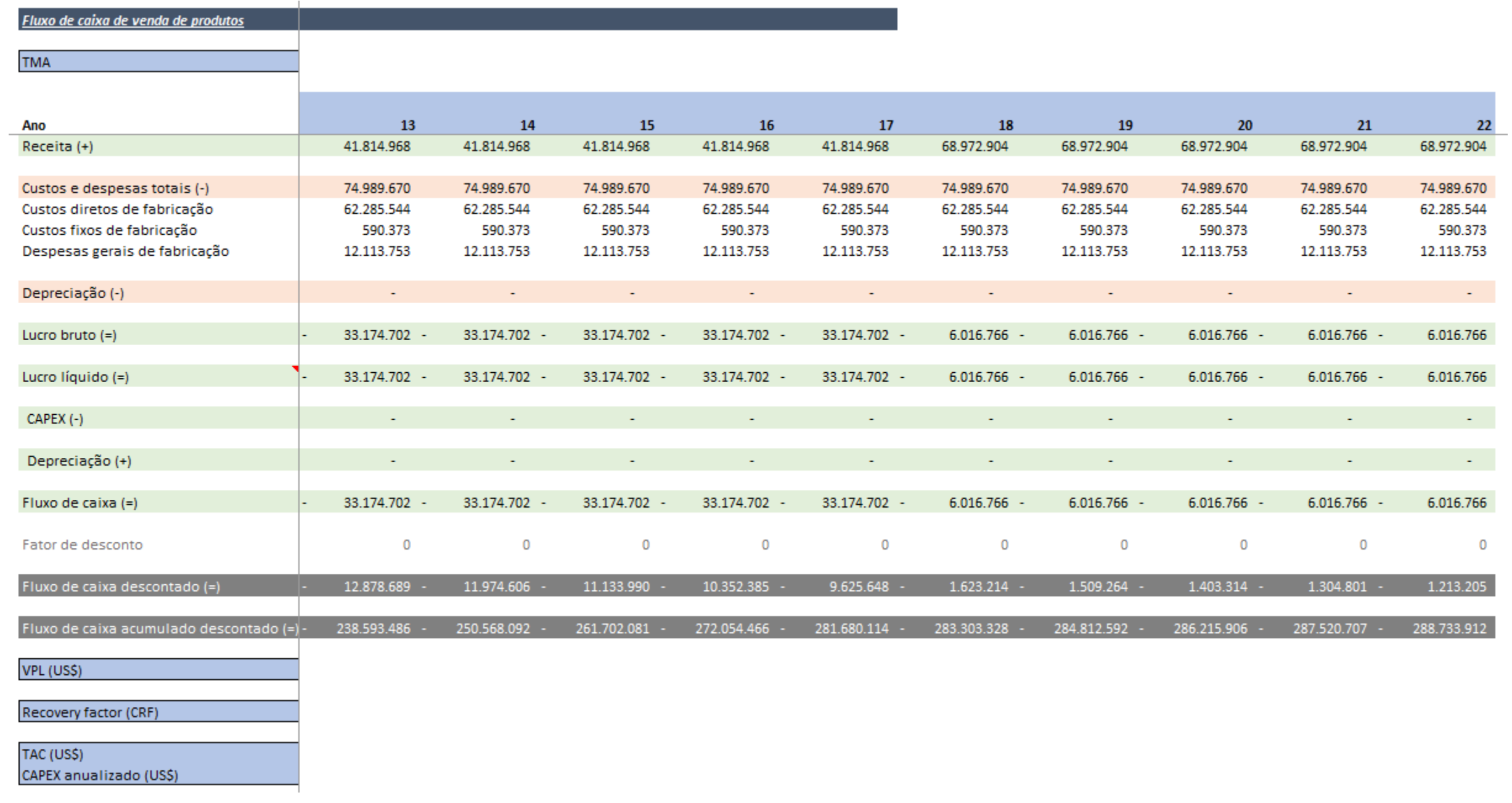


Figura 22 - Projeção de 10 anos da unidade de extração utilizando limoneno como solvente. Premissas de preço de venda do óleo de microalga de US\$2,07/kg. Exibição dos 12 primeiros anos por espaço.

\begin{tabular}{|c|c|c|c|c|c|c|c|c|c|c|c|c|c|}
\hline TMA & $7.55 \%$ & & & & & & & & & & & & \\
\hline & Construc & & Operação & & & & & & & & & & \\
\hline Ano & 0 & 1 & 2 & 3 & 4 & 5 & 6 & 7 & 8 & 9 & 10 & 11 & 12 \\
\hline Receita $(+)$ & - & - & $37,715,431.96$ & $37,715,431.96$ & $37,715,431.96$ & $37,715,431.96$ & $37,715,431.96$ & $37,715,431.96$ & $37,715,431.96$ & $37,715,431.96$ & $37,715,431.96$ & $37,715,431.96$ & $37,715,431.96$ \\
\hline Custos e despesas totais (-) & - & - & $78,307,280.68$ & $78,307,280.68$ & $78,307,280.68$ & $78,307,280.68$ & $78,307,280.68$ & $78,307,280.68$ & $78,307,280.68$ & $78,307,280.68$ & $78,307,280.68$ & $78,307,280.68$ & $78,307,280.68$ \\
\hline Custos diretos de fabricação & - & - & $65,033,588.42$ & $65,033,588.42$ & $65,033,588.42$ & $65,033,588.42$ & $65,033,588.42$ & $65,033,588.42$ & $65,033,588.42$ & $65,033,588.42$ & $65,033,588.42$ & $65,033,588.42$ & $65,033,588.42$ \\
\hline Custos fixos de fabricação & - & - & $620,844.89$ & $620,844.89$ & $620,844.89$ & $620,844.89$ & $620,844.89$ & $620,844.89$ & $620,844.89$ & $620,844.89$ & $620,844.89$ & $620,844.89$ & $620,844.89$ \\
\hline Despesas gerais de fabricação & - & & $12,652,847.38$ & $12,652,847.38$ & $12,652,847.38$ & $12,652,847.38$ & $12,652,847.38$ & $12,652,847.38$ & $12,652,847.38$ & $12,652,847.38$ & $12,652,847.38$ & $12,652,847.38$ & $12,652,847.38$ \\
\hline Depreciação(-) & - & - & $109,323.57$ & $109,323.57$ & $109,323.57$ & $109,323.57$ & $109,323.57$ & $109,323.57$ & $109,323.57$ & $109,323.57$ & $109,323.57$ & $109,323.57$ & - \\
\hline Lucro bruto ( $=)$ & - & - & $-40,701,172.29$ & - $40,701,172.29$ & $-40,701,172.29$ & $-40,701,172.29$ & $40,701,172.29$ & $-40,701,172.29$ & $40,701,172.29$ & $40,701,172.29$ & $40,701,172.29$ & - $40,701,172.29$ & $40,591,848.72$ \\
\hline Lucro líquido (=) & - & - & - $40,701,172.29$ & - $40,701,172.29$ & $-40,701,172.29$ & $40,701,172.29$ & - $40,701,172.29$ & - $40,701,172.29$ & $-40,701,172.29$ & - 40,701,172.29 - & $40,701,172.29$ & - $40,701,172.29$ - & $40,591,848.72$ \\
\hline Depreciação (+) & - & - & $109,323.57$ & $109,323.57$ & $109,323.57$ & $109,323.57$ & $109,323.57$ & $109,323.57$ & $109,323.57$ & $109,323.57$ & $109,323.57$ & $109,323.57$ & - \\
\hline CAPEX (-) & $437,294.29$ & $655,941.43$ & - & - & - & - & - & - & - & - & - & - & - \\
\hline Fluxo de caixa ( $=)$ & $437,294.29$ & $655,941.43$ & - $40,591,848.72$ & - $40,591,848.72$ & - $40,591,848.72$ & $40,591,848.72$ & - $40,591,848.72$ & - $40,591,848.72$ & - $40,591,848.72$ & - 40,591,848.72 - & $40,591,848.72$ & - 40,591,848.72 - & $40,591,848.72$ \\
\hline Fator de desconto & 1 & 0.929800093 & 0.864528213 & 0.803838413 & 0.747409031 & 0.694940986 & 0.646156194 & 0.600796089 & 0.558620259 & 0.519405169 & 0.482942975 & 0.449040423 & 0.417517827 \\
\hline Fluxo de caixa descontado (=) & $437,294.29$ & $609,894.40$ & $35,092,798.43$ & $32,629,287.25$ & - $30,338,714.32$ & $28,208,939.39$ & - $26,228,674,47$ & $24,387,423.96$ & - $22,675,429.07$ & - $21,083,616.05$ & $19,603,548.17$ & $-18,227,380.91$ & $16,947,820.46$ \\
\hline Fluxo de caixa acumulado descontado ( $=$ ) & $437,294.29$ & $1,047,188.69$ & $36,139,987.13$ & $68,769,274.37$ & - $99,107,988.69$ & $-127,316,928.08$ & $-153,545,602.55$ & $-177,933,026.51$ & $-200,608,455.58$ & $-221,692,071.63-$ & $241,295,619.80$ & $-259,523,000.71$ & $276,470,821.17$ \\
\hline VPL(US\$) & $392,536,909.06$ & & & & & & & & & & & & \\
\hline Recovery factor (CRF) & $10.64 \%$ & & & & & & & & & & & & \\
\hline TAC (US\$) & $78,418,660.23$ & & & & & & & & & & & & \\
\hline CAPEX anualizado (US\$) & $111,379.55$ & & & & & & & & & & & & \\
\hline
\end{tabular}


Figura 23 - Projeção de 10 anos restantes da unidade de extração utilizando limoneno como solvente. Premissas de preço de venda do óleo de microalga de US $\$ 2,07 / \mathrm{kg}$.

\begin{tabular}{|c|c|c|c|c|c|c|c|c|c|c|}
\hline \multicolumn{11}{|l|}{ Fluxo de caixa de venda de produtos } \\
\hline \multicolumn{11}{|l|}{ TMA } \\
\hline Ano & 13 & 14 & 15 & 16 & 17 & 18 & 19 & 20 & 21 & 22 \\
\hline Receita (+) & $37.715 .431,96$ & $37.715 .431,96$ & $37.715 .431,96$ & $37.715 .431,96$ & $37.715 .431,96$ & $37.715 .431,96$ & $37.715 .431,96$ & $37.715 .431,96$ & $37.715 .431,96$ & $37.715 .431,96$ \\
\hline Custos e despesas totais (-) & $78.307 .280,68$ & 78.307.280,68 & 78.307.280,68 & $78.307 .280,68$ & $78.307 .280,68$ & $78.307 .280,68$ & $78.307 .280,68$ & $78.307 .280,68$ & $78.307 .280,68$ & $78.307 .280,68$ \\
\hline Custos diretos de fabricação & $65.033 .588,42$ & $65.033 .588,42$ & $65.033 .588,42$ & $65.033 .588,42$ & $65.033 .588,42$ & $65.033 .588,42$ & $65.033 .588,42$ & $65.033 .588,42$ & $65.033 .588,42$ & $65.033 .588,42$ \\
\hline Custos fixos de fabricação & $620.844,89$ & $620.844,89$ & $620.844,89$ & $620.844,89$ & $620.844,89$ & $620.844,89$ & $620.844,89$ & $620.844,89$ & $620.844,89$ & $620.844,89$ \\
\hline Despesas gerais de fabricação & $12.652 .847,38$ & $12.652 .847,38$ & $12.652 .847,38$ & $12.652 .847,38$ & $12.652 .847,38$ & $12.652 .847,38$ & $12.652 .847,38$ & $12.652 .847,38$ & $12.652 .847,38$ & $12.652 .847,38$ \\
\hline Depreciação (-) & - & - & - & - & - & - & - & - & - & - \\
\hline Lucro bruto (=) & $-40.591 .848,72$ & $40.591 .848,72$ & $40.591 .848,72$ & $40.591 .848,72$ & $-40.591 .848,72$ & $-40.591 .848,72$ & - $40.591 .848,72$ & - $40.591 .848,72$ & $-40.591 .848,72$ & $-40.591 .848,72$ \\
\hline Lucro líquido (=) & $-40.591 .848,72$ & $40.591 .848,72$ & $40.591 .848,72$ & $40.591 .848,72$ & - $40.591 .848,72$ & - $40.591 .848,72$ & - $40.591 .848,72$ & - $40.591 .848,72$ & - $40.591 .848,72$ & - $40.591 .848,72$ \\
\hline Depreciação (+) & - & - & - & - & - & - & - & - & - & - \\
\hline CAPEX (-) & - & - & - & - & - & - & - & - & - & - \\
\hline Fluxo de caixa (=) & - $40.591 .848,72$ & $-40.591 .848,72$ & - $40.591 .848,72$ & - $40.591 .848,72$ & - $40.591 .848,72$ & - $40.591 .848,72$ & - $40.591 .848,72$ & - $40.591 .848,72$ & - $40.591 .848,72$ & - $40.591 .848,72$ \\
\hline Fator de desconto & 0,388208114 & 0,360955941 & 0,335616867 & 0,312056594 & 0,29015025 & 0,26978173 & 0,250843077 & 0,233233917 & 0,216860917 & 0,201637301 \\
\hline Fluxo de caixa descontado ( $=$ ) & $15.758 .085,04$ & - $14.651 .868,94$ & $13.623 .309,10$ & $12.666 .954,07$ & $11.777 .735,07$ & $10.950 .939,16$ & $10.182 .184,25$ & $9.467 .395,87$ & $8.802 .785,56$ & $8.184 .830,83$ \\
\hline Fluxo de caixa acumulado descontado ( $=$ ) & $-292.228 .906,21$ & $-306.880 .775,15$ & $-320.504 .084,25$ & $-333.171 .038,32$ & $-344.948 .773,39$ & $-355.899 .712,56$ & $-366.081 .896,81$ & $-375.549 .292,67$ & $-384.352 .078,23$ & $-392.536 .909,06$ \\
\hline VPL (US\$) & & & & & & & & & & \\
\hline Recovery factor (CRF) & & & & & & & & & & \\
\hline \begin{tabular}{|l|} 
TAC (US\$) \\
CAPEX anualizado (US\$)
\end{tabular} & & & & & & & & & & \\
\hline
\end{tabular}


Figura 24 - Projeção de 10 anos da unidade de extração utilizando palmitato de metila como solvente. Premissas de preço de venda do óleo de microalga de US\$2,07/kg. Exibição dos 12 primeiros anos por espaço.

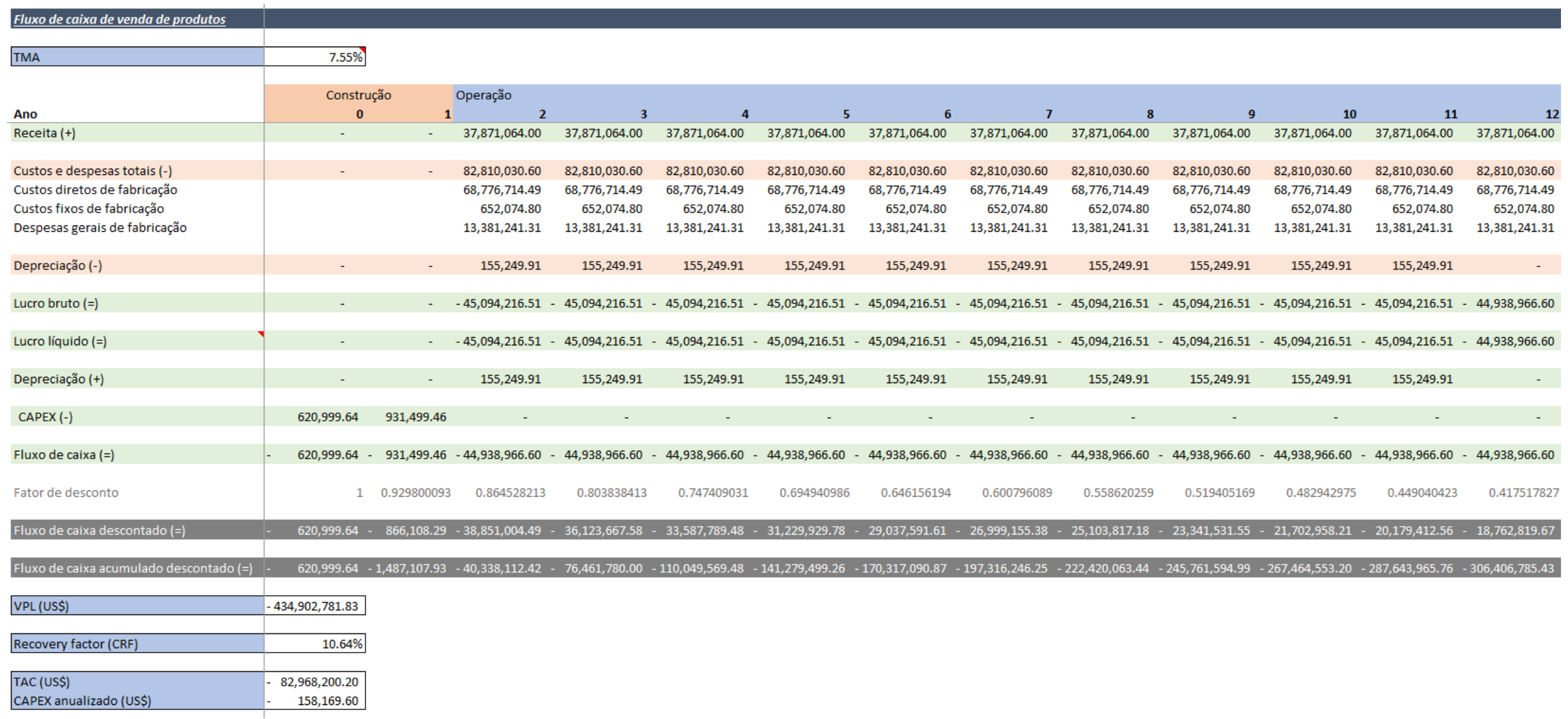


Figura 25 - Projeção de 10 anos restantes da unidade de extração utilizando palmitato de metila como solvente. Premissas de preço de venda do óleo de microalga de US $\$ 2,07 / \mathrm{kg}$.

\begin{tabular}{|c|c|c|c|c|c|c|c|c|c|c|}
\hline \multicolumn{11}{|l|}{ Fluxo de caixa de venda de produtos } \\
\hline \multicolumn{11}{|l|}{ TMA } \\
\hline Ano & 13 & \multirow{2}{*}{$\begin{array}{r}14 \\
37.871 .064,00\end{array}$} & 15 & 16 & 17 & 18 & 19 & 20 & 21 & \multirow{2}{*}{$\begin{array}{r}22 \\
37.871 .064,00\end{array}$} \\
\hline Receita (+) & $37.871 .064,00$ & & $37.871 .064,00$ & $37.871 .064,00$ & $37.871 .064,00$ & $37.871 .064,00$ & $37.871 .064,00$ & $37.871 .064,00$ & $37.871 .064,00$ & \\
\hline Custos e despesas totais (-) & $82.810 .030,60$ & $82.810 .030,60$ & $82.810 .030,60$ & $82.810 .030,60$ & $82.810 .030,60$ & $82.810 .030,60$ & $82.810 .030,60$ & $82.810 .030,60$ & $82.810 .030,60$ & $82.810 .030,60$ \\
\hline Custos diretos de fabricação & $68.776 .714,49$ & $68.776 .714,49$ & $68.776 .714,49$ & $68.776 .714,49$ & $68.776 .714,49$ & $68.776 .714,49$ & $68.776 .714,49$ & $68.776 .714,49$ & $68.776 .714,49$ & $68.776 .714,49$ \\
\hline Custos fixos de fabricação & $652.074,80$ & $652.074,80$ & $652.074,80$ & $652.074,80$ & $652.074,80$ & $652.074,80$ & $652.074,80$ & $652.074,80$ & $652.074,80$ & $652.074,80$ \\
\hline Despesas gerais de fabricação & $13.381 .241,31$ & $13.381 .241,31$ & 13.381.241,31 & $13.381 .241,31$ & $13.381 .241,31$ & $13.381 .241,31$ & $13.381 .241,31$ & $13.381 .241,31$ & $13.381 .241,31$ & $13.381 .241,31$ \\
\hline Depreciação (-) & - & - & - & - & - & - & - & - & - & - \\
\hline Lucro bruto (=) & $44.938 .966,60$ & - $44.938 .966,60$ & $44.938 .966,60$ & - $44.938 .966,60$ & - $44.938 .966,60$ & $44.938 .966,60$ & - $44.938 .966,60$ & - $44.938 .966,60$ & $44.938 .966,60$ & - $44.938 .966,60$ \\
\hline Lucro líquido ( $=)$ & $44.938 .966,60$ & - $44.938 .966,60$ & $44.938 .966,60$ & - $44.938 .966,60$ & $44.938 .966,60$ & $44.938 .966,60$ & - $44.938 .966,60$ & $44.938 .966,60$ & $44.938 .966,60$ & $44.938 .966,60$ \\
\hline Depreciação (+) & - & - & - & - & - & - & - & - & - & - \\
\hline CAPEX $(-)$ & - & - & - & - & - & - & - & - & - & - \\
\hline Fluxo de caixa (=) & - $44.938 .966,60$ & - $44.938 .966,60$ & $44.938 .966,60$ & - $44.938 .966,60$ & - $44.938 .966,60$ & $44.938 .966,60$ & - $44.938 .966,60$ & - 44.938.966,60 & $44.938 .966,60$ & - $44.938 .966,60$ \\
\hline Fator de desconto & 0,388208114 & 0,360955941 & 0,335616867 & 0,312056594 & 0,29015025 & 0,26978173 & 0,250843077 & 0,233233917 & 0,216860917 & 0,201637301 \\
\hline Fluxo de caixa descontado ( $=$ ) & $17.445 .671,48$ & - $16.220 .986,96$ & $15.082 .275,19$ & $14.023 .500,87$ & $13.039 .052,41$ & $12.123 .712,15$ & $11.272 .628,68$ & - $10.481 .291,19$ & $9.745 .505,53$ & $9.061 .371,95$ \\
\hline Fluxo de caixa acumulado descontado (=) & $-323.852 .456,91$ & $-340.073 .443,87$ & $355.155 .719,06$ & $-369.179 .219,93$ & $-382.218 .272,34$ & 394.341.984,48 & $-405.614 .613,16$ & $-416.095 .904,36$ & $425.841 .409,89$ & $-434.902 .781,83$ \\
\hline VPL (US\$) & & & & & & & & & & \\
\hline Recovery factor (CRF) & & & & & & & & & & \\
\hline $\begin{array}{l}\text { TAC (US\$) } \\
\text { CAPEX anualizado (US\$) }\end{array}$ & & & & & & & & & & \\
\hline
\end{tabular}




\subsection{SMILES dos compostos utilizados (TAGs e solventes)}

Tabela 29 - SMILES dos triacilgliceróis presentes no lipídio da microalga.

(continua)

\section{TAG}

\section{SMILES}

$\mathrm{DPaD} 4 \mathrm{ADPa} \quad \mathrm{O}=\mathrm{C}(\mathrm{CCC} / \mathrm{C}=\mathrm{C} \mid \mathrm{C} / \mathrm{C}=\mathrm{C} \backslash \mathrm{C} / \mathrm{C}=\mathrm{C} \backslash \mathrm{C} / \mathrm{C}=\mathrm{C} \backslash \mathrm{CCCCC}) \mathrm{OC}(\mathrm{COC}(=\mathrm{O}) \mathrm{CCCCCCC} \backslash \mathrm{C}=\mathrm{C} \backslash \mathrm{CCCCCC}) \mathrm{COC}(=\mathrm{O}) \mathrm{CCCCCCC} \backslash \mathrm{C}=\mathrm{C} \backslash \mathrm{CCCCCC}$

$\mathrm{PamD} 4 \mathrm{ADPa} \quad \mathrm{O}=\mathrm{C}(\mathrm{CCC} / \mathrm{C}=\mathrm{C} \backslash \mathrm{C} / \mathrm{C}=\mathrm{C} \mid \mathrm{C} / \mathrm{C}=\mathrm{C} \backslash \mathrm{C} / \mathrm{C}=\mathrm{C} \backslash \mathrm{CCCCC}) \mathrm{OC}(\mathrm{COC}(=\mathrm{O}) \mathrm{CCCCCCC}|\mathrm{C}=\mathrm{C}| \mathrm{CCCCCC}) \operatorname{COC}(=\mathrm{O}) \mathrm{CCCCCCCCCCCCCCC}$

$\mathrm{PamD} 4 \mathrm{APam} \quad \mathrm{O}=\mathrm{C}(\mathrm{CCC} / \mathrm{C}=\mathrm{C}|\mathrm{C} / \mathrm{C}=\mathrm{C}| \mathrm{C} / \mathrm{C}=\mathrm{C}|\mathrm{C} / \mathrm{C}=\mathrm{C}| \mathrm{CCCCC}) \mathrm{OC}(\mathrm{COC}(=\mathrm{O}) \mathrm{CCCCCCCCCCCCCCC}) \operatorname{COC}(=\mathrm{O}) \mathrm{CCCCCCCCCCCCCCC}$

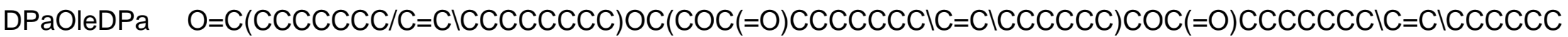

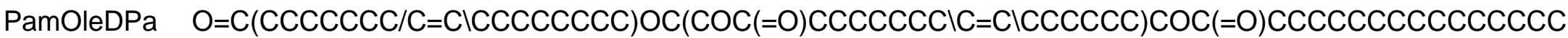

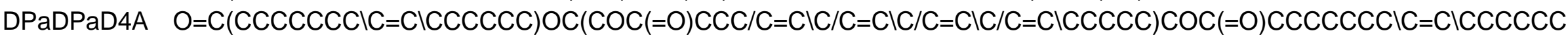

PamDPaD4A $\mathrm{O}=\mathrm{C}(\mathrm{CCCCCCC} \backslash \mathrm{C}=\mathrm{C} \backslash \mathrm{CCCCCC}) \mathrm{OC}(\mathrm{COC}(=\mathrm{O}) \mathrm{CCC} / \mathrm{C}=\mathrm{C} \backslash \mathrm{C} / \mathrm{C}=\mathrm{C} \backslash \mathrm{C} / \mathrm{C}=\mathrm{C} \backslash \mathrm{C} / \mathrm{C}=\mathrm{C} \backslash \mathrm{CCCCC}) \operatorname{COC}(=\mathrm{O}) \mathrm{CCCCCCCCCCCCCCC}$

MyrPamPam $\mathrm{O}=\mathrm{C}(\operatorname{CcccccccccccCCC}) \mathrm{OC}(\operatorname{COC}(=\mathrm{O}) \operatorname{ccccccccccccccC}) \operatorname{COC}(=\mathrm{O}) \operatorname{CcCCCCCCCCCCC}$

PamDPaOle $\mathrm{O}=\mathrm{C}(\mathrm{CcccccC} \backslash \mathrm{C}=\mathrm{C} \backslash \mathrm{CCCCCC}) \mathrm{OC}(\mathrm{COC}(=\mathrm{O}) \mathrm{CCCCCCC} / \mathrm{C}=\mathrm{C} \backslash \mathrm{CCCCCCCC}) \mathrm{COC}(=\mathrm{O}) \mathrm{CcCCCCCCCCCCCCC}$

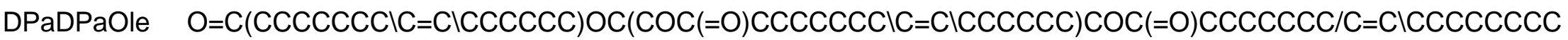

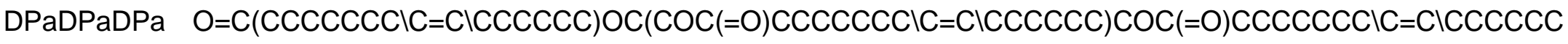

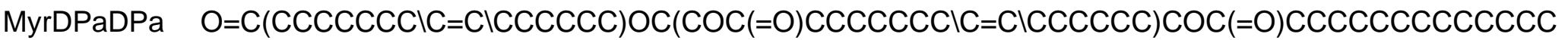

$\mathrm{PamDPaDPa} \quad \mathrm{O}=\mathrm{C}(\mathrm{CCCCCCC} \backslash \mathrm{C}=\mathrm{C} \backslash \mathrm{CCCCCC}) \mathrm{OC}(\mathrm{COC}(=\mathrm{O}) \operatorname{CCCCCCC} \backslash \mathrm{C}=\mathrm{C} \backslash \mathrm{CCCCCC}) \mathrm{COC}(=\mathrm{O}) \operatorname{CCCCCCCCCCCCCCC}$

SteDPaDPa O=C(CCCCCCC $\backslash \mathrm{C}=\mathrm{C} \backslash$ CCCCCC $) \mathrm{OC}(\operatorname{COC}(=\mathrm{O}) \operatorname{CCCCCCC} \backslash \mathrm{C}=\mathrm{C} \backslash \mathrm{CCCCCC}) \mathrm{COC}(=\mathrm{O}) \mathrm{CCCCCCCCCCCCCCCCC}$

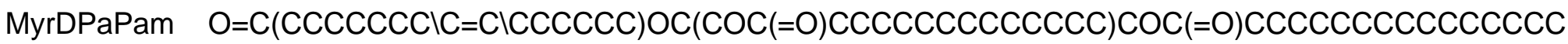

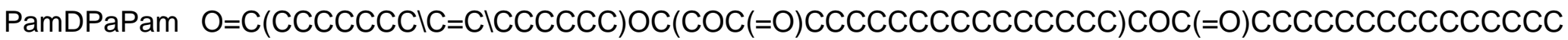

PamDPaSte $\mathrm{O}=\mathrm{C}(\operatorname{CCCCCCC} \mid \mathrm{C}=\mathrm{C} \backslash \mathrm{CCCCCC}) \mathrm{OC}(\mathrm{COC}(=\mathrm{O}) \operatorname{CcCCCCCCCCCCCCCCC}) \operatorname{COC}(=\mathrm{O}) \operatorname{CcCCCCCCCCCCCCC}$

DPaMyrDPa $\mathrm{O}=\mathrm{C}(\operatorname{CccccccccccCC}) \mathrm{OC}(\operatorname{COC}(=\mathrm{O}) \operatorname{CcCCCCC} \backslash \mathrm{C}=\mathrm{C} \backslash \mathrm{CCCCCC}) \operatorname{COC}(=\mathrm{O}) \mathrm{CCCCCCC} \backslash \mathrm{C}=\mathrm{C} \backslash \mathrm{CCCCCC}$

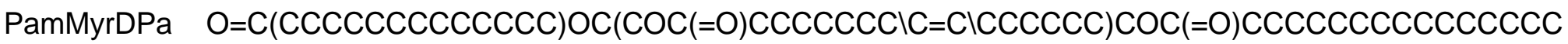


(conclusão)

\section{TAG}

SMILES

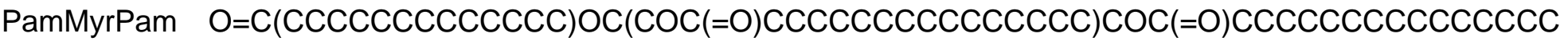

$\mathrm{DPaPamD} 4 \mathrm{~A} \quad \mathrm{O}=\mathrm{C}(\mathrm{CcCcccccccccccC}) \mathrm{OC}(\mathrm{COC}(=\mathrm{O}) \mathrm{CCC} / \mathrm{C}=\mathrm{C} \mid \mathrm{C} / \mathrm{C}=\mathrm{ClC} / \mathrm{C}=\mathrm{ClC} / \mathrm{C}=\mathrm{ClCCCCC}) \mathrm{COC}(=\mathrm{O}) \mathrm{CcccccC}|\mathrm{C}=\mathrm{C}| \mathrm{Cccccc}$

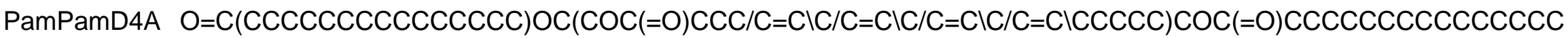

DPaPamOle $\mathrm{O}=\mathrm{C}(\mathrm{CCCCCCCCCCCCCCC}) \mathrm{OC}(\mathrm{COC}(=\mathrm{O}) \mathrm{CCCCCCC} / \mathrm{C}=\mathrm{C} \backslash \mathrm{CCCCCCCC}) \mathrm{COC}(=\mathrm{O}) \mathrm{CCCCCCC}|\mathrm{C}=\mathrm{C}| \mathrm{CCCCCC}$

PamPamOle $\mathrm{O}=\mathrm{C}(\mathrm{CCCCCCCCCCCCCCC}) \mathrm{OC}(\mathrm{COC}(=\mathrm{O}) \mathrm{CCCCCCC} / \mathrm{C}=\mathrm{ClCCCCCCCC}) \mathrm{COC}(=\mathrm{O}) \mathrm{CCCCCCCCCCCCCCC}$

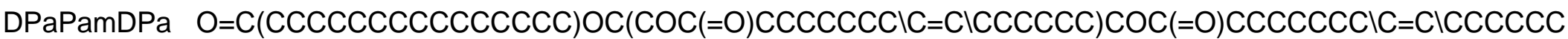

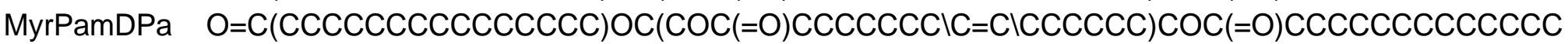

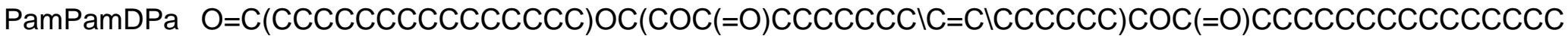

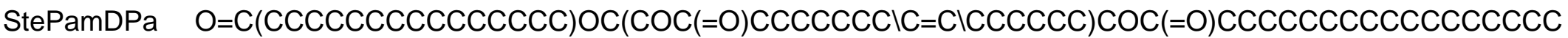

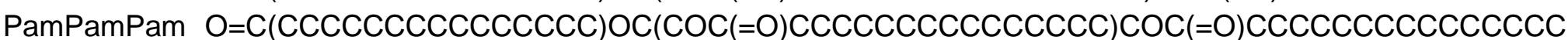

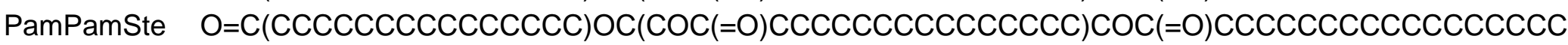

PamSteDPa $\mathrm{O}=\mathrm{C}(\mathrm{CCCCCCCCCCCCCCCCC}) \mathrm{OC}(\mathrm{COC}(=)) \mathrm{CCCCCCCIC}=\mathrm{ClCCCCCC}) \mathrm{COC}(=\mathrm{O}) \mathrm{CCCCCCCCCCCCCCC}$

Fonte: Próprio autor. 
Tabela 30 - SMILES dos solventes selecionados para estudo.

(continua)

\begin{tabular}{|c|c|}
\hline Solvente & Smiles \\
\hline p-cymene & $\operatorname{c1cc}(\operatorname{ccc} 1 \mathrm{C}(\mathrm{C}) \mathrm{C}) \mathrm{C}$ \\
\hline 1,3-Dioxan-5-ol & $\mathrm{C} 1 \mathrm{C}(\mathrm{COCO} 1) \mathrm{O}$ \\
\hline 1,3-Dioxolane & O1CCOC1 \\
\hline 1,3-Dioxolane-4-methanol & $\mathrm{C} 1 \mathrm{C}(\mathrm{OCO} 1) \mathrm{CO}$ \\
\hline 1,3-Propanediol & OCCCO \\
\hline 1,4-Cineol & $\mathrm{CC}(\mathrm{C}) \mathrm{C} 12 \mathrm{CCC}(\mathrm{O} 1)(\mathrm{CC} 2) \mathrm{C}$ \\
\hline 1,8-Cineol & $\mathrm{O} 2 \mathrm{C} 1(\mathrm{CCC}(\mathrm{CC} 1) \mathrm{C} 2(\mathrm{C}) \mathrm{C}) \mathrm{C}$ \\
\hline 1-Butanol & CCCCO \\
\hline 1-Decanol & occccccecce \\
\hline 1-Octanol & cccccccco \\
\hline 2-Furfuraldehyde & $\operatorname{c1cc}(\mathrm{oc} 1) \mathrm{C}=\mathrm{O}$ \\
\hline 2-Methyltetrahydrofuran & $\mathrm{O} 1 \mathrm{C}(\mathrm{C}) \mathrm{CCC} 1$ \\
\hline 2-Pyrrolidone & $\mathrm{O}=\mathrm{C} 1 \mathrm{NCCC} 1$ \\
\hline 3-Butyl-1-methylimidazolium & $\operatorname{CCCCN} 1 \mathrm{C}=\mathrm{C}[\mathrm{N}+](=\mathrm{C} 1) \mathrm{C}$ \\
\hline 3-Hydroxypropionic acid & $\mathrm{C}(\mathrm{CO}) \mathrm{C}(=\mathrm{O}) \mathrm{O}$ \\
\hline 3-Methoxy-3-methyl-1-butanol & $\mathrm{CC}(\mathrm{C})(\mathrm{CCO}) \mathrm{OC}$ \\
\hline 5-(Hydroxymethyl)furfural & $\mathrm{C} 1=\mathrm{C}(\mathrm{OC}(=\mathrm{C} 1) \mathrm{C}=\mathrm{O}) \mathrm{CO}$ \\
\hline Acetic acid & $\mathrm{CC}(\mathrm{O})=\mathrm{O}$ \\
\hline Acetone & $\mathrm{CC}(=\mathrm{O}) \mathrm{C}$ \\
\hline Benzyl alcohol & $\mathrm{c} 1 \mathrm{ccc}(\mathrm{cc} 1) \mathrm{CO}$ \\
\hline Benzyl benzoate & $\mathrm{O}=\mathrm{C}(\mathrm{OCc} 1 \mathrm{ccccc} 1) \mathrm{c} 2 \mathrm{ccccc} 2$ \\
\hline Butanone & $\operatorname{ccC}(=0) \mathrm{C}$ \\
\hline Butyl acetate & $\operatorname{ccccoc}(=0) \mathrm{C}$ \\
\hline Butyl laurate & $\operatorname{cccccccccccc}(=0) \mathrm{Occcc}$ \\
\hline Butyl myristate & $\operatorname{cccccccccccccc}(=0)$ Occcc \\
\hline Butyl palmitate & $\operatorname{cccccccccccccccc}(=0)$ Occcc \\
\hline Butyl stearate & $\operatorname{cccccccccccccccccc}(=0) \mathrm{Occcc}$ \\
\hline Caprylic acid diethanolamide & $\operatorname{Cccccccc}(=0) \mathrm{N}(\mathrm{CCO}) \mathrm{CcO}$ \\
\hline Cyclohexane & C1CCCCC1 \\
\hline Cyclopentyl methyl ether & $\operatorname{coc} 1 \mathrm{CCCC} 1$ \\
\hline Decamethylcyclopentasiloxane & $\mathrm{C}[\mathrm{Si}] 1(\mathrm{O}[\mathrm{Si}](\mathrm{O}[\mathrm{Si}](\mathrm{O}[\mathrm{Si}](\mathrm{O}[\mathrm{Si}](\mathrm{O} 1)(\mathrm{C}) \mathrm{C})(\mathrm{C}) \mathrm{C})(\mathrm{C}) \mathrm{C})(\mathrm{C}) \mathrm{C}) \mathrm{C}$ \\
\hline Dibutyl sebacate & $\operatorname{ccccoc}(=0) \operatorname{cccccccc}(=0) 0 \operatorname{Occc}$ \\
\hline Dihydromyrcenol (2 tipos) & $\operatorname{cc}(\operatorname{Cccc}(C)(C) O) C=C$ \\
\hline Diisoamyl succinate & $\operatorname{cc}(\mathrm{C}) \operatorname{ccoc}(=0) \operatorname{ccc}(=0) \operatorname{Occc}(\mathrm{C}) \mathrm{C}$ \\
\hline Diisobutyl glutarate & $\operatorname{cc}(\mathrm{C}) \operatorname{coc}(=0) \operatorname{Cccc}(=0) \operatorname{Occ}(\mathrm{C}) \mathrm{C}$ \\
\hline Diisooctyl succinate & $\operatorname{cc}(\mathrm{C}) \operatorname{cccccoc}(=0) \operatorname{ccc}(=0) O \operatorname{ccccc}(\mathrm{C}) \mathrm{C}$ \\
\hline Dimethyl 2-methyl glutarate & $\operatorname{cc}(\operatorname{CcC}(=0) O C) C(=0) O C$ \\
\hline Dimethyl glutarate & $\operatorname{coc}(=0) \operatorname{cccc}(=0) O C$ \\
\hline Dimethyl isosorbide & COC1COC2C1OCC2OC \\
\hline Dioctyl succinate (2 tipos) & $\operatorname{ccccccccoc}(=0) \operatorname{ccc}(=0)$ occcccccc \\
\hline D-Limonene & $\mathrm{CC} 1=\mathrm{CCC}(\mathrm{CC} 1) \mathrm{C}(=\mathrm{C}) \mathrm{C}$ \\
\hline Ethanol & $\mathrm{CCO}$ \\
\hline Ethyl acetate & $\operatorname{ccoc}(=0) C$ \\
\hline Ethyl ether & CCOCC \\
\hline
\end{tabular}


(continua)

\begin{tabular}{|c|c|}
\hline Solvente & Smiles \\
\hline Ethyl lactate & $\operatorname{ccoc}(=0) \mathrm{C}(\mathrm{C}) \mathrm{O}$ \\
\hline Ethyl laurate & $\operatorname{cccccccccccc}(=0) \mathrm{OCC}$ \\
\hline Ethyl linoleate & $\operatorname{CccccC}=\mathrm{CCC}=\mathrm{CCCC \operatorname {ccc }}(=\mathrm{O}) \mathrm{OCC}$ \\
\hline Ethyl linolenate & $\mathrm{CCC}=\mathrm{CCC}=\mathrm{CCC}=\mathrm{CCCCCCCCC}(=\mathrm{O}) \mathrm{OCC}$ \\
\hline Ethyl myristate & $\operatorname{cccccccccccccc}(=0) O c c$ \\
\hline Ethyl oleate & $\operatorname{cccccccc}=\operatorname{cccccccc}(=0) O C C$ \\
\hline Ethyl palmitate & $\operatorname{cccccccccccccccc}(=0) O c c$ \\
\hline Ethylene dichloride & $\mathrm{CICCCl}$ \\
\hline Ethylene glycol & $\mathrm{C}(\mathrm{CO}) \mathrm{O}$ \\
\hline Furfuryl alcohol & $\mathrm{C} 1=\mathrm{COC}(=\mathrm{C} 1) \mathrm{CO}$ \\
\hline Geraniol & $\operatorname{cC}(=\operatorname{CccC}(=\operatorname{CcO}) \mathrm{C}) \mathrm{C}$ \\
\hline Geranyl acetate & $\operatorname{CC}(=\operatorname{Cccc}(=\operatorname{ccoc}(=0) C) C) C$ \\
\hline Glycerol & $\mathrm{C}(\mathrm{C}(\mathrm{CO}) \mathrm{O}) \mathrm{O}$ \\
\hline Glycerol carbonate & $\mathrm{C} 1 \mathrm{C}(\mathrm{OC}(=\mathrm{O}) \mathrm{O} 1) \mathrm{CO}$ \\
\hline Glycerol triacetate & $\operatorname{cC}(=0) O C C(\operatorname{coc}(=0) C) O C(=O) C$ \\
\hline Glycerol-1,2,3-tributyl ether & ccccocc(COCcCC)Occcc \\
\hline Glycerol-1,2,3-triethyl ether & $\operatorname{ccocc}(\operatorname{COCC}) \mathrm{OCC}$ \\
\hline Glycerol-1,2,3-trimethyl ether & $\operatorname{cocc}(\mathrm{COC}) \mathrm{OC}$ \\
\hline Glycerol-1,2-dimethyl ether & $\operatorname{cocc}(\mathrm{CO}) \mathrm{OC}$ \\
\hline Glycerol-1,3-diethyl ether & $\operatorname{ccocc}(\operatorname{cocc}) \mathrm{O}$ \\
\hline Glycerol-1,3-dimethyl ether & $\operatorname{cocc}(\mathrm{COC}) \mathrm{O}$ \\
\hline Hexane & $\operatorname{CCCCCC}$ \\
\hline Isoamyl acetate & $\operatorname{cc}(\mathrm{C}) \operatorname{ccoc}(=\mathrm{O}) \mathrm{C}$ \\
\hline Isoamyl alcohol & $\mathrm{CC}(\mathrm{C}) \mathrm{CCO}$ \\
\hline Isobutyl acetate & $\operatorname{cc}(\mathrm{C}) \mathrm{COC}(=\mathrm{O}) \mathrm{C}$ \\
\hline Isobutyl alcohol & $\mathrm{CC}(\mathrm{C}) \mathrm{CO}$ \\
\hline Isodecane & $\operatorname{cc}(\mathrm{C}) \operatorname{cccccccoc}(\mathrm{Occccccc}(\mathrm{C}) \mathrm{C}) \mathrm{OCcccccc}(\mathrm{C}) \mathrm{C}$ \\
\hline Isopropyl acetate & $\operatorname{CC}(\mathrm{C}) \operatorname{CC}(=\mathrm{O})[\mathrm{O}-]$ \\
\hline Isopropyl alcohol & $\mathrm{CC}(\mathrm{O}) \mathrm{C}$ \\
\hline Isopropyl palmitate & $\operatorname{ccccccccccccccc}(=0) O C(C) C$ \\
\hline Methanol & $\mathrm{CO}$ \\
\hline Methyl abietate & $\mathrm{CC}(\mathrm{C}) \mathrm{C} 1=\mathrm{CC} 2=\mathrm{CCC} 3 \mathrm{C}(\mathrm{C} 2 \mathrm{CC} 1)(\mathrm{CCCC} 3(\mathrm{C}) \mathrm{C}(=\mathrm{O}) \mathrm{OC}) \mathrm{C}$ \\
\hline Methyl acetate & $\mathrm{O}=\mathrm{C}(\mathrm{OC}) \mathrm{C}$ \\
\hline Methyl laurate & $\operatorname{cccccccccccc}(=0) O C$ \\
\hline Methyl linoleate & $\operatorname{CccccC}=\mathrm{CCC}=\mathrm{CCCCCCCCC}(=\mathrm{O}) \mathrm{OC}$ \\
\hline Methyl linolenate & $C C C=C C C=C C C=C \operatorname{ccccccc}(=0) O C$ \\
\hline Methyl myristate & $\operatorname{cccccccccccccc}(=0) O C$ \\
\hline Methyl oleate & $\operatorname{ccccccccc}=\operatorname{ccccccccc}(=0) O C$ \\
\hline Methyl palmitate & $\operatorname{ccccccccccccccc}(=0) O C$ \\
\hline Methyl ricinoleate & $\operatorname{ccccccc}(\operatorname{cc}=\operatorname{cccccccc}(=0) O C) O$ \\
\hline Methyl stearate & $\operatorname{cccccccccccccccccc}(=0) O C$ \\
\hline N,N-Diethylolcapramide & $\operatorname{cccccccccc}(=0) \mathrm{N}(\mathrm{CCO}) \mathrm{CcO}$ \\
\hline N,N-Dimethyldecanamide & $\operatorname{cccccccccc}(=O) N(C) C$ \\
\hline N,N-Dimethyloctanamide & $\operatorname{cccccccc}(=0) N(C) C$ \\
\hline Nopol & $\mathrm{CC} 1(\mathrm{C} 2 \mathrm{CC}=\mathrm{C}(\mathrm{C} 1 \mathrm{C} 2) \mathrm{CCO}) \mathrm{C}$ \\
\hline n-Propyl acetate & $\operatorname{cccoc}(=0) \mathrm{C}$ \\
\hline Oleic acid & $\operatorname{cccccccc} \mathrm{C}=\operatorname{cccccccc}(=0) \mathrm{O}$ \\
\hline
\end{tabular}


(conclusão)

\begin{tabular}{|c|c|}
\hline Solvente & Smiles \\
\hline Oleyl alcohol & $\operatorname{CCCCCCCCC~}=\operatorname{Ccccccccco}$ \\
\hline p-Cymene & $\mathrm{CC} 1=\mathrm{CC}=\mathrm{C}(\mathrm{C}=\mathrm{C} 1) \mathrm{C}(\mathrm{C}) \mathrm{C}$ \\
\hline Perfluoroctane & $\mathrm{C}(\mathrm{C}(\mathrm{C}(\mathrm{C}(\mathrm{C}(\mathrm{F})(\mathrm{F}) \mathrm{F})(\mathrm{F}) \mathrm{F})(\mathrm{F}) \mathrm{F})(\mathrm{F}) \mathrm{F})(\mathrm{C}(\mathrm{C}(\mathrm{C}(\mathrm{F})(\mathrm{F}) \mathrm{F})(\mathrm{F}) \mathrm{F})(\mathrm{F}) \mathrm{F})(\mathrm{F}) \mathrm{F}$ \\
\hline Propionic acid & $\operatorname{CCC}(=0) O$ \\
\hline Propylene carbonate & $\operatorname{CC} 1 \mathrm{COC}(=0) \mathrm{O} 1$ \\
\hline Propylene glycol & $\mathrm{CC}(\mathrm{CO}) \mathrm{O}$ \\
\hline Ricinoleic acid & $\operatorname{ccccccc}(\operatorname{CC}=\operatorname{ccccccccc}(=0) 0) 0$ \\
\hline Solketal & $\operatorname{CC1}(\mathrm{OCC}(\mathrm{O} 1) \mathrm{CO}) \mathrm{C}$ \\
\hline Terpinolene & $\mathrm{CC} 1=\mathrm{CCC}(=\mathrm{C}(\mathrm{C}) \mathrm{C}) \mathrm{CC} 1$ \\
\hline Tetrachloromethane & $\mathrm{C}(\mathrm{Cl})(\mathrm{Cl})(\mathrm{Cl}) \mathrm{Cl}$ \\
\hline Tetrahydrofurfuryl(ic) alcohol & $\mathrm{C} 1 \mathrm{CC}(\mathrm{OC} 1) \mathrm{CO}$ \\
\hline Tributyl citrate & $\operatorname{ccccoc}(=0) \operatorname{cc}(\operatorname{Cc}(=0) \operatorname{Occcc})(\mathrm{C}(=\mathrm{O}) \mathrm{OCCCC}) \mathrm{O}$ \\
\hline Trichloroethylene & $\mathrm{ClC}=\mathrm{C}(\mathrm{Cl}) \mathrm{Cl}$ \\
\hline Triethyl citrate & $\operatorname{ccoc}(=0) \operatorname{cc}(\mathrm{CC}(=0) \mathrm{OCC})(\mathrm{C}(=\mathrm{O}) \mathrm{OCC}) \mathrm{O}$ \\
\hline Ît-Pinene & $\mathrm{CC} 1=\mathrm{CCC} 2 \mathrm{CC} 1 \mathrm{C} 2(\mathrm{C}) \mathrm{C}$ \\
\hline Ît-Terpineol & $\mathrm{CC} 1=\mathrm{CCC}(\mathrm{CC} 1) \mathrm{C}(\mathrm{C})(\mathrm{C}) \mathrm{O}$ \\
\hline$\hat{\mid}^{2}$-Farnesene & $\operatorname{CC}(=\operatorname{CcCC}(=\operatorname{CcCC}(=C) C=C) C) C$ \\
\hline$\hat{\mid}^{2}$-Myrcene & $\operatorname{CC}(=\operatorname{CcCC}(=C) \mathrm{C}=\mathrm{C}) \mathrm{C}$ \\
\hline$\hat{\mid}^{2}$-Pinene & $\operatorname{CC} 1(\mathrm{C} 2 \mathrm{CCC}(=\mathrm{C}) \mathrm{C} 1 \mathrm{C} 2) \mathrm{C}$ \\
\hline î2-Terpineol & $\mathrm{CC}(=\mathrm{C}) \mathrm{C} 1 \mathrm{CCC}(\mathrm{CC} 1)(\mathrm{C}) \mathrm{O}$ \\
\hline
\end{tabular}

Fonte: Próprio autor 


\subsection{Tabela com propriedades dos compostos utilizados (TAGs e solventes).}

Tabela 31 - Propriedades dos triacilgliceróis estimadas pelo software IBSS $\AA$.

\begin{tabular}{|c|c|c|c|c|c|c|c|}
\hline TAG code & $\begin{array}{r}\text { Molar } \\
\text { Fraction } \\
\end{array}$ & $\begin{array}{r}\text { Mass } \\
\text { Fraction } \\
\end{array}$ & $\begin{array}{r}\text { Molecular Weight } \\
{[\mathrm{g} / \mathrm{mol}]}\end{array}$ & $\begin{array}{r}\text { HSP_d } \\
\text { MB2010 }\end{array}$ & $\begin{array}{r}\text { HSP_p } \\
\text { MB2010 }\end{array}$ & $\begin{array}{r}\text { HSP h } \\
\text { MB2010 }\end{array}$ & $\begin{array}{r}\text { Density } \\
\text { MB2010 } \\
\end{array}$ \\
\hline PamDPaDPa & 0.1808 & 0.1791 & 803.31 & 16.3 & 3.4 & 3.4 & 0.919 \\
\hline PamPamDPa & 0.1578 & 0.1567 & 805.32 & 16.4 & 3.1 & 4.2 & 0.915 \\
\hline DPaDPaDPa & 0.1035 & 0.1023 & 801.29 & 16.3 & 3.6 & 2.6 & 0.923 \\
\hline DPaPamDPa & 0.0904 & 0.0895 & 803.31 & 16.3 & 3.4 & 3.4 & 0.919 \\
\hline PamDPaPam & 0.0789 & 0.0784 & 805.32 & 16.4 & 3.1 & 4.2 & 0.915 \\
\hline PamPamPam & 0.0689 & 0.0686 & 807.34 & 16.6 & 2.7 & 4.9 & 0.911 \\
\hline DPaDPaD4A & 0.0226 & 0.0237 & 851.35 & 16.2 & 3.9 & 0.9 & 0.930 \\
\hline DPaPamD4A & 0.0197 & 0.0207 & 853.37 & 16.1 & 4.0 & 1.6 & 0.926 \\
\hline PamD4ADPa & 0.0197 & 0.0207 & 853.37 & 16.1 & 4.0 & 1.6 & 0.926 \\
\hline PamDPaD4A & 0.0197 & 0.0207 & 853.37 & 16.1 & 4.0 & 1.6 & 0.926 \\
\hline PamPamD4A & 0.0172 & 0.0181 & 855.38 & 16.1 & 4.0 & 2.4 & 0.922 \\
\hline MyrDPaDPa & 0.0163 & 0.0156 & 775.25 & 16.3 & 3.4 & 4.6 & 0.922 \\
\hline DPaDPaOle & 0.0134 & 0.0137 & 829.35 & 16.2 & 3.7 & 2.8 & 0.920 \\
\hline MyrDPaPam & 0.0143 & 0.0137 & 777.27 & 16.5 & 3.1 & 5.2 & 0.917 \\
\hline MyrPamDPa & 0.0143 & 0.0137 & 777.27 & 16.5 & 3.1 & 5.2 & 0.917 \\
\hline PamMyrDPa & 0.0143 & 0.0137 & 777.27 & 16.5 & 3.1 & 5.2 & 0.917 \\
\hline DPaPamOle & 0.0117 & 0.012 & 831.36 & 16.3 & 3.5 & 3.6 & 0.916 \\
\hline MyrPamPam & 0.0125 & 0.012 & 779.29 & 16.7 & 2.7 & 5.7 & 0.913 \\
\hline PamDPaOle & 0.0117 & 0.012 & 831.36 & 16.3 & 3.5 & 3.6 & 0.916 \\
\hline PamOleDPa & 0.0117 & 0.012 & 831.36 & 16.3 & 3.5 & 3.6 & 0.916 \\
\hline
\end{tabular}




\begin{tabular}{|c|c|c|c|c|c|c|c|}
\hline DPaD4ADPa & 0.0113 & 0.0118 & 851.35 & 16.2 & 3.9 & 0.9 & 0.930 \\
\hline SteDPaDPa & 0.0114 & 0.0116 & 831.36 & 16.3 & 3.3 & 4.7 & 0.917 \\
\hline PamPamOle & 0.0102 & 0.0105 & 833.38 & 16.4 & 3.1 & 4.3 & 0.913 \\
\hline PamDPaSte & 0.0099 & 0.0102 & 833.38 & 16.5 & 3.0 & 5.2 & 0.913 \\
\hline PamSteDPa & 0.0099 & 0.0102 & 833.38 & 16.5 & 3.0 & 5.2 & 0.913 \\
\hline StePamDPa & 0.0099 & 0.0102 & 833.38 & 16.5 & 3.0 & 5.2 & 0.913 \\
\hline PamD4APam & 0.0086 & 0.0091 & 855.38 & 16.1 & 4.0 & 2.4 & 0.922 \\
\hline PamPamSte & 0.0087 & 0.0089 & 835.39 & 16.7 & 2.5 & 5.7 & 0.909 \\
\hline DPaMyrDPa & 0.0082 & 0.0078 & 775.25 & 16.3 & 3.4 & 4.6 & 0.922 \\
\hline DPaOleDPa & 0.0067 & 0.0068 & 829.35 & 16.2 & 3.7 & 2.8 & 0.920 \\
\hline PamMyrPam & 0.0062 & 0.006 & 779.29 & 16.7 & 2.7 & 5.7 & 0.913 \\
\hline
\end{tabular}

Fonte: Próprio autor. 
Tabela 32 - Propriedades dos solventes estimadas pelo software IBSS $\AA_{\text {. }}$

\begin{tabular}{|c|c|c|c|c|}
\hline ID & Solvente & $\begin{array}{r}\log (W s) \text { MG2002 [mg.L- } \\
1]\end{array}$ & $\begin{array}{l}\text { Density } \\
\text { MB2010 }\end{array}$ & $\begin{array}{r}\text { Enthalpy of vaporization at 298K HSKASG2012 } \\
\text { [kJ.mol-1] }\end{array}$ \\
\hline 1 & p-cymene & 1.83818 & 0.863719434 & 49.2203 \\
\hline 2 & 1,3-Dioxan-5-ol & 5.027235 & 1.178992072 & 67.4367 \\
\hline 3 & 1,3-Dioxolane & 4.756315 & 1.01617284 & 34.6439 \\
\hline 4 & 1,3-Dioxolane-4-methanol & 4.721925 & 1.176327684 & 64.3336 \\
\hline 5 & 1,3-Propanediol & 5.212735 & 1.045260989 & 72.7779 \\
\hline 6 & 1,4-Cineol & 3.008265 & 0.927001202 & 48.7021 \\
\hline 7 & 1,8-Cineol & 3.488335 & 0.924778177 & 49.8125 \\
\hline 8 & 1-Butanol & 4.310495 & 0.799600863 & 50.4215 \\
\hline 9 & 1-Decanol & 2.037785 & 0.826985371 & 79.2299 \\
\hline 10 & 1-Octanol & 2.795355 & 0.821128625 & 69.6271 \\
\hline 11 & 2-Furfuraldehyde & -9999.9999 & 1.136920375 & -9999.9999 \\
\hline 12 & 2-Methyltetrahydrofuran & 4.01727 & 0.86134 & 34.8289 \\
\hline 13 & 2-Pyrrolidone & 4.29628 & 1.086922095 & 55.8649 \\
\hline 14 & 3-Butyl-1-methylimidazolium & -9999.9999 & 0.83416417 & -9999.9999 \\
\hline 15 & 3-Hydroxypropionic acid & 5.34812 & 1.227220708 & 59.1419 \\
\hline 16 & 3-Methoxy-3-methyl-1-butanol & 4.5689 & 0.901418764 & 59.6076 \\
\hline 17 & 5-(Hydroxymethyl)furfural & 5.308575 & 1.249861249 & 70.4682 \\
\hline 18 & Acetic acid & 5.20345 & 1.017830508 & 27.1827 \\
\hline 19 & Acetone & 4.6844 & 0.794528044 & 24.8965 \\
\hline 20 & Benzyl alcohol & 4.37957 & 1.044830918 & 63.8855 \\
\hline 21 & Benzyl benzoate & 1.97484 & 1.123005291 & 83.4216 \\
\hline 22 & Butanone & 4.731115 & 0.802973274 & 31.7659 \\
\hline 23 & Butyl acetate & 3.60184 & 0.873383459 & 46.6159 \\
\hline 24 & Butyl laurate & -0.05186 & 0.858199465 & 92.29 \\
\hline
\end{tabular}


25 Butyl myristate

26 Butyl palmitate

27 Butyl stearate

28 Caprylic acid diethanolamide

29 Cyclohexane

30 Cyclopentyl methyl ether

31 Decamethylcyclopentasiloxane

32 Dibutyl sebacate

33 Dihydromyrcenol (2 tipos)

34 Diisoamyl succinate

35 Diisobutyl glutarate

36 Diisooctyl succinate

37 Dimethyl 2-methyl glutarate

38 Dimethyl glutarate

39 Dimethyl isosorbide

40 Dioctyl succinate (2 tipos)

41 D-Limonene

42 Ethanol

43 Ethyl acetate

44 Ethyl ether

45 Ethyl lactate

46 Ethyl laurate

47 Ethyl linoleate

48 Ethyl linolenate

49 Ethyl myristate

50 Ethyl oleate

51 Ethyl palmitate

52 Ethylene dichloride

$\begin{array}{rr}-0.80943 & 0.857654507 \\ -1.567 & 0.856972854 \\ -2.32457 & 0.85683522 \\ 3.94185 & 1.029074733 \\ 4.04105 & 0.785826331 \\ 4.512185 & 0.856809239 \\ -9999.9999 & 0.939371675 \\ -0.10291 & 0.931751111 \\ 3.514705 & 0.842420485 \\ 1.25862 & 0.947754952 \\ 1.839655 & 0.952186282 \\ -1.01409 & 0.920752688 \\ 3.86286 & 1.025889282 \\ 4.063725 & 1.044126467 \\ 4.81638 & 1.0962618 \\ -1.06273 & 0.924979746 \\ 2.98829 & 0.843056931 \\ 5.068065 & 0.784821124 \\ 4.35941 & 0.889959596 \\ 4.565965 & 0.733891089 \\ 2.59604 & 1.034430823 \\ 0.70571 & 0.86244713 \\ -1.5773 & 0.878433941 \\ -1.58245 & 0.890441604 \\ -0.05186 & 0.861659946 \\ -1.57215 & 0.868107353 \\ -0.80943 & 0.860508167 \\ 3.78771 & 1.243140704\end{array}$

101.8928

111.4956

121.0984

137.217

32.5727

37.5428

$-9999.9999$

113.3023

70.1471

89.1651

84.3637

117.9735

62.9881

60.4869

62.1623

122.9051

38.8515

40.8187

37.0131

27.283

64.3322

82.6872

108.9314

107.6493

92.29

110.2135

101.8928

35.3543 
53 Ethylene glycol

54 Furfuryl alcohol

55 Geraniol

56 Geranyl acetate

57 Glycerol

58 Glycerol carbonate

59 Glycerol triacetate

60 Glycerol-1,2,3-tributyl ether

61 Glycerol-1,2,3-triethyl ether

62 Glycerol-1,2,3-trimethyl ether

63 Glycerol-1,2-dimethyl ether

64 Glycerol-1,3-diethyl ether

65 Glycerol-1,3-dimethyl ether

66 Hexane

67 Isoamyl acetate

68 Isoamyl alcohol

69 Isobutyl acetate

70 Isobutyl alcohol

71 Isodecane

72 Isopropyl acetate

73 Isopropyl alcohol

74 Isopropyl palmitate

75 Methanol

76 Methyl abietate

77 Methyl acetate

78 Methyl laurate

79 Methyl linoleate

80 Methyl linolenate

$\begin{array}{rr}5.25101 & 1.098548673 \\ 5.006205 & 1.127597701 \\ 1.324895 & 0.874450113 \\ 0.61624 & 0.90581449 \\ 5.1197 & 1.293455056 \\ 4.57298 & 1.419326923 \\ 3.908165 & 1.14123954 \\ 2.02171 & 0.869799599 \\ 4.29442 & 0.893340091 \\ 5.281105 & 0.911514946 \\ 5.43659 & 0.988059211 \\ 5.72642 & 0.951232349 \\ 6.4341 & 0.981601307 \\ 3.02947 & 0.674319249 \\ 3.247375 & 0.867913333 \\ 3.95603 & 0.80355515 \\ 3.62616 & 0.867513069 \\ 4.334815 & 0.791912393 \\ -3.96589 & 0.857079724 \\ -9999.9999 & 0.914330922 \\ 5.26873 & 0.784543081 \\ -1.163895 & 0.858530342 \\ 5.44685 & 0.762904762 \\ 0.887355 & 1.003122029 \\ 4.738195 & 0.900109356 \\ 1.084495 & 0.864310484 \\ -1.198515 & 0.880355755 \\ -1.203665 & 0.893016794\end{array}$

62.3454

59.1632

75.616

71.8104

86.4401

78.8727

83.9535

85.9036

57.0952

48.1561

$-9999.9999$

$-9999.9999$

$-9999.9999$

32.8665

48.9515

52.7571

44.1501

47.9557

155.3286

$-9999.9999$

44.2226

104.2284

36.0173

88.9293

32.2117

77.8858

104.13

102.8479 
81 Methyl myristate

82 Methyl oleate

83 Methyl palmitate

84 Methyl ricinoleate

85 Methyl stearate

86 N,N-Diethylolcapramide

$87 \mathrm{~N}, \mathrm{~N}$-Dimethyldecanamide

88 N,N-Dimethyloctanamide

$89 \mathrm{Nopol}$

90 n-Propyl acetate

91 Oleic acid

92 Oleyl alcohol

93 p-Cymene

94 Perfluoroctane

95 Propionic acid

96 Propylene carbonate

97 Propylene glycol

98 Ricinoleic acid

99 Solketal

100 Terpinolene

101 Tetrachloromethane

102 Tetrahydrofurfuryl(ic) alcohol

103 Tributyl citrate

104 Trichloroethylene

105 Triethyl citrate

106 Ît-Pinene

107 Ît-Terpineol

$108 \hat{\imath}^{2}$-Farnesene

$\begin{array}{rr}0.326925 & 0.862951228 \\ -1.193365 & 0.869486804 \\ -0.430645 & 0.861602421 \\ -0.05025 & 0.920996169 \\ -1.188215 & 0.860758362 \\ 3.18428 & 1.006948758 \\ 2.47585 & 0.871613467 \\ 3.23342 & 0.874790603 \\ 3.256 & 0.974012888 \\ 3.980625 & 0.880456897 \\ -0.86226 & 0.889102927 \\ -0.997645 & 0.845888469 \\ 1.83818 & 0.863719434 \\ 0.448032 & 1.711837436 \\ 4.824665 & 0.978586526 \\ 4.158045 & 1.195421546 \\ 4.936755 & 1.036716621 \\ 0.280855 & 0.944515823 \\ 4.539275 & 1.080613246 \\ -9999.9999 & 0.855229127 \\ 3.096745 & 1.636287234 \\ 4.432205 & 1.044304703 \\ -1.820705 & 1.057029326 \\ 2.3889 & 1.469574944 \\ 0.452005 & 1.15648807 \\ 3.51502 & 0.871644274 \\ 4.153115 & 0.925888355 \\ -0.922875 & 0.818737981\end{array}$

87.4886

105.4121

97.0914

131.4048

106.6942

146.8198

88.6543

79.0515

72.095

41.8145

102.723

116.359

49.2203

38.1803

31.9841

52.2486

64.9134

128.7157

68.8969

$-9999.9999$

34.4015

61.453

142.6678

33.0254

113.8594

40.6759

69.6567

69.9599 
$109 \hat{\imath}^{2}$-Myrcene

1.21026

0.782527283

47.9352

$110 \hat{\imath}^{2}$-Pinene

3.70247

0.868311026

40.2398

Fonte: Próprio autor.

3.357205

0.924778177

64.2551

Tabela 33 - Parâmetros EHS dos solventes estimadas pelo software IBSS® com o modelo de Weis e Visco (2011).

\begin{tabular}{|c|c|c|c|c|c|c|}
\hline ID & Solvente & $\begin{array}{r}\text { Env. Waste } \\
\text { Weis2009 } \\
\end{array}$ & $\begin{array}{r}\text { Env. Impact } \\
\text { Weis2009 }\end{array}$ & $\begin{array}{r}\text { Health } \\
\text { Weis2009 } \\
\end{array}$ & $\begin{array}{r}\text { Safety } \\
\text { Weis2009 } \\
\end{array}$ & $\begin{array}{r}\text { LCA } \\
\text { Weis2009 } \\
\end{array}$ \\
\hline 1 & p-cymene & 11.3182 & 1.0527 & 7.0841 & 3.5585 & 8.2564 \\
\hline 2 & 1,3-Dioxan-5-ol & 3.4157 & 8.0058 & 12.1104 & 6.8765 & 6.6908 \\
\hline 3 & 1,3-Dioxolane & 2.6658 & 6.0737 & 9.5021 & 4.4129 & 5.6772 \\
\hline 4 & 1,3-Dioxolane-4-methanol & 3.4157 & 8.0058 & 12.1104 & 6.8765 & 6.6908 \\
\hline 5 & 1,3-Propanediol & 4.5574 & 10.319 & 8.2982 & 9.9929 & 7.7044 \\
\hline 6 & 1,4-Cineol & 8.0302 & 11.8095 & 11.5215 & 3.8401 & 7.9482 \\
\hline 7 & 1,8-Cineol & 8.0302 & 11.8095 & 11.5215 & 3.8401 & 7.9482 \\
\hline 8 & 1-Butanol & 3.9697 & 7.3141 & 7.2038 & 6.1221 & 6.9525 \\
\hline 9 & 1-Decanol & 7.2937 & 5.7961 & 10.2644 & 5.3445 & 6.9525 \\
\hline 10 & 1-Octanol & 6.1857 & 6.3013 & 9.2442 & 4.9621 & 6.9525 \\
\hline 11 & 2-Furfuraldehyde & 2.3888 & 7.6646 & 5.9895 & 7.069 & 2.405 \\
\hline 12 & 2-Methyltetrahydrofuran & 3.7738 & 4.9756 & 9.4975 & 3.1577 & 5.9389 \\
\hline 13 & 2-Pyrrolidone & 2.6658 & 7.4971 & 8.3101 & 8.7427 & 5.3249 \\
\hline 14 & 3-Butyl-1-methylimidazolium & 5.1588 & 3.1567 & 7.8631 & 5.0099 & 5.135 \\
\hline 15 & 3-Hydroxypropionic acid & 5.4715 & 12.8496 & 7.56 & 13.1507 & 7.9661 \\
\hline 16 & 3-Methoxy-3-methyl-1-butanol & 5.0777 & 8.433 & 10.2417 & 6.1723 & 8.5895 \\
\hline 17 & 5-(Hydroxymethyl)furfural & 3.1537 & 8.7562 & 6.1836 & 9.8907 & 5.1251 \\
\hline 18 & Acetic acid & 3.7758 & 10.3015 & 5.4454 & 10.9659 & 7.2142 \\
\hline
\end{tabular}




\begin{tabular}{|c|c|c|c|c|c|c|}
\hline 19 & Acetone & 2.6658 & 7.036 & 6.9933 & 6.6391 & 2.6667 \\
\hline 20 & Benzyl alcohol & 6.8547 & 5.0029 & 7.4361 & 6.8765 & 5.2393 \\
\hline 21 & Benzyl benzoate & 16.3239 & 1.9507 & 9.2403 & 5.5675 & 2.5125 \\
\hline 22 & Butanone & 3.2198 & 6.7313 & 7.5034 & 5.9313 & 2.6667 \\
\hline 23 & Butyl acetate & 5.7959 & 7.1823 & 7.7555 & 5.3139 & 5.9389 \\
\hline 24 & Butyl laurate & 11.3359 & 3.1323 & 12.8565 & 11.5339 & 5.9389 \\
\hline 25 & Butyl myristate & 12.4439 & 2.3247 & 13.8767 & 14.7027 & 5.9389 \\
\hline 26 & Butyl palmitate & 13.5519 & 1.5179 & 14.8969 & 18.5131 & 5.9389 \\
\hline 27 & Butyl stearate & 14.6599 & 0.7119 & 15.9171 & 22.9651 & 5.9389 \\
\hline 28 & Caprylic acid diethanolamide & 9.2664 & 8.8095 & 12.6847 & 17.5231 & 5.7631 \\
\hline 29 & Cyclohexane & 4.3278 & 5.5567 & 7.6397 & 1.0589 & 6.2006 \\
\hline 30 & Cyclopentyl methyl ether & 4.3278 & 4.5387 & 10.1675 & 2.3269 & 6.9638 \\
\hline 31 & Decamethylcyclopentasiloxane & 9.3138 & -5.8769 & 4.5791 & 15.6353 & 6.2006 \\
\hline 32 & Dibutyl sebacate & 16.2942 & 10.2413 & 8.6553 & 21.3017 & 5.6772 \\
\hline 33 & Dihydromyrcenol (2 tipos) & 8.7801 & 5.9129 & 8.7177 & 7.6091 & 8.088 \\
\hline 34 & Diisoamyl succinate & 22.2398 & 9.8221 & 4.5745 & 18.7833 & 5.6772 \\
\hline 35 & Diisobutyl glutarate & 21.6858 & 10.7358 & 4.0644 & 17.2867 & 5.6772 \\
\hline 36 & Diisooctyl succinate & 25.5638 & 4.3441 & 7.6351 & 31.1313 & 5.6772 \\
\hline 37 & Dimethyl 2-methyl glutarate & 12.7946 & 14.3295 & 0.1459 & 12.2097 & 7.727 \\
\hline 38 & Dimethyl glutarate & 10.2002 & 15.2444 & 0.656 & 11.6755 & 7.727 \\
\hline 39 & Dimethyl isosorbide & 4.8818 & 4.0417 & -0.4769 & 3.5585 & 7.2036 \\
\hline 40 & Dioctyl succinate (2 tipos) & 17.4022 & 9.2305 & 9.6755 & 25.0449 & 5.6772 \\
\hline 41 & D-Limonene & 7.4762 & 2.76 & 6.1094 & 3.4923 & 6.2006 \\
\hline 42 & Ethanol & 2.8617 & 7.8217 & 6.1836 & 7.6645 & 6.9525 \\
\hline 43 & Ethyl acetate & 4.6879 & 7.9947 & 6.7353 & 5.9947 & 5.9389 \\
\hline 44 & Ethyl ether & 3.7738 & 5.2609 & 7.4735 & 3.4113 & 5.6772 \\
\hline 45 & Ethyl lactate & 5.4378 & 9.876 & 9.3436 & 8.6019 & 6.9525 \\
\hline 46 & Ethyl laurate & 10.2279 & 3.9407 & 11.8363 & 9.0067 & 5.9389 \\
\hline
\end{tabular}




\author{
47 Ethyl linoleate \\ 48 Ethyl linolenate \\ 49 Ethyl myristate \\ 50 Ethyl oleate \\ 51 Ethyl palmitate \\ 52 Ethylene dichloride \\ 53 Ethylene glycol \\ 54 Furfuryl alcohol \\ 55 Geraniol \\ 56 Geranyl acetate \\ 57 Glycerol \\ 58 Glycerol carbonate \\ 59 Glycerol triacetate \\ 60 Glycerol-1,2,3-tributyl ether \\ 61 Glycerol-1,2,3-triethyl ether \\ 62 Glycerol-1,2,3-trimethyl ether \\ 63 Glycerol-1,2-dimethyl ether \\ 64 Glycerol-1,3-diethyl ether \\ 65 Glycerol-1,3-dimethyl ether \\ 66 Hexane \\ 67 Isoamyl acetate \\ 68 Isoamyl alcohol \\ 69 Isobutyl acetate \\ 70 Isobutyl alcohol \\ 71 Isodecane \\ 72 Isopropyl acetate \\ 73 Isopropyl alcohol \\ 74 Isopropyl palmitate
}

$\begin{array}{rrrr}-0.3221 & 12.8565 & 17.9995 & 5.9389 \\ -0.7837 & 11.8363 & 17.4127 & 5.9389 \\ 3.1323 & 12.8565 & 11.5339 & 5.9389 \\ 0.4451 & 13.8767 & 18.3663 & 5.9389 \\ 2.3247 & 13.8767 & 14.7027 & 5.9389 \\ 5.3499 & 4.5791 & 5.3445 & 6.2006 \\ 10.5221 & 7.7881 & 10.9879 & 7.7044 \\ 6.8161 & 6.1836 & 7.6645 & 5.1251 \\ 4.6725 & 7.2038 & 6.9909 & 6.9525 \\ 3.9311 & 7.7555 & 7.9059 & 5.9389 \\ 12.505 & 10.3964 & 13.3079 & 8.718 \\ 10.2507 & 12.1104 & 9.8907 & 6.6908 \\ 28.9312 & -7.0207 & 23.5943 & 5.6772 \\ -3.1748 & 8.7065 & 16.1549 & 4.8921 \\ 2.9176 & 5.6459 & 5.9333 & 4.8921 \\ 4.0417 & -3.5287 & 3.5585 & 7.9668 \\ 7.0914 & 6.6944 & 6.1621 & 8.2172 \\ 6.7484 & 10.1028 & 6.5965 & 6.1674 \\ 7.0914 & 6.6944 & 6.1621 & 8.2172 \\ 3.8783 & 6.6195 & 2.5441 & 6.2006 \\ 6.3692 & 7.2454 & 5.7213 & 5.9389 \\ 6.6534 & 6.6937 & 6.0987 & 6.9525 \\ 6.9787 & 6.7353 & 5.5675 & 5.9389 \\ 7.1105 & 6.1836 & 6.3757 & 6.9525 \\ -28.5078 & 16.8353 & 81.7869 & 5.4155 \\ 7.3408 & 3.3472 & 5.7168 & 6.2006 \\ 7.028 & 7.1874 & 6.8765 & 7.2142 \\ -0.0438 & 14.8805 & 18.3663 & 6.2006\end{array}$




\begin{tabular}{|c|c|c|c|c|c|c|}
\hline 75 & Methanol & 2.3077 & 7.536 & 5.8334 & 8.7397 & 7.9774 \\
\hline 76 & Methyl abietate & 29.6995 & -2.8538 & 9.4457 & 18.3811 & 6.9638 \\
\hline 77 & Methyl acetate & 4.1339 & 7.8614 & 6.3851 & 6.6391 & 6.9638 \\
\hline 78 & Methyl laurate & 9.6739 & 4.8234 & 11.4861 & 6.7791 & 6.9638 \\
\hline 79 & Methyl linoleate & 11.8899 & 0.967 & 12.5063 & 14.6231 & 6.9638 \\
\hline 80 & Methyl linolenate & 11.3359 & 0.4038 & 11.4861 & 14.3235 & 6.9638 \\
\hline 81 & Methyl myristate & 10.7819 & 4.2182 & 12.5063 & 8.7319 & 6.9638 \\
\hline 82 & Methyl oleate & 12.4439 & 1.8358 & 13.5265 & 14.7027 & 6.9638 \\
\hline 83 & Methyl palmitate & 11.8899 & 3.6138 & 13.5265 & 11.3263 & 6.9638 \\
\hline 84 & Methyl ricinoleate & 12.6398 & 3.4604 & 15.6247 & 17.5121 & 7.9774 \\
\hline 85 & Methyl stearate & 12.9979 & 3.0102 & 14.5467 & 14.5623 & 6.9638 \\
\hline 86 & N,N-Diethylolcapramide & 10.3744 & 7.6947 & 13.7049 & 19.6287 & 5.7631 \\
\hline 87 & N,N-Dimethyldecanamide & 7.9288 & 2.8133 & 6.8719 & 11.9013 & 2.5803 \\
\hline 88 & N,N-Dimethyloctanamide & 6.8208 & 3.7249 & 5.8517 & 10.3701 & 2.5803 \\
\hline 89 & Nopol & 14.3473 & 4.927 & 7.7139 & 6.6739 & 6.9525 \\
\hline 90 & n-Propyl acetate & 5.2419 & 7.5884 & 7.2454 & 5.5741 & 5.9389 \\
\hline 91 & Oleic acid & 12.0858 & 6.5619 & 12.5868 & 12.5675 & 7.2142 \\
\hline 92 & Oleyl alcohol & 11.1717 & 2.5581 & 13.325 & 13.5741 & 6.9525 \\
\hline 93 & p-Cymene & 11.3182 & 1.0527 & 7.0841 & 3.5585 & 8.2564 \\
\hline 94 & Perfluoroctane & 1.0038 & 5.5531 & 4.5791 & 8.0693 & 6.2006 \\
\hline 95 & Propionic acid & 4.3298 & 10.1492 & 5.9555 & 9.8273 & 7.2142 \\
\hline 96 & Propylene carbonate & 2.6658 & 7.5249 & 10.5059 & 6.6391 & 5.9389 \\
\hline 97 & Propylene glycol & 4.5574 & 9.7792 & 8.7919 & 10.0563 & 7.9661 \\
\hline 98 & Ricinoleic acid & 13.2275 & 8.1103 & 14.685 & 15.5923 & 8.2278 \\
\hline 99 & Solketal & 4.5237 & 7.0914 & 12.1104 & 6.1621 & 6.6908 \\
\hline 100 & Terpinolene & 5.4358 & 2.76 & 6.1094 & 3.4923 & 6.2006 \\
\hline 101 & Tetrachloromethane & 1.0038 & 5.5531 & 4.5791 & 8.0693 & 6.2006 \\
\hline 102 & Tetrahydrofurfuryl(ic) alcohol & 3.9697 & 7.803 & 11.102 & 6.1221 & 6.6908 \\
\hline
\end{tabular}




\begin{tabular}{|c|c|c|c|c|c|}
\hline 103 Tributyl citrate & 23.2766 & 27.4486 & -1.3354 & 35.8003 & 7.3029 \\
\hline 104 Trichloroethylene & 1.2808 & 5.5404 & 4.5791 & 7.2804 & 6.2006 \\
\hline 105 Triethyl citrate & 19.9526 & 32.0146 & -4.396 & 27.9619 & 7.3029 \\
\hline 106 Ît-Pinene & 13.5974 & 2.5055 & 5.5993 & 3.8093 & 6.2006 \\
\hline 107 l̂t-Terpineol & 8.2261 & 6.8273 & 8.7177 & 6.6739 & 8.088 \\
\hline $108 \hat{\mid ̂}^{2}$-Farnesene & 7.6518 & -0.9477 & 6.6195 & 7.9381 & 6.2006 \\
\hline $109 \hat{\imath}^{2}$-Myrcene & 5.4358 & 2.5055 & 5.5993 & 3.8093 & 6.2006 \\
\hline 110 î2-Pinene & 13.5974 & 2.76 & 6.1094 & 3.4923 & 6.2006 \\
\hline $111 \hat{i}^{2}$-Terpineol & 8.2261 & 7.1836 & 9.2278 & 6.2301 & 8.088 \\
\hline
\end{tabular}

Fonte: Próprio autor.

Tabela 34 - Parâmetros de Hansen dos solventes estimados pelo software IBSS $\AA_{\text {. }}$

\begin{tabular}{|c|c|c|c|c|c|}
\hline ID & Solvente & $\begin{array}{l}\text { HSP_d } \\
\text { MB2010 }\end{array}$ & $\begin{array}{r}\text { HSP_p } \\
\text { MB2010 }\end{array}$ & $\begin{array}{r}\text { HSP_h } \\
\text { MB2010 }\end{array}$ & $\begin{array}{r}\text { HildebrandSolub Parameter } \\
\text { HSKASG2012 }\end{array}$ \\
\hline 1 & p-cymene & 18.5 & 2.6 & 1.9 & 17.4733 \\
\hline 2 & 1,3-Dioxan-5-ol & 18.3 & 10.1 & 19.9 & 21.9862 \\
\hline 3 & 1,3-Dioxolane & 17.7 & 6.5 & 8.3 & 21.801 \\
\hline 4 & 1,3-Dioxolane-4-methanol & 18.1 & 9.6 & 19.1 & 24.4189 \\
\hline 5 & 1,3-Propanediol & 16.4 & 12.8 & 27.3 & 26.4418 \\
\hline 6 & 1,4-Cineol & 17 & 3.4 & 3.7 & 19.4913 \\
\hline 7 & 1,8-Cineol & 17 & 4 & 3.3 & 17.3247 \\
\hline 8 & 1-Butanol & 15.6 & 6.6 & 15.8 & 21.5865 \\
\hline 9 & 1-Decanol & 16.1 & 3.7 & 9.7 & 20.7927 \\
\hline 10 & 1-Octanol & 15.9 & 4.5 & 11.1 & 21.0573 \\
\hline 11 & 2-Furfuraldehyde & 17.9 & 12.2 & 11.9 & -9999.9999 \\
\hline 12 & 2-Methyltetrahydrofuran & 16.8 & 5 & 4 & 19.2373 \\
\hline
\end{tabular}




\begin{tabular}{|c|c|c|c|c|c|}
\hline 13 & 2-Pyrrolidone & 18.2 & 16 & 7.6 & 24.7693 \\
\hline 14 & 3-Butyl-1-methylimidazolium & 17.9 & 13.1 & 7.8 & -9999.9999 \\
\hline 15 & 3-Hydroxypropionic acid & 16.8 & 9.6 & 25.3 & 27.2036 \\
\hline 16 & 3-Methoxy-3-methyl-1-butanol & 15.6 & 7.2 & 12.3 & 19.7686 \\
\hline 17 & 5-(Hydroxymethyl)furfural & 18.1 & 14.1 & 18.7 & 29.6761 \\
\hline 18 & Acetic acid & 15.7 & 8.5 & 14.9 & 22.6129 \\
\hline 19 & Acetone & 15.8 & 10.1 & 5 & 19.334 \\
\hline 20 & Benzyl alcohol & 19.3 & 6.4 & 12.6 & 23.2466 \\
\hline 21 & Benzyl benzoate & 19.8 & 6.3 & 4.7 & 21.2807 \\
\hline 22 & Butanone & 15.7 & 8.5 & 4.6 & 18.6714 \\
\hline 23 & Butyl acetate & 15.8 & 5.1 & 6.5 & 18.1986 \\
\hline 24 & Butyl laurate & 16.2 & 2.9 & 4 & 16.664 \\
\hline 25 & Butyl myristate & 16.3 & 2.2 & 3.3 & 16.3994 \\
\hline 26 & Butyl palmitate & 16.3 & 2.3 & 3.5 & 16.1348 \\
\hline 27 & Butyl stearate & 16.4 & 1.7 & 3 & 15.8702 \\
\hline 28 & Caprylic acid diethanolamide & 17 & 9.6 & 15.9 & 33.2095 \\
\hline 29 & Cyclohexane & 17 & 1.5 & 1.8 & 18.8829 \\
\hline 30 & Cyclopentyl methyl ether & 16.6 & 3.7 & 3.7 & 15.9913 \\
\hline 31 & Decamethylcyclopentasiloxane & 12.9 & 1.3 & 0.5 & 9.2479 \\
\hline 32 & Dibutyl sebacate & 16.5 & 3.2 & 4.9 & 17.7875 \\
\hline 33 & Dihydromyrcenol (2 tipos) & 16.1 & 4.6 & 10 & 17.4848 \\
\hline 34 & Diisoamyl succinate & 16.5 & 3.8 & 6.3 & 16.9275 \\
\hline 35 & Diisobutyl glutarate & 16.4 & 4.3 & 6.8 & 16.7764 \\
\hline 36 & Diisooctyl succinate & 16.6 & 2.7 & 4.7 & 16.1337 \\
\hline 37 & Dimethyl 2-methyl glutarate & 16.1 & 4.8 & 8.3 & 18.428 \\
\hline 38 & Dimethyl glutarate & 16.2 & 6.2 & 9.1 & 19.2428 \\
\hline 39 & Dimethyl isosorbide & 17.5 & 7.4 & 7.6 & 13.9397 \\
\hline 40 & Dioctyl succinate (2 tipos) & 16.5 & 2.9 & 4.8 & 17.8063 \\
\hline
\end{tabular}




\begin{tabular}{|c|c|c|c|c|}
\hline 41 D-Limonene & 16.7 & 2.2 & 4.9 & 17.474 \\
\hline 42 Ethanol & 15.4 & 9.2 & 19.6 & 21.8511 \\
\hline 43 Ethyl acetate & 15.6 & 6 & 7.2 & 18.4632 \\
\hline 44 Ethyl ether & 15.1 & 4.8 & 3.5 & 17.0949 \\
\hline 45 Ethyl lactate & 15.9 & 8 & 14.8 & 22.1598 \\
\hline 46 Ethyl laurate & 16.2 & 3.4 & 5.3 & 16.9286 \\
\hline 47 Ethyl linoleate & 16.2 & 3.4 & 4.3 & 15.1464 \\
\hline 48 Ethyl linolenate & 16.2 & 4 & 4.5 & 14.6522 \\
\hline 49 Ethyl myristate & 16.3 & 2.7 & 5 & 16.664 \\
\hline 50 Ethyl oleate & 16.2 & 3 & 4.6 & 15.6406 \\
\hline 51 Ethyl palmitate & 16.3 & 2.7 & 5 & 16.3994 \\
\hline 52 Ethylene dichloride & 17.6 & 9.4 & 2.8 & 20.6887 \\
\hline 53 Ethylene glycol & 16.8 & 11.5 & 20.5 & 25.9534 \\
\hline 54 Furfuryl alcohol & 18 & 9.5 & 18.5 & 26.0688 \\
\hline 55 Geraniol & 16.4 & 3.7 & 10 & 19.9432 \\
\hline 56 Geranyl acetate & 16.3 & 3.2 & 6.1 & 16.5553 \\
\hline 57 Glycerol & 17 & 12.3 & 24.2 & 29.399 \\
\hline 58 Glycerol carbonate & 18.7 & 22.1 & 18.2 & 27.8822 \\
\hline 59 Glycerol triacetate & 16.4 & 5.7 & 9.6 & 20.609 \\
\hline 60 Glycerol-1,2,3-tributyl ether & 15.7 & 3.8 & 3.2 & 15.578 \\
\hline 61 Glycerol-1,2,3-triethyl ether & 15.5 & 4.8 & 3.6 & 16.3718 \\
\hline 62 Glycerol-1,2,3-trimethyl ether & 15.5 & 5.7 & 7.5 & 17.3066 \\
\hline 63 Glycerol-1,2-dimethyl ether & 15.8 & 7.5 & 15.5 & -9999.9999 \\
\hline 64 Glycerol-1,3-diethyl ether & 15.7 & 6.9 & 8.9 & 20.8401 \\
\hline 65 Glycerol-1,3-dimethyl ether & 15.8 & 8 & 12.5 & 21.284 \\
\hline 66 Hexane & 15.2 & 0.8 & 2 & 16.5989 \\
\hline 67 Isoamyl acetate & 15.8 & 4 & 6 & 17.23 \\
\hline 68 Isoamyl alcohol & 15.3 & 5.2 & 12.2 & 20.6179 \\
\hline
\end{tabular}


69 Isobutyl acetate

70 Isobutyl alcohol

71 Isodecane

72 Isopropyl acetate

73 Isopropyl alcohol

74 Isopropyl palmitate

75 Methanol

76 Methyl abietate

77 Methyl acetate

78 Methyl laurate

79 Methyl linoleate

80 Methyl linolenate

81 Methyl myristate

82 Methyl oleate

83 Methyl palmitate

84 Methyl ricinoleate

85 Methyl stearate

86 N,N-Diethylolcapramide

87 N,N-Dimethyldecanamide

$88 \mathrm{~N}, \mathrm{~N}-$ Dimethyloctanamide

89 Nopol

90 n-Propyl acetate

91 Oleic acid

92 Oleyl alcohol

93 p-Cymene

94 Perfluoroctane

95 Propionic acid

96 Propylene carbonate
10.9523 $-9999.9999$

20.466

15.4308

21.9834

17.2782

18.5955

17.0609

15.2787

14.7845

16.7963

15.7729

16.5317

19.555

16.2671

32.9449

21.111

21.3756

20.3116

18.3309

20.0019

19.2401

17.4733

10.0519

22.4806

12.3

24.0054 


\begin{tabular}{|c|c|c|c|c|c|}
\hline 97 & Propylene glycol & 16.1 & 10 & 23.3 & 25.2967 \\
\hline 98 & Ricinoleic acid & 16.4 & 5 & 10.1 & 23.784 \\
\hline 99 & Solketal & 16.8 & 8.6 & 14.2 & 22.1383 \\
\hline 100 & Terpinolene & 16.9 & 1.8 & 4.8 & 18.0777 \\
\hline 101 & Tetrachloromethane & 17.9 & 1.5 & 2 & 18.0743 \\
\hline 102 & Tetrahydrofurfuryl(ic) alcohol & 17.5 & 8.8 & 15.3 & 23.1141 \\
\hline 103 & Tributyl citrate & 16.7 & 3.5 & 10.3 & -9999.9999 \\
\hline 104 & Trichloroethylene & 18 & 6.8 & 2.6 & 18.865 \\
\hline 105 & Triethyl citrate & 16.5 & 4.8 & 13.4 & -9999.9999 \\
\hline 106 & Ît-Pinene & 17 & 1.3 & 2 & 14.6165 \\
\hline 107 & Ît-Terpineol & 17 & 3.8 & 10 & 17.9552 \\
\hline 108 & $\hat{\mid}^{2}$-Farnesene & 16.1 & 1.9 & 4.4 & 13.5854 \\
\hline 109 & $\hat{\mid}^{2}$-Myrcene & 15.8 & 2 & 4.2 & 14.653 \\
\hline 110 & $\hat{\mid}^{2}$-Pinene & 16.9 & 1.6 & 1.8 & 16.0032 \\
\hline 111 & $\hat{I}^{2}$-Terpineol & 17.5 & 6.3 & 10.3 & 20.4184 \\
\hline
\end{tabular}

Fonte: Próprio autor.

\section{Notas explicativas:}

MB2010: modelo de Yamamoto (2010)

HSKASG2012: modelo de Hukkerikar et al. (2012)

MG2002: modelo de Marrero e Gani (2002)

Weis2009: modelo de Weis e Visco (2010). 


\subsection{Especificações e correntes da simulação}

\section{Hexano}

Figura 26 - Flowsheet hexano.

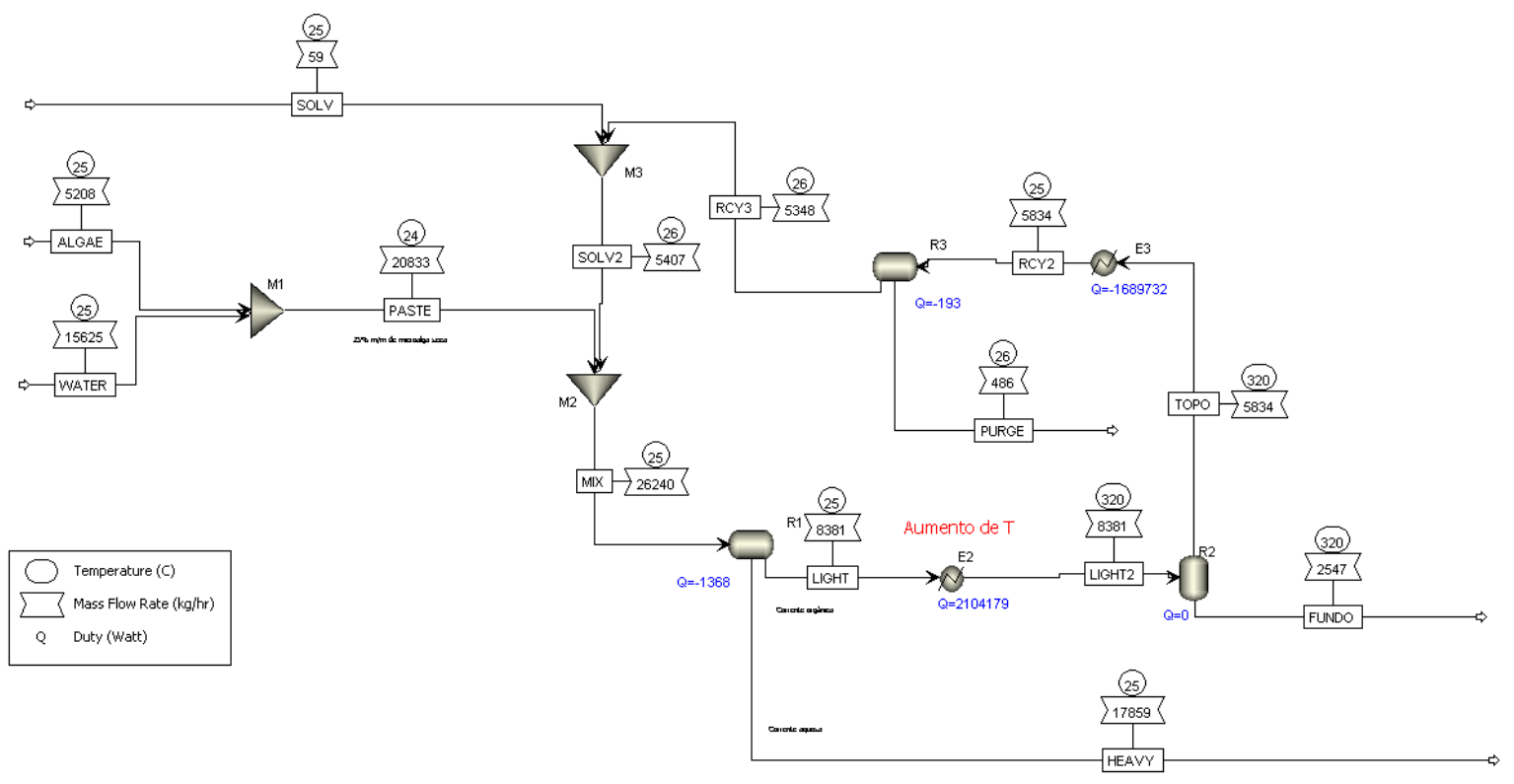

Fonte: Próprio autor.

Tabela 35 - Correntes da simulação para o n-hexano.

\begin{tabular}{lrrrrrrr}
\hline & WATER & ALGAE & PASTE & SOLV & RCY3 & SOLV2 & MIX \\
\hline Temperature C & 25 & 25 & 24 & 25 & 26.3 & 26.2 & 24.7 \\
Pressure bar & 1 & 1 & 1 & 1 & 1 & 1 & 1 \\
Vapor Frac & 0 & 0 & 0 & 0 & 0 & 0 & 0 \\
Mole Flow kmol/hr & 867.319 & 14.83 & 882.15 & 0.684 & 60.38 & 61.064 & 943.213 \\
Mass Flow kg/hr & 15625 & 5208.33 & 20833.3 & 58.95 & 5348.12 & 5407.07 & 26240.4 \\
Volume Flow & & & & & & & \\
cum/hr & 15.72 & 5.518 & 25.904 & 0.09 & 7.891 & 7.98 & 33.338 \\
Enthalpy Gcal/hr & -59.205 & -4.114 & -63.32 & -0.032 & -2.992 & -3.024 & -66.344 \\
Mass Flow kg/hr & & & & & & & \\
HEXANE & & & & 58.95 & 5065.69 & 5124.64 & 5124.64 \\
WATER & 15625 & & 15625 & & 0.804 & 0.804 & 15625.8 \\
SUCROSE & & 1407.29 & 1407.29 & & 48.258 & 48.258 & 1455.55 \\
L-PHE-01 & 1250 & 1250 & & 233.172 & 233.172 & 1483.17 \\
PDD & & 901.041 & 901.041 & & 0.081 & 0.081 & 901.122 \\
PPD & 788.541 & 788.541 & & 0.058 & 0.058 & 788.599 \\
DDD & 343.229 & 343.229 & & 0.038 & 0.038 & 343.267 \\
PPP & 230.208 & 230.208 & & 0.009 & 0.009 & 230.217 \\
DD4 & 79.687 & 79.687 & & 0.001 & 0.001 & 79.688 \\
P4D & 208.333 & 208.333 & & 0.002 & 0.002 & 208.335
\end{tabular}

Mass Frac 


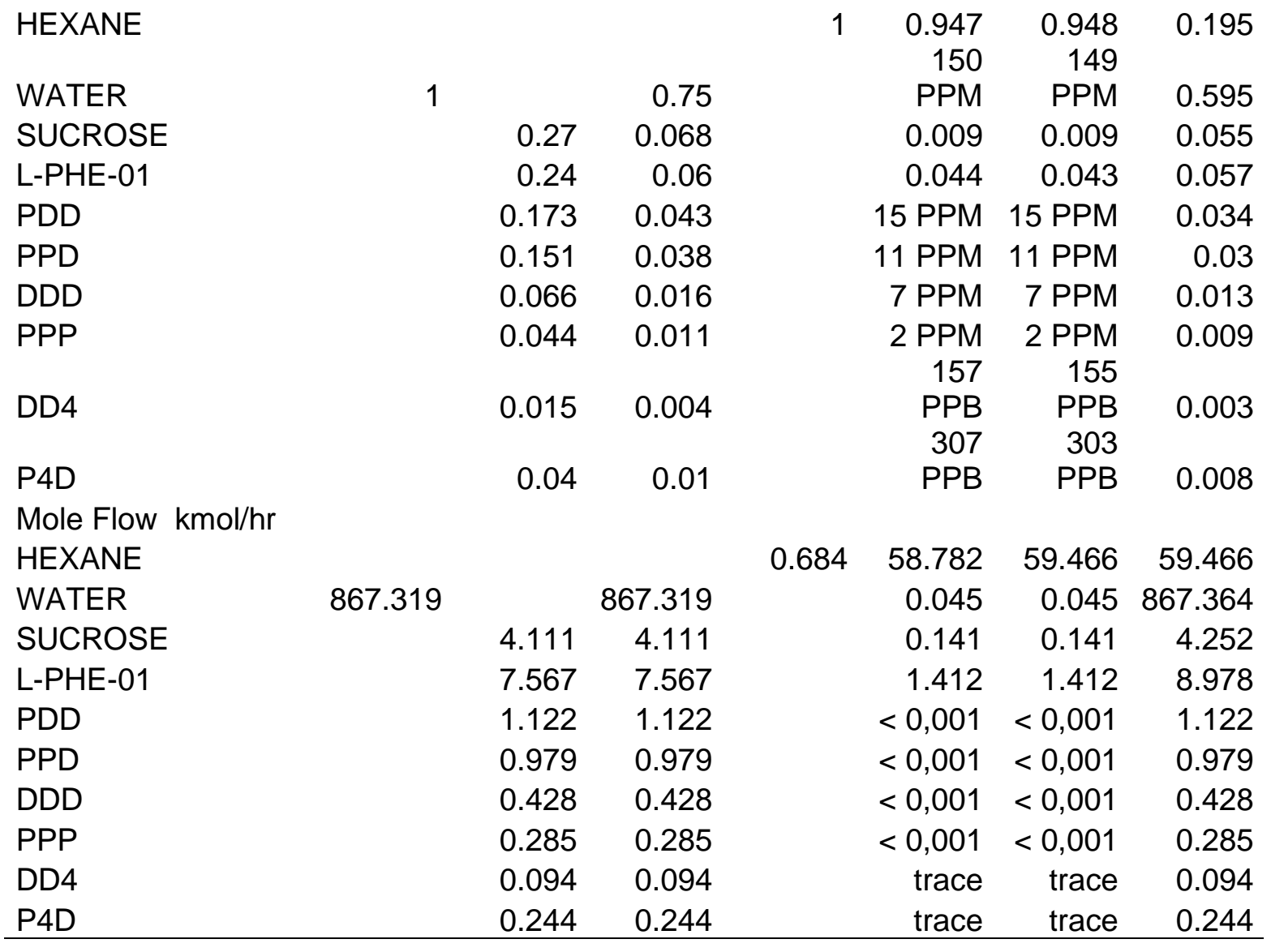

\begin{tabular}{lrrrrrrr}
\hline & HEAVY & LIGHT & LIGHT2 & FUNDO & TOPO & RCY2 & PURGE \\
\hline Temperature C & 24.7 & 24.7 & 320 & 320 & 320 & 25 & 26.3 \\
Pressure bar & 1 & 1 & 1 & 1 & 1 & 1 & 1 \\
Vapor Frac & 0 & 0 & 0.949 & 0 & 1 & 0 & 0 \\
Mole Flow kmol/hr & 875.838 & 67.375 & 67.375 & 3.447 & 63.928 & 63.928 & 3.551 \\
Mass Flow kg/hr & 17859.2 & 8381.21 & 8381.21 & 2547.43 & 5833.78 & 5833.78 & 485.828 \\
Volume Flow & & & & & & & \\
cum/hr & 17.748 & 15.591 & 3153.67 & 0.944 & 3152.73 & 8.232 & 0.378 \\
Enthalpy Gcal/hr & -61.583 & -4.762 & -2.953 & -1.1 & -1.853 & -3.305 & -0.314 \\
Mass Flow kg/hr & & & & & & & \\
HEXANE & 1.222 & 5123.42 & 5123.42 & 3.005 & 5120.42 & 5120.42 & 54.884 \\
WATER & 15618.6 & 7.218 & 7.218 & 0.001 & 7.217 & 7.217 & 6.412 \\
SUCROSE & 1331.74 & 123.809 & 123.809 & 71.703 & 52.107 & 52.107 & 3.849 \\
L-PHE-01 & 798.84 & 684.331 & 684.331 & 30.483 & 653.848 & 653.848 & 420.681 \\
PDD & 39.838 & 861.285 & 861.285 & 861.203 & 0.082 & 0.082 & 0.001 \\
PPD & 29.168 & 759.431 & 759.431 & 759.373 & 0.058 & 0.058 & 0.001 \\
DDD & 18.311 & 324.956 & 324.956 & 324.917 & 0.038 & 0.038 & $<0,001$ \\
PPP & 7.195 & 223.022 & 223.022 & 223.013 & 0.009 & 0.009 & $<0,001$ \\
DD4 & 4.565 & 75.123 & 75.123 & 75.122 & 0.001 & 0.001 & $<0,001$ \\
P4D & 9.724 & 198.611 & 198.611 & 198.609 & 0.002 & 0.002 & $<0,001$ \\
Mass Frac & & & & & & & \\
HEXANE & 68 PPM & 0.611 & 0.611 & 0.001 & 0.878 & 0.878 & 0.113 \\
& & & & & & &
\end{tabular}




\begin{tabular}{lrrrrrrr} 
WATER & 0.875 & PPM & PPM & PPB & 0.001 & 0.001 & 0.013 \\
SUCROSE & 0.075 & 0.015 & 0.015 & 0.028 & 0.009 & 0.009 & 0.008 \\
L-PHE-01 & 0.045 & 0.082 & 0.082 & 0.012 & 0.112 & 0.112 & 0.866 \\
PDD & 0.002 & 0.103 & 0.103 & 0.338 & 14 PPM & 14 PPM & 2 PPM \\
PPD & 0.002 & 0.091 & 0.091 & 0.298 & 10 PPM & 10 PPM & 1 PPM \\
& & & & & & & 833 \\
DDD & 0.001 & 0.039 & 0.039 & 0.128 & 7 PPM & 7 PPM & PPB \\
& 403 & & & & & & 169 \\
PPP & PPM & 0.027 & 0.027 & 0.088 & 2 PPM & 2 PPM & PPB \\
& 256 & & & & 146 & 146 & \\
DD4 & PPM & 0.009 & 0.009 & 0.029 & PPB & PPB & 22 PPB \\
& 544 & & & & 284 & 284 & \\
P4D & PPM & 0.024 & 0.024 & 0.078 & PPB & PPB & 40 PPB \\
Mole Flow kmol/hr & & & & & & & \\
HEXANE & 0.014 & 59.452 & 59.452 & 0.035 & 59.417 & 59.417 & 0.637 \\
WATER & 866.963 & 0.401 & 0.401 & $<0,001$ & 0.401 & 0.401 & 0.356 \\
SUCROSE & 3.891 & 0.362 & 0.362 & 0.209 & 0.152 & 0.152 & 0.011 \\
L-PHE-01 & 4.836 & 4.143 & 4.143 & 0.185 & 3.958 & 3.958 & 2.547 \\
PDD & 0.05 & 1.072 & 1.072 & 1.072 & $<0,001$ & $<0,001$ & trace \\
PPD & 0.036 & 0.943 & 0.943 & 0.943 & $<0,001$ & $<0,001$ & trace \\
DDD & 0.023 & 0.406 & 0.406 & 0.405 & $<0,001$ & $<0,001$ & trace \\
PPP & 0.009 & 0.276 & 0.276 & 0.276 & $<0,001$ & $<0,001$ & trace \\
DD4 & 0.005 & 0.088 & 0.088 & 0.088 & trace & trace & trace \\
P4D & 0.011 & 0.233 & 0.233 & 0.233 & trace & trace & trace \\
\hline FOnte:Propio & & & & & & &
\end{tabular}

Fonte: Próprio autor. 


\section{Limoneno}

Figura 27 - Flowsheet limoneno.

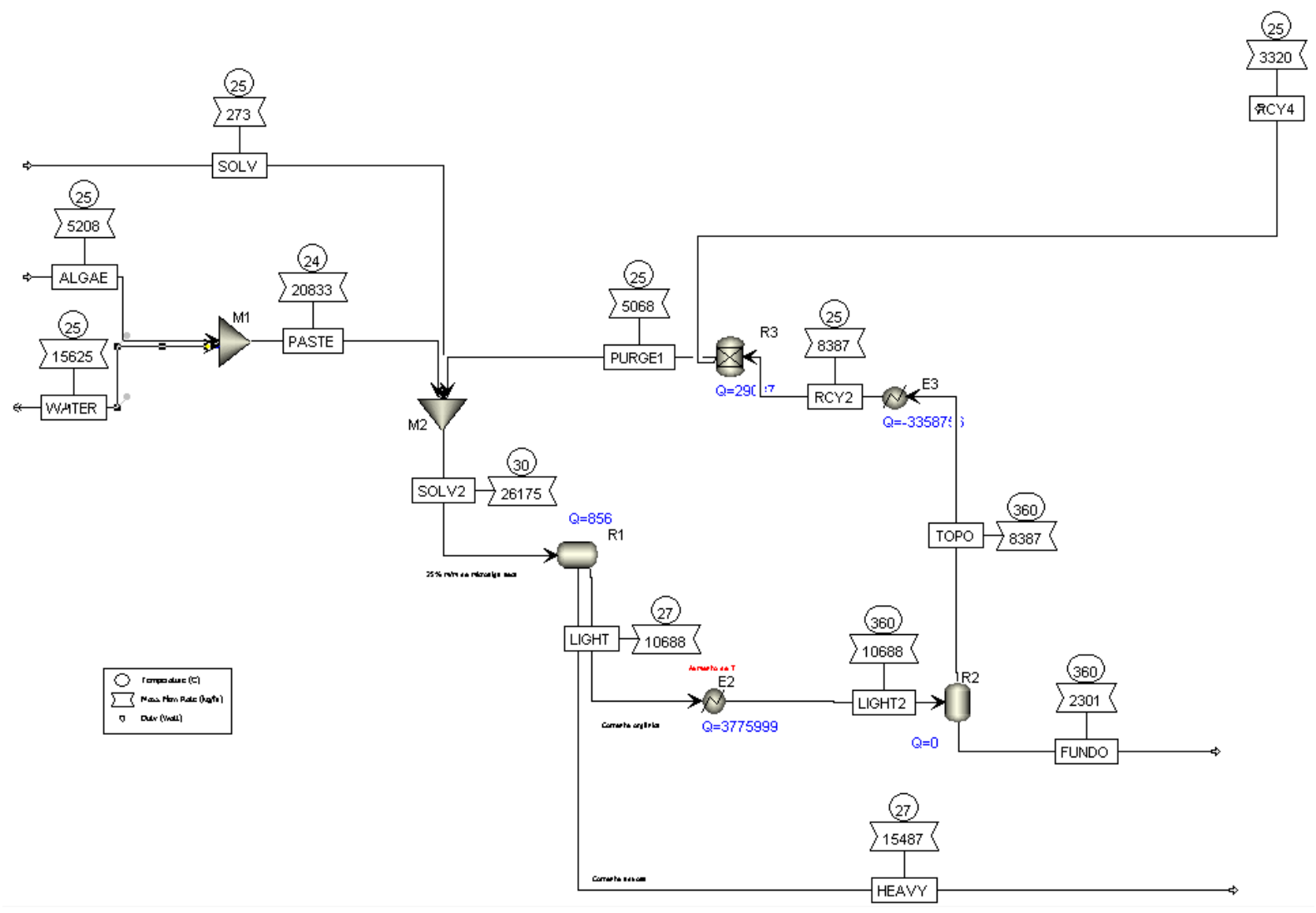

Fonte: Próprio autor.

Tabela 36 - Correntes da simulação para o limoneno.

\begin{tabular}{lrrrrrrr}
\hline & WATER & ALGAE & PASTE SOLV & PURGE1 & SOLV2 & HEAVY \\
\hline Temperature C & 25 & 25 & 24 & 25 & 25 & 29.8 & 26.5 \\
Pressure bar & 1 & 1 & 1 & 1 & 1 & 1 & 1 \\
Vapor Frac & 0 & 0 & 0 & 0 & 0 & 0 & 0 \\
Mole Flow kmol/hr & 867.32 & 14.83 & 882.15 & 2.007 & 37.177 & 921.334 & 784.887 \\
Mass Flow kg/hr & 15625 & 5208.33 & 20833.3 & 273.5 & 5067.73 & 26174.54 & 15486.57 \\
Volume Flow & & & & & & & \\
cum/hr & 15.72 & 5.518 & 25.904 & 0.326 & 6.039 & 32.065 & 16.12 \\
Enthalpy Gcal/hr & -59.21 & -4.114 & -63.32 & -0.03 & -0.489 & -63.835 & -54.81 \\
Mass Flow kg/hr & & & & & & & \\
WATER & 15625 & & 15625 & & & 15625 & 14065.04 \\
SUCROSE & & 1407.29 & 1407.29 & & & 1407.291 & 882.192 \\
L-PHE-01 & & 1250 & 1250 & & & 1249.999 & 185.311 \\
PDD & & 901.041 & 901.041 & & 1.457 & 902.498 & 126.627 \\
PPD & 788.541 & 788.541 & & 1.068 & 789.609 & 107.671 \\
DDD & 343.229 & 343.229 & & 0.656 & 343.885 & 50.043
\end{tabular}




\begin{tabular}{|c|c|c|c|c|c|c|c|}
\hline PPP & & 230.208 & 230.208 & & 0.191 & 230.399 & 30.766 \\
\hline DD4 & & 79.687 & 79.687 & & 0.02 & 79.708 & 10.159 \\
\hline P4D & & 208.333 & 208.333 & & 0.042 & 208.375 & 25.225 \\
\hline D-LIM-01 & & & & 273.5 & 5064.29 & 5337.772 & 3.538 \\
\hline \multicolumn{8}{|l|}{ Mass Frac } \\
\hline WATER & 1 & & 0.75 & & & 0.597 & 0.908 \\
\hline SUCROSE & & 0.27 & 0.068 & & & 0.054 & 0.057 \\
\hline L-PHE-01 & & 0.24 & 0.06 & & & 0.048 & 0.012 \\
\hline PDD & & 0.173 & 0.043 & & 287 PPM & 0.034 & 0.008 \\
\hline PPD & & 0.151 & 0.038 & & 211 PPM & 0.03 & 0.007 \\
\hline DDD & & 0.066 & 0.016 & & 129 PPM & 0.013 & 0.003 \\
\hline PPP & & 0.044 & 0.011 & & 38 PPM & 0.009 & 0.002 \\
\hline DD4 & & 0.015 & 0.004 & & 4 PPM & 0.003 & 656 PPM \\
\hline P4D & & 0.04 & 0.01 & & 8 PPM & 0.008 & 0.002 \\
\hline D-LIM-01 & & & & 1 & 0.999 & 0.204 & 228 PPM \\
\hline \multicolumn{8}{|c|}{ Mole Flow $\mathrm{kmol} / \mathrm{hr}$} \\
\hline WATER & 867.32 & & 867.319 & & & 867.319 & 780.728 \\
\hline SUCROSE & & 4.111 & 4.111 & & & 4.111 & 2.577 \\
\hline L-PHE-01 & & 7.567 & 7.567 & & & 7.567 & 1.122 \\
\hline PDD & & 1.122 & 1.122 & & 0.002 & 1.123 & 0.158 \\
\hline PPD & & 0.979 & 0.979 & & 0.001 & 0.98 & 0.134 \\
\hline DDD & & 0.428 & 0.428 & & 0.001 & 0.429 & 0.062 \\
\hline PPP & & 0.285 & 0.285 & & $<0,001$ & 0.285 & 0.038 \\
\hline DD4 & & 0.094 & 0.094 & & $<0,001$ & 0.094 & 0.012 \\
\hline P4D & & 0.244 & 0.244 & & $<0,001$ & 0.244 & 0.03 \\
\hline D-LIM-01 & & & & 2.007 & 37.173 & 39.18 & 0.026 \\
\hline
\end{tabular}

\begin{tabular}{lrrrrrr}
\hline & LIGHT & LIGHT2 & FUNDO & TOPO & RCY2 & RCY4 \\
\hline Temperature C & 26.5 & 360 & 360 & 360 & 25 & 25 \\
Pressure bar & 1 & 1 & 1 & 1 & 1 & 1 \\
Vapor Frac & 0 & 0.978 & 0 & 1 & 0 & 0 \\
Mole Flow kmol/hr & 136.447 & 136.447 & 3.054 & 133.394 & 133.394 & 96.216 \\
Mass Flow kg/hr & 10687.97 & 10687.97 & 2300.51 & 8387.46 & 8387.46 & 3319.67 \\
Volume Flow & & & & & & \\
cum/hr & 15.066 & 7023.007 & 0.869 & 7022.14 & 8.678 & 3.057 \\
Enthalpy Gcal/hr & -9.024 & -5.777 & -0.963 & -4.814 & -7.702 & -7.188 \\
Mass Flow kg/hr & & & & & & \\
WATER & 1559.965 & 1559.965 & 0.074 & 1559.89 & 1559.89 & 1559.89 \\
SUCROSE & 525.098 & 525.098 & 89.063 & 436.035 & 436.035 & 436.035 \\
L-PHE-01 & 1064.688 & 1064.688 & 7.667 & 1057.02 & 1057.02 & 1057.02 \\
PDD & 775.87 & 775.87 & 774.337 & 1.533 & 1.533 & 0.077 \\
PPD & 681.939 & 681.939 & 680.814 & 1.125 & 1.125 & 0.056 \\
DDD & 293.842 & 293.842 & 293.151 & 0.69 & 0.69 & 0.035 \\
PPP & 199.633 & 199.633 & 199.432 & 0.201 & 0.201 & 0.01
\end{tabular}




\begin{tabular}{lrrrrrr} 
DD4 & 69.549 & 69.549 & 69.527 & 0.021 & 0.021 & 0.001 \\
P4D & 183.15 & 183.15 & 183.106 & 0.044 & 0.044 & 0.002 \\
D-LIM-01 & 5334.233 & 5334.233 & 3.336 & 5330.9 & 5330.9 & 266.545 \\
Mass Frac & & & & & & \\
WATER & 0.146 & 0.146 & 32 PPM & 0.186 & 0.186 & 0.47 \\
SUCROSE & 0.049 & 0.049 & 0.039 & 0.052 & 0.052 & 0.131 \\
L-PHE-01 & 0.1 & 0.1 & 0.003 & 0.126 & 0.126 & 0.318 \\
& & & & 183 & 183 & \\
PDD & 0.073 & 0.073 & 0.337 & PPM & PPM & 23 PPM \\
& & & & 134 & 134 & \\
PPD & 0.064 & 0.064 & 0.296 & PPM & PPM & 17 PPM \\
DDD & 0.027 & 0.027 & 0.127 & 82 PPM & 82 PPM & 10 PPM \\
PPP & 0.019 & 0.019 & 0.087 & 24 PPM & 24 PPM & 3 PPM \\
& & & & & & 322 \\
DD4 & 0.007 & 0.007 & 0.03 & 3 PPM & 3 PPM & PPB \\
& & & & & & 658 \\
P4D & 0.017 & 0.017 & 0.08 & 5 PPM & 5 PPM & PPB \\
D-LIM-01 & 0.499 & 0.499 & 0.001 & 0.636 & 0.636 & 0.08 \\
Mole Flow kmol/hr & & & & & & \\
WATER & 86.591 & 86.591 & 0.004 & 86.587 & 86.587 & 86.587 \\
SUCROSE & 1.534 & 1.534 & 0.26 & 1.274 & 1.274 & 1.274 \\
L-PHE-01 & 6.445 & 6.445 & 0.046 & 6.399 & 6.399 & 6.399 \\
PDD & 0.966 & 0.966 & 0.964 & 0.002 & 0.002 & $<0,001$ \\
PPD & 0.847 & 0.847 & 0.845 & 0.001 & 0.001 & $<0,001$ \\
DDD & 0.367 & 0.367 & 0.366 & 0.001 & 0.001 & $<0,001$ \\
PPP & 0.247 & 0.247 & 0.247 & $<0,001$ & $<0,001$ & $<0,001$ \\
DD4 & 0.082 & 0.082 & 0.082 & $<0,001$ & $<0,001$ & trace \\
P4D & 0.215 & 0.215 & 0.215 & $<0,001$ & $<0,001$ & trace \\
D-LIM-01 & 39.154 & 39.154 & 0.024 & 39.13 & 39.13 & 1.956 \\
\hline Fonte:Propri0a4tor & & & & & &
\end{tabular}

Fonte: Próprio autor. 


\section{Palmitato de metila}

Figura 28 - Flowsheet palmitato de metila.

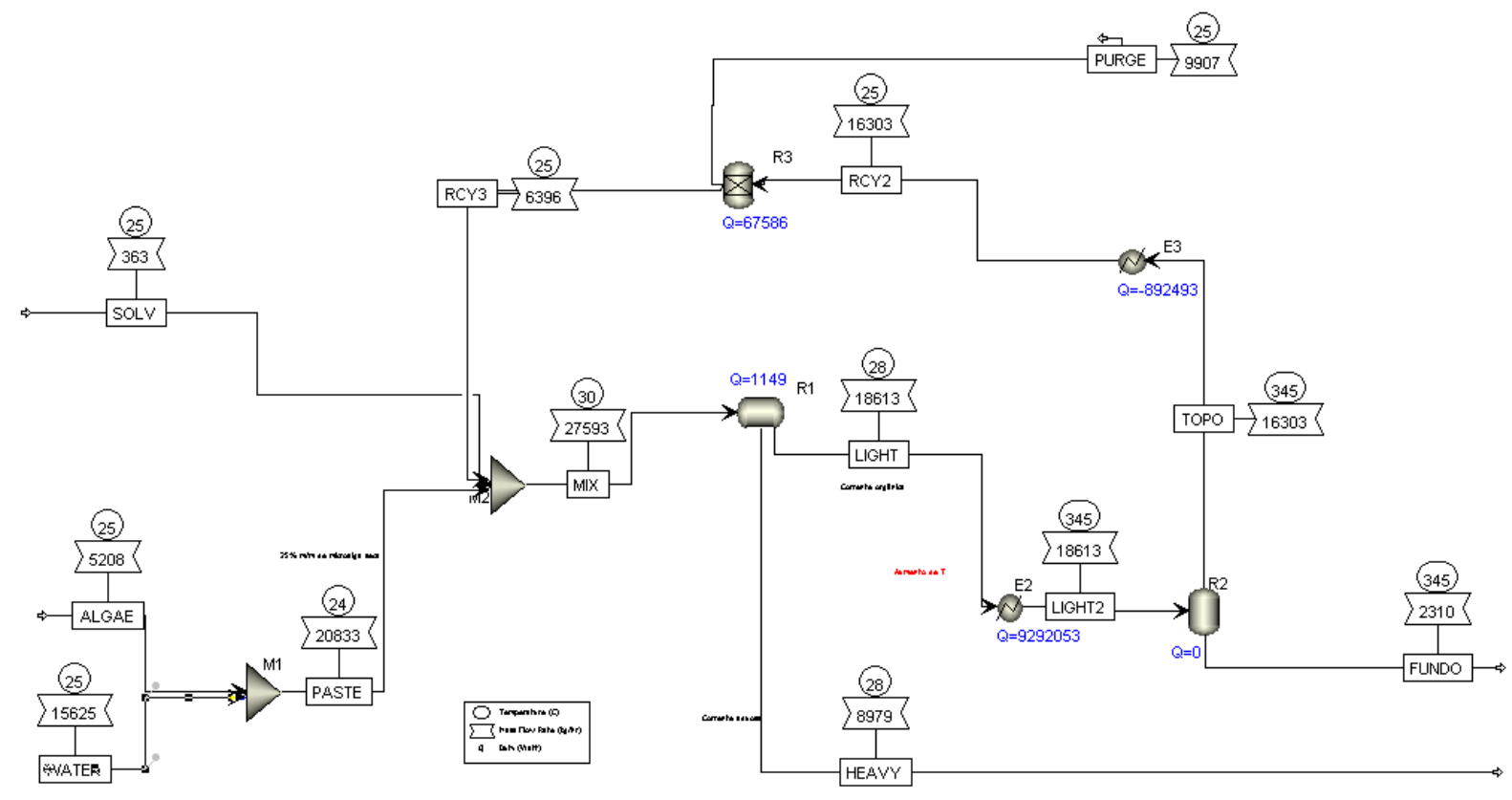

Fonte: Próprio autor.

Tabela 37 - Correntes da simulação para o palmitato de metila.

\begin{tabular}{lrrrrrrr}
\hline & WATER & ALGAE & PASTE & SOLV & RCY3 & MIX & HEAVY \\
\hline Temperature C & 25 & 25 & 24 & 25 & 25 & 29.6 & 27.6 \\
Pressure bar & 1 & 1 & 1 & 1 & 1 & 1 & 1 \\
Vapor Frac & 0 & 0 & 0 & 0 & 0 & 0 & 0 \\
Mole Flow kmol/hr & 867.319 & 14.83 & 882.15 & 1.342 & 23.637 & 907.129 & 448.875 \\
Mass Flow kg/hr & 15625 & 5208.33 & 20833.3 & 363.06 & 6396.17 & 27592.6 & 8979.47 \\
Volume Flow & & & & & & & \\
cum/hr & 15.72 & 5.518 & 25.904 & 0.472 & 8.325 & 35.757 & 9.703 \\
Enthalpy Gcal/hr & -59.205 & -4.114 & -63.32 & -0.254 & -4.47 & -68.043 & -31.281 \\
Mass Flow kg/hr & & & & & & & \\
WATER & 15625 & & 15625 & & & 15625 & 8035.62 \\
SUCROSE & & 1407.29 & 1407.29 & & & 1407.29 & 385.823 \\
L-PHE-01 & 1250 & 1250 & & & 1250 & 209.656 \\
PDD & & 901.041 & 901.041 & & 2.253 & 903.294 & 123.226 \\
PPD & 788.541 & 788.541 & & 1.626 & 790.167 & 106.365 \\
DDD & 343.229 & 343.229 & & 1.031 & 344.26 & 47.856 \\
PPP & 230.208 & 230.208 & & 0.279 & 230.488 & 30.736 \\
DD4 & 79.687 & 79.687 & & 0.028 & 79.716 & 10.867 \\
P4D & 208.333 & 208.333 & & 0.056 & 208.389 & 27.714 \\
METHY-01 & & & 363.06 & 6390.9 & 6753.96 & 1.604 \\
Mass Frac & & & & & & &
\end{tabular}




\begin{tabular}{|c|c|c|c|c|c|c|c|}
\hline WATER & 1 & & 0.75 & & & 0.566 & 0.895 \\
\hline SUCROSE & & 0.27 & 0.068 & & & 0.051 & 0.043 \\
\hline L-PHE-01 & & 0.24 & 0.06 & & & 0.045 & 0.023 \\
\hline PDD & & 0.173 & 0.043 & & $\begin{array}{r}352 \\
\text { PPM } \\
254\end{array}$ & 0.033 & 0.014 \\
\hline PPD & & 0.151 & 0.038 & & $\begin{array}{r}\text { PPM } \\
161\end{array}$ & 0.029 & 0.012 \\
\hline DDD & & 0.066 & 0.016 & & PPM & 0.012 & 0.005 \\
\hline PPP & & 0.044 & 0.011 & & 44 PPM & 0.008 & 0.003 \\
\hline DD4 & & 0.015 & 0.004 & & 4 PPM & 0.003 & 0.001 \\
\hline P4D & & 0.04 & 0.01 & & 9 PPM & 0.008 & $\begin{array}{r}0.003 \\
179\end{array}$ \\
\hline METHY-01 & & & & 1 & 0.999 & 0.245 & PPM \\
\hline \multicolumn{8}{|l|}{ Mole Flow $\mathrm{kmol} / \mathrm{hr}$} \\
\hline WATER & 867.319 & & 867.319 & & & 867.319 & 446.045 \\
\hline SUCROSE & & 4.111 & 4.111 & & & 4.111 & 1.127 \\
\hline L-PHE-01 & & 7.567 & 7.567 & & & 7.567 & 1.269 \\
\hline PDD & & 1.122 & 1.122 & & 0.003 & 1.124 & 0.153 \\
\hline PPD & & 0.979 & 0.979 & & 0.002 & 0.981 & 0.132 \\
\hline DDD & & 0.428 & 0.428 & & 0.001 & 0.43 & 0.06 \\
\hline PPP & & 0.285 & 0.285 & & $<0,001$ & 0.285 & 0.038 \\
\hline DD4 & & 0.094 & 0.094 & & $<0,001$ & 0.094 & 0.013 \\
\hline P4D & & 0.244 & 0.244 & & $<0,001$ & 0.244 & 0.032 \\
\hline METHY-01 & & & & 1.342 & 23.63 & 24.973 & 0.006 \\
\hline
\end{tabular}

\begin{tabular}{lrrrrrr}
\hline & LIGHT & LIGHT2 & FUNDO & TOPO & RCY2 & PURGE \\
\hline Temperature C & 27.6 & 345 & 345 & 345 & 25 & 25 \\
Pressure bar & 1 & 1 & 1 & 1 & 1 & 1 \\
Vapor Frac & 0 & 0.993 & 0 & 1 & 0 & 0 \\
Mole Flow kmol/hr & 458.253 & 458.253 & 3.069 & 455.185 & 455.185 & 431.548 \\
Mass Flow kg/hr & 18613.1 & 18613.1 & 2310.19 & 16302.9 & 16302.9 & 9906.8 \\
Volume Flow & & & & & & \\
cum/hr & 25.377 & 23395.1 & 0.862 & 23394.2 & 18.851 & 9.748 \\
Enthalpy Gcal/hr & -36.761 & -28.772 & -0.98 & -27.791 & -35.465 & -30.938 \\
Mass Flow kg/hr & & & & & & \\
WATER & 7589.38 & 7589.38 & 0.119 & 7589.26 & 7589.26 & 7589.26 \\
SUCROSE & 1021.47 & 1021.47 & 77.931 & 943.537 & 943.537 & 943.537 \\
L-PHE-01 & 1040.34 & 1040.34 & 2.981 & 1037.36 & 1037.36 & 1037.36 \\
PDD & 780.068 & 780.068 & 777.696 & 2.372 & 2.372 & 0.119 \\
PPD & 683.802 & 683.802 & 682.091 & 1.711 & 1.711 & 0.086 \\
DDD & 296.403 & 296.403 & 295.318 & 1.085 & 1.085 & 0.054 \\
PPP & 199.751 & 199.751 & 199.457 & 0.294 & 0.294 & 0.015 \\
DD4 & 68.849 & 68.849 & 68.819 & 0.03 & 0.03 & 0.001 \\
P4D & 180.676 & 180.676 & 180.616 & 0.059 & 0.059 & 0.003 \\
METHY-01 & 6752.36 & 6752.36 & 25.163 & 6727.19 & 6727.19 & 336.36 \\
Mass Frac & & & & & &
\end{tabular}




\begin{tabular}{lrrrrrr} 
WATER & 0.408 & 0.408 & 51 PPM & 0.466 & 0.466 & 0.766 \\
SUCROSE & 0.055 & 0.055 & 0.034 & 0.058 & 0.058 & 0.095 \\
L-PHE-01 & 0.056 & 0.056 & 0.001 & 0.064 & 0.064 & 0.105 \\
PDD & & & & 145 & 145 & \\
& 0.042 & 0.042 & 0.337 & PPM & PPM & 12 PPM \\
PPD & & & & 105 & 105 & \\
DDD & 0.037 & 0.037 & 0.295 & PPM & PPM & 9 PPM \\
PPP & 0.016 & 0.016 & 0.128 & 67 PPM & 67 PPM & 5 PPM \\
& 0.011 & 0.011 & 0.086 & 18 PPM & 18 PPM & 1 PPM \\
DD4 & & & & & & 149 \\
& 0.004 & 0.004 & 0.03 & 2 PPM & 2 PPM & PPB \\
P4D & & & & & & 299 \\
METHY-01 & 0.01 & 0.01 & 0.078 & 4 PPM & 4 PPM & PPB \\
Mole Flow kmol/hr & 0.363 & 0.363 & 0.011 & 0.413 & 0.413 & 0.034 \\
WATER & & & & & & \\
SUCROSE & 421.275 & 421.275 & 0.007 & 421.268 & 421.268 & 421.268 \\
L-PHE-01 & 2.984 & 2.984 & 0.228 & 2.756 & 2.756 & 2.756 \\
PDD & 6.298 & 6.298 & 0.018 & 6.28 & 6.28 & 6.28 \\
PPD & 0.971 & 0.971 & 0.968 & 0.003 & 0.003 & $<0,001$ \\
DDD & 0.849 & 0.849 & 0.847 & 0.002 & 0.002 & $<0,001$ \\
PPP & 0.37 & 0.37 & 0.369 & 0.001 & 0.001 & $<0,001$ \\
DD4 & 0.247 & 0.247 & 0.247 & $<0,001$ & $<0,001$ & $<0,001$ \\
P4D & 0.081 & 0.081 & 0.081 & $<0,001$ & $<0,001$ & trace \\
METHY-01 & 0.212 & 0.212 & 0.212 & $<0,001$ & $<0,001$ & trace \\
\hline FOnte:Propro autor & 24.967 & 24.967 & 0.093 & 24.874 & 24.874 & 1.244 \\
\hline
\end{tabular}

Fonte: Próprio autor. 